\title{
C-terminal tyrosine residue modifications modulate $\alpha$-synuclein \\ toxicity in yeast as unicellular model for Parkinson's disease
}

\author{
Dissertation \\ For the award of the degree \\ "Doctor rerum naturalium" \\ of the Georg-August-Universität Göttingen \\ within the doctoral program \\ "Molecular Physiology of the Brain" (CMPB) \\ of Georg-August University School of Science (GAUSS)
}

Submitted by

Alexandra Kleinknecht

from

Jawlenka (Kazakhstan) 


\section{Thesis Committee:}

Prof. Dr. Gerhard H. Braus (Department of Molecular Microbiology and Genetics, Institute for Microbiology and Genetics, Georg-August-Universität Göttingen)

Prof. Dr. Tiago F. Outeiro (Department of NeuroDegeneration and Restorative Research, University Medical Center Göttingen)

Prof. Dr. Blanche Schwappach (Department of Molecular Biology, University Medical Center Göttingen)

\section{Members of the Examination Board:}

$1^{\text {st }}$ Referee: Prof. Dr. Stefanie Pöggeler (Department of Genetics of Eukaryotic Microorganisms, Institute for Microbiology and Genetics, Georg-August-Universität Göttingen)

$2^{\text {nd }}$ Referee: Jun.-Prof. Dr. Kai Heimel (Department of Molecular Microbiology and Genetics, Institute for Microbiology and Genetics, Georg-August-Universität Göttingen)

$3^{\text {rd }}$ Referee: PD Dr. Michael Hoppert (Department of General Microbiology, Institute for Microbiology and Genetics, Georg-August-Universität Göttingen) 


\section{Declaration}

Herewith I declare that the PhD Thesis entitled "C-terminal tyrosine residue modifications modulate $\alpha$-synuclein toxicity in yeast as unicellular model for Parkinson's disease" has been written independently and with no other sources and aids than quoted.

Alexandra Kleinknecht Göttingen 2016 
This work was accomplished in the group of Prof. Dr. Gerhard H. Braus at the Department of Molecular Microbiology and Genetics at the Institute of Microbiology and Genetics, GeorgAugust-Universität Göttingen.

\section{Publications:}

Kleinknecht, A, Popova, B, Lázaro, DF, Pinho, R, Valerius, O, Outeiro, TF and Braus, GH (2016) C-terminal Tyrosine Residue Modifications Modulate the Protective Phosphorylation of Serine 129 of a-synuclein in a Yeast Model of Parkinson's Disease. PLOS Genetics, Accepted for publication Mai 10, 2016.

Popova, B, Kleinknecht, A, and Braus, GH (2015) Posttranslational Modifications and Clearing of $\alpha$-Synuclein Aggregates in Yeast. Biomolecules 5(2):617-634.

Shahpasandzadeh, H, Popova, B, Kleinknecht, A, Fraser, PE, Outeiro, TF and Braus, GH (2014) Interplay between sumoylation and phosphorylation for protection against alphasynuclein inclusions. J Biol Chem. 289(45):31224-40. 


\section{Table of Contents}

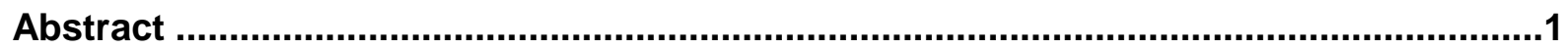

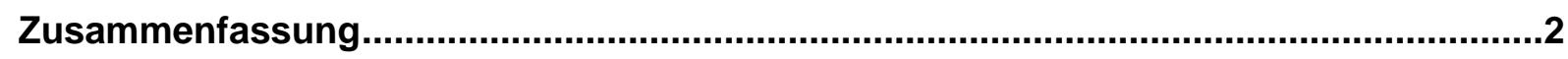

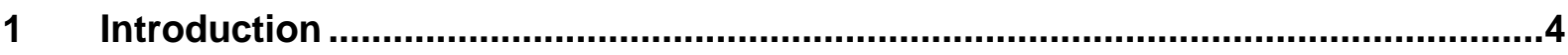

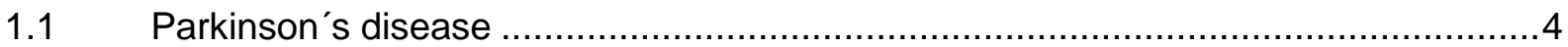

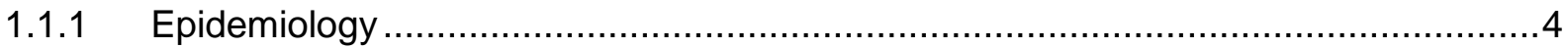

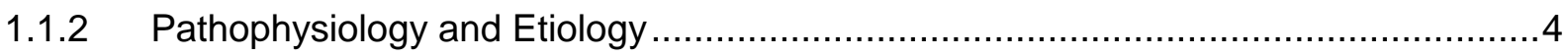

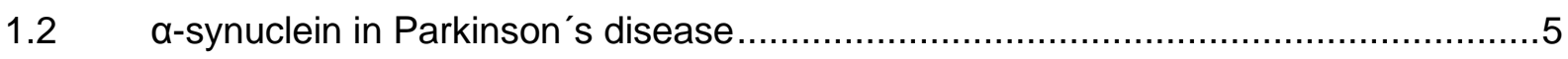

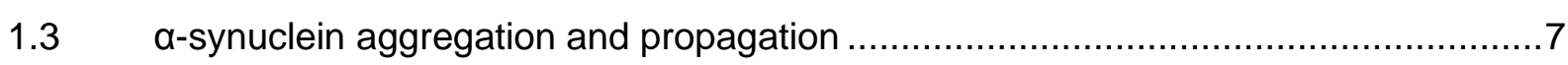

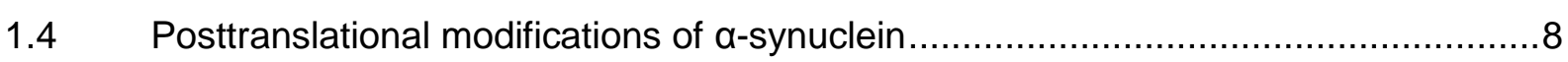

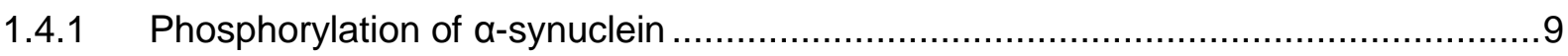

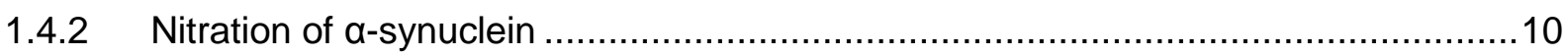

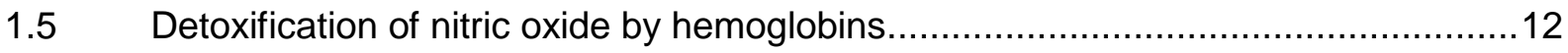

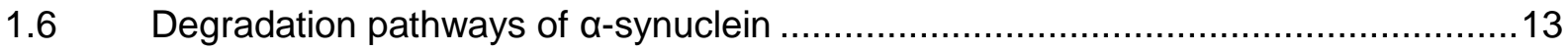

1.7 Saccharomyces cerevisiae as model for Parkinson's disease .............................14

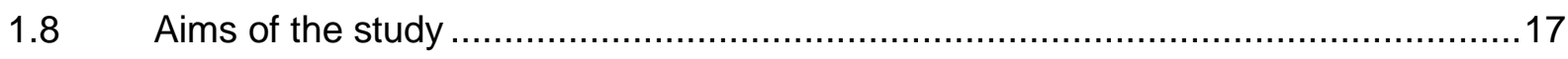

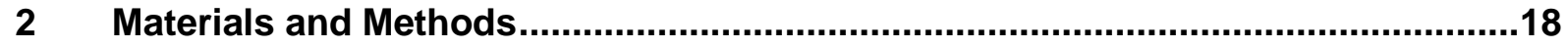

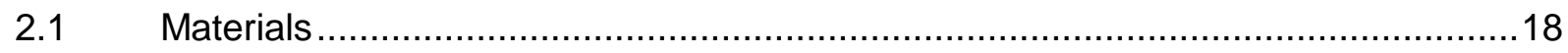

2.1.1 Companies of chemicals, molecular biological substances and equipment............18

2.1.2 Strains, plasmids and oligonucleotides ...........................................................19

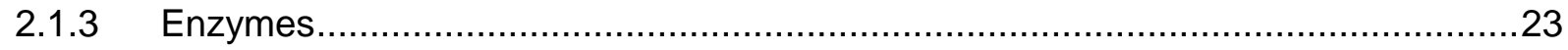

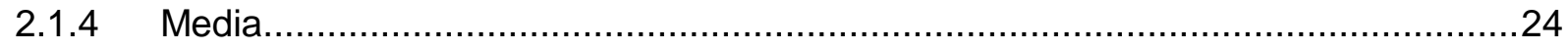

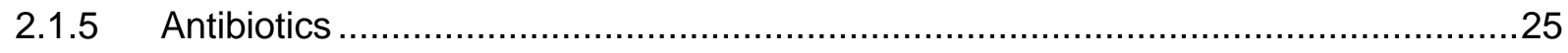

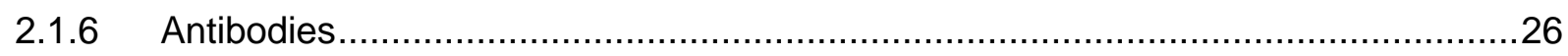

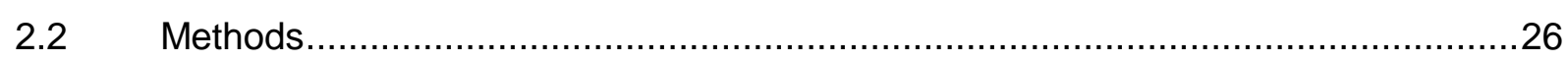

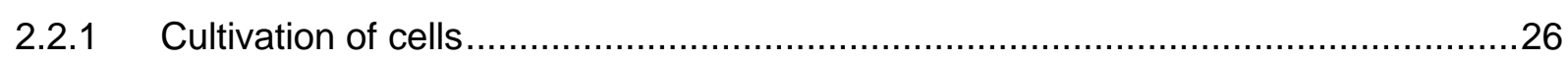

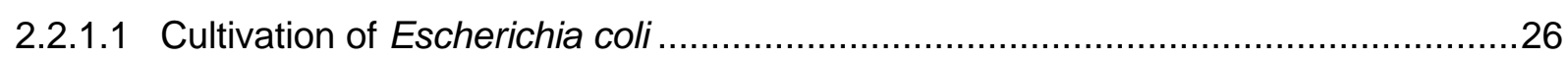

2.2.1.2 Cultivation of Saccharomyces cerevisiae ......................................................26

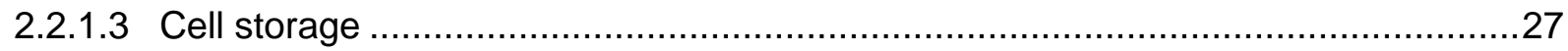

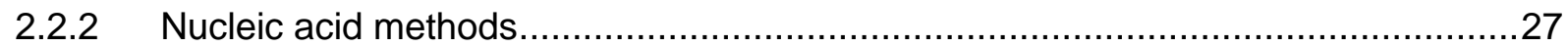

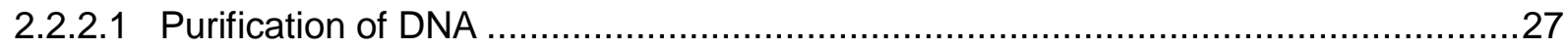

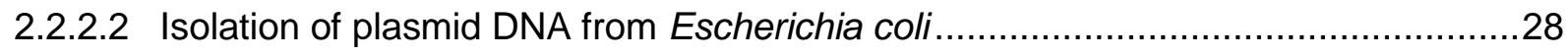

2.2.2.3 Isolation of genomic DNA from Saccharomyces cerevisiae ................................28

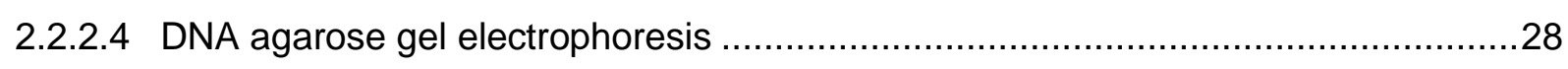

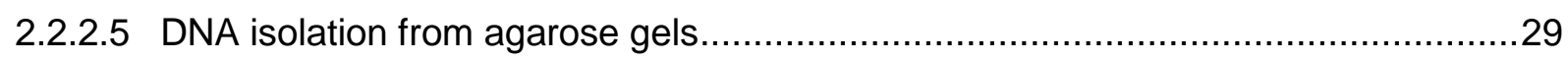

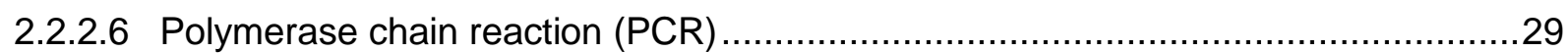




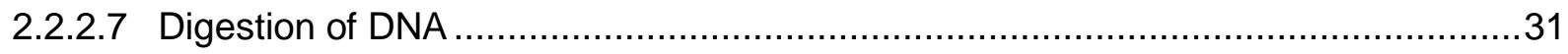

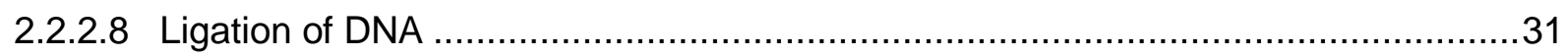

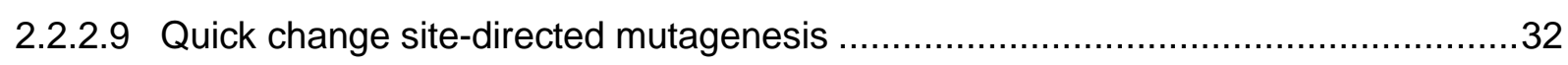

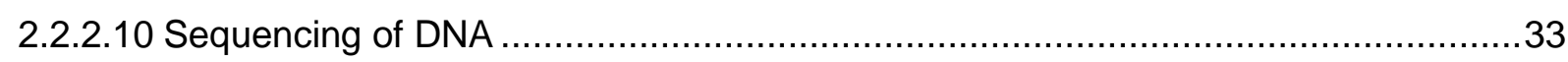

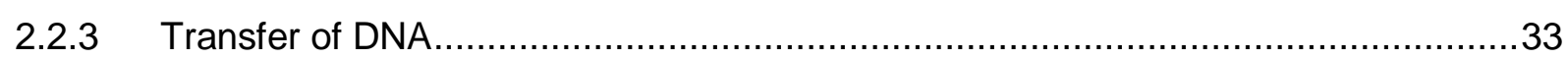

2.2.3.1 Transformation of plasmid DNA into Escherichia coli ..........................................33

2.2.3.2 Transformation of plasmid DNA into Saccharomyces cerevisiae ...........................34

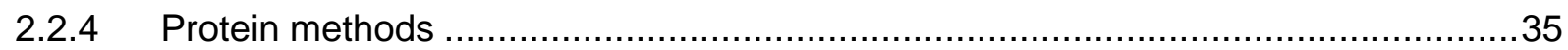

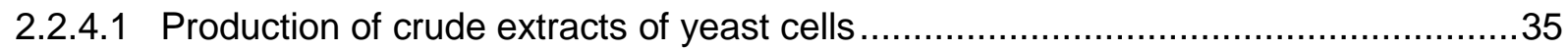

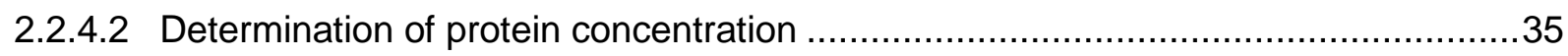

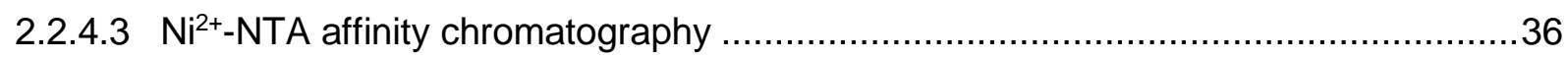

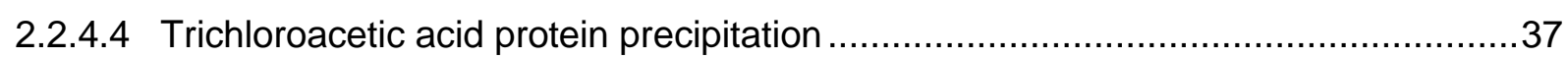

2.2.4.5 Discontinuous SDS-polyacrylamide gel electrophoresis (SDS-PAGE) ...................37

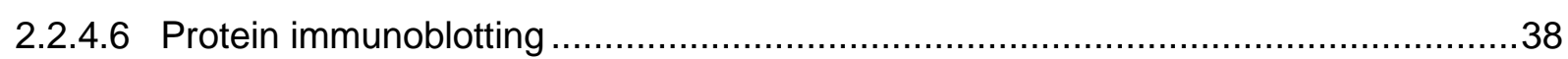

2.2.4.7 Staining of proteins with Coomassie brilliant blue R-250 .......................................39

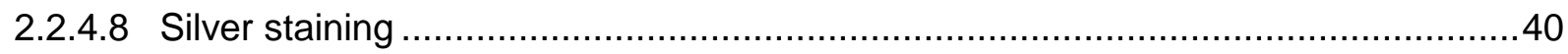

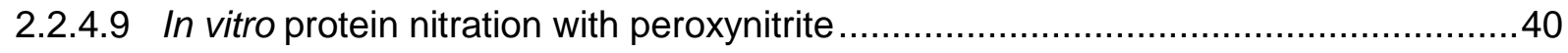

2.2.5 Liquid chromatography-mass spectrometry ....................................................

2.2.5.1 In-gel protein digestion with trypsin ............................................................... 41

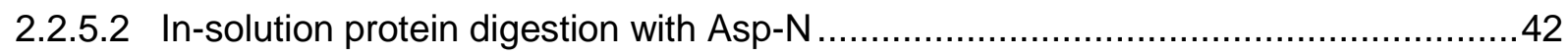

2.2.5.3 C18 StageTip purification........................................................................ 42

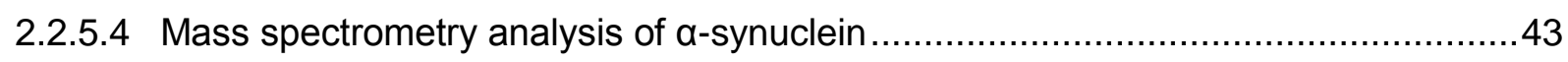

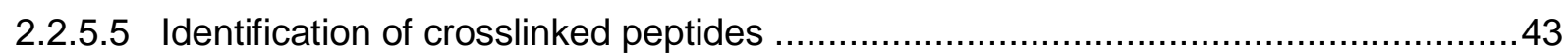

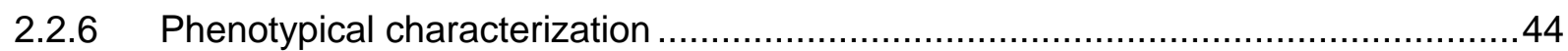

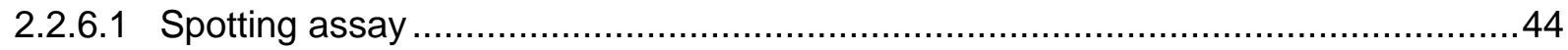

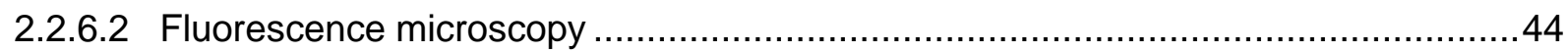

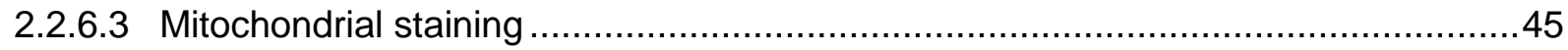

2.2.6.4 Detection of reactive oxygen and nitrogen species .......................................45

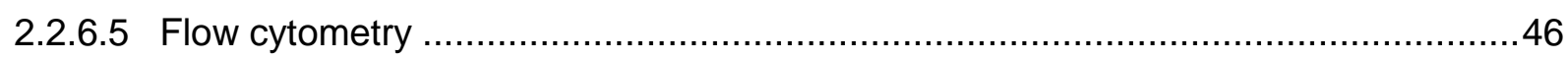

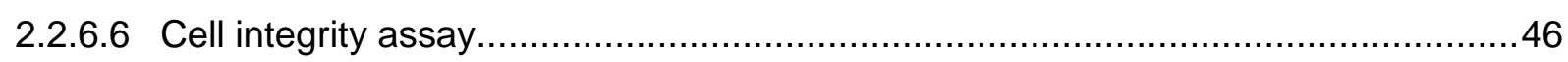

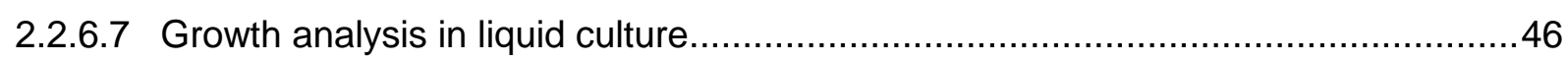

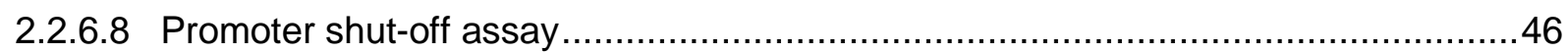

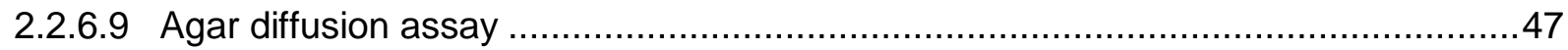

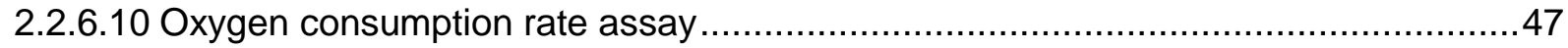

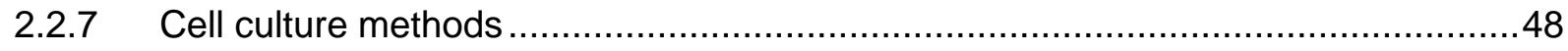

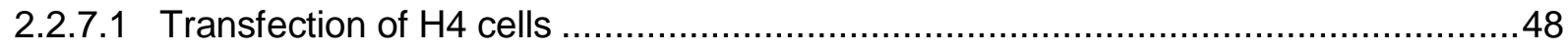

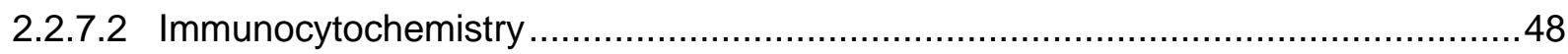


2.2.7.3 Quantification of $\alpha$-synuclein inclusions in $\mathrm{H} 4$ cells ........................................... 49

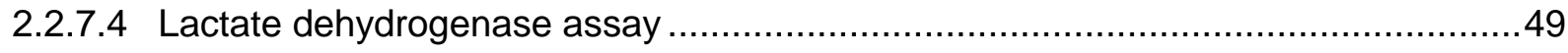

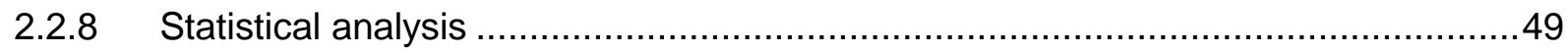

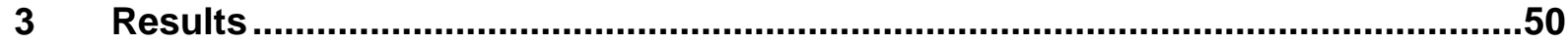

3.1 $\quad$ a-synuclein forms dimers in vivo in yeast cells ................................................

3.2 The C-terminus of $\alpha$-synuclein is preferentially modified by nitration and di-tyrosine

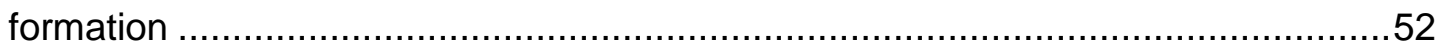

3.3 Tyrosine residues contribute to $\alpha$-synuclein cytotoxicity and aggregate formation ..56

3.4 The nitric oxide oxidoreductase Yhb1 reduces A30P aggregation and toxicity .......60

3.5 Overexpression of YHB1 impairs growth of Saccharomyces cerevisiae..................62

3.6 Yhb1 decreases sensitivity of A30P expressing cells to nitrative stress .................64

3.7 a-synuclein expression does not affect the sensitivity of yeast cells to $\mathrm{H}_{2} \mathrm{O}_{2} \ldots \ldots \ldots . .65$

3.8 Blockage of tyrosine nitration protects against $\mathrm{A} 30 \mathrm{P}$ toxicity and aggregate formation under nitrative stress

3.9 Yhb1 reduces the accumulation of reactive nitrogen species in A30P expressing cells

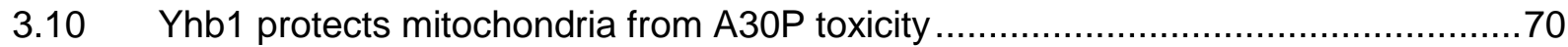

3.11 Mitochondrial functionality is not affected by Yhb1 in A30P expressing yeast cells.72

3.12 Human neuroglobin protects against $\alpha$-synuclein aggregate formation in yeast and

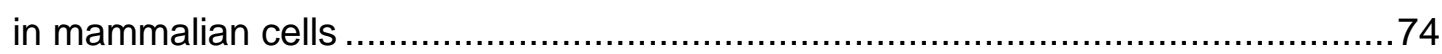

3.13 Yhb1 affects nitration but not dimerization level of A30P...................................77

3.14 Tyrosine 133 is required for phosphorylation of $\alpha$-synuclein at serine $129 \ldots \ldots \ldots \ldots . .78$

3.15 C-terminal $\alpha$-synuclein modifications promote autophagy clearance of $\alpha$-synuclein aggregates

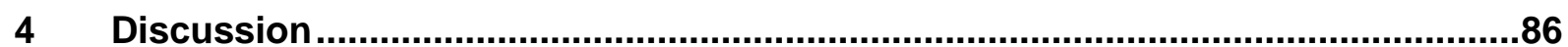

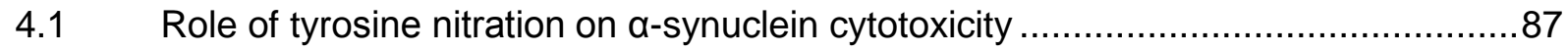

4.2 Role of Yhb1 and neuroglobin on $\alpha$-synuclein cytotoxicity .................................89

4.3 Dimerization of $\alpha$-synuclein by covalent di-tyrosine crosslinking ............................

4.4 Interplay between tyrosine nitration and serine 129 phosphorylation of $\alpha$-synuclein in yeast......

4.5 C-terminal tyrosine residue modifications modulate $\alpha$-synuclein toxicity in yeast as unicellular model for Parkinson's disease 


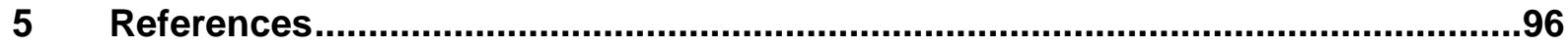

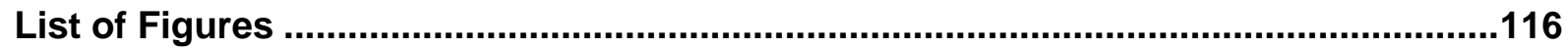

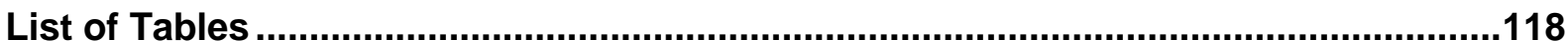

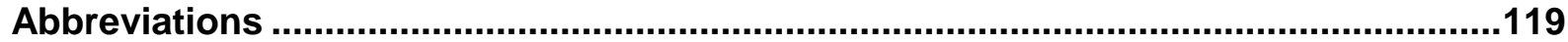

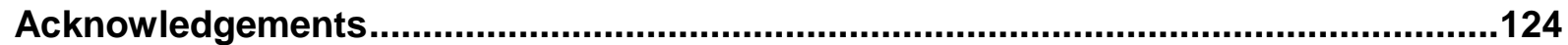

Curriculum Vitae............................................................................................................126 


\section{Abstract}

The presence of protein inclusions called Lewy bodies (LBs) that are mainly composed of misfolded and accumulated $\alpha$-synuclein ( $\alpha$ Syn) represents a hallmark of Parkinson's disease (PD). Oligomeric aSyn species are thought to play a central role in the neurodegeneration of PD. Elevated levels of oxidative or nitrative stresses have been implicated in aSyn-related toxicity. Phosphorylation of aSyn on serine 129 (S129) is prominently found in Lewy bodies and modulates autophagic aggregates clearance. The neighboring tyrosine residues $\mathrm{Y} 125$, Y133 and Y136 are phosphorylation and nitration sites. Overexpression of aSyn in the unicellular eukaryotic model Saccharomyces cerevisiae results in growth impairment and cytoplasmic protein inclusions resembling the aggregates observed within LBs. In this study, yeast was used as reference cell to study the contribution of tyrosine modifications on aSynrelated toxicity. $\mathrm{Y} 133$ is required for protective $\mathrm{S} 129$ phosphorylation and for S129independent proteasome clearance. aSyn can be nitrated and forms stable dimers originating from covalent crosslinking of two tyrosine residues. LC-MS analysis of tyrosine residues involved in nitration and crosslinking revealed that the C-terminus, rather than the $\mathrm{N}$-terminus of aSyn, is modified by nitration and di-tyrosine formation. The nitration level of wild-type aSyn was higher than the A30P mutant that is non-toxic in yeast. A30P formed more dimers than wild-type aSyn supporting dimer formation as a cellular detoxification pathway in yeast. In contrast to A30P, expression of aSyn significantly increased the accumulation of reactive oxygen species, which was independent from tyrosine modifications. Deletion of the yeast flavohemoglobin gene $Y H B 1$ resulted in an increase of cellular nitrative stress and enhanced aggregation and cytotoxicity of A30P. Yhb1 protected yeast from A30P-induced mitochondrial fragmentation. Deletion of $Y H B 1$ elevated the level of reactive nitrogen species in A30P expressing cells, which can be diminished by mutating the nitration sites. Protein analysis showed that Yhb1 affects nitration but not dimerization levels of $\mathrm{A} 30 \mathrm{P}$ indicating that nitrated tyrosine residues, but not di-tyrosine crosslinked dimers, contribute to aSyn cytotoxicity and aggregation. Under nitrative stress, deletion of YHB1 severely inhibited yeast growth in cells expressing wild-type and A30P aSyn. A30P was as toxic as wild-type aSyn indicating that increase in nitrative stress converts $A 30 P$ to a toxic protein. Overexpression of neuroglobin, the human homolog of $Y H B 1$, protected against aSyn inclusion formation in mammalian cells. This study suggests that C-terminal Y133 plays a major role in aSyn aggregate clearance by supporting the protective $\$ 129$ phosphorylation for autophagy and by promoting proteasome clearance. C-terminal tyrosine nitration increases pathogenicity and can be partially detoxified by aSyn di-tyrosine dimers. This novel complex interplay between S129 phosphorylation and C-terminal tyrosine modifications of aSyn likely participates in PD pathology. 


\section{Zusammenfassung}

Morbus Parkinson ist durch Lewy Bodies als Protein-Einschlusskörper gekennzeichnet, die hauptsächlich aus dem Protein $\alpha$-Synuclein ( $\alpha$ Syn) bestehen. Dieses Protein hat zytotoxische Intermediate und erhöhter oxidativer sowie nitrosativer Stress sind an der Toxizität von aSyn beteiligt. Phosphorylierung von aSyn an Serin 129 (S129) wurde in Lewy Bodies gefunden und reguliert den Autophagie-abhängigen Aggregat-Abbau. Die benachbarten Tyrosin-Reste Y125, Y133 und Y136 sind Phosphorylierungs- und Nitrierungsstellen. Überexpression von aSyn in Saccharomyces cerevisiae als unizelluläres eukaryotisches Zell-Modell löst Wachstumsstörungen sowie die Fehlfaltung des Proteins mit darauffolgenden zytoplasmatischen Aggregationen aus, die an die in den Lewy Bodies beobachteten Aggregate erinnern. Mithilfe dieses Hefemodells für Morbus Parkinson wurde die Wirkung von Tyrosin-Modifikationen auf die von aSyn hervorgerufene Toxizität untersucht. Es konnte gezeigt werden, dass Y133 für die protektive Phosphorylierung von S129 und für den S129-abhängigen Proteasom-Abbau benötigt wird. aSyn kann nitriert werden und formt daraufhin stabile Dimere, die durch kovalente Verbindung von zwei Tyrosinen entstehen. LC-MS Analysen von Tyrosin-Resten, die bei der Nitrierung und Dimerisierung involviert sind, haben gezeigt, dass der C-Terminus von aSyn mehr als der $\mathrm{N}$ Terminus durch Nitrierung und Di-Tyrosin-Bildung modifiziert wird. Der Grad an Nitrierung des normalen aSyn war höher als bei der A30P-Variante, die in Hefe nicht toxisch ist. Die A30P-Mutante bildete mehr Dimere im Vergleich zum aSyn Wildtyp, was darauf hindeutet, dass die Dimerizierung ein zellulärer Detoxifikationsmechanismus in Hefe sein könnte. Im Gegensatz zu der A30P-Mutante, erhöhte die Expression von aSyn unabhängig von der Tyrosin-Modifikation die Akkumulation von reaktiven Sauerstoffspezies. Die Deletion des Yeast Flavohemoglobin Gens, YHB1, führte zu einer Erhöhung von Nitrierungsstress sowie zum Anstieg von Aggregation und Zytotoxizität der A30P-Mutante. Yhb1 wirkte protektiv gegen A30P-induzierte Mitochondrien-Fragmentierung. Die Deletion von YHB1 führte zum Anstieg von reaktiven Stickstoffspezies in Zellen, die A30P exprimieren, was durch den Austausch der Tyrosin-Reste verringert werden kann. Yhb1 beeinflusst den Nitrierungs-, aber nicht den Dimerisierungslevel von A30P. Es sind daher eher nitrierte Tyrosin-Reste als Di-Tyrosin-Verbindungen an der Zytotoxizität und Aggregation von aSyn beteiligt. Unter nitrativen Stress-Bedingungen, bei dem Peroxynitrit als Stickstoffmonoxid-Donor eingesetzt wurde, führte die Deletion von YHB1 zur Wachstumshemmung von Wildtyp aSyn- und A30Pexprimierenden Zellen. Dabei war die A30P-Mutante gleichermaßen toxisch wie das normale aSyn. Der Anstieg von Nitrierungsstress verwandelt daher A30P vermutlich in ein toxisches Protein. Die Überexpression vom NGB, dem humanen Homolog von YHB1, wirkte protektiv gegen aSyn Aggregation in Säugetierzellen. Der C-terminale Y133 Rest spielt damit eine 
wesentliche Rolle im aSyn-Aggregate-Abbau. Dieser Rest fördert die protektive S129Phosphorylierung und damit den Autophagie-Abbau und stimuliert den Proteasom-Abbau. Cterminale Tyrosin-Nitrierung erhöht die Pathogenität und kann durch Di-Tyrosin-Dimere teilweise detoxifiziert werden. Diese neue komplexe Wechselwirkung zwischen der S129 Phosphorylierung und den C-terminalen Tyrosin-Modifikationen von aSyn ist wahrscheinlich an der Pathologie von Morbus Parkinson beteiligt. 


\section{Introduction}

\subsection{Parkinson's disease}

\subsubsection{Epidemiology}

Parkinson's disease (PD) is the second most frequent neurodegenerative disorder after Alzheimer's disease. It causes a wide range of physical and mental impairments. Six million people are affected worldwide by PD with the prevalence of approximately $0.3 \%$ of the population in industrialized countries (Dexter and Jenner, 2013). The cause of PD remains unknown although several risk factors such as environmental factors, aging and genetic susceptibility were identified to contribute to the onset of the pathogenic process. No curative therapies exist that slow the degenerative progression. PD therapies are usually restricted to systematic treatments. The average age of diagnoses is around 60 years. The prevalence increases to $1 \%$ in the population older than 60 years and to $4 \%$ older than 80 . Hence, PD is considered as an age-related disease (de Lau and Breteler, 2006; de Rijk et al., 2000; Dexter and Jenner, 2013). Whereas in $95 \%$ of PD patients an idiopathic background is diagnosed, approx. $5 \%$ of patients are affected by inherited forms of PD. The familial cases of $P D$ result in early-onset of disease and are caused by point missense mutations and multiplications of certain genes, e.g. SNCA, Parkin, PINK1, LRRK2, DJ-1 and ATP13A2 (Bonifati et al., 2003; Di Fonzo et al., 2007; Kitada et al., 1998; Polymeropoulos et al., 1997; Valente et al., 2001; Zimprich et al., 2004). In 1817, the British physician James Parkinson firstly described the core clinical features of the disorder in his historic publication "An Essay on the Shaking Palsy", which are today classified as common symptoms of PD (Parkinson, 2002). Characteristic clinical symptoms comprise akinesia (muscle rigidity), bradykinesia (slowness of movement), resting tremor and loss of postural reflexes. Furthermore, PD can also cause dysarthria, hypomimia, dysphagia, anosmia, insomnia and urinary incontinence (Galvin et al., 2001; Jankovic, 2008).

\subsubsection{Pathophysiology and Etiology}

Although many parts of the brain are affected by PD, its best known pathological hallmark is the selective loss of dopamine-producing neurons in the substantia nigra (SN), a core complex of melanin- and iron-containing neurons in the ventral midbrain involved in motor control (German et al., 1989; German et al., 1992). SN is a part of basal ganglia which regulates the dopamine maintenance of the striatum, the largest component of basal ganglia controlling complex regulatory circuits of voluntary movements. Although degeneration also occurs in other neuron types (Pillon et al., 1989), the mid-section of the substantia nigra, 
zona compacta, is mostly affected by neurodegeneration. Loss of dopaminergic neurons is accompanied by the loss of neuromelanin neurons leading to depigmentation (Fearnley and Lees, 1991; Fedorow et al., 2005; Gibb and Lees, 1991). Degeneration of nigral dopaminergic neurons consequently results in dopamine depletion in the striatum leading to observed motoric and non-motoric dysfunctions of PD (Hornykiewicz, 2001; Obeso et al., 2002). The persistent reduction of dopamine misbalances other neurotransmitters including acetylcholine, glutamate or $\mathrm{y}$-aminobutyric acid (GABA), which can result in mental disorders such as emotional instability and depression (Giupponi et al., 2008). PD is also described to be associated with non-motoric and non-dopaminergic symptoms that extend beyond the nigrostiatal dopamine pathway and often occur years or even decades prior to the clinical diagnosis (Chaudhuri et al., 2006; Sung and Nicholas, 2013). At the time of symptom onset, approx. $50 \%$ of dopamine-producing neurons are already degenerated (Fearnley and Lees, 1991). Degeneration of neurons coincides with the formation of intraneuronal proteinaceous inclusion bodies that can be observed in post mortem brain histology. Firstly, these inclusion bodies were described in 1912 by Friedrich Lewy and were later referred to as Lewy bodies (LBs). Together with the loss of dopaminergic neurons in the midbrain, LBs are defined as characteristic pathological hallmarks of PD (Gibb and Lees, 1988). LBs consist of various molecules including a-synuclein (aSyn), neurofilaments and ubiquitin (Baba et al., 1998; Spillantini et al., 1998; Spillantini et al., 1997). Similar pathologies are observed in other neurodegenerative diseases such as dementia with LBs, multiple lateral sclerosis and Alzheimer's disease, which are summarized as synucleinopathies (Hashimoto and Masliah, 1999; Spillantini et al., 1998; Spillantini and Goedert, 2000).

\section{2 a-synuclein in Parkinson's disease}

In 1997, Spillantini and colleagues discovered the small neuronal protein aSyn as the major constituent of LBs (Spillantini et al., 1997). In the same year, a missense mutation in the aSyn encoding gene was identified that causes autosomal dominant inherited form of PD resulting in earlier disease-onset than sporadic PD (Polymeropoulos et al., 1997). Since these findings, aSyn has been implicated as a key pathogenic factor in sporadic and familial form of PD. aSyn is a highly soluble protein of 140 amino acids, which is enriched in high concentration at presynaptic terminals (Maroteaux et al., 1988; Totterdell and Meredith, 2005). It is presumably involved in the regulation of SNARE-complex assembly of presynaptic vesicles and vesicle release of neurotransmitters (Abeliovich et al., 2000; Burre et al., 2010; Chandra et al., 2004; Lundblad et al., 2012). Moreover, several lines of evidence suggest a role in regulation of cell differentiation and phospholipid metabolism (Golovko et al., 2009; Oliveira et al., 2015). However, the physiological function of aSyn is still not 
completely defined. The nuclear localization of aSyn is a matter of intense debate. Numerous studies have shown that aSyn is localized in the nucleus (Huang et al., 2011; Yu et al., 2007). It may impair histone acetylation and thereby promote neurotoxicity (Goers et al., 2003; Kontopoulos et al., 2006).

aSyn is composed of three distinct regions (Figure 1). The N-terminus comprises of six 11amino acid repeats with a highly conserved hexamer motif (KTKEGV), which likely favours binding to phospholipid membranes (Jensen et al., 1998; Karube et al., 2008; Vamvaca et al., 2009). Interaction of aSyn to phospholipids promotes an unfolded-to-folded transition of the protein resulting in the formation of two long $\alpha$-helices interacting with the lipid micelles of the membrane (Chandra et al., 2003; Davidson et al., 1998; Sharon et al., 2001). The hydrophobic middle part of $\alpha$ Syn is defined as non-amyloid- $\beta$ component (NAC) and promotes formation of amyloid-like fibrils known as $\beta$-sheets (Giasson et al., 2001; Waxman et al., 2009). The acidic C-terminus, which is highly negatively charged, facilitates protein solubility and exhibits chaperone-like activity (Ahn et al., 2006; Souza et al., 2000b). aSyn can be targeted to nuclear compartments, which can be induced by oxidative stress (Specht et al., 2005; Xu et al., 2006).

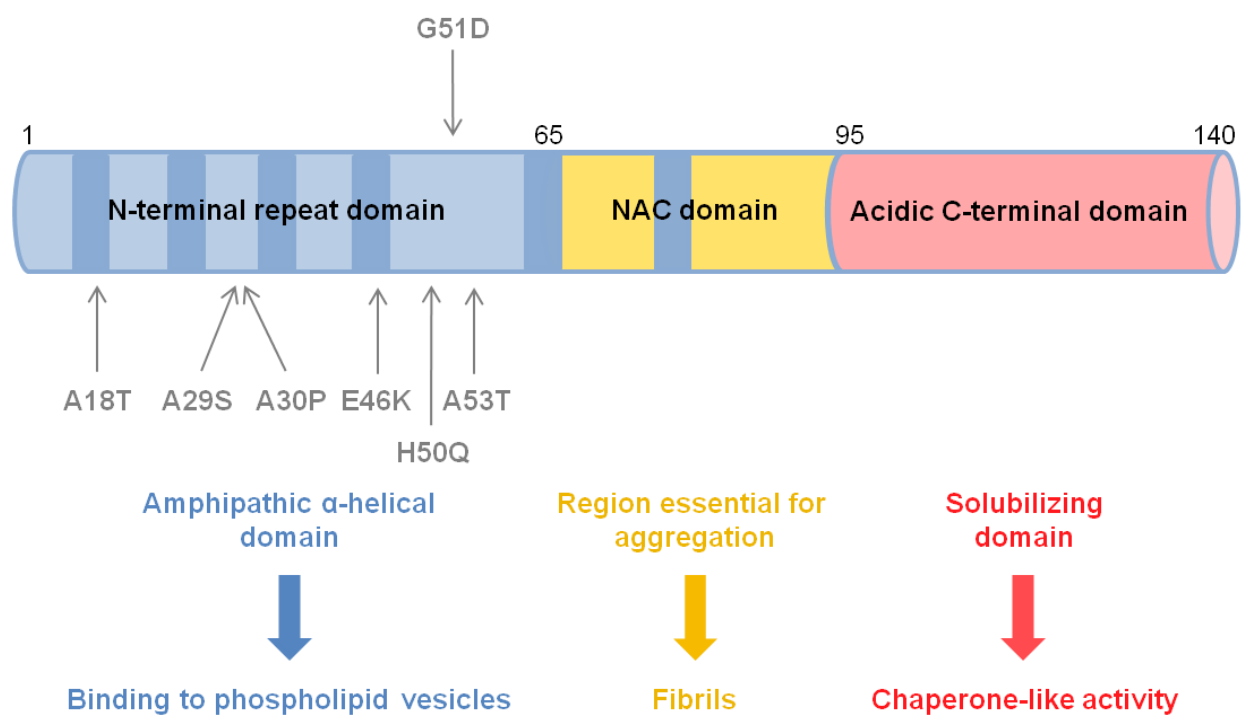

Figure 1. Schematic overview of human aSyn with the three distinct domains.

The six imperfect KTKEGV repeats are shown in dark blue. The N-terminus is indicated in blue, the non-amyloid- $\beta$ component (NAC domain) in yellow and the acidic $\mathrm{C}$-terminus in red. The N-terminus exhibits a binding affinity to phospholipids. The strong hydrophobic NAC domain promotes aggregate formation and the acidic C-terminus promotes solubility of aSyn. Grey arrows indicate the seven disease-associated mutation sites A18T, A29S, A30P, E46K, H50Q, G51D and A53T (for details and references, see Recchia et al., 2004; Sekiyama et al., 2014).

aSyn is encoded by the SNCA gene in the PARK1 gene locus (Campion et al., 1995; Chen et al., 1995) and belongs to a protein family of soluble proteins including $\beta$-synuclein and $\gamma$ synuclein (Clayton and George, 1998; Jakes et al., 1994; Maroteaux and Scheller, 1991). 
Seven independent point mutations in the SNCA gene locus as well as duplications or triplications of the wild-type aSyn locus have been described in familial inherited forms of PD (Figure 1; Appel-Cresswell et al., 2013; Athanassiadou et al., 1999; Kruger et al., 1998; Lesage et al., 2013; Polymeropoulos et al., 1997; Singleton et al., 2003; Zarranz et al., 2004). This makes aSyn a hallmark protein in the pathogenesis of PD and other synucleinopathies, which sparked an intense research to uncover the correlation between structural features of aSyn and its toxicity (Karpinar et al., 2009). All known missense mutations are confined to the $\mathrm{N}$-terminal repeat region of aSyn. Numerous reports have shown that the mutated aSyn variants exhibit aberrant molecular properties and physical features (Sahay et al., 2015). They affect oligomerization, aggregation, formation of fibrillar structures and subcellular distribution of the aSyn protein through the cell (Conway et al., 1998; Conway et al., 2000; Goncalves and Outeiro, 2013; Greenbaum et al., 2005; Lazaro et al., 2014; Li et al., 2001). For instance, the substitution of an alanine to proline at position 30 of A30P mutant disrupts the $\alpha$-helix and thereby reduces the affinity for binding phosholipid vesicles and shows increased propensities to aggregate (Jensen et al., 1998; Jo et al., 2002; Kruger et al., 1998; Li et al., 2001; Sahay et al., 2015).

\section{3 a-synuclein aggregation and propagation}

Parkinson's disease is characterized among others by pathological accumulation of misfolded aSyn proteins. These aSyn species are suggested to disrupt molecular mechanisms of specific cellular processes resulting in mitochondrial dysfunction, inhibition of protein degradation, ER-Golgi trafficking defects, disruption of vesicle-membrane fusion and impairment of histone acetylation (Chinta et al., 2010; Cooper et al., 2006; Devi et al., 2008; Emmanouilidou et al., 2010; Hsu et al., 2000; Kontopoulos et al., 2006; Martinez-Vicente et al., 2008; Snyder et al., 2003; Thayanidhi et al., 2010). aSyn aggregation was implicated in disruption of membranes, cytoskeleton changes and induction of oxidative stress (Chen et al., 2007; Junn and Mouradian, 2002; van Rooijen et al., 2009). aSyn was defined for a long time as a natively unfolded monomeric protein (Weinreb et al., 1996). This view was recently questioned by Bartels and colleagues showing aSyn as a helically folded tetramer that is resistant to amyloid-like aggregation (Bartels et al., 2011). Aggregation of aSyn is assumed to constitute the central pathological process in synucleinopathies. However, it is still not clear, which aSyn forms are the pathological species, how the aggregation pathway is initiated and whether LBs represent toxic or protective features. Accumulating evidence suggests oligomeric or protofibrillar forms of aSyn, rather than mature aggregates and fibrils, to be responsible for neurotoxicity (Choi et al., 2013; Conway et al., 2000; Karpinar et al., 2009; Winner et al., 2011). A wide range of factors can trigger aSyn misfolding and 
accumulation, e.g. mitochondrial dysfunction, abnormal proteasome function, oxidative stress, metals and neurotoxins such as 1-methyl-4-phenyl-1,2,3,6-tetrahydropyridine (MPTP) (Hashimoto et al., 1999; Kowall et al., 2000; Lee et al., 2002; Uversky et al., 2001; Vila et al., 2000; Yamin et al., 2003a). The initiation of the aSyn aggregation pathway either starts in the cytoplasm or in association with the plasma membrane. In the cytoplasm, unfolded aSyn monomers interact to generate unstable dimers, which are further converted to oligomers, protofibrillar oligomers and mature amyloid fibrils. Further accumulation of amyloid fibrils results in deposits within LBs (Auluck et al., 2010). Up to a third of the cellular aSyn population in the cell is bound to synaptic membranes (Visanji et al., 2011). The N-terminal region of aSyn possesses a high binding affinity to phospholipids. The $\mathrm{N}$-terminus binds to the membrane and triggers together with the central domain an unfolded-to-folded transition of aSyn resulting in the formation of two amphipathic $\alpha$-helices that interact with the lipid micelles (Chandra et al., 2003; Lorenzen et al., 2014). At high concentrations, this conformational change subsequently leads to the formation of membrane-bound- $\beta$-sheet-rich structures that self-assemble to oligomers and fibrils (Zhu et al., 2003). aSyn does not accomplish its regular biological role in this composition but gains cytotoxic ability.

Recently, a novel concept of progressive interneuronal spreading of Lewy pathology emerged that might contribute to the development and progression of PD and other synucleinopathies (Braak et al., 2003). Braak and colleagues suggest a prion-like propagation of pathological aSyn forms by transmission from one neuron to another. Several lines of evidence support this idea showing that propagation of pathological aSyn between cells leads to subsequent initiation of "LB-like aggregates" in the acceptor cells as well as progressive neurodegeneration (Desplats et al., 2009; Luk et al., 2012a; Luk et al., 2012b; Masuda-Suzukake et al., 2013; Recasens et al., 2014; Sacino et al., 2014).

\subsection{Posttranslational modifications of $\alpha$-synuclein}

Posttranslational modifications (PTMs) represent consistent markers of aSyn pathology within LBs (Anderson et al., 2006; Duda et al., 2000; Fujiwara et al., 2002; Giasson et al., 2000; Hasegawa et al., 2002; Paleologou et al., 2010). The precise contribution of different PTMs to the disease is still controversial. Several studies illustrated that PTMs influence the aSyn aggregation process and contribute to cellular neurotoxicity (Chen and Feany, 2005; Hodara et al., 2004; Norris et al., 2003; Oueslati et al., 2010). Major PTMs of aSyn include phosphorylation, ubiquitination, sumoylation, nitration, glycosylation or acetylation at multiple amino acid residues (Figure 2; Bartels et al., 2014; Dorval and Fraser, 2006; Duda et al., 2000; Fujiwara et al., 2002; Giasson et al., 2000; Guerrero et al., 2013; Hasegawa et al., 2002; Shimura et al., 2001). 


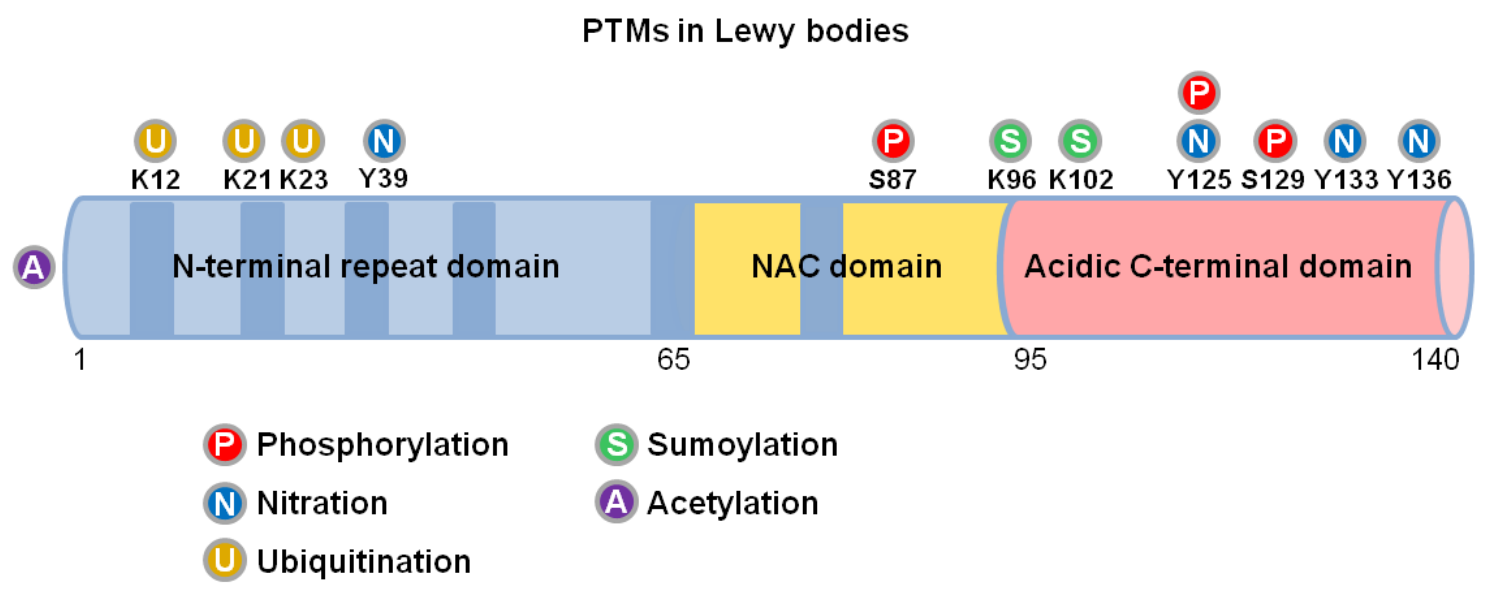

Figure 2. Posttranslational modifications of aSyn in Lewy bodies.

The locations of amino acid residues of the main disease-associated PTMs of aSyn (phosphorylation, nitration, ubiquitination, sumoylation and acetylation) identified in LBs are shown (for details and references, see Schmid et al., 2013).

PTMs such as phosphorylation, ubiquitination or sumoylation are primarily involved in modulating aSyn degradation by various proteolytic pathways. These PTMs are suggested to act as molecular switches that determine the preference of aSyn for a certain proteolytic process indicating their important role in balancing the protein level of aSyn. Since discovering posttranslationally modified aSyn in human cerebrospinal fluid and blood plasma (Borghi et al., 2000; El-Agnaf et al., 2003; Foulds et al., 2011), PTMs are considered as potential targets for biomarkers.

\subsubsection{Phosphorylation of $\alpha$-synuclein}

The predominant aSyn modification in LBs is phosphorylation at the residue serine 129 (S129). Approximately $90 \%$ of aSyn found in LBs is phosphorylated at this residue, whereas only $4 \%$ of the soluble monomeric aSyn is accordingly modified at physiological conditions (Anderson et al., 2006; Fujiwara et al., 2002). The molecular function of phosphorylation at S129 and its relevance in pathogenicity is still under debate (Tenreiro et al., 2014a). It was shown to play a role in regulation of $\alpha$ Syn localization, aggregation and toxicity. Studies in several mammalian models of PD have demonstrated a protective role of $\mathrm{S} 129$ phosphorylation on neuronal dysfunction (Gorbatyuk et al., 2008; Kuwahara et al., 2012). In contrast, neurotoxicity tests in rats revealed no protective effect of $\$ 129$ phosphorylation on aSyn toxicity (McFarland et al., 2009). In a Drosophila model of PD, a pathogenic role of aSyn S129 phosphorylation was observed (Chen and Feany, 2005). There, increase in the phosphorylation status of aSyn correlates with enhanced neurotoxicity. A number of 
heterologous studies in yeast support a suppressive effect of $\mathbf{S 1 2 9}$ phosphorylation on aSyn aggregation, vesicle trafficking and cytotoxicity (Sancenon et al., 2012; Zabrocki et al., 2008). This modification modulates clearance of aSyn inclusions in yeast cells (Tenreiro et al., 2014b). Phosphorylation at S129 suppressed the defects induced by impaired sumoylation such as increased number of cells with inclusions and reduced yeast growth (Shahpasandzadeh et al., 2014).

In human cells, several kinase families participate in S129 phosphorylation of aSyn, including Polo-like kinases (PLKs), G protein-coupled receptor kinases (GRKs), casein kinases (CKs) 1 and 2 and the leucine-rich repeat kinase 2 (LRRK2) (Oueslati et al., 2013; Pronin et al., 2000; Qing et al., 2009; Waxman and Giasson, 2008). GRK5-dependent phosphorylation of aSyn plays an important role in the pathogenesis of PD (Arawaka et al., 2006). The yeast Cdc5, ortholog of human PLK2, phosphorylates aSyn at the conserved S129 residue and rescues aSyn toxicity upon overexpression of the kinase (Gitler et al., 2009; Wang et al., 2012). Similar protective effects were provided by the yeast kinase Yck3, corresponding to human CK-1 (Zabrocki et al., 2008). Co-expression of PLK2 or GRK5 with aSyn in yeast significantly increased aSyn S129 phosphorylation (Shahpasandzadeh et al., 2014). Thereby, aSyn-induced cytotoxicity, which resulted from impairment of sumoylation, could be rescued by GRK5-mediated S129 phosphorylation. Recent studies in yeast revealed that expression of phosphorylation deficient variants, S129A or S129G, promotes aSyn-induced toxicity and inclusion formation (Tenreiro et al., 2014b). These findings support a protective function of $\mathrm{S} 129$ phosphorylation in yeast.

\subsubsection{Nitration of $\alpha$-synuclein}

Nitrated aSyn represents another classical posttranslational modification found in LBs (Duda et al., 2000; Giasson et al., 2000). Nitration is a chemical process which incorporates a nitro group $\left(\mathrm{NO}_{2}{ }^{-}\right)$into proteins, lipids or nucleic acids via a radical-based mechanism. Tyrosine residues are the preferred nitration sites of proteins. Nitration changes the tyrosine residue into a negatively charged hydrophilic 3-nitrotyrosine (Figure 3). This modification modulates key properties of the amino acid including phenol group $\mathrm{pK}_{\mathrm{a}}$ redox potential, hydrophobicity and volume, which leads to profound structural and functional changes (Radi, 2012). Tyrosine nitration is a marker for nitrative stress, which is mediated by reactive nitrogen species (RNS) such as peroxynitrite anion (ONOO, $\mathrm{PON}$ ) or nitrogen dioxide ( $\left.{ }^{\circ} \mathrm{NO}_{2}\right)$ formed as secondary products of the small gaseous molecule nitric oxide ('NO) metabolism (Ischiropoulos, 1998; Radi, 2004; Schildknecht et al., 2013). "NO is enzymatically generated from L-arginine by nitric oxide synthases. 
A

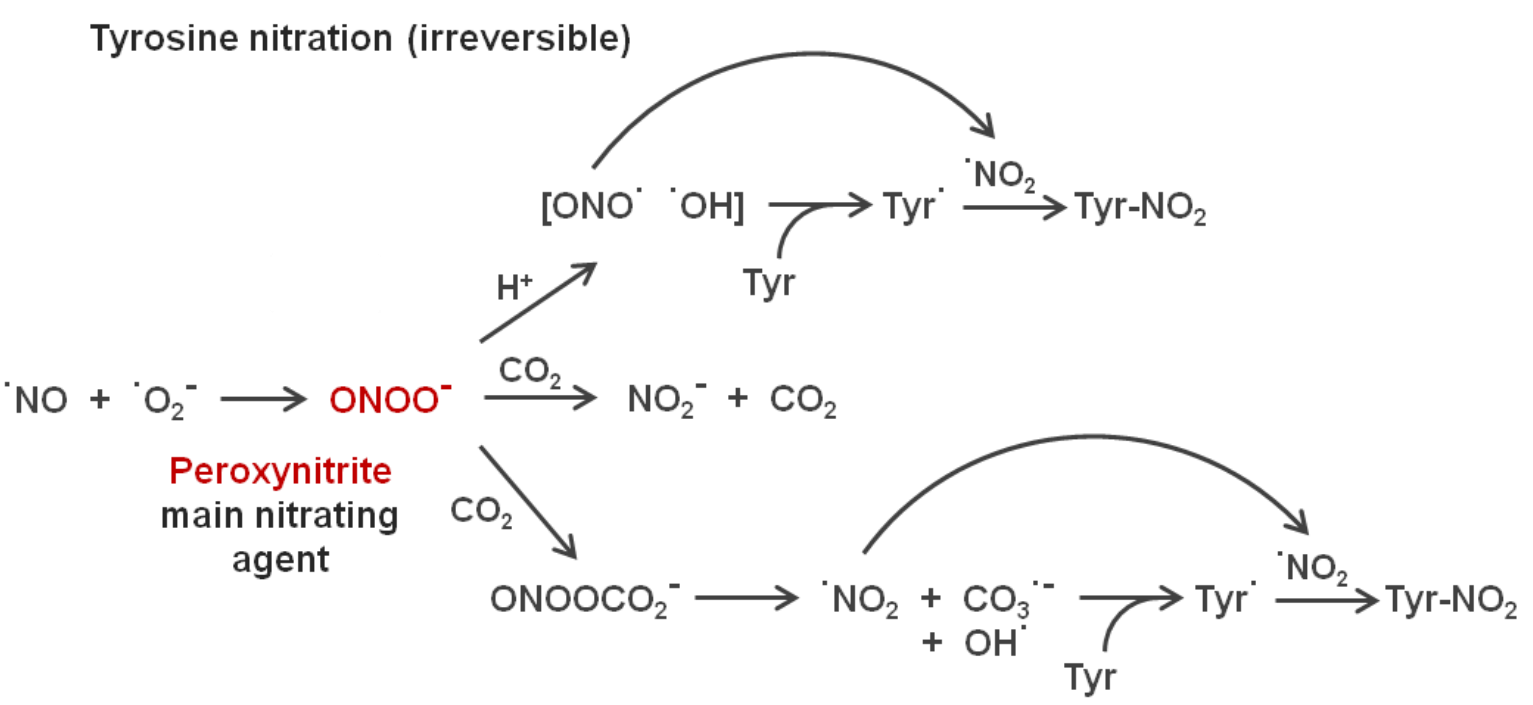

B

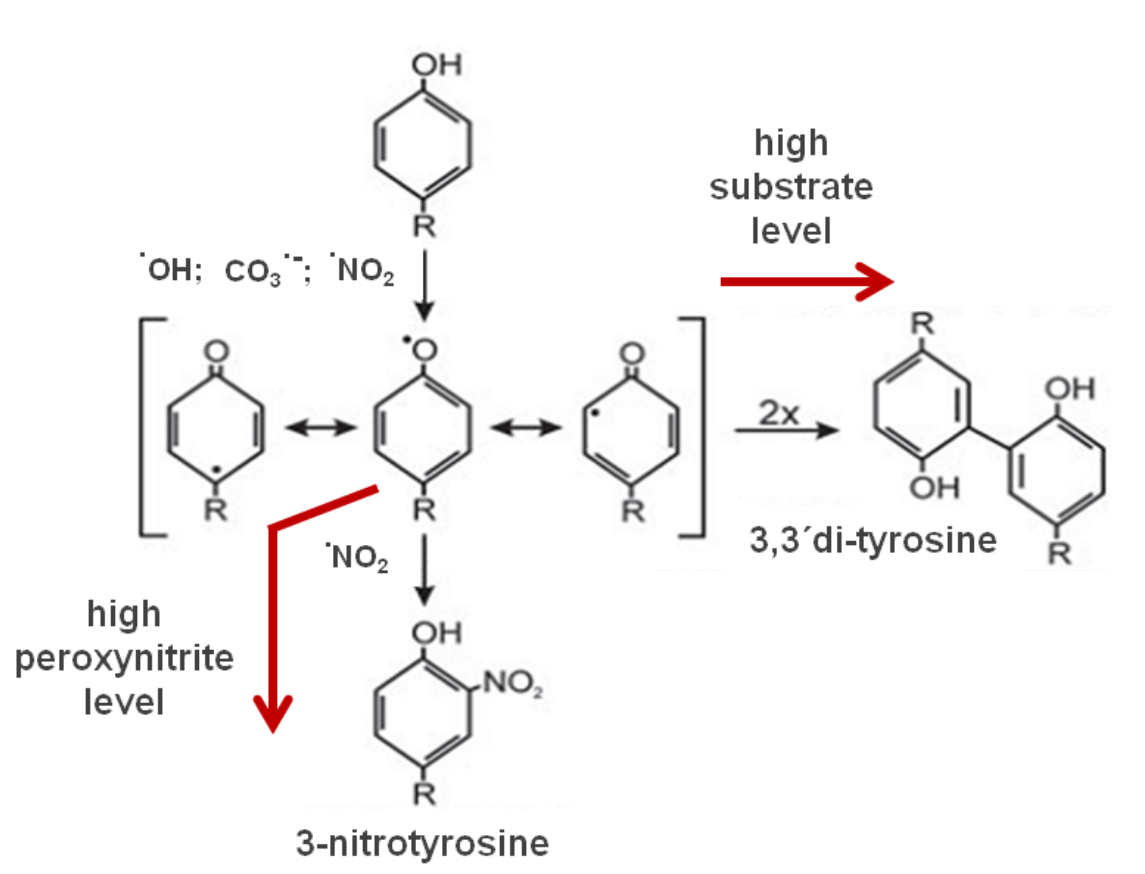

Figure 3. Tyrosine nitration and di-tyrosine formation.

(A) The free radicals nitric oxide $\left({ }^{\circ} \mathrm{NO}\right)$ and superoxide $\left({ }^{\circ} \mathrm{O}_{2}{ }^{-}\right)$react to generate peroxynitrite (ONOO-). Under physiological $\mathrm{pH}$ conditions, 20-30\% of peroxynitrite is protonated to peroxynitrous acid $(\mathrm{ONOOH})$. This strong oxidant is chemically unstable and dissociates readily into the highly reactive nitrogen dioxide $\left({ }^{\circ} \mathrm{NO}_{2}\right)$ and hydroxyl radicals $\left({ }^{\circ} \mathrm{OH}\right)$. ${ }^{\circ} \mathrm{NO}_{2}$ radicals represent the actual nitrating species, which can react with tyrosine residues to generate tyrosyl radicals. In the presence of high concentrations of carbon dioxide/bicarbonate $\left(\mathrm{CO}_{2}\right)$ in the cell, ONOO can also interact with $\mathrm{CO}_{2}$, which either results in the production of $\mathrm{NO}_{2}^{-}$and $\mathrm{CO}_{2}$ (two thirds of product) or ${ }^{\circ} \mathrm{NO}_{2}$ and $\mathrm{CO}_{3}{ }^{-}$(one third of product). These radicals can interact with tyrosine residues to produce tyrosyl radicals. Further reaction with ${ }^{\circ} \mathrm{NO}_{2}$ results in the formation of 3-nitrotyrosine. (B) ${ }^{\circ} \mathrm{NO}_{2}, \mathrm{CO}_{3}{ }^{\cdot-}$ and ${ }^{\circ} \mathrm{OH}$ radicals react in radical-based mechanism with tyrosine residues and an unstable tyrosyl radical is formed. This tyrosyl radical either reacts with a ${ }^{\prime} \mathrm{NO}_{2}$ radical to form 3-nitrotyrosine or alternatively reacts with another tyrosyl residues, which results in the formation of a covalent 3,3'di-tyrosine bond (modified from Schildknecht et al., 2013). 
Nitric oxide can serve as an endogenous signalling molecule involved in the regulation of physiological processes, e.g. cardiovascular, immune and nervous system (Martinez-Ruiz and Lamas, 2009; Moncada, 1999; Schildknecht and Ullrich, 2009). NO-mediated signalling processes are summarized as "redox regulation" (Frein et al., 2005; Schildknecht and Ullrich, 2009).

aSyn possesses four tyrosine residues at position 39, 125, 133 and 136 that were identified as nitration sites (Sevcsik et al., 2011). In vitro studies demonstrated that all four tyrosine residues are also phosphorylation targets (Ahn et al., 2002; Ellis et al., 2001; Mahul-Mellier et al., 2014; Nakamura et al., 2001; Negro et al., 2002; Takahashi et al., 2002). In vivo, only Y39 and Y125 were identified as phosphorylation sites (Kiely et al., 2013; Mahul-Mellier et al., 2014). Y39 is located within the N-terminal KTKEGV repeat region and the other three tyrosine residues are located at the C-terminal end of aSyn in close neighbourhood to the protective S129 phosphorylation site. Exposure of aSyn to nitrative agents results in the formation of aSyn oligomers and higher molecular weight aSyn species that are resistant to strong denaturing conditions. This suggests that aSyn proteins are covalently crosslinked (Paxinou et al., 2001; Souza et al., 2000a; Takahashi et al., 2002; Uversky et al., 2005; Yamin et al., 2003b). This oligomerization can be abolished in vitro when aSyn lacks the four tyrosine residues at positions 39, 125, 133 and 136 (Norris et al., 2003).

Nitrating agents such as PON can nitrate tyrosine residues of aSyn to generate 3nitrotyrosine (3-NT). Alternatively, highly stable 3,3'-di-tyrosine oligomers can be formed including dimers, trimers and higher oligomeric species (Hodara et al., 2004; Pfeiffer et al., 2000; Souza et al., 2000a). The majority of studies were performed in vitro after exposure of aSyn to nitrating agents leading to non-specific nitration at all tyrosine residues. It is still unclear, whether the nitration-modified aSyn intermediates are toxic and what are the functional consequences of these modifications. Even the precise positions or preferred combinations of the tyrosines involved in di-tyrosine formation in vivo are unknown yet.

\subsection{Detoxification of nitric oxide by hemoglobins}

Nitric oxide is a free radical which acts under normal conditions as signalling molecule in a diverse set of physiological processes (Martinez-Ruiz and Lamas, 2009; Schildknecht and Ullrich, 2009). High concentrations of nitric oxide harm the cell due to increased oxidative and nitrative stresses. Eukaryotes evolved many strategies for combating the damaging effects of nitric oxide. The use of detoxification enzymes is one valuable strategy to prevent the attack by nitric oxide. The flavohemoglobins are prominent among the detoxification enzymes. The heme of the hemoglobin domain binds $\mathrm{NO}$ and catalyses the conversion of 
- $N O$ to the more stable nitrous oxide $\left(\mathrm{N}_{2} \mathrm{O}\right)$ via a $\mathrm{NO}$ dioxygenase reaction to detoxify the nitric oxide radical. In yeast, the gene YHB1 (yeast flavohemoglobin) is involved in oxidative and nitrative stress responses (Cassanova et al., 2005). This gene encodes a nitric oxide oxidoreductase, which protects against nitration of cellular targets and against cell growth inhibition under aerobic and anaerobic conditions (Liu et al., 2000). Expression of YHB1 is increased under aerobic conditions (Crawford et al., 1995; Zhao et al., 1996).

A BLAST search for human homologues of yeast $Y H B 1$ revealed $49 \%$ sequence similarity of the globin domain of Yhb1 to the human neuroglobin. Both Yhb1 and neuroglobin contain a globin domain and are members of the globin gene family. Neuroglobins are oxygen-binding proteins that are highly conserved among other vertebrates and are expressed in the central and peripheral nervous system. They provide protection against hypoxic induced cell injury in the brain, which is associated with ROS and RNS accumulation (Greenberg et al., 2008).

\subsection{Degradation pathways of $\alpha$-synuclein}

One hypothesis of aSyn-induced toxicity includes gain of toxic function due to increased expression levels which is caused by the multiplication of the SNCA gene leading to enhanced amounts of misfolded or aggregated aSyn (Outeiro and Lindquist, 2003; Petroi et al., 2012; Singleton et al., 2003). This is further confirmed by findings which demonstrate that inhibition of degradation pathways resulting in inefficient protein clearance is sufficient to trigger neurotoxicity (Vilchez et al., 2014). The understanding of aSyn turnover machinery is an essential aspect to uncover the pathological mechanism of PD.

In eukaryotic cells, degradation of non-functional or potentially toxic proteins is primarily carried out by two pathways, the ubiquitin-proteasome or the autophagy-lysosome/vacuole system (Goldberg, 2003; Klionsky and Emr, 2000). Both pathways were suggested to contribute to aSyn degradation (Webb et al., 2003). The ubiquitin-proteasome pathway mostly degrades short-lived, soluble proteins (Goldberg, 2003). Numerous studies demonstrated that the 26S proteasome is important for aSyn degradation (Bennett et al., 1999; McLean et al., 2001; Tofaris et al., 2001). It is considered as the main degradation pathway for aSyn under normal conditions (Ebrahimi-Fakhari et al., 2011). The involvement of the 26S proteasome in aSyn toxicity is conserved in yeast (Chen et al., 2005; Outeiro and Lindquist, 2003; Sharma et al., 2006).

The ubiquitin-proteasome pathway shows only a minor contribution in yeast compared to the autophagy-vacuole system for degradation of aSyn aggregates (Petroi et al., 2012). Generally, the autophagy-lysosome/vacuole system is suggested to degrade longer-lived macromolecules such as large oligomeric and aggregated species (Klionsky and Emr, 2000; 
Lee et al., 2004). It takes care of misfolded proteins under pathological conditions when the ubiquitin-proteasome system is impaired as during aSyn-induced toxicity (Ebrahimi-Fakhari et al., 2011; Lee et al., 2004). Numerous studies demonstrated a contribution of the autophagy-lysosome/vacuole system to aSyn degradation. The autophagy-stimulating drug rapamycin promotes aSyn clearance (Webb et al., 2003) and causes reduction of aSyn aggregates (Zabrocki et al., 2005).

PTMs serve as molecular switches that determine the preference of aSyn degradation for a certain proteolytic pathway. It was shown that de-ubiquitinated aSyn is preferentially degraded by autophagy system, whereas mono-ubiquitinated aSyn favours the proteasome (Rott et al., 2011). S129-phorphorylated aSyn is targeted to the $26 \mathrm{~S}$ proteasome in an ubiquitin-independent manner (Machiya et al., 2010). In yeast, increased phosphorylation of aSyn mediated by PLK2 leads to aggregate clearance by the autophagy-vacuole system and suppressed cytotoxicity (Oueslati et al., 2013). Further studies in yeast revealed that sumoylation preferentially directs aSyn aggregates towards autophagy (Shahpasandzadeh et al., 2014). Impaired aSyn sumoylation results in growth inhibition and increased aggregate formation. Phosphorylation at S129 suppresses this defect by shifting the fate of aSyn to increased ubiquitination and proteasome degradation (Shahpasandzadeh et al., 2014).

\subsection{Saccharomyces cerevisiae as model for Parkinson's disease}

The budding yeast Saccharomyces cerevisiae is a simple eukaryotic model system which is used to uncover the correlation between structural features of aSyn and its toxicity. Although a homologue of the SNCA gene is not present in the yeast genome (Lavedan, 1998), it provides a unique tool to study the molecular basis of PD in vivo (Franssens et al., 2010). Protein quality control systems are highly conserved between yeast and humans manifesting yeast as valuable model system for studying protein misfolding and cellular pathways associated with neurodegenerative diseases (Botstein et al., 1997; Tenreiro et al., 2013). Due to its high susceptibility to genetic manipulations, the short generation time of $\sim 90$ minutes and a wide range of genetic tools available, yeast is ideally convenient to study the function of genes implicated in human disease (Mager and Winderickx, 2005).

The yeast genome is well characterized. It consists of 16 chromosomes and contains 6217 genes (Goffeau et al., 1996). $44 \%$ of the yeast genes reveal significant sequence similarities to human genes (Hughes, 2002). Yeast and humans share significant cellular pathways that regulate key aspects of eukaryotic cell biology, including cell cycle, vesicular transport and programmed cell death (Bonifacino and Glick, 2004; Botstein et al., 1997; Brodsky and Skach, 2011; Hartwell, 2002; Munoz et al., 2012). 
Heterologous expression of different forms of human aSyn in yeast cells recapitulates central features of PD, including dose-dependent toxicity and aggregation (Outeiro and Lindquist, 2003; Petroi et al., 2012). In yeast, aggregation of aSyn causes vesicle traffic defects, proteasome dysfunction and damage to cellular membranes (Cooper et al., 2006; Gitler et al., 2008; Outeiro and Lindquist, 2003; Soper et al., 2008). Aggregation of aSyn induces mitochondrial dysfunction and the formation of reactive oxygen and nitrogen species in yeast cells (Flower et al., 2005; Hsu et al., 2000; Junn and Mouradian, 2002; Outeiro and Lindquist, 2003; Parihar et al., 2008; Parihar et al., 2009; Su et al., 2010; Witt and Flower, 2006), which is similar to mammalian cells.

To probe the toxicity of aSyn in yeast, transgenic yeast cells were engineered carrying human aSyn (Outeiro and Lindquist, 2003; Petroi et al., 2012). Thereby, aSyn was Cterminally fused to GFP via KLID linker. The fusion construct is integrated into the genome or is externally present on a plasmid under the control of galactose-inducible promoter (GAL1promoter). The benefit of the GAL1-promoter is that it can be switched on and off by supplementing galactose into the medium as an inducer of expression. This allows investigating the situation in the presence or absence of the gene of interest.

When expressing a single copy of the gene in yeast, aSyn associates with plasma membrane in a highly selective manner and has no obvious effect on yeast viability (Figure 4). Expression of two GAL1-driven copies causes formation of cytoplasmic inclusions and expression of three copies results in yeast growth impairment and strong increase in aggregate formation. Thus, aSyn toxicity increases in a copy number-dependent manner, similar to a familial form of PD linked with allele multiplication of the wild-type SNCA locus driven by its own human promoter (Chartier-Harlin et al., 2004; Hardy et al., 2006; Singleton et al., 2003). Three GAL1-driven copies of wild-type aSyn and two copies of A53T were determined as thresholds for cytotoxicity and aggregation in yeast (Petroi et al., 2012). Similar to wild-type and A53T aSyn, expression of E46K mutant results in significant growth inhibition and formation of inclusions (Lazaro et al., 2014). 
A

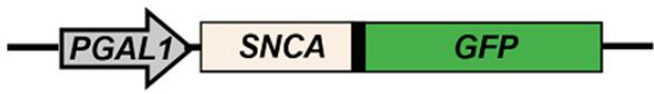

B

aSyn-GFP

C
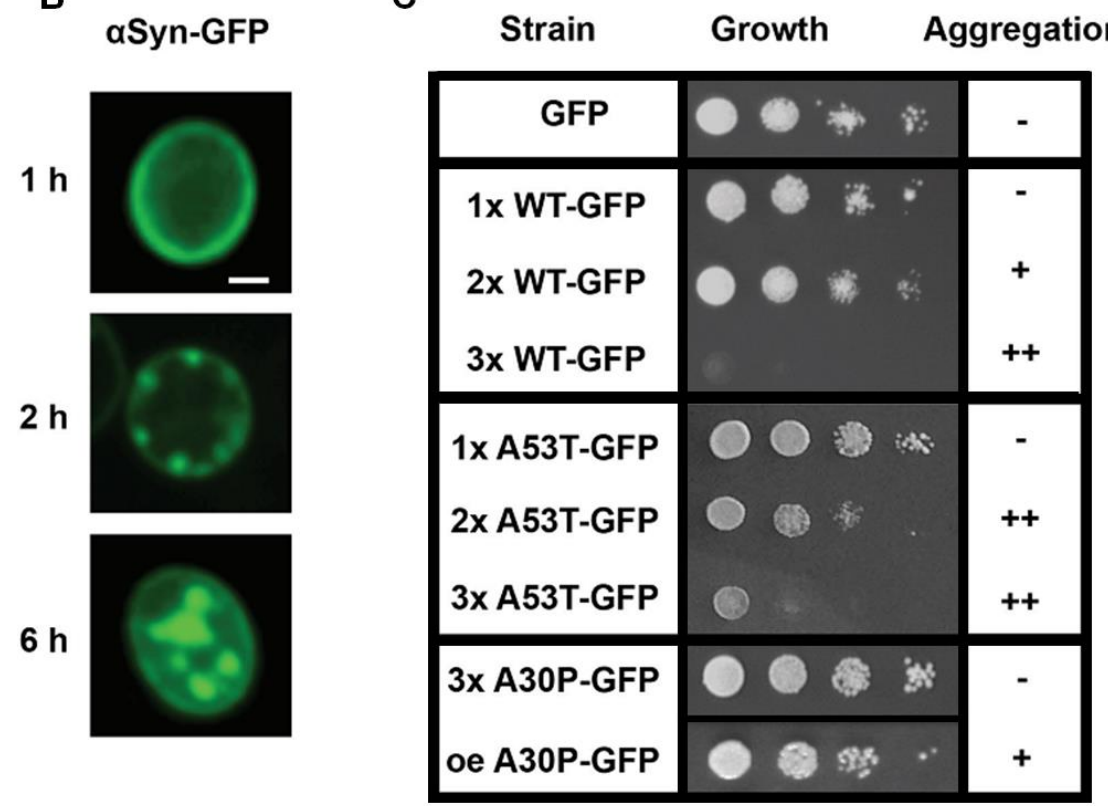

Figure 4. Localization of aSyn in yeast and its impact on growth.

(A) GFP-fused human aSyn (SNCA) is expressed from the galactose-inducible yeast GAL1promoter (PGAL1). GFP was C-terminally fused to aSyn via KLID linker. (B) Fluorescence microscopy of time-dependent aggregate formation of aSyn, expressed from a high-copy plasmid $(2 \mu)$. After one hour $(\mathrm{h})$ induction of aSyn expression, the protein is localized at the plasma membrane. Two hours of aSyn expression results in nucleation of aSyn at the plasma membrane and formation of small membrane-localised aggregates. After six hours of aSyn expression, large cytoplasmic aggregates are formed. Scale bar $=1 \mu \mathrm{m}$. (C) Growth behaviour of yeast cells expressing increasing copy numbers of GAL1-driven wild-type aSyn fused to GFP (WT-GFP) and two different familial mutants of aSyn. Growth analysis indicates decreased growth with increasing copy number of wild-type and A53T aSyn but not A30P; oe, overexpression (Popova et al., 2015).

An unusual feature of the yeast system, which is different from PD and other models, is that the A30P variant only forms inclusions when highly expressed and fails to display a growth inhibition in yeast, because aggregation of A30P is only transient (Dixon et al., 2005; Petroi et al., 2012). Expression of A30P aSyn has different toxicity properties in yeast compared to human cells. Whereas wild-type and A53T aSyn are delivered to the plasma membrane, A30P is located in the cytoplasm. Three integrated copies of A30P aSyn do not impair yeast growth. Only overexpression from a high-copy number plasmid results in formation of fluorescent foci, similar to the foci obtained by the other variants. However, the impact of A30P overexpression on yeast growth is not considerable in comparison with wild-type and A53T variants (Petroi et al., 2012). 


\subsection{Aims of the study}

A pathological hallmark of PD is the accumulation of posttranslationally modified aSyn aggregates in susceptible neurons in the form of LBs. PTMs of aSyn are important triggers for aggregation and cytotoxicity properties. Nitrative stress leading to aSyn nitration is implicated in the pathogenesis of the disease. Four tyrosine residues of aSyn were identified as nitration sites. aSyn nitration results in the formation of 3-NT or alternatively in the formation of covalently crosslinked di-tyrosine dimers. It is still not resolved whether the nitration-modified aSyn intermediates are toxic or what is the functional consequence of these modifications. The precise positions or preferred combinations of the tyrosines involved in di-tyrosine formation in vivo are also still elusive. Moreover, the interplay between nitration and other PTMs such as phosphorylation at the protective S129 residue was never sufficiently addressed.

In this study, the budding yeast was used as reference cell to study the impact of nitration on aSyn aggregation and aSyn-mediated toxicity. The toxic wild-type aSyn and the A30P mutant that is not toxic in yeast were compared. In the first part of the thesis, nitration, phosphorylation and dimerization sites were determined in vivo using LC-MS. In vitro nitrated aSyn after PON-exposure was used to examine the effect of nitration on aSyn dimer and oligomer formation. aSyn tyrosine mutants inhibited in modification were explored by growth and aggregation tests to address the question, whether nitration is involved in aSyn aggregation and toxicity. A yeast strain was used that lacks $Y H B 1$, a gene involved in nitrative stress response, to investigate aSyn-induced cytotoxicity under increased intracellular nitrative stress. Tyrosine and S129 mutants impaired in modifications were analyzed by growth, aggregation and immunoblot analysis using a phospho-S129 antibody in order to elucidate, whether there is an interplay between nitration and phosphorylation at S129. In the last part of the thesis, it was examined how tyrosine modifications affect autophagy or proteasome-mediated clearance of aSyn aggregates. 


\section{Materials and Methods}

\subsection{Materials}

\subsubsection{Companies of chemicals, molecular biological substances and equipment}

Chemicals for the preparation of buffers, solutions and media were obtained from the companies Carl Roth GmbH \& CO. KG (Karlsruhe, Germany), Invitrogen (Carlsbad, USA), Roche (Basel, Switzerland), Sigma-Aldrich (St. Louis, USA), AppliChem GmbH (Darmstadt, Germany), Becton Dickinson (Franklin Lakes, USA) and Merck KGaA (Darmstadt, Germany). Agarose was used from Biozyme Scientific GmbH (Hessisch Oldendorf, Germany). Bradford solution "Roti®-Quant" for the determination of protein concentration was used from Carl Roth GmbH \& CO. KG (Karlsruhe, Germany).

Restriction enzymes and polymerases were purchased from Thermo Fisher Scientific (Waltham, USA). For RNA degradation, RNase A from Roche (Basel, Switzerland) was used. Proteases, trypsin and Asp-N, were purchased from Serva Electrophoresis GmbH (Heidelberg, Germany) and Sigma-Aldrich (St. Louis, USA). Primary antibodies were purchased from Abcam (Cambridge, UK), JaICA (Shizuoka, Japan), Upstate Biotechnology Inc (Lake Placid, USA), Wako Pure Chemical Industries Ltd (Osaka, Japan), Santa Cruz Biotechnology Inc (Dallas, USA), AnaSpec Inc (Fremont, USA) and Thermo Fisher Scientific (Waltham, USA). Secondary antibodies were purchased from Invitrogen (Carlsbad, USA) and Jackson ImmunoResearch Laboratories (West Grove, USA). Synthetic oligonucleotides were purchased from Sigma-Aldrich (St. Louis, USA). For cloning, the GeneArt ${ }^{\circledR}$ Seamless Cloning and Assembly Enzyme Mix from Invitrogen (Carlsbad, USA) was used. Substitution of amino acids was performed with the QuikChange II Site-Directed Mutagenesis Kit from Agilent Technologies (Santa Clara, USA). As DNAsize and protein-weight standards the DNA-marker "GeneRuler 1kb DNA ladder" and the protein-marker "PageRuler Prestained Protein Ladder" were used from Thermo Fisher Scientific (Waltham, USA). Saccharomyces cerevisiae wild-type and deletion strains were purchased from EUROSCARF (Frankfurt, Germany). Mammalian expression vector pcDNA3.1 was obtained from Invitrogen (Carlsbad, USA).

Solutions were filtered to sterility using Filtropur S 0.2 and S 0.45 filters from Sarstedt AG \& Co (Nümbrecht, Germany). For plasmid DNA purification from Escherichia coli and DNA extraction from agarose gels the kits "QIAGEN Plasmid Mini Prep Kit" and "QIAquick Gel Extraction Kit" from QIAGEN (Hilden, Germany) were used. DNA concentrations were measured using the "NanoDrop ND-1000 photospectrometer" from Peqlab Biotechnologie GmbH (Erlangen, Germany). PCR reactions were performed using the "MWG Biotech Inc Primus 96 Thermal Cycler" from MWG-Biotech (Ebersberg, Germany). Gel electrophoresis 
was done in the "Mini-Sub Cell GT" chamber using the "Powerpac 300" power supply from Bio-Rad Laboratories (Hercules, USA). SDS-PAGE and protein immunoblotting were performed using the "Mini-PROTEAN® 3 Cell", "Mini Trans-Blot ${ }^{\circledR}$ Electrophoretic Cell" and the "Powerpac 300" power supply from Bio-Rad Laboratories (Hercules, USA). For protein transfer, the nitrocellulose membrane "Amersham ${ }^{\mathrm{TM}}$ Protran $^{\mathrm{TM}} 0.45 \mu \mathrm{m}$ NC" from GE Healthcare (Little Chalfont, UK) and the "Amersham ${ }^{\mathrm{TM}}$ Hybond-PTM $0.45 \mu \mathrm{m}$ PVDF" from GE Healthcare (Little Chalfont, UK) were used. Chemiluminescence was detected using the "Amersham ${ }^{T M}$ Hyperfilm $^{T M}$ ECL" from GE Healthcare (Little Chalfont, UK). Exposing Hyperfilms $^{\mathrm{TM}}$ for immunoblot techniques occurred with the "Optimax X-ray Film Processor" from PROTEC GmbH \& Co. KG (Oberstenfeld, Germany). Optical density was measured by T80 UV/VIS spectrometer from PG Instruments Ltd (Lutterworth, UK) or alternatively by the microplate reader "Infinite $\AA$ M200" from Tecan Group (Männedorf, Switzerland). Centrifugations were performed with the centrifuge "Biofuge pico" from the company Heraeus (Hanau, Germany), "Centrifuge 5804R" from Eppendorf AG (Hamburg, Germany), "Centrifuge 4K15" from Sigma Laborzentrifugen GmbH (Osterode am Harz, Germany) or "Sorvall RC-3B Plus Refrigerated Centrifuge" from Thermo Fisher Scientific (Waltham, USA). Incubation of agar plates at $37^{\circ} \mathrm{C}$ was performed in the incubator "BD 53/E2" from BINDER GmbH (Tuttlingen, Germany) and incubation at $30{ }^{\circ} \mathrm{C}$ was performed in the incubator "BE 400" from Memmert GmbH + Co. KG (Schwabach, Germany). Other instrumentation, manufacturers or certain variations are named in the further work.

\subsubsection{Strains, plasmids and oligonucleotides}

The Saccharomyces cerevisiae strains, plasmids and oligonucleotides used in this study are listed in Table 1 to 3. Escherichia coli strain DH5a [ $\triangle 80$ dlacZ $\triangle M 15$, recA1, endA1, gyrA96, thi-1, hsdR17 (rK-, mK+), supE44, relA1, deoR, $\triangle$ (lacZYA-argF) U169] was used for general cloning procedures and purification of plasmid DNA (Meselson and Yuan, 1968; Woodcock et al., 1989). Human aSyn cDNA sequence and the corresponding A30P sequence were expressed from yeast high expression vector pME2795 $(2 \mu)$ under the GAL1-promoter and CYC1 terminator as described previously (Petroi et al., 2012). YHB1 sequence was amplified on genomic DNA from Saccharomyces cerevisiae and cloned into pME2788 low expression vector (CEN/ARS) or pME2792 high expression vector $(2 \mu)$ proceeded by GAL1-promoter and CYC1 terminator (Mumberg et al., 1994). NGB was amplified on CDNA sequence and cloned into pME2788 low expression vector (CEN/ARS). Additionally, NGB was cloned into the mammalian high expression vector pcDNA3.1 (Invitrogen), which is proceeded by $C M V$ promoter. The 4(Y/F) aSyn mutant constructs were generated by site-directed mutagenesis using QuikChange II Site-Directed Mutagenesis Kit (Agilent Technologies). Plasmids 
pME3763, pME3764, pME4095 and pME4101 were used as templates to substitute successively the four tyrosines (Y39, Y125, Y133, and Y136) by phenylalanine. Plasmids pME3763, pME3764 and pME4095 were used as templates to substitute serine 129 to alanine. For growth and microscopy studies, aSyn variants were used that are C-terminally tagged with GFP via the KLID linker (Petroi et al., 2012). For $\mathrm{Ni}^{2+}-\mathrm{NTA}$ affinity chromatography, aSyn and A30P were C-terminally fused to His ${ }_{6}$-tag using pME3760 and pME3761 as templates. All constructs were verified by DNA sequencing. As negative control, the empty vector pME2788, pME2792 and pME2795, or the GFP expressing vector pME3759 was used.

Table 1. Yeast strains

\begin{tabular}{|c|c|c|}
\hline Strain & Genotype & Source \\
\hline BY4741 & 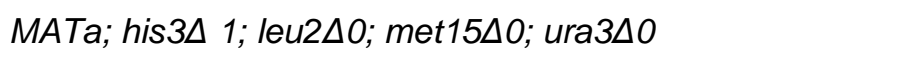 & EUROSCARF \\
\hline$\Delta y h b 1$ & $\begin{array}{l}\text { Y05887 (EUROSCARF): BY4741; MATa; his3D1; leu2Do; } \\
\text { met15D0; ura3D0; YGR234w::kanMX4 }\end{array}$ & EUROSCARF \\
\hline
\end{tabular}

Table 2. Plasmids

\begin{tabular}{|c|c|c|}
\hline Plasmid & Description & Source \\
\hline pME2788 & $\begin{array}{l}\text { pRS413-GAL1-promoter, CYC1-terminator, HIS3, CEN/ARS, } \\
\text { pUC origin, Amp }{ }^{R}\end{array}$ & $\begin{array}{l}\text { (Mumberg et al., } \\
\text { 1994) }\end{array}$ \\
\hline pME2792 & $\begin{array}{l}\text { pRS426-GAL1-promoter, CYC1-terminator, HIS3, } 2 \mu m, p U C \\
\text { origin, } A m p^{R}\end{array}$ & $\begin{array}{l}\text { (Mumberg et al., } \\
\text { 1994) }\end{array}$ \\
\hline pME2795 & $\begin{array}{l}\text { pRS426-GAL1-promoter, CYC1-terminator, URA3, } 2 \mu m, p U C \\
\text { origin, } A m p^{R}\end{array}$ & $\begin{array}{l}\text { (Mumberg et al., } \\
\text { 1994) }\end{array}$ \\
\hline pME3759 & pME2795 with GAL1::GFP & (Petroi et al., 2012) \\
\hline pME3760 & pME2795 with GAL1::SNCA ${ }^{\mathrm{WT}}$ & (Petroi et al., 2012) \\
\hline pME3761 & pME2795 with GAL1::SNCA A30P & (Petroi et al., 2012) \\
\hline pME3763 & pME2795 with GAL1::SNCA ${ }^{\mathrm{WT}}::$ GFP & (Petroi et al., 2012) \\
\hline pME3764 & pME2795 with GAL1::SNCA A30P::GFP & (Petroi et al., 2012) \\
\hline pME4088 & pME2795 with GAL1::SNCAWTY125F::GFP & (Lazaro et al., 2014) \\
\hline pME4095 & pME2795 with GAL1::SNCAWT::6 x HIS & $\begin{array}{l}\text { (Shahpasandzadeh } \\
\text { et al., 2014) }\end{array}$ \\
\hline pME4101 & pME2795 with GAL1::SNCA A30P::6 $\times$ HIS & This study \\
\hline pME4104 & pME2788 with $G A L 1:: N G B$ & This study \\
\hline pME4351 & pME2788 with GAL1::YHB1 & This study \\
\hline pME4352 & pME2795 with GAL1::SNCAWTY39/125/133/136F::GFP & This study \\
\hline pME4353 & pME2795 with GAL1::SNCAWTY39/125/133/136F::6 x HIS & This study \\
\hline pME4354 & 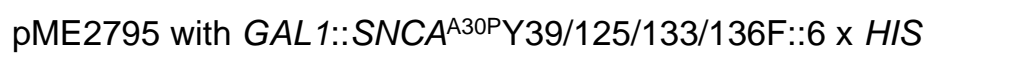 & This study \\
\hline
\end{tabular}




\begin{tabular}{|c|c|c|}
\hline Plasmid & Description & Source \\
\hline pME4355 & pME2795 with GAL1::SNCA ${ }^{\mathrm{A} 30 \mathrm{P} Y 39 / 125 / 133 / 136 \mathrm{~F}:: G F P}$ & This study \\
\hline pME4356 & pcDNA3.1 & Invitrogen \\
\hline pME4357 & pcDNA3.1. with $C M V:: N G B:: m$ Cherry & This study \\
\hline pME4451 & pME2795 with GAL1::SNCAWTY39F::GFP & This study \\
\hline pME4452 & pME2795 with GAL1::SNCA ${ }^{\mathrm{WT} Y 39 F:: 6} \times$ x HIS & This study \\
\hline pME4453 & 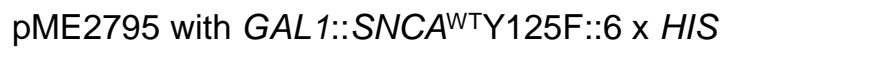 & This study \\
\hline pME4454 & pME2795 with GAL1::SNCA ${ }^{\mathrm{WT} Y 125 / 133 / 136 \mathrm{~F}:: G F P}$ & This study \\
\hline pME4455 & pME2795 with GAL1::SNCAWTY125/133/136F::6 x HIS & This study \\
\hline pME4456 & pME2795 with GAL1::SNCAWTS129A::GFP & This study \\
\hline pME4457 & pME2795 with GAL1::SNCAWTS129A::6 x HIS & This study \\
\hline pME4460 & pME2795 with GAL1::SNCAWT Y133F::6 x HIS & This study \\
\hline pME4461 & pME2795 with GAL1:: SNCAWT Y133F ::GFP & This study \\
\hline pME4462 & pME2795 with GAL1::SNCAWT Y136F::6 x HIS & This study \\
\hline pME4463 & pME2795 with GAL1:: SNCAWT Y136F ::GFP & This study \\
\hline pME4466 & pME2795 with GAL1:: SNCA ${ }^{A 30 P}$ S129A ::GFP & This study \\
\hline pME4467 & pME2795 with GAL1:: SNCA ${ }^{A 30 P}$ Y133F ::GFP & This study \\
\hline pME4470 & pME2795 with GAL1::SNCA ${ }^{W T}:: m$ Cherry & This study \\
\hline pME4471 & cDNA_NGB (neuroglobin) & This study \\
\hline pME4472 & pME2792 with $G A L 1:: Y H B 1$ & This study \\
\hline
\end{tabular}

Table 3. Oligonucleotides

\begin{tabular}{cccc}
\hline Name & Size & \multicolumn{1}{c}{ Sequence (5'-3') } & Use \\
\hline NTTP79 & 21-mer & GCT GCA TAA CCA CTT TAA CTA & GAL1 forward primer used for sequencing \\
BP20 & 18-mer & GTT AGA GCG GAT GTG GGG & CYC1 reverse primer used for sequencing \\
BP40 & 27-mer & $\begin{array}{l}\text { AAG GAT CCA TGC TAG CCG } \\
\text { AAA AAA CCC }\end{array}$ & $\begin{array}{l}\text { YHB1 forward primer used for YHB1 } \\
\text { amplification with BamH restriction site }\end{array}$ \\
BP41 & 28-mer & $\begin{array}{l}\text { GAC TCG AGC TAA ACT TGC } \\
\text { ACG GTT GAC A }\end{array}$ & $\begin{array}{l}\text { YHB1 reverse primer used for YHB1 } \\
\text { amplification with Xhol restriction site }\end{array}$ \\
\hline
\end{tabular}




\begin{tabular}{|c|c|c|c|}
\hline Name & Size & Sequence $\left(5^{\prime}-3^{\prime}\right)$ & Use \\
\hline BP42 & 33-mer & $\begin{array}{l}\text { TTA CTA GTA TGG ATG TAT TCA } \\
\text { TGA AAG GAC TTT }\end{array}$ & $\begin{array}{l}\text { SNCA forward primer used for C-terminal } \\
6 \times \text { HIS tag with Spel restriction }\end{array}$ \\
\hline BP43 & $45-\mathrm{mer}$ & $\begin{array}{l}\text { TTC TCG AGT TAG TGG TGG } \\
\text { TGG TGG TGG TGG GCT TCA } \\
\text { GGT TCG TAG }\end{array}$ & $\begin{array}{l}\text { SNCA reverse primer used for C-terminal } \\
6 \times \text { HIS tag with Xhol restriction site }\end{array}$ \\
\hline BP46 & 37-mer & $\begin{array}{l}\text { CAA AAG AGG GTG TTC TCG } \\
\text { CAG TAG GCT CCA AAA CCA A }\end{array}$ & $\begin{array}{l}\text { Quick change mutagenesis forward primer } \\
\text { used for substitution of tyrosine } 39 \text { to } \\
\text { alanine in SNCA }\end{array}$ \\
\hline BP47 & 37-mer & $\begin{array}{l}\text { TTG GTT TTG GAG CCT ACT } \\
\text { GCG AGA ACA CCC TCT TTT G }\end{array}$ & $\begin{array}{l}\text { Quick change mutagenesis reverse primer } \\
\text { used for substitution of tyrosine } 39 \text { to } \\
\text { alanine in SNCA }\end{array}$ \\
\hline BP59 & 34-mer & $\begin{array}{l}\text { GCT TAT GAA ATG CCT GCC } \\
\text { GAG GAA GGG TAT CAA G }\end{array}$ & $\begin{array}{l}\text { Quick change mutagenesis forward primer } \\
\text { used for substitution of serine } 129 \text { to } \\
\text { alanine in SNCA }\end{array}$ \\
\hline BP60 & 34-mer & $\begin{array}{l}\text { CTT GAT ACC CTT CCT CGG } \\
\text { CAG GCA TTT CAT AAG C }\end{array}$ & $\begin{array}{l}\text { Quick change mutagenesis reverse primer } \\
\text { used for substitution of serine129 to } \\
\text { alanine in SNCA }\end{array}$ \\
\hline BP61 & 29-mer & $\begin{array}{l}\text { AAA CTA GTA TGG AGC GCC } \\
\text { CGG AGC CCG AG }\end{array}$ & $\begin{array}{l}N G B \text { forward primer used for } N G B \\
\text { amplification with Spel restriction site }\end{array}$ \\
\hline BP62 & 26-mer & $\begin{array}{l}\text { AAC TCG AGT TAC TCG CCA } \\
\text { TCC CAG CC }\end{array}$ & $\begin{array}{l}N G B \text { reverse primer used for } N G B \\
\text { amplification with } X \text { hol restriction site }\end{array}$ \\
\hline BP69 & 28-mer & $\begin{array}{l}\text { GAC AAT GAG GCT TTT GAA } \\
\text { ATG CCT TCT G }\end{array}$ & $\begin{array}{l}\text { Quick change mutagenesis forward primer } \\
\text { used for substitution of tyrosine } 125 \text { to } \\
\text { phenylalanine in SNCA }\end{array}$ \\
\hline BP70 & 28-mer & $\begin{array}{l}\text { CAG AAG GCA TTT CAA AAG } \\
\text { CCT CAT TGT C }\end{array}$ & $\begin{array}{l}\text { Quick change mutagenesis reverse primer } \\
\text { used for substitution of tyrosine } 125 \text { to } \\
\text { phenylalanine in SNCA }\end{array}$ \\
\hline BP71 & 29-mer & $\begin{array}{l}\text { GAG GGT GTT CTC TTT GTA } \\
\text { GGC TCC AAA AC }\end{array}$ & $\begin{array}{l}\text { Quick change mutagenesis forward primer } \\
\text { used for substitution of tyrosine } 39 \text { to } \\
\text { phenylalanine in SNCA }\end{array}$ \\
\hline BP72 & 29-mer & $\begin{array}{l}\text { GTT TTG GAG CCT ACA AAG } \\
\text { AGA ACA CCC TC }\end{array}$ & $\begin{array}{l}\text { Quick change mutagenesis reverse primer } \\
\text { used for substitution of tyrosine } 39 \text { to } \\
\text { phenylalanine in SNCA }\end{array}$ \\
\hline BP73 & 38-mer & $\begin{array}{l}\text { CTT CTG AGG AAG GGT TTC } \\
\text { AAG ACT TCG AAC CTG AAG CC }\end{array}$ & $\begin{array}{l}\text { Quick change mutagenesis forward primer } \\
\text { used for substitution of tyrosine } 133 \text { and } \\
136 \text { to phenylalanine in SNCA }\end{array}$ \\
\hline BP74 & 38-mer & $\begin{array}{l}\text { GGC TTC AGG TTC GAA GTC } \\
\text { TTG AAA CCC TTC CTC AGA AG }\end{array}$ & $\begin{array}{l}\text { Quick change mutagenesis reverse primer } \\
\text { used for substitution of tyrosine } 133 \text { and } \\
136 \text { to phenylalanine in SNCA }\end{array}$ \\
\hline BP147 & 34-mer & $\begin{array}{l}\text { TGG AAT TCT GCA GAT ATG } \\
\text { GAG CGC CCG GAG CCC G }\end{array}$ & $\begin{array}{l}N G B \text { forward primer used for } N G B \\
\text { amplification with subsequent seamless } \\
\text { cloning with EcoRV restriction }\end{array}$ \\
\hline BP148 & 30-mer & $\begin{array}{l}\text { CTT GCT CAC ATC GAT CTC } \\
\text { GCC ATC CCA GCC }\end{array}$ & $\begin{array}{l}N G B \text { reverse primer used for } N G B \\
\text { amplification with subsequent seamless } \\
\text { cloning with } E c o R V \text { restriction }\end{array}$ \\
\hline
\end{tabular}




\begin{tabular}{|c|c|c|c|}
\hline Name & Size & Sequence $\left(5^{\prime}-3^{\prime}\right)$ & Use \\
\hline BP149 & 33-mer & $\begin{array}{l}\text { ATC GAT GTG AGC AAG GGC } \\
\text { GAG GAG GAT AAC ATG }\end{array}$ & $\begin{array}{l}\text { mCherry forward primer used for mCherry } \\
\text { amplification with subsequent seamless } \\
\text { cloning with } E c o R V \text { restriction }\end{array}$ \\
\hline BP150 & 33-mer & $\begin{array}{l}\text { GCC ACT GTG CTG GAT CTA } \\
\text { CTT GTA CAG CTC GTC }\end{array}$ & $\begin{array}{l}\text { mCherry reverse primer used for mCherry } \\
\text { amplification with subsequent seamless } \\
\text { cloning with EcoRV restriction }\end{array}$ \\
\hline BP151 & 19-mer & TAA TAC GAC TCA CTA TAG G & T7 forward primer used for sequencing \\
\hline BP240 & 31-mer & $\begin{array}{l}\text { CTT CTG AGG AAG GGT TTC } \\
\text { AAG ACT ACG AAC C }\end{array}$ & $\begin{array}{l}\text { Quick change mutagenesis forward primer } \\
\text { used for substitution of tyrosine } 133 \text { to } \\
\text { phenylalanine in SNCA }\end{array}$ \\
\hline BP241 & 31-mer & $\begin{array}{l}\text { GGT TCG TAG TCT TGA AAC } \\
\text { CCT TCC TCA GAA G }\end{array}$ & $\begin{array}{l}\text { Quick change mutagenesis reverse primer } \\
\text { used for substitution of tyrosine } 133 \text { to } \\
\text { phenylalanine in SNCA }\end{array}$ \\
\hline BP247 & 33-mer & $\begin{array}{l}\text { GAA GGG TAT CAA GAC TTC } \\
\text { GAA CCT GAA GCC TAA }\end{array}$ & $\begin{array}{l}\text { Quick change mutagenesis forward primer } \\
\text { used for substitution of tyrosine } 136 \text { to } \\
\text { phenylalanine in SNCA }\end{array}$ \\
\hline BP248 & 33-mer & $\begin{array}{l}\text { TTA GGC TTC AGG TTC GAA } \\
\text { GTC TTG ATA CCC TTC }\end{array}$ & $\begin{array}{l}\text { Quick change mutagenesis reverse primer } \\
\text { used for substitution of tyrosine } 136 \text { to } \\
\text { phenylalanine in SNCA }\end{array}$ \\
\hline
\end{tabular}

\subsubsection{Enzymes}

Table 4. Enzymes

\begin{tabular}{ccccc}
$\begin{array}{c}\text { Enzyme } \\
\text { (Buffer) }\end{array}$ & $\begin{array}{c}\text { Concentration } \\
\text { Activity }\end{array}$ & Temperature & $\begin{array}{c}\text { Target sequence } \\
\left(5^{\prime}-3^{\prime}\right)\end{array}$ & Company \\
\hline
\end{tabular}

\section{Restriction enzymes}

\begin{tabular}{|c|c|c|c|c|}
\hline $\begin{array}{c}\text { BamHI } \\
\text { (10x buffer BamHI) }\end{array}$ & $\begin{array}{l}10 \mathrm{U} / \mu \mathrm{L} \\
4000 \mathrm{U}\end{array}$ & $37^{\circ} \mathrm{C}$ & $G^{\prime} G$ A T C C & $\begin{array}{l}\text { Thermo Fisher } \\
\text { Scientific }\end{array}$ \\
\hline $\begin{array}{c}\text { EcoRV } \\
\text { (10x buffer } \mathrm{R}(\text { red)) }\end{array}$ & $\begin{array}{l}10 \mathrm{U} / \mu \mathrm{L} \\
2000 \mathrm{U}\end{array}$ & $37^{\circ} \mathrm{C}$ & GAT'ATC & $\begin{array}{c}\text { Thermo Fisher } \\
\text { Scientific }\end{array}$ \\
\hline $\begin{array}{c}\text { Xhol } \\
\text { (10x buffer R (red)) }\end{array}$ & $\begin{array}{l}10 \mathrm{U} / \mu \mathrm{L} \\
2000 \mathrm{U}\end{array}$ & $37^{\circ} \mathrm{C}$ & $C^{\prime} T C G A G$ & $\begin{array}{c}\text { Thermo Fisher } \\
\text { Scientific }\end{array}$ \\
\hline $\begin{array}{c}\text { Spel } \\
\text { (10x Tango buffer) }\end{array}$ & $\begin{array}{l}10 \mathrm{U} / \mu \mathrm{L} \\
400 \mathrm{U}\end{array}$ & $37^{\circ} \mathrm{C}$ & $A^{\prime} C T A G T$ & $\begin{array}{c}\text { Thermo Fisher } \\
\text { Scientific }\end{array}$ \\
\hline $\begin{array}{c}D p n l \\
\text { (10x Tango buffer) }\end{array}$ & $\begin{array}{l}10 \mathrm{U} / \mu \mathrm{L} \\
500 \mathrm{U}\end{array}$ & $37^{\circ} \mathrm{C}$ & $\mathrm{GA} \mathrm{A}^{\mathrm{m} 6^{\prime}} \mathrm{TC}$ & $\begin{array}{c}\text { Thermo Fisher } \\
\text { Scientific }\end{array}$ \\
\hline $\begin{array}{c}\text { Taq DNA } \\
\text { polymerase } \\
\text { (10x Taq DNA } \\
\text { polymerase buffer) }\end{array}$ & $\begin{array}{l}1 \mathrm{U} / \mu \mathrm{L} \\
500 \mathrm{U}\end{array}$ & $72^{\circ} \mathrm{C}$ & & $\begin{array}{c}\text { Thermo Fisher } \\
\text { Scientific }\end{array}$ \\
\hline $\begin{array}{c}\text { T4 DNA ligase } \\
\text { (10x T4 DNA ligase } \\
\text { buffer) }\end{array}$ & $\begin{array}{l}1 \mathrm{U} / \mu \mathrm{L} \\
500 \mathrm{U}\end{array}$ & $16^{\circ} \mathrm{C} / 22^{\circ} \mathrm{C}$ & & $\begin{array}{c}\text { Thermo Fisher } \\
\text { Scientific }\end{array}$ \\
\hline
\end{tabular}




\begin{tabular}{|c|c|c|c|c|}
\hline $\begin{array}{l}\text { Enzyme } \\
\text { (Buffer) }\end{array}$ & $\begin{array}{l}\text { Concentration } \\
\text { Activity }\end{array}$ & Temperature & $\begin{array}{c}\text { Target sequence } \\
\left(5^{\prime}-3^{\prime}\right)\end{array}$ & Company \\
\hline $\begin{array}{l}\text { Phusion polymerase } \\
\text { (5x HF buffer) }\end{array}$ & $\begin{array}{l}2 \mathrm{U} / \mu \mathrm{L} \\
500 \mathrm{U}\end{array}$ & $72{ }^{\circ} \mathrm{C}$ & & $\begin{array}{l}\text { Thermo Fisher } \\
\text { Scientific }\end{array}$ \\
\hline $\begin{array}{l}\text { PfuTurbo } C_{x} \text { hotstart } \\
\text { DNA polymerase } \\
\text { (10x PfuTurbo } C_{x} \\
\text { reaction buffer) }\end{array}$ & $\begin{array}{c}2.5 \mathrm{U} / \mu \mathrm{L} \\
100 \mathrm{U}\end{array}$ & $68^{\circ} \mathrm{C}$ & & $\begin{array}{c}\text { Agilent } \\
\text { Technologies }\end{array}$ \\
\hline RNase A & $50 \mathrm{U} / \mathrm{mg}$ & $25^{\circ} \mathrm{C}$ & & Roche \\
\hline $\begin{array}{c}\text { Trypsin } \\
\text { (Trypsin resuspension } \\
\text { buffer) }\end{array}$ & $1: 2.5$ & $37^{\circ} \mathrm{C}$ & & $\begin{array}{c}\text { Serva } \\
\text { Electrophoresis } \\
\text { GmbH }\end{array}$ \\
\hline $\begin{array}{c}\text { AspN } \\
\left(100 \mathrm{mM} \mathrm{NH}_{4} \mathrm{HCO}_{3}\right. \\
{[\mathrm{pH} \mathrm{8.5])}}\end{array}$ & $1: 100$ & $37^{\circ} \mathrm{C}$ & & Sigma-Aldrich \\
\hline
\end{tabular}

\subsubsection{Media}

If not indicated otherwise, buffers and media were dissolved in $\mathrm{H}_{2} \mathrm{O}$ and autoclaved for 20 minutes at $121^{\circ} \mathrm{C}$ and 2 bar. Thermally unstable substances were dissolved and filtered to sterility using Filtropur S 0.2 filters (Sarstedt AG \& Co). For cultivation of bacterial and yeast strains the following media were used.

Table 5. Media

\begin{tabular}{lll}
\hline Ingredients & Agar-plates & Liquid medium \\
\hline LB medium (Escherichia coli) & & \\
Bacto-Tryptone & $10 \mathrm{~g}$ & $10 \mathrm{~g}$ \\
Yeast extract & $5 \mathrm{~g}$ & $5 \mathrm{~g}$ \\
$\mathrm{NaCl}$ & $10 \mathrm{~g}$ & $10 \mathrm{~g}$ \\
$\mathrm{Agar}$ & $20 \mathrm{~g}$ & \\
$\mathrm{H}_{2} \mathrm{O}$ & ad $1000 \mathrm{~mL}$ & $\mathrm{ad} 1000 \mathrm{~mL}$ \\
SC medium (Saccharomyces cerevisiae) & & \\
YNB-aa-as (yeast nitrogen base w/o AA and AS) & $0.9 \mathrm{~g}$ & $1.5 \mathrm{~g}$ \\
Ammonium sulfate & $3.0 \mathrm{~g}$ & $5.0 \mathrm{~g}$ \\
200 mM Inositol & $0.6 \mathrm{~mL}$ & $1.0 \mathrm{~mL}$ \\
Amino acid powder mix & $1.2 \mathrm{~g}$ & $2.0 \mathrm{~g}$ \\
Glucose/Galactose & $12 \mathrm{~g}$ & \\
Raffinose/Galactose & & $20 \mathrm{~g}$ \\
Agar & $9 \mathrm{~g}$ & \\
$\mathrm{H}_{2} \mathrm{O}$ & $\mathrm{ad} 600 \mathrm{~mL}$ & $\mathrm{ad} 1000 \mathrm{~mL}$ \\
\hline
\end{tabular}




\begin{tabular}{|c|c|c|}
\hline Ingredients & Agar-plates & Liquid medium \\
\hline \multicolumn{3}{|l|}{ YEPD medium (Saccharomyces cerevisiae) } \\
\hline Bacto-Peptone & $6 \mathrm{~g}$ & $6 \mathrm{~g}$ \\
\hline Yeast extract & $3 \mathrm{~g}$ & $3 \mathrm{~g}$ \\
\hline Glucose/Galactose & $6 \mathrm{~g}$ & $6 \mathrm{~g}$ \\
\hline Agar & $6 \mathrm{~g}$ & \\
\hline $\mathrm{H}_{2} \mathrm{O}$ & ad $300 \mathrm{~mL}$ & ad $300 \mathrm{~mL}$ \\
\hline \multicolumn{3}{|l|}{ MV medium (Saccharomyces cerevisiae) [pH 7.2] } \\
\hline YNB-aa-as (yeast nitrogen base w/o AA and AS) & $1.45 \mathrm{~g}$ & \\
\hline Ammonium sulfate & $5.52 \mathrm{~g}$ & \\
\hline Succinic acid & $10 \mathrm{~g}$ & \\
\hline Potassium hydroxide & $10 \mathrm{~g}$ & \\
\hline Glucose/Galactose & $20 \mathrm{~g}$ & \\
\hline Agar & $20 \mathrm{~g}$ & \\
\hline $\mathrm{H}_{2} \mathrm{O}$ & ad $1000 \mathrm{~mL}$ & \\
\hline \multicolumn{3}{|l|}{ adjust $\mathrm{pH}$ with $10 \mathrm{mM} \mathrm{KOH}$} \\
\hline \multicolumn{3}{|l|}{ Amino acid mix (-His, -Leu, -Trp, -Ura) } \\
\hline Adenine (Ade), L-Alanine (Ala), & $2 \mathrm{~g}$ (each) & \\
\hline \multicolumn{3}{|l|}{ L-Argenine (Arg), L-Asparagine (Asn), } \\
\hline \multicolumn{3}{|l|}{ L-Aspartic acid (Asp), L-Cysteine (Cys), } \\
\hline \multicolumn{3}{|l|}{ L-Glutamine (Gln), L-Glutamic acid (Glu), } \\
\hline \multicolumn{3}{|l|}{ Glycine (Gly), L-Isoleucine (lle), } \\
\hline \multicolumn{3}{|l|}{ L-Lysine (Lys), L-Methionine (Met), } \\
\hline \multicolumn{3}{|l|}{ L-Phenylalanine (Phe), L-Proline (Pro), } \\
\hline \multicolumn{3}{|l|}{ L-Serine (Ser), L-Threonine (Thr), } \\
\hline \multicolumn{3}{|l|}{ L-Tyrosine (Tyr), L-Valine (Val), } \\
\hline para-Aminobenzoic acid (Paba) & $0.2 \mathrm{~g}$ & \\
\hline
\end{tabular}

\subsubsection{Antibiotics}

For antibiotic selection, stock solutions of all antibiotics used in this study were prepared. Autoclaved media had to cool down to approx. $50{ }^{\circ} \mathrm{C}$ before the antibiotic stock solutions were added. The final concentrations for all antibiotics are listed below.

Table 6. Antibiotics

\begin{tabular}{cccc}
\hline Antibiotic & stock solution & storage temperature & final concentration \\
\hline Ampicillin & $100 \mathrm{mg} / \mathrm{mL}$ & $-20^{\circ} \mathrm{C}$ & $100 \mu \mathrm{g} / \mathrm{mL}$ \\
G418 & $100 \mathrm{mg} / \mathrm{mL}$ & $-20^{\circ} \mathrm{C}$ & $200 \mu \mathrm{g} / \mathrm{mL}$ \\
\hline
\end{tabular}




\subsubsection{Antibodies}

Table 7. Primary antibodies

\begin{tabular}{ccccc}
\hline Antibody & Animal & Type & Dilution & Source \\
\hline anti-3-nitrotyrosine & mouse & monoclonal & $1: 1400$ & Abcam \\
anti-di-tyrosine & mouse & monoclonal & $1: 1000$ & JalCA \\
anti-nitroY39 aSyn & mouse & monoclonal & $1: 1000$ & Upstate Biotechnology Inc \\
anti-phosphoY133 aSyn & rabbit & polyclonal & $1: 1000$ & Abcam \\
anti-phosphoY125 aSyn & rabbit & polyclonal & $1: 1000$ & Abcam \\
anti- phosphoS129 aSyn & mouse & monoclonal & $1: 2500$ & Wako Pure Chemical Industries Ltd \\
anti-aSyn & rabbit & polyclonal & $1: 2500$ & Santa Cruz Biotechnology Inc \\
anti-aSyn & mouse & monoclonal & $1: 2000$ & AnaSpec Inc \\
anti-GAPDH & mouse & monoclonal & $1: 5000$ & Thermo Fisher Scientific \\
\hline
\end{tabular}

Table 8. Secondary antibodies

\begin{tabular}{cccc}
\hline Antibody & Type & Dilution & Source \\
\hline HRP-conjugated & polyclonal & $1: 2000$ & Invitrogen \\
$\begin{array}{c}\text { Goat anti-Rabbit IgG } \\
(\mathrm{H}+\mathrm{L})\end{array}$ & $1: 5000$ & \\
$\begin{array}{c}\text { Peroxidase-conjugated } \\
\text { AffiniPure Goat anti- }\end{array}$ & polyclonal & $1: 2000$ & $\begin{array}{c}\text { Jackson ImmunoResearch } \\
\text { Laboratories }\end{array}$ \\
\hline Mouse IgG $(\mathrm{H}+\mathrm{L})$ & & $1: 5000$ & \\
\hline
\end{tabular}

\subsection{Methods}

\subsubsection{Cultivation of cells}

\subsubsection{Cultivation of Escherichia coli}

Escherichia coli strains were grown in $5 \mathrm{~mL}$ Lysogeny Broth (LB) medium (1\% (w/v) bactotryptone, $0.5 \%(\mathrm{w} / \mathrm{v})$ yeast extract, $1 \%(\mathrm{w} / \mathrm{v}) \mathrm{NaCl}$, for solid medium: $2 \%(\mathrm{w} / \mathrm{v})$ agar) on a rotation shaker (Infors AG) at $37^{\circ} \mathrm{C}$ overnight (Bertani, 1951). In this study, the Escherichia coli strain DH5a was used for general cloning procedures and purification of plasmid DNA. To select the colonies harboring the plasmid of interest, $100 \mu \mathrm{g} / \mathrm{mL}$ of ampicillin (Carl Roth $\mathrm{GmbH} \& \mathrm{CO}$. KG) was added to LB medium. Solid LB media contained $2 \%$ agar (Carl Roth $\mathrm{GmbH} \& \mathrm{CO} . \mathrm{KG})$.

\subsubsection{Cultivation of Saccharomyces cerevisiae}

Saccharomyces cerevisiae strains were cultivated in $10 \mathrm{~mL}$ YEPD medium (2\% (w/v) bactopeptone, $1 \%(\mathrm{w} / \mathrm{v})$ yeast extract, $2 \%(\mathrm{w} / \mathrm{v})$ glucose, for solid medium: $2 \%(\mathrm{w} / \mathrm{v})$ agar) at 
$30{ }^{\circ} \mathrm{C}$ on a rotation shaker (Fröbel Labortechnik $\mathrm{GmbH}$ ) overnight. On solid YEPD medium Saccharomyces cerevisiae strains were cultivated at $30{ }^{\circ} \mathrm{C}$ for two to three days. In this study, strains BY4741 (EUROSCARF) and $\Delta y h b 1$ (5887-EUROSCARF) were used. For cultivation of the $\Delta y h b 1$ strain, $200 \mu \mathrm{g} / \mathrm{mL}$ G418 (Geneticin® Selective Antibiotic, Thermo Fisher Scientific) was added to YEPD medium. After transformation, plasmid carrying strains were selected in Synthetic Complete (SC) medium (0,15\% (w/v) YNB-aa-as (yeast nitrogen base w/o AA and AS), $0.5 \%$ (w/v) ammonium sulfate, $0.2 \mathrm{mM}$ inositol, $0.2 \%$ (w/v) amino acid powder mix, for liquid medium: $2 \%(\mathrm{w} / \mathrm{v})$ raffinose, for solid medium: $2 \%(\mathrm{w} / \mathrm{v})$ glucose, $1.5 \%(\mathrm{w} / \mathrm{v})$ agar) supplemented with appropriate amino acids (Guthrie and Fink, 1991). Transformants harboring aSyn constructs were selected in SC medium lacking uracil (SCUra). For growth of cells co-expressing aSyn with YHB1 or NGB, SC medium lacking uracil and histidine (SC-Ura-His) was used. As carbon source SC medium contained either $2 \%$ raffinose / $2 \%$ glucose for growth without aSyn induction or $2 \%$ galactose to induce the GAL1-promoter of aSyn. Expression of aSyn was induced for five hours by shifting overnight cultures from $2 \%$ raffinose- to $2 \%$ galactose-containing medium at an $\mathrm{OD}_{600}$ of 0.1 . Cell growth was controlled by measuring the optical density at $600 \mathrm{~nm}$ using the T80 UV/VIS spectrometer (PG Instruments Ltd).

\subsubsection{Cell storage}

For long-term storage Escherichia coli and Saccharomyces cerevisiae strains were stored at $-80^{\circ} \mathrm{C}$ in $1.8 \mathrm{~mL}$ CryoPure Tubes (Sarstedt AG \& Co). To prevent freezing damage, Escherichia coli cells were mixed with $50 \%$ (v/v) glycerol (Carl Roth $\mathrm{GmbH} \& \mathrm{CO}$. KG). For storage of Saccharomyces cerevisiae, cells were mixed with $15 \%(\mathrm{v} / \mathrm{v})$ glycerol.

\subsubsection{Nucleic acid methods}

\subsubsection{Purification of DNA}

Linear DNA fragments were purified using the QIAquick Gel Extraction Kit (QIAGEN) according to the manufacturer's instructions. QIAquick Kits contain a silica membrane assembly which binds DNA in high-salt buffer and allows elution of the DNA with water. The purification procedure removes primers, nucleotides, enzymes, mineral oil, salts, agarose, ethidium bromide, and other impurities from DNA samples. To elute DNA from the columns, $30 \mu \mathrm{L} \mathrm{dH_{2 }} \mathrm{O}$ was used. The concentration of purified DNA was determined by a NanoDrop ND-1000 spectrophotometer (Peqlab Biotechnologie GmbH). Purified DNA was stored at $-20{ }^{\circ} \mathrm{C}$ or used for further procedures. 


\subsubsection{Isolation of plasmid DNA from Escherichia coli}

Escherichia coli colonies containing a plasmid harboring the gene of interest were grown in $5 \mathrm{~mL}$ LB medium supplemented with $100 \mu \mathrm{g} / \mathrm{mL}$ of ampicillin at $37^{\circ} \mathrm{C}$ overnight. Cells were collected by centrifugation at $13000 \mathrm{rpm}$ for one minute in a benchtop centrifuge (Biofuge pico, Heraeus) and plasmid DNA was isolated using the QIAprep Spin Miniprep Kit (QIAGEN) according to the manufacturer's advice. For elution of DNA from the columns,

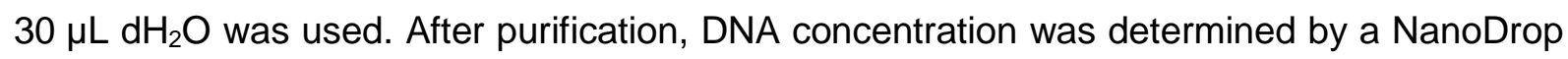
ND-1000 spectrophotometer (Peqlab Biotechnologie $\mathrm{GmbH}$ ). Purified plasmid DNA was stored at $-20^{\circ} \mathrm{C}$ or used for further procedures.

\subsubsection{Isolation of genomic DNA from Saccharomyces cerevisiae}

Isolation of yeast genomic DNA was performed according to standard procedures (Hoffman and Winston, 1987). Saccharomyces cerevisiae cells were grown in $10 \mathrm{~mL}$ YEPD medium at $30{ }^{\circ} \mathrm{C}$ overnight. After harvesting the cells by centrifugation at $3000 \mathrm{rpm}$ for three minutes, the cell suspension was washed in $1 \mathrm{~mL}$ TE buffer $(10 \mathrm{mM}$ Tris- $\mathrm{HCl}$ [pH 8.0], $1 \mathrm{mM}$ EDTA [pH 8.0]). Afterwards, $200 \mu \mathrm{L}$ breaking buffer ( $2 \%(\mathrm{v} / \mathrm{v})$ triton X-100, $1 \%(\mathrm{w} / \mathrm{v}) \mathrm{SDS}, 100 \mathrm{mM}$ $\mathrm{NaCl}, 10 \mathrm{mM}$ Tris- $\mathrm{HCl}$ [pH8.0], $1 \mathrm{mM}$ EDTA [pH8.0]) together with $200 \mu \mathrm{L}$ of phenol:chloroform:isoamyl-alcohol (25:24:1) and 0.25-0.5 mm glass beads were added to the cell precipitates. Cells were broken by mechanical agitation at $4{ }^{\circ} \mathrm{C}$ for 10 minutes using a vortex mixer (Vortex-Genie 2, Scientific Industries Inc) and centrifuged at $13000 \mathrm{rpm}$ at $4{ }^{\circ} \mathrm{C}$ for five minutes. For DNA precipitation, the supernatant was collected and mixed with $1 \mathrm{~mL}$ cold ethanol (96\%). After short centrifugation, the precipitates were incubated with $400 \mu \mathrm{L}$ TE buffer and $3 \mu \mathrm{L}$ RNase (10 mg/mL, Roche) to a final concentration of $75 \mu \mathrm{g} / \mathrm{mL}$ at $37^{\circ} \mathrm{C}$ for 50 minutes. Thereafter, $1 \mathrm{~mL}$ cold ethanol $(96 \%(\mathrm{v} / \mathrm{v}))$ was added and the samples were centrifuged at $13000 \mathrm{rpm}$ for five minutes. After discarding the supernatant, the DNA precipitate was additionally centrifuged at $13000 \mathrm{rpm}$ for 30 seconds and dried at room temperature. Finally, genomic DNA was dissolved in $50 \mu \mathrm{L}$ TE buffer and verified by agarose gel electrophoresis.

\subsubsection{DNA agarose gel electrophoresis}

Analytical and preparative separation of DNA fragments was performed using DNA agarose gel electrophoresis (Lee et al., 2012). During this procedure, lower molecular weight nucleic acids migrate faster through the gel than larger fragments. Thereby, DNA size can be estimated. For DNA agarose gel electrophoresis, $1 \%$ agarose gel $(1 \%(\mathrm{w} / \mathrm{v})$ agarose, $0.001 \mathrm{mg} / \mathrm{mL}$ ethidium bromide) was prepared in TAE buffer (40 mM Tris base, $20 \mathrm{mM}$ acetic 
acid, $1 \mathrm{mM}$ EDTA). For subsequent visualization of DNA, the gel was supplemented with ethidium bromide to a final concentration of $0.001 \mathrm{mg} / \mathrm{mL}$. The samples were mixed with 6x DNA loading dye (10\% (v/v) ficoll typ 400, $0.25 \%(\mathrm{w} / \mathrm{v})$ bromphenol blue, $0.25 \%(\mathrm{w} / \mathrm{v})$ xylene cyanol ff, $200 \mathrm{mM}$ EDTA [pH 8.0]) and separated until the bromophenol blue band reached the last third of the gel. As size standard, the GeneRuler 1kb DNA ladder (250 to $10000 \mathrm{bp}$, Thermo Fisher Scientific) was loaded onto the gel. The separation was performed in a Mini-Sub Cell GT chamber (Bio-Rad Laboratories) using Bio-Rad Powerpac 300 power supply (Bio-Rad Laboratories) in an electric field at $90 \mathrm{~V}$ in TAE buffer. Afterwards, UV light with $254 \mathrm{~nm}$ was applied to detect the DNA and a photograph was taken using a gel documentation imager (Gel iX20 Imager Windows Version, Intas Science Imaging Instruments $\mathrm{GmbH}$ ).

\subsubsection{DNA isolation from agarose gels}

For purification of DNA fragments from a DNA mixture, the fragments were separated according to their length by agarose gel electrophoresis. Then, the desired fragment was excised from the gel and purified using the QIAquick Gel extraction Kit (QIAGEN). This purification method depends on the ability of DNA to bind to silica membranes. After elution

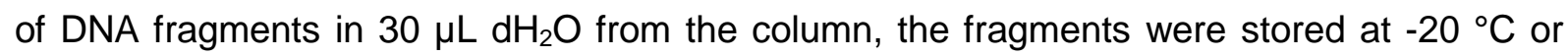
used for further procedures.

\subsubsection{Polymerase chain reaction (PCR)}

PCR is a technique to amplify specific DNA in vitro, which allows the amplification of DNA fragments with partly known sequences (Saiki et al., 1988). The polymerase chain reaction is based on two specific oligonucleotides which anneal to the 5 ' ends of DNA fragment of interest. Next, the DNA polymerase binds to the oligonucleotides and synthesizes the complementary strand. The oligonucleotides used for PCR reactions were purchased from Sigma-Aldrich (St. Louis, USA) and are listed in Table 3. For cloning reactions the high fidelity DNA polymerase Phusion High-Fidelity DNA Polymerase (Thermo Fisher Scientific) was required which exhibits a 3' $\rightarrow$ 5' exonuclease activity. Due to its proof reading function, an accurate oligonucleotide extension reaction with very low error rate can be obtained. Temperature of annealing depends on the melting temperature of used oligonucleotides. Usually, the annealing temperature is $5{ }^{\circ} \mathrm{C}$ below the melting temperature. Chromosomal DNA or plasmid DNA was used as template DNA. The polymerase chain reaction was performed in a Thermo cycler (MWG Biotech Inc Primus 96 Thermal Cycler, MWG-Biotech). An example for a Phusion reaction mix and PCR program is listed in Table 9 and 10. 
Table 9. Reaction mix for Phusion DNA polymerase

\begin{tabular}{ccc}
\hline Component & $\mathbf{5 0} \boldsymbol{\mu \mathrm { L } \text { Reaction }}$ & Final concentration \\
\hline 5x HF buffer & $10 \mu \mathrm{L}$ & $1 \mathrm{x}$ \\
dNTP mix & $1 \mu \mathrm{L}$ & $200 \mu \mathrm{M}$ each \\
Primer 1 & $1 \mu \mathrm{L}$ & $0.2 \mu \mathrm{M}$ \\
Primer 2 & $1 \mu \mathrm{L}$ & $0.2 \mu \mathrm{M}$ \\
Template DNA & $x \mu \mathrm{L}$ & $300-500 \mathrm{ng}$ \\
DMSO & $1.5 \mu \mathrm{L}$ & $3 \%$ \\
Phusion DNA polymerase & $0.5 \mu \mathrm{L}$ & $0.02 \mathrm{U} / \mu \mathrm{L}$ \\
\hline
\end{tabular}

Table 10. PCR program for Phusion DNA polymerase

\begin{tabular}{lccc}
\hline \multicolumn{1}{c}{ Cycle step } & Temperature & Time & Cycles \\
\hline Denaturation & $98^{\circ} \mathrm{C}$ & $3 \mathrm{~min}$ & 1 \\
Denaturation & $98^{\circ} \mathrm{C}$ & $30 \mathrm{sec}$ & 30 \\
Annealing & $\mathrm{Tm}-5^{\circ} \mathrm{C}$ & $30 \mathrm{sec}$ & 30 \\
Elongation & $72^{\circ} \mathrm{C}$ & $15-30 \mathrm{sec} / \mathrm{kb}$ & 30 \\
Final extension & $72^{\circ} \mathrm{C}$ & $10 \mathrm{~min}$ & 1 \\
Pause & $4{ }^{\circ} \mathrm{C}$ & $\infty$ & 1 \\
\hline
\end{tabular}

If the amplified DNA fragments were required for analytical PCR reaction, the thermostable Taq polymerase (Thermo Fisher Scientific) was applied. This DNA polymerase lacks a proof reading function leading to higher error prone oligonucleotides extension. For analytical PCR reaction, the transformants were used as DNA template. Thereby, clones can be tested for the correct integration of DNA fragments into a vector. The colonies to be analyzed were picked from a plate and resuspended in $25 \mu \mathrm{L}$ PCR reaction mix. Positive colonies were isolated using the QIAprep Spin Miniprep Kit (QIAGEN) and used for subsequent investigation in yeast. An example for a Taq reaction mix and PCR program is listed in Table 11 and 12.

Table 11. Reaction mix for Taq DNA polymerase

\begin{tabular}{|c|c|c|}
\hline Component & $25 \mu \mathrm{L}$ Reaction & Final concentration \\
\hline 10x Taq DNA polymerase buffer & $2.5 \mu \mathrm{L}$ & $1 \mathrm{x}$ \\
\hline dNTP mix & $1 \mu \mathrm{L}$ & $200 \mu \mathrm{M}$ each \\
\hline Primer 1 & $1 \mu \mathrm{L}$ & $0.4 \mu \mathrm{M}$ \\
\hline Primer 2 & $1 \mu \mathrm{L}$ & $0.4 \mu \mathrm{M}$ \\
\hline Taq DNA polymerase & $1 \mu \mathrm{L}$ & $0.04 \mathrm{U} / \mu \mathrm{L}$ \\
\hline $\mathrm{Mg}_{2} \mathrm{SO}_{4}$ & $3 \mu \mathrm{L}$ & $3 \mathrm{mM}$ \\
\hline
\end{tabular}


Table 12. PCR program for Taq DNA polymerase

\begin{tabular}{lccc}
\hline \multicolumn{1}{c}{ Cycle step } & Temperature & Time & Cycles \\
\hline Denaturation & $95^{\circ} \mathrm{C}$ & $3 \mathrm{~min}$ & 1 \\
Denaturation & $95^{\circ} \mathrm{C}$ & $30 \mathrm{sec}$ & 30 \\
Annealing & $\mathrm{Tm}-5^{\circ} \mathrm{C}$ & $30 \mathrm{sec}$ & 30 \\
Elongation & $72{ }^{\circ} \mathrm{C}$ & $1 \mathrm{~min} / \mathrm{kb}$ & 30 \\
Final extension & $72^{\circ} \mathrm{C}$ & $10 \mathrm{~min}$ & 1 \\
Pause & $4{ }^{\circ} \mathrm{C}$ & $\infty$ & 1 \\
\hline
\end{tabular}

\subsubsection{Digestion of DNA}

Restriction enzymes purchased from Thermo Fisher Scientific were used to digest DNA molecules according to the manufacturer's instructions. Restriction enzymes cut DNA fragments at specific recognition sequences. PCR amplified DNA fragments and plasmid DNA were digested with the appropriate restriction enzymes. Usually, $10 U$ enzyme was used per 3-6 $\mu \mathrm{g}$ DNA. Final volume of $30 \mu \mathrm{L}$ reaction mixture was incubated in corresponding reaction buffer at $37{ }^{\circ} \mathrm{C}$ for two to four hours. Afterwards, digested DNA fragments were purified from the digestion mixture using the QIAquick Gel extraction Kit (QIAGEN).

\subsubsection{Ligation of DNA}

T4 DNA ligase (Thermo Fisher Scientific) was used for ligation of linearized vector and the respective insert. In presence of ATP, it catalysis the formation of phosphodiester bond between 3 '-OH and a 5'- $\mathrm{PO}_{4}$ ends of nucleic acids. For ligation, 100 or $300 \mathrm{ng}$ of the prepared vector DNA and a threefold number of insert DNA was used. Ligation was carried out in T4 ligase buffer (Thermo Fisher Scientific) using $2 \mu \mathrm{L}$ T4 DNA ligase (2 U) in a final volume of $20 \mu \mathrm{L}$ at $16{ }^{\circ} \mathrm{C}$ overnight. Subsequently, $1 \mu \mathrm{L}$ of ligation mix was used for transformation into Escherichia coli $\mathrm{DH} 5 \alpha$ strains and incubated on selective LB plates containing $100 \mu \mathrm{g} / \mathrm{mL}$ ampicillin at $37^{\circ} \mathrm{C}$ overnight. Alternatively to T4 DNA ligation, the GeneArt@ Seamless Cloning and Assembly Enzyme Mix (Invitrogen) was used to assemble DNA fragments. For assembly reaction, $100 \mathrm{ng}$ linearized vector DNA was mixed with $200 \mathrm{ng}$ insert DNA and $4 \mu \mathrm{L}$ of $5 \mathrm{x}$ reaction buffer. After adjusting the total volume of $20 \mu \mathrm{L}$ with $\mathrm{dH}_{2} \mathrm{O}, 1 \mu \mathrm{L}$ of $10 \mathrm{x}$ enzyme mix was added to the reaction mixture and incubated at room temperature for 30 minutes. Finally, $8 \mu \mathrm{L}$ of ligation mix was transformed into Escherichia coli $\mathrm{DH} 5 \alpha$ strains and incubated on selective LB plates containing $100 \mu \mathrm{g} / \mathrm{mL}$ ampicillin at $37^{\circ} \mathrm{C}$ overnight. In order to verify successful integration of the insert into the vector, plasmid DNA 
was isolated using the QIAprep Spin Miniprep Kit (QIAGEN) and sequenced as described in section 2.2.2.10.

\subsubsection{Quick change site-directed mutagenesis}

The quick change site-directed mutagenesis system was used to modify amino acids in proteins. This method is based on PCR amplification allowing introduction of multiple mutations, deletions and insertions into genes in vitro (Wang and Malcolm, 1999). Thereby, one pair of complementary oligonucleotide primer containing the mutation of interest introduces the mutation during a PCR amplification process. The mutagenic oligonucleotide primers used in this method were designed individually according to the desired mutation. Both 5'-phosphorylated mutagenic primers should be 25 to 45 bases in length with melting temperature above or equal to $78{ }^{\circ} \mathrm{C}$. The desired mutagenic section should be located at the middle of the primer and flaked on both sides by stretches of 10 to 20 bases complementary to the template DNA. Importantly, the amplification of target DNA was carried out using the thermostable high fidelity PfuTurbo Cx hotstart DNA polymerase (Agilent Technologies), which replicates target DNA without displacing the mutagenic primers. For this study, plasmid DNA containing the gene of interest was used as template DNA. An example for a quick change site-directed mutagenesis reaction mix and PCR program is listed in Table 13 and 14.

Table 13. Reaction mix for PfuTurbo Cx hotstart DNA polymerase

\begin{tabular}{ccc}
\hline Component & $\mathbf{5 0} \boldsymbol{\mu L}$ Reaction & Final concentration \\
\hline 10x PfuTurbo Cx reaction buffer & $5 \mu \mathrm{L}$ & $1 \times$ \\
methylated plasmid DNA & $x \mu \mathrm{L}$ & $300-500 \mathrm{ng}$ \\
mutagenic primer 1 & $1 \mu \mathrm{L}$ & $0.2 \mu \mathrm{M}$ \\
mutagenic primer 2 & $1 \mu \mathrm{L}$ & $0.2 \mu \mathrm{M}$ \\
dNTP mix & $1 \mu \mathrm{L}$ & $200 \mu \mathrm{M}$ each \\
DMSO & $1.5 \mu \mathrm{L}$ & $3 \%$ \\
PfuTurbo Cx hotstart DNA polymerase & $1 \mu \mathrm{L}$ & $0.05 \mathrm{U} / \mu \mathrm{L}$ \\
\hline
\end{tabular}

Table 14. PCR program for PfuTurbo Cx hotstart DNA polymerase

\begin{tabular}{lccc}
\hline \multicolumn{1}{c}{ Cycle step } & Temperature & Time & Cycles \\
\hline Denaturation & $95^{\circ} \mathrm{C}$ & $5 \mathrm{~min}$ & 1 \\
Denaturation & $95^{\circ} \mathrm{C}$ & $30 \mathrm{sec}$ & 20 \\
Annealing & $60^{\circ} \mathrm{C}$ & $1 \mathrm{~min}$ & 20 \\
Elongation & $68^{\circ} \mathrm{C}$ & $60 \mathrm{sec} / \mathrm{kb}$ & 20 \\
Final extension & $68^{\circ} \mathrm{C}$ & $10 \mathrm{~min}$ & 1 \\
Pause & $4{ }^{\circ} \mathrm{C}$ & $\infty$ & 1 \\
\hline
\end{tabular}


Afterwards, the PCR product was purified by the QIAquick Gel extraction Kit (QIAGEN). In order to remove parental DNA template and to select for mutation-containing synthesized DNA, $2 \mu \mathrm{L}$ of Dpnl endonuclease (20 U) and $2 \mu \mathrm{L}$ Tango buffer (Thermo Fisher Scientific) was directly added to $16 \mu \mathrm{L}$ mutagenesis reaction and incubated at $37^{\circ} \mathrm{C}$ for two hours. This restriction enzyme specifically digests methylated DNA. DNA isolated from Escherichia coli strains is commonly methylated, therefore, the synthesized DNA is susceptible to Dpnl digestion. As control for effective elimination of parental DNA template reaction, one reaction mix was simultaneously incubated lacking $D p n l$ restriction enzyme. Subsequently, $15 \mu \mathrm{L}$ of digested reaction mix was transformed into Escherichia coli $\mathrm{DH} 5 \alpha$ strains and incubated on selective LB plates containing $100 \mu \mathrm{g} / \mathrm{mL}$ ampicillin at $37^{\circ} \mathrm{C}$ overnight. In order to verify mutated genes, plasmid DNA was isolated using the QIAprep Spin Miniprep Kit (QIAGEN) and sequenced as described in section 2.2.2.10.

\subsubsection{Sequencing of DNA}

All DNA constructs used for this work were verified by the Göttingen Genomics Laboratory (G2L, Göttingen, Germany) or the Seqlab-Microsynth GmbH (Göttingen, Germany) using the Sanger Cycle Sequencing method (Sanger et al., 1992). For each G2L sequencing reaction $300 \mathrm{ng}$ plasmid DNA purified by the QIAprep Spin Miniprep Kit (QIAGEN) was mixed with $1 \mu \mathrm{L}$ of respective sequencing primer $(5 \mathrm{pmol})$ and adjusted to a final volume of $5 \mu \mathrm{L}$. Annealing temperature was chosen between $53^{\circ} \mathrm{C}$ and $60{ }^{\circ} \mathrm{C}$ according to the length and nucleotide composition of sequencing primer. For each DNA sample sequenced by the Seqlab test laboratory $1200 \mathrm{ng}$ plasmid DNA in a volume of $12 \mu \mathrm{L}$ was mixed with $3 \mu \mathrm{L}$ of respective sequencing primer $(30 \mathrm{pmol})$. The received sequences were analyzed using the Chromas 2.3.0.0 software (Technelysium Pty Ltd) and the multiple sequence align tool MultAlin (Corpet, 1988). Yeast chromosomal sequences were obtained from the SGD (Saccharomyces genome database) website (www.yeastgenome.org) (Cherry et al., 2012).

\subsubsection{Transfer of DNA}

\subsubsection{Transformation of plasmid DNA into Escherichia coli}

Plasmid DNA was transformed into Escherichia coli performing the heat shock method (Inoue et al., 1990). For transformation, $100 \mu \mathrm{L}$ competent DH5a Escherichia coli cells were thawed for 20 minutes on ice and mixed with $0.5 \mu \mathrm{g}$ of the desired plasmid DNA or $10 \mu \mathrm{L}$ of ligation reaction. To allow annealing of plasmid DNA to the cell envelope of Escherichia coli cells, the mixture was incubated for 10 minutes on ice. Afterwards, the cells were heated at $42{ }^{\circ} \mathrm{C}$ for 90 seconds and stored on ice for five minutes. Thereby, the cells take up the 
plasmid DNA. After transformation, cells were supplemented with $1 \mathrm{~mL}$ LB medium and recovered at $37{ }^{\circ} \mathrm{C}$ for 45 minutes. Finally, $100 \mu \mathrm{L}$ cell suspension was transferred to LB plates containing the respective antibiotics to select for transformants containing the desired plasmid DNA. For sufficient transformation yield, remaining cell suspension was centrifuged at $13000 \mathrm{rpm}$ in a benchtop centrifuge (Biofuge pico, Heraeus) for one minute and the supernatant was decanted. The precipitate was resuspended in $100 \mu \mathrm{L}$ LB medium and platted on another LB plate. After incubation overnight at $37^{\circ} \mathrm{C}$, the colonies were analyzed by PCR and sequencing as described in section 2.2.2.6 and 2.2.2.10.

\subsubsection{Transformation of plasmid DNA into Saccharomyces cerevisiae}

Transformation of plasmid DNA into Saccharomyces cerevisiae cells was performed by the LiAc/SS Carrier DNA/PEG method (Ito et al., 1983). In this technique, alkali cations treated yeast cells take up plasmid DNA after heat pulse in the presence of polyethylene glycol. For transformation, $800 \mu \mathrm{L}$ of an overnight culture grown in $10 \mathrm{~mL}$ YEPD medium at $30^{\circ} \mathrm{C}$ was used to inoculate $10 \mathrm{~mL}$ YEPD medium and incubated at $30^{\circ} \mathrm{C}$ on a rotation shaker (Fröbel Labortechnik $\mathrm{GmbH}$ ) for five hours. Afterwards, the total cell culture was harvested by centrifugation at $3000 \mathrm{rpm}$ for three minutes using the centrifuge 5804R (Eppendorf $A G$ ). The cell precipitate was repeatedly washed with $10 \mathrm{~mL}, 5 \mathrm{~mL}$ and $2 \mathrm{~mL}$ of LiOAc/TE buffer (100 mM LiOAc, $1 \mathrm{mM}$ Tris-HCL [pH 8.0], $0.1 \mathrm{mM}$ EDTA [pH 8.0]) and dissolved in $400 \mu \mathrm{L}$ $\mathrm{LiOAc/TE}$ buffer. From now on, the yeast cells are competent for transformation. $50 \mu \mathrm{L}$ of cell suspension was mixed with $5 \mu \mathrm{L}$ SS carrier DNA (single stranded salmon sperm DNA), $800 \mu \mathrm{L}$ of $50 \%$ polyethylene glycol 4000 (PEG 4000, Carl Roth GmbH \& CO. KG) dissolved in LiOAc/TE buffer and $2.5 \mu \mathrm{L}$ plasmid DNA. After incubation of the transformation mixture at $30{ }^{\circ} \mathrm{C}$ for 30 minutes, cells were exposed to heat shock at $42{ }^{\circ} \mathrm{C}$ for 25 minutes. After centrifugation at $13000 \mathrm{rpm}$ for one minute, the cell precipitate was resuspended in $1 \mathrm{~mL}$ YEPD medium and incubated at $30^{\circ} \mathrm{C}$ for one hour. Subsequently, cells were collected by centrifugation at 13000 for one minute, the supernatant was discarded and the remaining cell suspension was transferred on solid SC medium which lacks the appropriate amino acid to select for colonies carrying the plasmid with corresponding auxotrophic marker. After two to three days cultivation at $30{ }^{\circ} \mathrm{C}$, colonies were restreaked on new solid SC medium to select for colonies carrying the desired plasmid. 


\subsubsection{Protein methods}

\subsubsection{Production of crude extracts of yeast cells}

The strains to be analyzed were grown in $10 \mathrm{~mL} \mathrm{SC}$ medium containing the respective amino acids and $2 \%$ raffinose at $30{ }^{\circ} \mathrm{C}$ overnight. For induction of the GAL1-promoter, the overnight culture was centrifuged at $3000 \mathrm{rpm}$ for three minutes and the cell precipitate was used to inoculate $10 \mathrm{~mL} \mathrm{SC}$ medium containing $2 \%$ galactose. The cultures were rotative grown at $30^{\circ} \mathrm{C}$ for five hours. Afterwards, the samples were stored for 10 minutes on ice and centrifuged at $3000 \mathrm{rpm}$ for one minute at $4{ }^{\circ} \mathrm{C}$. The cell precipitate was then washed with $1 \mathrm{~mL}$ TE buffer (10 mM Tris-HCl [pH 8.0], $1 \mathrm{mM}$ EDTA [pH 8.0]) and dissolved in $200 \mu \mathrm{L}$ buffer $\mathrm{R}$ (50 mM Tris-HCl [pH 7.5], 1 mM EDTA [pH 8.0], $50 \mathrm{mM} \mathrm{DTT,} 6 \mu \mathrm{L} / \mathrm{mL}$ protease

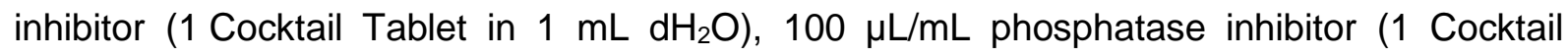

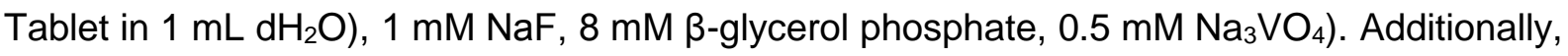
the same amount of $0.25-0.5 \mathrm{~mm}$ glass beads was added to the mixture. In order to break the cells, the samples were vigorously shaken at $4{ }^{\circ} \mathrm{C}$ using a vortex mixer (Vortex-Genie 2, Scientific Industries Inc) for 10 minutes. Subsequently, the suspension was centrifuged at $13000 \mathrm{rpm}$ for one minute at $4{ }^{\circ} \mathrm{C}$ and the crude cell extract was obtained by collecting the supernatant. After determination of the protein concentration by the Bradford assay (Bradford, 1976), the protein samples were resuspended in $6 x$ sample buffer ( $250 \mathrm{mM}$ Tris$\mathrm{HCl}[\mathrm{pH}$ 6.8], $15 \%$ (v/v) $\beta$-mercaptoethanol, $7 \%$ (w/v) SDS, $30 \%$ (v/v) glycerol, $0.3 \%$ (w/v) bromophenol blue) and boiled at $95{ }^{\circ} \mathrm{C}$ for 10 minutes. In order to analyze the isolated protein extracts, the samples were loaded onto a SDS polyacrylamide gel and separated by electrophoresis as described in section 2.2.4.5.

\subsubsection{Determination of protein concentration}

The protein content of a sample was determined by the Bradford protein concentration assay which is based on the proportional binding of Coomassie dye to proteins (Bradford, 1976). Thereby, the protein concentration is quantified by comparison to that of a series of known protein standards. In this study, BSA (Albumin Fraktion V, AppliChem $\mathrm{GmbH}$ ) was used as protein reference. In order to exhibit a linear calibration line, $2 \mu \mathrm{L}, 5 \mu \mathrm{L}, 10 \mu \mathrm{L}, 15 \mu \mathrm{L}, 20 \mu \mathrm{L}$ and $40 \mu \mathrm{L}$ of $1 \mathrm{mg} / \mathrm{mL}$ BSA solutions were added to $990 \mu \mathrm{L}$ of $1: 5$ diluted Bradford reagent (Rotiß-Quant, Carl Roth $\mathrm{GmbH} \& \mathrm{CO}$. KG) and incubated for five minutes at room temperature. Subsequently, extinction was measured at $595 \mathrm{~nm}$ using a light absorption photometer (T80 UV/VIS spectrometer, PG Instruments Ltd). The same procedure was performed with $10 \mu \mathrm{L}$ of the protein sample of interest in $990 \mu \mathrm{L}$ of 1:5 diluted Bradford reagent. On the basis of the linear calibration line, the protein concentration was calculated. 
Alternatively, protein concentration was determined using a microplate reader (Infinite ${ }^{\circledR}$ M200, Tecan Group). Here, $200 \mu \mathrm{L}$ of 1:5 diluted Bradford reagent was mixed with $5 \mu \mathrm{L}$ of $1: 10$ or $1: 100$ diluted protein sample and measured at $595 \mathrm{~nm}$ after five minutes incubation. For standard curve, $0 \mu \mathrm{L}, 1 \mu \mathrm{L}, 2 \mu \mathrm{L}, 5 \mu \mathrm{L}, 10 \mu \mathrm{L}$ and $20 \mu \mathrm{L}$ of $1 \mathrm{mg} / \mathrm{mL}$ BSA solution was used with $200 \mu \mathrm{L}$ of $1: 5$ diluted Bradford reagent. All samples were prepared in triplicates.

\subsubsection{3 $\mathrm{Ni}^{2+}-\mathrm{NTA}$ affinity chromatography}

Purification of $\mathrm{HIS}_{6}$-tagged recombinant proteins expressed in Saccharomyces cerevisiae was performed using the $\mathrm{Ni}^{2+}$-NTA affinity chromatography (Porath et al., 1975). This technique is based on the high binding affinity of nickel ions to histidine residues. Thereby, immobilized nickel ions of nickel-nitrilotriacetic acid beads ( $\left.\mathrm{Ni}^{2+}-\mathrm{NTA}\right)$ located on a highly crosslinked agarose matrix bind to HIS-tagged proteins and retain them until elution by competition with imidazole. At first, a $\mathrm{HIS}_{6}$-tag was fused to the C-terminus of the protein of interest and cloned into the desired plasmid. After verification of effective cloning, the constructs were transformed into yeast strains of interest and selected on selective SC medium. Cells cultured overnight in $200 \mathrm{~mL}$ selective SC liquid medium supplemented with $2 \%$ glucose were collected by centrifugation at $4000 \mathrm{rpm}$ for 20 minutes using the

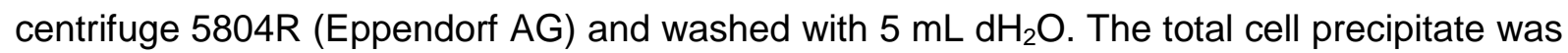
used to inoculate $1.5 \mathrm{~L}$ YEPD medium containing $2 \%$ galactose. After 12 hours induction of aSyn expression at $30{ }^{\circ} \mathrm{C}$, cells were harvested by centrifugation at $4000 \mathrm{rpm}$ for 20 minutes at $4{ }^{\circ} \mathrm{C}$ in the Sorvall RC-3B Plus Refrigerated Centrifuge (Thermo Fisher Scientific) and lysed by $25 \mathrm{~mL} 1.85 \mathrm{M} \mathrm{NaOH}$ containing $7.5 \%$ B-mercaptoethanol on ice for 10 minutes. To precipitate the protein crude extract, $25 \mathrm{~mL} 50 \%$ trichloroacetic acid (TCA, Carl Roth GmbH \& CO. KG) were added to the cell lysate and incubated on ice for 30 minutes. After centrifugation at $4000 \mathrm{rpm}$ for 15 minutes at $4{ }^{\circ} \mathrm{C}$, the precipitate was washed with $25 \mathrm{~mL}$ of $100 \%$ acetone and resuspended in $25 \mathrm{~mL}$ buffer $\mathrm{A}(6 \mathrm{M}$ guanidine $\mathrm{HCl}, 100 \mathrm{mM}$ sodium phosphate buffer [pH 8.0], $10 \mathrm{mM}$ Tris- $\mathrm{HCl}$ [pH 8.0]). Then, the mixture was rotated at $25^{\circ} \mathrm{C}$ for at least one hour and again centrifuged as described above. The collected supernatant was calibrated by $1 \mathrm{M}$ Tris [pH 8.5] to $\mathrm{pH} 7.0$ and supplemented with imidazole (AppliChem $\mathrm{GmbH}$ ) to reach the total concentration of $20 \mathrm{mM}$. For column preparation, $1 \mathrm{~mL}$ of $\mathrm{Ni}^{2+}-\mathrm{NTA}$ agarose (Qiagen) was added into a Poly-Prep $\AA$ Chromatography Column (Bio-Rad Laboratories). After equilibration with $5 \mathrm{~mL}$ of buffer $\mathrm{A}$ containing $20 \mathrm{mM}$ imidazole, the protein crude extracts were applied to the columns. Afterwards, the columns were washed with $10 \mathrm{~mL}$ buffer A containing $20 \mathrm{mM}$ imidazole and equilibrated with $5 \mathrm{~mL}$ buffer $\mathrm{B}$ (8 M urea, $100 \mathrm{mM}$ sodium phosphate buffer [pH 6.3], $10 \mathrm{mM}$ Tris- $\mathrm{HCl}$ [pH 6.3]). Elution of the $\mathrm{HIS}_{6}$-tagged protein was carried out using four times $1 \mathrm{~mL}$ of $200 \mathrm{mM}$ imidazole resolved in 
buffer B. Thereby, imidazole rings bind to the nickel ions and disrupt the binding of histidine residues. The protein content of the elution fractions was determined by Bradford protein concentration assay. Afterwards, the protein samples were resuspended in $6 x$ sample buffer and boiled for 10 minutes at $95^{\circ} \mathrm{C}$. The protein samples were stored at $-80^{\circ} \mathrm{C}$ or subjected to immunoblot analysis (2.2.4.6). To reuse the columns, they were first washed with $20 \mathrm{~mL}$ $\mathrm{dH}_{2} \mathrm{O}$ followed by $10 \mathrm{~mL} 0.2 \mathrm{M} \mathrm{NaOH}$ and another washing step with $20 \mathrm{~mL} \mathrm{dH}_{2} \mathrm{O}$. After equilibration of the columns by $5 \mathrm{~mL}$ buffer $A$, they were stored in ethanol $(20 \%(\mathrm{v} / \mathrm{v}))$.

\subsubsection{Trichloroacetic acid protein precipitation}

2,2,2-trichloroacetic acid (TCA) is widely used for precipitating soluble proteins from an aqueous solution. TCA triggers protein precipitation by inducing hydrophobic aggregation (Sivaraman et al., 1997). For TCA protein precipitation, $100 \%$ TCA solution (500 g TCA in $350 \mathrm{~mL} \mathrm{dH_{2 }}$ ) was added to the protein sample with a ratio of $1: 4$ and incubated at $4{ }^{\circ} \mathrm{C}$ for 10 minutes. After centrifugation at $13000 \mathrm{rpm}$ for five minutes at $4{ }^{\circ} \mathrm{C}$, the supernatant was discarded and the protein precipitate was washed with cold acetone. Next, the protein precipitate was centrifuged at $13000 \mathrm{rpm}$ for five minutes at $4{ }^{\circ} \mathrm{C}$ and the washing step was repeated. The precipitate was dried at $95{ }^{\circ} \mathrm{C}$ for five minutes and dissolved in $2 x$ sample buffer. After heating the protein precipitates at $95^{\circ} \mathrm{C}$ for 10 minutes, the samples were stored at $-80^{\circ} \mathrm{C}$ or used for further procedures.

\subsubsection{Discontinuous SDS-polyacrylamide gel electrophoresis (SDS-PAGE)}

SDS-PAGE is an electrophoretic technique which is used to separate proteins by their molecular mass (Laemmli, 1970). The charge of proteins as well as the three dimensional fold is superimposed by the addition of SDS which denatures the proteins and mediates a strong negative charge. Due to this effect, the proteins are separated by mass and not by charge. The vertical SDS gel used for protein separation is composed of a stacking and a separation gel. The stacking gel contains $5 \%$ polyacrylamide and allows fast migration of the proteins until the separation gel containing $12 \%$ polyacrylamide is reached. This concentration is suitable for separation of proteins of medium size. First, the separation gel

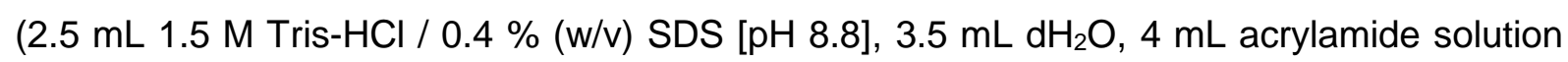
[30\% acrylamide, $0.8 \%$ bisacrylamide], $30 \mu \mathrm{L}$ APS [10\% (w/v)], $15 \mu \mathrm{L}$ TEMED) was poured and covered with isopropanol. After the separation gel was completely polymerized, the isopropanol was removed and the stacking gel $(1.5 \mathrm{~mL} 500 \mathrm{mM}$ Tris- $\mathrm{HCl} / 0.4 \%(\mathrm{w} / \mathrm{v})$ SDS

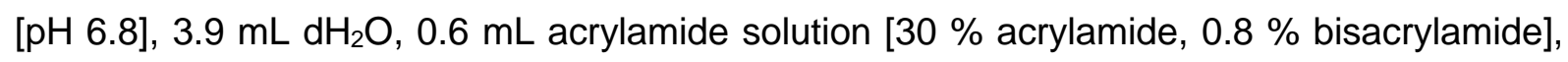
$40 \mu \mathrm{L}$ APS [10 \% (w/v)], $20 \mu \mathrm{L}$ TEMED) was poured on top of the separation gel. According 
to the volume of the samples, $1 \mathrm{~mm}$ or $1.5 \mathrm{~mm} \mathrm{10}$-well comb was inserted into the stacking gel. Before the protein samples were loaded onto the gel, they were mixed with 6x sample buffer and denatured at $95{ }^{\circ} \mathrm{C}$ for 10 minutes. Electrophoresis was performed in running buffer (25 mM Tris base, $250 \mathrm{mM}$ glycine, $0.1 \%$ (w/v) SDS) using the Mini-PROTEAN® 3 Cell and the Bio-Rad Powerpac 300 power supply (Bio-Rad Laboratories) at $100 \mathrm{~V}$ until the samples reached the separation gel. Thereafter, the electric current was raised to $200 \mathrm{~V}$ and electrophoresis was performed until the blue band of the $6 \mathrm{x}$ sample buffer ran out of the gel. PageRuler Prestained Protein Ladder (10 to $180 \mathrm{kDa}$, Thermo Fisher Scientific) was used as size standard to monitor separation of the proteins.

\subsubsection{Protein immunoblotting}

The protein immunoblotting technique is used to identify individual proteins in a protein mixture by specific recognition of antigens by antibodies on a carrier membrane. The proteins were first separated by discontinuous SDS-polyacrylamide gel electrophoresis and afterwards transferred electrophoretically on a nitrocellulose membrane (Amersham ${ }^{\mathrm{TM}}$ Protran $^{\mathrm{TM}} 0.45 \mu \mathrm{m}$ NC, GE Healthcare) or polyvinylidenflouride (PVDF) membrane (Amersham $^{\mathrm{TM}}$ Hybond-P ${ }^{\mathrm{TM}} 0.45 \mu \mathrm{m}$ PVDF, GE Healthcare), respectively (Towbin et al., 1979). The transfer was performed in transfer buffer $(25 \mathrm{mM}$ Tris base, $192 \mathrm{mM}$ glycine, $0.02 \%$ (w/v) SDS) with $20 \%$ methanol using a Mini Trans-Blot ${ }^{\circledR}$ Electrophoretic Cell (BioRad Laboratories). Due to the prior treatment with SDS, the proteins have a strong negative charge. By applying an electric current of $100 \mathrm{~V}$ to the blotting device for 1.5 hours, the proteins migrate towards the anode, which allows the transfer to the membrane. A schematic assembly of an immunoblot transfer stack is shown in Figure 5.

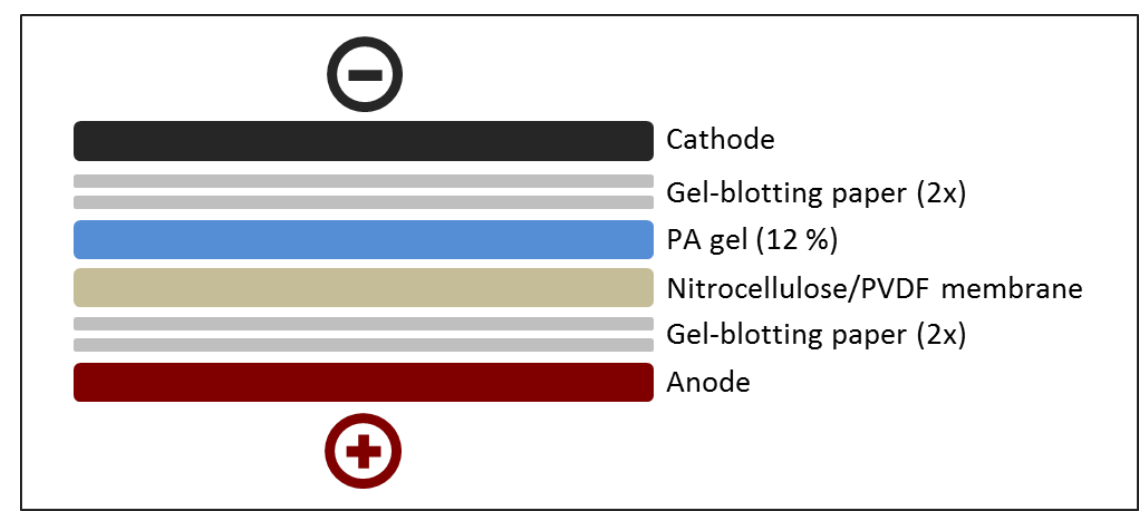

Figure 5. Schematic assembly of an immunoblot device.

For immunoblotting using tank transfer system, the polyacrylamide gel and the nitrocellulose membrane are placed between two layers of gel-blotting papers (Schleicher and Schuell BioScience $\mathrm{GmbH}$ ) that have to be soaked in transfer buffer before the stack is assembled. The electric current moves from the cathode to the anode. In this way, proteins are transferred from the polyacrylamide gel to the membrane. 
As soon as the proteins were transferred to the membrane, they could be visualized with specific antibodies. In order to achieve this, membrane was shaken after blotting in TBST buffer (10 mM Tris- $\mathrm{HCl}$ [pH 8.0], $150 \mathrm{mM} \mathrm{NaCl}, 0.05 \%$ (v/v) tween-20) containing $5 \%$ milk powder for at least one hour. Thereby, the free binding sites of the membrane are blocked to avoid binding of the antibody directly to the membrane. Next, a primary antibody, diluted in TBST buffer with $5 \%$ milk powder, was incubated with the membrane overnight. Primary and secondary antibodies that were used in this study are listed in Table 7 and 8 . Subsequently, the membrane was washed with TBST buffer three times for 20 minutes. The second antibody, which specifically binds to the first antibody and is conjugated to horseradish peroxidase, was diluted 1:2000 or 1:5000 in TBST buffer with $5 \%(\mathrm{w} / \mathrm{v})$ milk powder and incubated with the membrane for one hour. After removing the unbound antibody by washing the membrane as described before, the proteins were detected using the Enhanced Chemiluminescence $(E C L)$ technology. For that an ECL solution was prepared by mixing

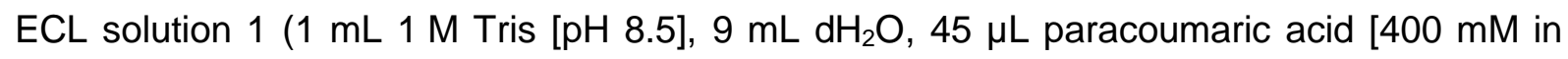
DMSO], $100 \mu \mathrm{L}$ luminol [250 mM in DMSO]) with ECL solution 2 (1 mL $1 \mathrm{M}$ Tris [pH 8.5],

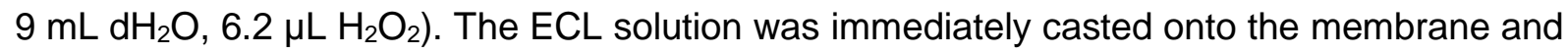
incubated for two minutes. Hereby, the enzymatic reaction of the horseradish peroxidase was started. This enzyme catalyzes the transfer of electrons from $\mathrm{H}_{2} \mathrm{O}_{2}$ to the luminol substrate which is thereby converted to a light releasing substance. The membrane was then covered in foil and exposed in the dark to Amersham ${ }^{\mathrm{TM}}$ Hyperfilm $^{\mathrm{TM}}$ - ECL (GE Healthcare) in time periods of several seconds and minutes leading to chemiluminescence signals visualized on the film. For the hybridization of the anti-nitrotyrosine antibody, the proteins were transferred to a PVDF membrane. Before electrophoretic blotting, the PVDF membrane had to be activated by methanol for 15 seconds. The following procedure was performed as described above. Detected bands were quantified using the Java-based image processing software ImageJ (Wayne Rasband, National Institutes of Health). To remove the antibodies, the membrane was incubated in $10 \mathrm{~mL}$ stripping solution $(50 \mathrm{mM}$ Tris- $\mathrm{HCl}[\mathrm{pH} 7.0], 2 \%(\mathrm{w} / \mathrm{v})$ SDS, $50 \mathrm{mM} \mathrm{DTT}$ ) at $60^{\circ} \mathrm{C}$ for 30 minutes. Afterwards, the membrane was washed in TBST buffer for five minutes and the free binding sites of the membrane were blocked by incubating the membrane in TBST buffer containing $5 \%(\mathrm{w} / \mathrm{v})$ milk powder for at least one hour.

\subsubsection{Staining of proteins with Coomassie brilliant blue R-250}

Coomassie brilliant blue R-250 (Serva Electrophoresis $\mathrm{GmbH}$ ) was used to stain unspecific protein bands on SDS gel (Fairbanks et al., 1971) based on its capability to attach to basic side chains of amino acids. Detection limit of Coomassie dye amounts of $100 \mathrm{ng}$ per protein 
band. Therefore, proteins separated on SDS gel were fixated for two hours in the fixation solution $\left(40 \%(\mathrm{v} / \mathrm{v})\right.$ ethanol, $10 \%(\mathrm{v} / \mathrm{v})$ acetic acid) and washed in $\mathrm{H}_{2} \mathrm{O}$ for one minute. The gel was then incubated overnight with Coomassie stain solution (50\% (v/v) methanol, $10 \%$ (v/v) acetic acid, $0.2 \%(w / v)$ Coomassie brilliant blue R-250) and again rinsed in water. To remove background, the gel was incubated in Coomassie destain solution $(50 \%(\mathrm{v} / \mathrm{v})$ methanol, $10 \%$ (v/v) acetic acid) for at least 30 minutes and washed three times in water for one minute.

\subsubsection{Silver staining}

A more sensitive technique to visualize protein bands on an SDS gel is the silver staining (Blum et al., 1987). In this method, silver ions bind to glutamic acid-, aspartic acid-, and cysteine residues of the proteins which are then reduced to elementary silver by formaldehyde resulting in a dark staining of the protein bands. Detection limit of silver stain is at 1-10 ng per band. The proteins separated on SDS gel were first incubated in fixing solution $(40 \%(\mathrm{v} / \mathrm{v})$ ethanol, $10 \%(\mathrm{v} / \mathrm{v})$ acetic acid) for at least two hours or overnight and then washed three times for 20 minutes in $30 \%$ ethanol. After incubation in $0.02 \%$ sodium thiosulfate for one minute the gel was rinsed three times for 20 seconds with $\mathrm{H}_{2} \mathrm{O}$ and incubated in $0.2 \%$ silver-nitrate solution for 20 minutes. The gel was again washed two times with $\mathrm{H}_{2} \mathrm{O}$ for 20 seconds and the developing solution (3\% (w/v) sodium carbonate, $0.05 \%$ $(\mathrm{v} / \mathrm{v})$ formaldehyde [37\% (v/v)], $0.0004 \%(\mathrm{w} / \mathrm{v})$ sodium thiosulfate) was applied on the gel. As soon as the protein bands are visible ( five minutes), the gel was washed twice with $\mathrm{H}_{2} \mathrm{O}$ for one minutes and the reaction was stopped by incubating the gel in $0.5 \%$ glycine for five minutes. Finally, the gel was washed in $\mathrm{H}_{2} \mathrm{O}$ for 30 minutes. All procedure steps were performed under shaking.

\subsubsection{In vitro protein nitration with peroxynitrite}

In vitro nitration of proteins was carried of using the highly reactive nitrating agent peroxynitrite (PON, Cayman Chemical). Because of its oxidizing ability, the peroxynitrite anion can participate directly in electron oxidation reactions with biomolecules (Lymar and Hurst, 1998). In proteins, tyrosine residues can be nitrated by PON that may alter protein function. For nitration, $20 \mu \mathrm{L}$ of purified protein was filled into a $50 \mu \mathrm{L}$ reaction tube. $1 \mu \mathrm{L}$ of $\mathrm{PON}$ was placed into the lid of the reaction tube. Because the reactivity of $\mathrm{PON}$ is highly $\mathrm{pH}$ dependent, $1 \mu \mathrm{L}$ of $0.3 \mathrm{M} \mathrm{HCl}$ was additionally placed into the lid. To induce the reaction, the tube was immediately vortexed for approx. 10 seconds. Subsequently, the nitrated protein was subjected to immunoblot analysis. 


\subsubsection{Liquid chromatography-mass spectrometry}

\subsubsection{In-gel protein digestion with trypsin}

Digesting and recovering proteins from stained protein bands excised from polyacrylamide gel were performed using trypsin restriction (Shevchenko et al., 1996). This protein hydrolase cleaves the peptide chain at specific sites. Its property is used to identify proteins by analyzing the resultant peptides using Liquid chromatography-mass spectrometry (LC-MS). In order to prepare proteins of interest for LC-MS, they were separated by $12 \%$ SDS-PAGE and stained with Coomassie dye as described in section 2.2.4.5 and 2.2.4.7. To improve the recovery rate of the samples and to prevent contamination with silicon, detergents and plastic softening agents, low-bind cups (Protein Lobind Tubes, Eppendorf AG) and vinyl gloves were used in all procedure steps. Excised polyacrylamide gel slices of Coomassie stained proteins were digested with the proteases according to the protocol of Shevchenko and supplier's instructions. After excising the target bands from the polyacrylamide gel, $50 \mu \mathrm{L}$ acetonitrile were added to the gel fractions and incubated for 10 minutes at room temperature. Next, the supernatant was removed and the polyacrylamide gel slices were dried using a vacuum concentrator (Savant SPD111V SpeedVac concentrator, Thermo Fisher Scientific) at $50{ }^{\circ} \mathrm{C}$ for 10 minutes. Then, the samples were incubated with $150 \mu \mathrm{L}$ $100 \mathrm{mM}$ ammonium bicarbonate containing $10 \mathrm{mM}$ DTT at $56^{\circ} \mathrm{C}$ for one hour. After spinning down the condense water by centrifugation at $13000 \mathrm{rpm}$ for one minute and decanting the supernatant, the polyacrylamide gel fractions were incubated with $150 \mu \mathrm{L} 100 \mathrm{mM}$ ammonium bicarbonate containing $55 \mathrm{mM}$ iodoacetamide at room temperature in the dark for 45 minutes. The supernatant was again removed and the samples were incubated with $150 \mu \mathrm{L} 100 \mathrm{mM}$ ammonium bicarbonate for 10 minutes. Afterwards, the ammonium bicarbonate was changed against $150 \mu \mathrm{L}$ acetonitrile and the samples were shaken for 10 minutes. The supernatant was again extracted and the samples were covered with $150 \mu \mathrm{L}$ ammonium bicarbonate for 10 minutes. After additional incubation of the gel fractions with acetonitrile as described above, the samples were subjected to a drying step in the vacuum concentrator at $50{ }^{\circ} \mathrm{C}$ for 10 minutes. After that, the polyacrylamide gel slices were covered by approx. $50 \mu \mathrm{L}$ trypsin digestion buffer (Serva Trypsin (Serva Electrophoresis $\mathrm{GmbH}$ ) in $25 \mathrm{mM}$ ammonium bicarbonate (1:2.5)) and digested on ice for 45 minutes. Subsequently, the trypsin containing solution was discarded, the samples were covered by approx. $50 \mu \mathrm{L}$ of $25 \mathrm{mM}$ ammonium bicarbonate $\left[\mathrm{pH}\right.$ 8.0] and incubated at $37{ }^{\circ} \mathrm{C}$ overnight. After centrifugation at $13000 \mathrm{rpm}$ for one minute, the supernatant was collected and the gel slices were incubated in $50 \mu \mathrm{L} 20 \mathrm{mM}$ ammonium bicarbonate for 10 minutes. After centrifugation as described before, the supernatant was again gathered and the gel slices were incubated for 20 minutes in $50 \mu \mathrm{L} 50 \%$ acetonitrile containing $5 \%$ formic acid. The samples were 
centrifuged at $13000 \mathrm{rpm}$ for one minute and the supernatant was again collected. Acetonitrile/formic acid extraction was repeated twice. Finally, the united supernatant was humidified using the vacuum concentrator at $50^{\circ} \mathrm{C}$ and stored at room temperature.

\subsubsection{In-solution protein digestion with Asp-N}

Trypsin digested aSyn peptides were additionally digested by Asp- $\mathrm{N}$ to obtain appropriate peptides for LC-MS. For double digestion, aSyn peptides were digested by trypsin as described in section 2.2.5.1. Afterwards, humidified peptides were dissolved in $30 \mu \mathrm{L}$ $100 \mathrm{mM}$ ammonium bicarbonate [pH 8.0] and incubated with Asp-N (1:100, Sigma-Aldrich) at $37^{\circ} \mathrm{C}$ overnight. Finally, the peptides were humidified using the vacuum concentrator at $50^{\circ} \mathrm{C}$ and stored at room temperature.

\subsubsection{C18 StageTip purification}

Before performing analysis by LC-MS, the peptide mixture was purified by the C18 StageTip purification method using self-made C18 stop-and-go-extraction tips (C18 StageTips) (Rappsilber et al., 2007). During this procedure, peptides are enriched and purified from urea, salts and other contaminants through binding to reversed-phase material (C18) and eluted in organic solution. StageTips were prepared by placing a small portion of C18 material in a pipette tip. For equilibration, $100 \mu \mathrm{L}$ methanol containing $0.1 \%(\mathrm{v} / \mathrm{v})$ formic acid was added into the StageTips and centrifuged at $13000 \mathrm{rpm}$ for two minutes. After discarding the flow through, $100 \mu \mathrm{L}$ of $70 \%(\mathrm{v} / \mathrm{v})$ acetonitrile containing $0.1 \%(\mathrm{v} / \mathrm{v})$ formic acid was added and centrifuged at $13000 \mathrm{rpm}$ for two minutes. After the flow through was discarded, the $100 \mu \mathrm{L} \mathrm{dH_{2 }} \mathrm{O}$ containing $0.1 \%(\mathrm{v} / \mathrm{v})$ formic acid was added and centrifuged at $13000 \mathrm{rpm}$ for two minutes. The flow through was discarded and the StageTip equilibration was completed by repeating the last step. Humidified peptides were resolved in $20 \mu \mathrm{L}$ of $2 \%$ $(\mathrm{v} / \mathrm{v})$ acetonitrile containing $0.1 \%(\mathrm{v} / \mathrm{v})$ formic acid and incubated in an ultrasonic bath (Bandelin Sonorex ${ }^{\mathrm{TM}}$ Digital $10 \mathrm{P}$ ultrasonic bath, Bandelin electronic $\mathrm{GmbH}$ \& Co. KG) at $35^{\circ} \mathrm{C}$ at maximum power for three minutes. The peptide mixtures were loaded onto the StageTips, centrifuged at $1000 \mathrm{rpm}$ for five seconds and incubated for five minutes at room temperature. Afterwards, the peptide samples were centrifuged at $4000 \mathrm{rpm}$ for five minutes and the flow through was reloaded onto the StageTips and centrifuged at $4000 \mathrm{rpm}$ for five minutes. Next, the flow through was discarded and the columns were washed twice with

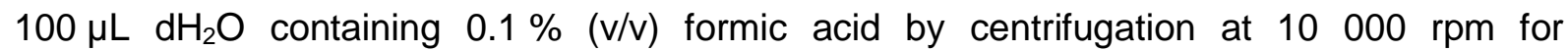
two minutes. After the StageTips were transferred into a low-bind cup, $60 \mu \mathrm{L}$ acetonitrile containing $0.1 \%(\mathrm{v} / \mathrm{v})$ formic acid was added and incubated for five minutes at room 
temperature. Finally, the StageTips were centrifuged for five minutes at $4000 \mathrm{rpm}$ and the peptides were humidified using the vacuum concentrator at $50{ }^{\circ} \mathrm{C}$. In order to prepare the resultant protein fragments for mass spectrometry, peptides were resolved in $20 \mu \mathrm{L}$ of $2 \%(\mathrm{v} / \mathrm{v})$ acetonitrile containing $0.1 \%(\mathrm{v} / \mathrm{v})$ formic acid and incubated in an ultrasonic bath at $35^{\circ} \mathrm{C}$ at maximum power for three minutes. Mass spectrometry was performed by Dr. Oliver Valerius (Department of Molecular Microbiology and Genetics, Georg-August-Universität Göttingen) using Orbitrap Velos Pro (Thermo Fisher Scientific).

\subsubsection{Mass spectrometry analysis of $\alpha$-synuclein}

The single digestions as well as the double digested tryptic/AspN peptides were analyzed by LC-MS. Peptides of 1-5 $\mu \mathrm{L}$ sample solution were trapped and washed with $0.07 \%(\mathrm{v} / \mathrm{v})$ trifluoroacetic acid containing $2.6 \%(\mathrm{v} / \mathrm{v})$ acetonitrile on an Acclaim® PepMap 100 column (100 $\mu \mathrm{m} \times 2 \mathrm{~cm}, \mathrm{C} 18,3 \mu \mathrm{m}, 100 \AA$, P/N164535, Thermo Fisher Scientific) at a flow rate of $25 \mu \mathrm{L} / \mathrm{min}$ for five minutes. Analytical peptide separation by reverse phase chromatography was performed on an Acclaim ${ }^{\circledR}$ PepMap RSLC column $(75 \mu \mathrm{m} \times 25 \mathrm{~cm}, \mathrm{C} 18,3 \mu \mathrm{m}, 100 \AA$, $\mathrm{P} / \mathrm{N} 164534$, Thermo Fisher Scientific) running a 40 minutes gradient from $100 \%$ solvent $A$ $(0.1 \%(\mathrm{v} / \mathrm{v})$ formic acid) to $65 \%$ solvent B $(80 \%(\mathrm{v} / \mathrm{v})$ acetonitrile, $0.1 \%(\mathrm{v} / \mathrm{v})$ formic acid) and further to $95 \%$ solvent $B$ within one minute at flow rates of $300 \mathrm{~nL} / \mathrm{min}$ (Fisher Chemicals). Chromatographically eluting peptides were on-line ionized by nano-electrospray (nESI) using the Nanospray Flex lon Source (Thermo Fisher Scientific) at $2.4 \mathrm{kV}$ and continuously transferred into the mass spectrometer. Full scans within $\mathrm{m} / \mathrm{z}$ of $300-1850$ were recorded with the Orbitrap-FT analyzer at a resolution of 30000 with parallel data-dependent top 10 MS2-fragmentation in the LTQ Velos Pro linear ion trap. LC-MS method programming and data acquisition was performed with the software Xcalibur 2.2 (Thermo Fisher Scientific). MS/MS2 data processing for protein analysis and PTM identification was done with the Proteome Discoverer 1.4 (PD, Thermo Fisher Scientific) software using the SequestHT search engine (Thermo Fisher Scientific) and Saccharomyces cerevisiae protein database extended by the most common contaminants with the following criteria: peptide mass tolerance $10 \mathrm{ppm}, \mathrm{MS} / \mathrm{MS}$ ion mass tolerance $0.8 \mathrm{Da}$, and up to two missed cleavages allowed. Only high confident peptides with a false discovery rate less than 0.01 were considered.

\subsubsection{Identification of crosslinked peptides}

The MS data of crosslinked peptides were analyzed with StavroX2.3.4.5 (Gotze et al., 2012). MS data in the Mascot generic file (mgf) format containing all MS/MS data of precursor ions 
were loaded into the program. The following parameters were used for the StavroX analysis: (i) cleavage sites: C-terminal: K, R; N-terminal: D; (ii) number of missed cleavages = 2; (iii) variable modifications: oxidation of methionine; nitration of tyrosine; cysteine-to-cysteine acetamide; (iv) mass of crosslinker: -H2; (v) crosslinks only between two tyrosines; (vi) precision precursor comparison $=10 \mathrm{ppm}$. The false-positive rate was evaluated by decoy analysis using the reversed protein sequence. The frequency of occurrence of candidates from the data analysis and decoy analysis was compared for each sample. Only scores with decoy frequencies below $8 \%$ of the data frequency were considered as possible crosslinks. The data were filtered for unique scans and each scan was considered only once with its highest score. Since multiple tyrosine residues are located on one and the same peptide, different combinations of crosslinked peptides with equal masses were possible. For each scan, the crosslinked tyrosine dimers were assigned according to the score calculated by the program based on the fragment ions series.

\subsubsection{Phenotypical characterization}

\subsubsection{Spotting assay}

Growth of yeast strains on solid medium was analyzed by performing spotting assay. Cells were grown in selective SC medium supplemented with $2 \%$ raffinose at $30{ }^{\circ} \mathrm{C}$ overnight. After normalizing the cells to equal densities $\left(\mathrm{OD}_{600}\right.$ of 0.1$), 10$-fold dilutions series were prepared $\left(10^{-1}, 10^{-2}, 10^{-3}, 10^{-4}\right)$ and spotted in a volume of $10 \mu \mathrm{L}$ on selective SC agar plates supplemented with either $2 \%$ glucose or $2 \%$ galactose. The growth intensity was documented after two to three days incubation at $30^{\circ} \mathrm{C}$.

\subsubsection{Fluorescence microscopy}

For fluorescence microscopy cells were pre-grown in selective SC medium containing $2 \%$ raffinose at $30{ }^{\circ} \mathrm{C}$ overnight and inoculated in $2 \%$ galactose-containing SC medium to an $\mathrm{OD}_{600}$ of 0.1 . aSyn expression was induced for five hours. $300 \mu \mathrm{L}$ of the cells were subjected to fluorescence microscopy. Fluorescent images were obtained with 63x magnification using a Zeiss Axio Observer. Z1 microscope (Zeiss) equipped with a CSU-X1 A1 confocal scanner unit (Yokogawa), QuantEM:512SC digital camera (Photometrics) and SlideBook 6.0 software package (Intelligent Imaging Innovations $\mathrm{GmbH}$ ). Depending on the fluorescent agent, ssGFP or sdRFP filter were applied. To quantify aggregation of aSyn, at least 300 cells were counted per strain and experiment and the number of cells displaying aSyn aggregation was referred to the total number of counted cells. 


\subsubsection{Mitochondrial staining}

To study mitochondrial morphology within live cells, the red-fluorescent dye MitoTracker ${ }^{\circledR}$ Red CMXRos-Special Packaging (Invitrogen) was used. MitoTracker Red accumulates in mitochondria depending on membrane potential. Cells were pre-grown in selective SC medium containing $2 \%$ raffinose and inoculated in $2 \%$ galactose-containing SC medium to an $\mathrm{OD}_{600}$ of 0.1. aSyn expression was induced for five hours. To label mitochondria, the cells were incubated for 45 minutes in the presence of $50 \mathrm{nM}$ MitoTracker Red, washed once with fresh medium and imaged.

\subsubsection{Detection of reactive oxygen and nitrogen species}

Reactive oxygen species (ROS) in yeast cells were visualized by microscopy using dihydrorhodamine 123 (DHR123, Cayman Chemical). The nonfluorescent ROS indicator passively diffuses across cell membranes where it is oxidized to the highly fluorescent product rhodamine 123 (Crow, 1997). It has an excitation and emission wavelengths of 500 and $536 \mathrm{~nm}$, respectively. In order to test yeast for production of ROS, cells were pregrown in selective SC medium containing $2 \%$ raffinose at $30{ }^{\circ} \mathrm{C}$ overnight and inoculated in $2 \%$ galactose-containing medium to an $\mathrm{OD}_{600}$ of 0.1 . aSyn expression was induced for

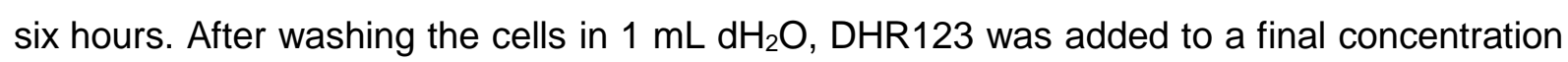
of $5 \mu \mathrm{g} / \mathrm{mL}$ to $300 \mu \mathrm{L}$ cells resuspended in $\mathrm{dH}_{2} \mathrm{O}$ and incubated in the dark at $30{ }^{\circ} \mathrm{C}$ for 1.5 hours. After washing, cells were re-suspended in $\mathrm{dH}_{2} \mathrm{O}$ and microscopy was performed using RFP filter. To test yeast for reactive nitrogene species (RNS) production, the sensitive fluorescent indicator DAF-2 diacetate (Genaxxon BioScience $\mathrm{GmbH}$ ) was used (Kojima et al., 1998). Upon entry into the cell, DAF-2 diacetate is transformed into DAF-2 by cellular esterases, which reacts with nitric oxide in the presence of oxygen to yield the highly fluorescent triazolofluorescein. It has an excitation and emission wavelengths of 485 and $538 \mathrm{~nm}$, respectively. Cells pre-grown overnight in $2 \%$ raffinose-containing SC medium were transferred to $2 \%$ galactose-containing SC medium at $\mathrm{OD}_{600}$ of 0.1 . After six hours induction of aSyn expression, cells were washed and diluted in PBS buffer [pH 7.5] (137 mM NaCl, $8 \mathrm{mM} \mathrm{Na}_{2} \mathrm{HPO}_{4}, 2 \mathrm{mM} \mathrm{NaH} \mathrm{PO}_{4}$ ) to $\mathrm{OD}_{600}$ of 0.1 . DAF-2 diacetate was added to a final concentration of $25 \mu \mathrm{g} / \mathrm{mL}$ and cells were incubated in the dark at $30^{\circ} \mathrm{C}$ for one hour. Before microscopy, the cells were washed in PBS buffer [pH 7.5] and RNS were visualized using GFP filter. 


\subsubsection{Flow cytometry}

For quantification of ROS and RNS stained by DHR123 and DAF-2 diacetate in yeast cells, flow cytometry was performed. This technique simultaneously measures and analyzes multiple physical characteristics of single particles, such as cells that flow in a fluid stream through a beam of light (Fulwyler, 1965). Cells were grown and treated with DHR123 or DAF2 diacetate as described in section 2.2.6.4. Before measuring, cells were resuspended in $50 \mathrm{mM}$ trisodium citrate buffer $\mathrm{pH}$ 7.0. Flow cytometry analysis was performed on a BD FACSCANTO II (Becton Dickinson). 100000 events were counted for each experiment. Data analysis was performed using the BD FACSDIVA ${ }^{\mathrm{TM}}$ software (Becton Dickinson). Representative examples were repeated at least three times.

\subsubsection{Cell integrity assay}

Yeast cell membrane integrity was analyzed with propidium iodide (PI) staining. After five hours induction of aSyn expression in $2 \%$ galactose-containing SC medium, yeast cells with an $\mathrm{OD}_{600}$ of 0.3 were washed in $500 \mu \mathrm{L}$ PBS and incubated with $12.5 \mu \mathrm{g} / \mathrm{mL} \mathrm{PI}$ in $500 \mu \mathrm{L}$ PBS for 30 minutes. As a positive control, cells were boiled for 10 minutes at $95{ }^{\circ} \mathrm{C}$. Flow cytometry analysis was performed as described in section 2.2.6.5.

\subsubsection{Growth analysis in liquid culture}

For growth tests in liquid cultures, cells were pre-grown in $2 \%$ raffinose-containing selective SC medium at $30{ }^{\circ} \mathrm{C}$ overnight and inoculated in $2 \%$ galactose-containing SC medium to equal densities of $\mathrm{OD}_{600}$ of 0.1 . Optical density measurements of $200 \mu \mathrm{L}$ cell cultures were performed in triplicates in 96-well plates for 48 hours using a microplate reader (Infinite ${ }^{\circledR}$ M200, Tecan Group). Growth analyses under nitrative stress conditions were performed using $600 \mu \mathrm{M}$ or $1 \mathrm{mM}$ DETA-NONOate (Cayman Chemical) as NO donor. This compound releases NO radicals and thereby induces nitrative stress in the cells. For DETA-NONOate use, the induction $2 \%$ galactose-containing SC medium was adjusted to $\mathrm{pH} 7.4$ by $200 \mathrm{mM}$ $\mathrm{NaOH}$ to avoid a fast release of the compound. Incubation without DETA-NONOate served as control.

\subsubsection{Promoter shut-off assay}

To study the ability of yeast cells to degrade aSyn, promoter shut-off analyses were performed. Yeast cells were pre-grown in selective SC medium containing $2 \%$ raffinose overnight and shifted to $2 \%$ galactose-containing selective SC medium to induce aSyn 
expression for four hours. Afterwards, cells were transferred to selective SC medium containing $2 \%$ glucose to shut-off the promoter. Four hours after promoter shut-off, cells were visualized by fluorescence microscopy and the reduction of number of cells displaying aSyn inclusions was recorded. To study the lysosome/vacuole degradation pathway (autophagy), $1 \mathrm{mM}$ phenylmethanesulfonyl fluoride (PMSF, Carl Roth $\mathrm{GmbH} \& \mathrm{CO}$. KG) dissolved in ethanol was applied to the cell suspension (Lee and Goldberg, 1996). As control, equal volume of ethanol was applied to the cells. For impairment of the proteasomal degradation system, Carbobenzoxyl-leucinylleucinyl-leucinal (MG132, Selleck Chemicals) dissolved in dimethyl sulfoxide (DMSO) was added to the cell suspension in a final concentration of $75 \mu \mathrm{M}$. In parallel, equal volume of DMSO was applied to the cells as a control. For drug treatment with MG132, induction-medium containing galactose and shut-offmedium containing glucose was supplemented with $0.003 \%(\mathrm{w} / \mathrm{v})$ SDS and $0.1 \%(\mathrm{w} / \mathrm{v})$ proline (Liu et al., 2007).

\subsubsection{Agar diffusion assay}

To analyze the sensitivity of Saccharomyces cerevisiae strains to reactive oxygen species, agar diffusion assay was performed using hydrogen peroxide $\left(\mathrm{H}_{2} \mathrm{O}_{2}\right) . \mathrm{H}_{2} \mathrm{O}_{2}$ is reduced to hydroxyl radical $(\mathrm{OH} \bullet)$, which is one of the strongest oxidants in nature leading to oxidative stress. For testing sensitivity to oxidative stress, cells were grown in selective SC medium containing $2 \%$ raffinose at $30{ }^{\circ} \mathrm{C}$ overnight and harvested by centrifugation at $3000 \mathrm{rpm}$ for three minutes using the centrifuge 5804R (Eppendorf AG). After washing the cells in $1 \mathrm{~mL}$ $\mathrm{dH}_{2} \mathrm{O}$, optical densities were normalized to $\mathrm{OD}_{600}$ of 1 in $1 \mathrm{~mL} \mathrm{dH}_{2} \mathrm{O}$. $100 \mu \mathrm{L}$ of cell suspension was resolved in $10 \mathrm{~mL}$ liquid top agar $(0.5 \%(\mathrm{w} / \mathrm{v}))$ and transferred on solid MV medium [pH 7.2] supplemented with $2 \%$ galactose. Small Whatman paper disks were soaked with $10 \mu \mathrm{L} 30 \% \mathrm{H}_{2} \mathrm{O}_{2}$ and placed in the middle of the agar plate. The size of the inhibition area was measured after two to three days incubation at $30^{\circ} \mathrm{C}$.

\subsubsection{Oxygen consumption rate assay}

Oxygen consumption rate $(\mathrm{OCR})$ is an indicator of mitochondrial respiration, which was assessed using the XF24 Extracellular Flux Analyzer (Seahorse Bioscience). This device measures the oxygen concentration in the medium and concludes the oxygen consumption rate $(\mathrm{OCR})$. Cells were pre-grown in selective SC medium containing $2 \%$ raffinose at $30{ }^{\circ} \mathrm{C}$ overnight and inoculated in $2 \%$ galactose-containing medium to an $\mathrm{OD}_{600}$ of 0.1 . aSyn expression was induced for six hours. For the assay, cells were seeded in galactosecontaining selective SC medium with $\mathrm{OD}_{600}$ of 0.075 . OCR was assessed at basal conditions, 
as well as after sequential addition of $2 \mu \mathrm{M}$ FCCP (protonophore), $20 \mu \mathrm{M}$ oligomycin A (ATP synthase inhibitor) and $50 \mu \mathrm{M}$ antimycin $\mathrm{A}$ (complex III inhibitor). Basal OCR was obtained after subtraction of non-mitochondrial respiration (difference between initial OCR and antimycin A OCR response). Bioenergetic parameters were calculated upon normalizing OCR values to the baseline. Measuring of OCR was performed in the Department of Neurodegeneration and Restorative Research of the University Medical Center Göttingen (Göttingen, Germany).

\subsubsection{Cell culture methods}

All experiments carried out in mammalian cell culture were performed by Diana F. Lázaro in the Department of Neurodegeneration and Restorative Research of the University Medical Center Göttingen (Göttingen, Germany).

\subsubsection{Transfection of $\mathrm{H} 4$ cells}

H4 neuroglioma cells were used to analyze aggregation propensity of aSyn in mammalian cells. $\mathrm{H} 4$ cells are tumor cells of human neuroglia. $\mathrm{H} 4$ cells were plated 24 hours prior to transfection in 12-well plates (Costar). Cells were transfected with FuGENE®6 Transfection Reagent (Promega) using equal amounts of plasmid DNA encoding for aSyn, synphilin-1 (McLean et al., 2001) and Neuroglobin-mCherry or pcDNA3.1 (Invitrogen), according to the manufacturer's instructions.

\subsubsection{Immunocytochemistry}

For visualization of aSyn in $\mathrm{H} 4$ cells, immunocytochemistry was performed. This technique is based on the principle of specific binding of antibodies to antigens and is used to detect antigens in biological tissues. 48 hours after transfection, cells were washed with PBS and fixed with $4 \%$ paraformaldehyde for 10 minutes at room temperature. After washing with PBS, cells were permeabilized with $0.5 \%$ Triton X-100/PBS (Sigma-Aldrich) for 20 minutes at room temperature and blocked in $1.5 \%$ normal goat serum (PAA)/PBS for one hour. Cells were incubated with a mouse anti-aSyn antibody (1:1000, BD Transduction Laboratory) overnight and then with a secondary antibody (Alexa Fluor 488 donkey anti-mouse lgG) for two hours at room temperature. Finally, cells were stained with Hoechst 33258 (1:5000 in PBS, Invitrogen) for five minutes and maintained in PBS prior to epifluorescence microscopy. 


\subsubsection{Quantification of $\alpha$-synuclein inclusions in $\mathrm{H} 4$ cells}

Transfected cells were scored based on the aSyn inclusion pattern and classified into: cells without inclusions, less than ten inclusions ( $<10$ inclusions), and more than ten inclusions ( $\geq 10$ inclusions), as described (Lazaro et al., 2014). The total number of transfected cells was expressed in percentage, as the average from three independent experiments.

\subsubsection{Lactate dehydrogenase assay}

The lactate dehydrogenase (LDH) cytotoxicity assay (Roche Diagnostics) was performed according to the manufacturer's instructions. Growth media from cells were applied in triplicates in a 96-well plate in a ratio 1:1 with the reaction mixture. The measurements were performed in a TECAN Infinite 200 Pro plate reader (Tecan Group) at $490 \mathrm{~nm}$. The percentage of toxicity was calculated as indicated by the manufacturer.

\subsubsection{Statistical analysis}

Data were analyzed using GraphPad Prism 5 Software (San Diego, USA) and were presented as mean \pm SEM of at least three independent experiments. The significance of differences was calculated using Students t-test, one-way ANOVA test with Bonferroni's multiple comparison test or Dunnett's multiple comparison test. $P$ value $<0.05$ was considered to indicate a significant difference. 


\section{Results}

Misfolded oligomeric aSyn species have been hypothesized to be involved in the neurodegeneration process of PD and other synucleinopathies. In this study, ability of an eukaryotic cell to overcome misfolded and accumulated aSyn species was explored. Moreover, the impact of oxidative stresses on these molecular processes was addressed. Therefore, aSyn was heterologously expressed in Saccharomyces cerevisiae cells and the influence of nitration on aSyn-mediated cytotoxicity was examined. Thereby, aggregation propensity, growth impact, ROS/RNS accumulation, protein and mitochondrial analysis served as instruments to question, whether nitration affects aSyn-induced cytotoxicity. Moreover, it was investigated, whether there is an interplay between nitration and phosphorylation of aSyn on S129 as the predominant posttranslational modification found in LBs.

\section{1 $\alpha$-synuclein forms dimers in vivo in yeast cells}

Exposure of aSyn to nitrating agents causes tyrosine nitration in vitro and leads to formation of covalently crosslinked aSyn dimers and inclusions (Hodara et al., 2004; Norris et al., 2003; Paxinou et al., 2001; Souza et al., 2000a; Takahashi et al., 2002). High levels of aSyn with C-terminal $\mathrm{HIS}_{6}$-tags were heterologously expressed in yeast cells to uncover how nitration influences in vivo aSyn toxicity and aggregate formation. The first approach was to examine, whether aSyn and A30P form dimers in vivo without additional exposure of the cells to nitrating or oxidative agents. aSyn and A3OP expression was driven by the GAL1-promoter, which was repressed in the presence of glucose and induced when shifted to $2 \%$ galactosecontaining medium for 12 hours. High copy number expression of the $\mathrm{HIS}_{6}$-tagged aSyn resulted in growth inhibition, whereas high expression of the A30P mutant resulted in a similar growth rate as the yeast control without any aSyn (Figure 6A). Similar results were previously reported with untagged or GFP-tagged aSyn and corroborate that the $\mathrm{HIS}_{6}$-tag does not interfere with the behavior of aSyn in yeast (Outeiro and Lindquist, 2003; Petroi et al., 2012).

Next, aSyn proteins were enriched by $\mathrm{Ni}^{2+}$ pull-down under denaturing conditions in the presence of urea. Immunoblotting with anti-aSyn antibody revealed distinct bands, corresponding to monomeric $(\sim 17 \mathrm{kDa})$, dimeric $(\sim 35 \mathrm{kDa})$ and higher molecular weight $\alpha$ Syn species (oligomers), detected from in vivo samples (Figure 6B). This supports that aSyn and the A30P mutant form dimers and oligomers in vivo even without additional exposure of the cells to nitrating or oxidative agents. 

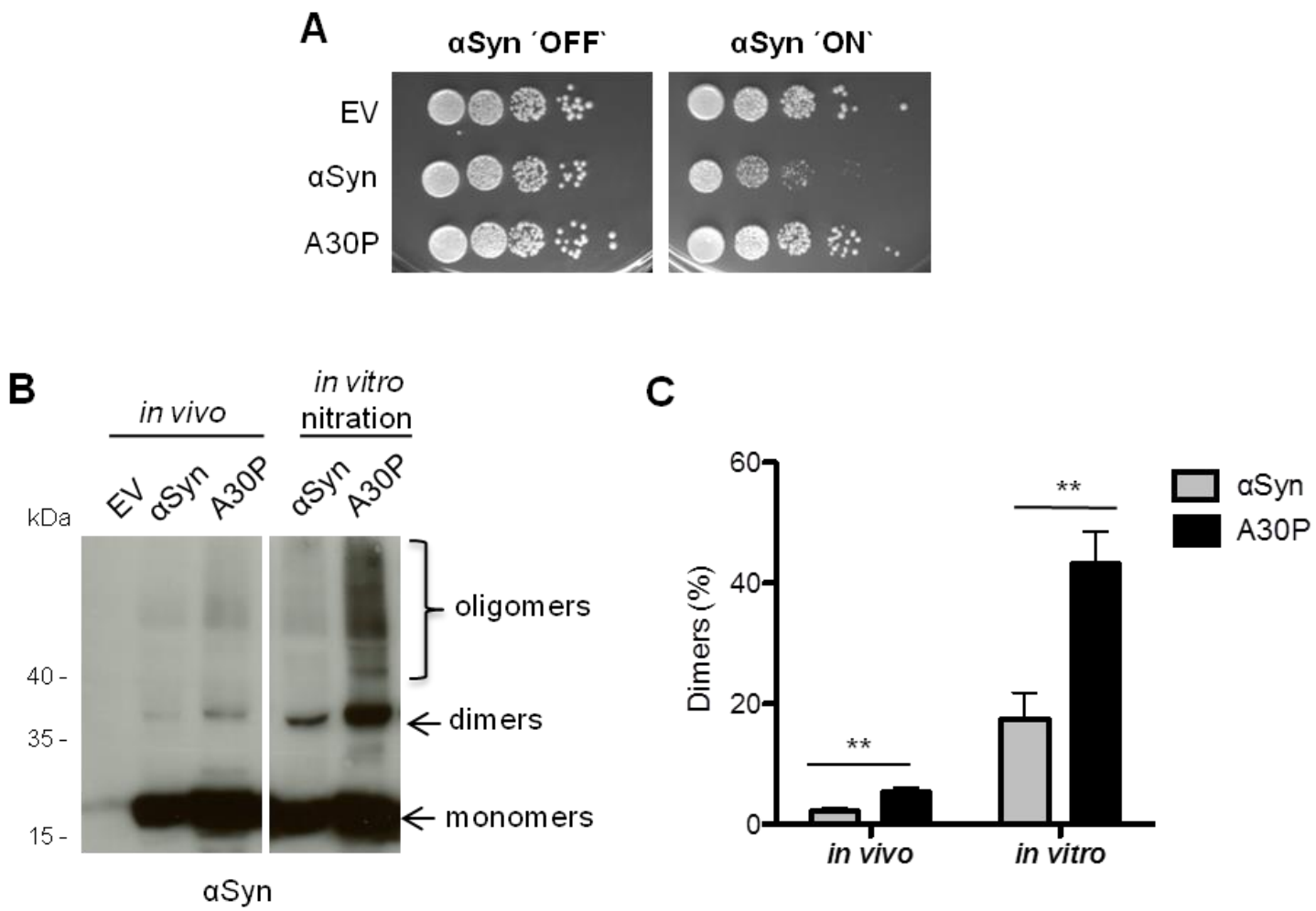

Figure 6. aSyn forms dimers in vivo in yeast.

(A) Spotting analysis of yeast cells expressing C-terminally $\mathrm{HIS}_{6}$-tagged aSyn and A30P aSyn on a high copy vector $(2 \mu)$ driven by the inducible GAL1-promoter on non-inducing ('OFF': glucose) and inducing ('ON': galactose) SC-Ura medium after three days. Control cells expressed only the empty vector pME2795 (EV). (B) Immunoblotting of aSyn and A30P enriched from cell extracts by $\mathrm{Ni}^{2+}$ pull-down with anti-aSyn antibody. In vitro nitration was carried out with $15 \mu \mathrm{g}$ of aSyn extracts using $1 \mu \mathrm{L}$ peroxynitrite (PON) in the presence of $1 \mu \mathrm{L} 0.3 \mathrm{M} \mathrm{HCl}$. (C) Quantification of dimers. Densitometric analysis of the immunodetection of aSyn and A30P dimers in vivo and in PON-treated samples. The amount of dimers is presented as percent of the total amount of aSyn detected per lane (monomer + dimer). Significance of differences was calculated with t-test $\left({ }^{* *}, p<0.01, n=4\right)$.

Dimer and oligomer formation of aSyn in vivo was further analyzed by comparison to additional in vitro nitration (Souza et al., 2000a). PON (ONOO-) was applied as nitrating agent for aSyn tyrosine residues because it leads to the formation of stable aSyn oligomers. PON is formed by the reaction of superoxide $\left({ }^{\circ} \mathrm{O}_{2}{ }^{-}\right)$with the free radical nitric oxide $\left({ }^{\circ} \mathrm{NO}\right)$ and represents a major nitrating agent that causes tissue injury in several neurological disorders (Beckman, 1994; Beckman, 1996). aSyn and A30P proteins were expressed in yeast, pulleddown using $\mathrm{Ni}^{2+}$-NTA and exposed to PON. Immunoblotting of the in vitro nitrated proteins revealed that the abundance of dimers and oligomers is significantly increased with the same pattern as for in vivo isolated aSyn species (Figure 6B). The major distinct band corresponds to the aSyn dimer species. Quantification of the dimer band intensities of in vivo isolated probes showed that A30P forms approximately twice as many dimers relative to monomers as wild-type aSyn (Figure 6C). In vitro nitration of aSyn and A30P increased the total amount 
of dimers. However, the dimer to monomer ratios between aSyn and A30P were not changed when the in vivo samples were enhanced by additional in vitro nitration (Figure 6C). This result suggests that the high molecular weight variants of aSyn, which can be isolated from yeast cells and which withstand strong denaturing conditions during the pull-down (8 M Urea, $2 \%$ SDS), represent covalently crosslinked aSyn species. These data support the formation of aSyn dimers in living cells. A remarkable result is that the toxicity of aSyn, which correlates to a high protein aggregation rate (Petroi et al., 2012), results in a reduced amount of aSyn dimer relative to monomer. In contrast, the non-toxic A30P mutant that does not inhibit cellular growth (Figure 6A), and has a reduced aggregation rate (Petroi et al., 2012), produces twice as many dimers relative to monomers in comparison to wild-type aSyn. This suggests that aSyn dimer formation is a molecular mechanism which can be used by the cell as salvage pathway for detoxification.

\subsection{The C-terminus of $\alpha$-synuclein is preferentially modified by nitration and di-tyrosine formation}

Liquid chromatography-mass spectrometry (LC-MS) analysis was performed to study aSyn and A30P nitration sites in vivo. Single trypsin or AspN digestions were employed and the resulting peptides were analyzed by LC-MS. In addition to single digestions, a combined proteolytic approach by double digestion of the proteins with trypsin and AspN was employed that enabled $100 \%$ sequence coverage. The modifications of the tyrosine residues identified from fragment spectra are summarized in Table 15.

Table 15. Determination of nitrated peptides from aSyn and A30P.

\begin{tabular}{lcccccccc} 
& \multicolumn{3}{c}{ in vivo } & \multicolumn{5}{c}{ in vitro (PON) } \\
\hline & Y39 & Y125 & Y133 & Y136 & Y39 & Y125 & Y133 & Y136 \\
\hline aSyn monomers & & 3-NT & 3-NT & 3-NT & 3-NT & 3-NT & 3-NT & 3-NT \\
aSyn dimers & & & & & 3-NT & & & \\
A30P monomers & & 3-NT & & & 3-NT & 3-NT & 3-NT & \\
A30P dimers & & & & & 3-NT & 3-NT & 3-NT & \\
\hline
\end{tabular}

aSyn and A30P were enriched by $\mathrm{Ni}^{2+}$ pull-down from yeast crude extracts and separated by SDS-PAGE. Monomeric and dimeric aSyn stained with Coomassie were excised from the gel and digested with trypsin and AspN. Untreated (in vivo) and subsequent peroxynitrite (PON) treated (in vitro) aSyn and A30P protein samples were analyzed with LC-MS for tyrosine nitration. 3-NT (3-nitrotyrosine) indicates identified nitration sites, supported by at least two peptides and two independent experiments.

As a positive control, aSyn was used, where nitration was enhanced after the pull-down by additional PON exposure. MS data revealed nitration of wild-type $\alpha$ Syn at all three C-terminal tyrosines (Y125, Y133, Y136). Nitration of A30P was restricted to $\mathrm{Y} 125$ and absent at $\mathrm{Y} 133$ 
or Y136. Nitration of the additional tyrosine residue Y39 in the N-terminal domain of aSyn could not be identified from any in vivo samples by LS-MS. Additional PON exposure, however, resulted in $\mathrm{Y} 39$ nitration in all samples. This suggests that $\mathrm{Y} 39$ is not a primary in vivo nitration target within cells. Additional PON-exposure after pull-down also revealed that the aSyn dimers can be potentially nitrated in vitro. The increased in vitro PON-mediated nitration of the A30P in comparison to wild-type could be due to the higher amounts of the dimer in this mutant strain. Beyond nitration, also phosphorylation of aSyn as well as of A30P at S129, Y125 or Y133 was identified but not at Y39 or Y136 (Table 16).

Table 16. Phospho-peptides identified by MS/MS.

\begin{tabular}{ccccc}
\hline Position & Modification & PTM Score $\boldsymbol{\alpha S y n}$ & PTM Score A30P & Sequence Motif \\
\hline Y39 & Phospho & 0 & 1.5 & KEGVLyVGSKT \\
Y125 & Phospho & 9.7 & 8 & PDNEAyEMPSE \\
S129 & Phospho & 100 & 100 & AYEMPsEEGYQ \\
Y133 & Phospho & 99.8 & 100 & PSEEGyQDYEP \\
Y136 & Phospho & 0 & 0 & EGYQDyEPEA \\
\hline
\end{tabular}

Posttranslational modification (PTM) scores were calculated with phosphoRS algorithm and represent the probability for phosphorylation modification. The corresponding amino acid is indicated by a small letter code in the sequence motif. Number of peptide sequence matches: $\alpha$ Syn $=332 ; \mathrm{A} 30 \mathrm{P}=414$.

The probabilities for possible phosphorylation sites were calculated with the phophoRS algorithm (Taus et al., 2011). Phosphorylation of Y125 was identified with only low probability scores (Table 16). In contrast, S129 and Y133 were almost completely co-phosphorylated with scores of $100 \%$ for S129 and $99 \%$ for Y133, respectively.

The LC-MS spectra of aSyn and A30P migrating in SDS-PAGE with the size of the dimer band were analyzed to assess whether di-tyrosines cause dimer formation of aSyn or A30P. The presence of di-tyrosine peptide crosslinks was validated using StavroX2.3.4.5 software (Gotze et al., 2012). This software compares the masses of all potential crosslinked peptides with the precursor ion masses, calculates b- and y-type ions for all possible crosslinks and compares them to MS2 data of the precursor ion. Different combinations of crosslinked peptides with an identical mass are possible when multiple tyrosine residues are located on one and the same peptide. The crosslinked tyrosine pairs were assigned according to the scores calculated by StavroX based on the fragment ion series of the MS2 spectra. The MS data analysis verified that aSyn dimers are crosslinked by tyrosine residues. The detected combinations of crosslinked tyrosines are depicted in Table 17. The results indicate a strong preference for crosslinking of defined combinations of tyrosines (Table 17, Figure 7, 8). 
Table 17. Number of verified crosslinks (in vivo).

\begin{tabular}{|c|l|l|l|l|}
\hline & Y39 & Y125 & Y133 & Y136 \\
\hline Y39 & & & & \\
\hline Y125 & & & & \\
\hline Y133 & & & & \\
\hline Y136 & & & & \\
\hline
\end{tabular}

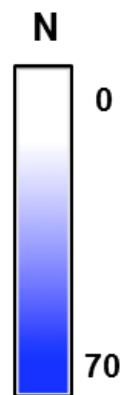

Determination of crosslinked peptides from aSyn and A30P. Exemplary heat map diagram of the number $(\mathrm{N})$ of identified di-tyrosine crosslinked peptides of the non-treated aSyn samples.

The most frequent combinations for either wild-type aSyn or A30P are Y125-Y136 and Y133Y136 dimers which are all located in the C-terminus. Only the C-terminal tyrosine residues can mutually interact. Only a small fraction of Y39-Y39 dimers were found and there are no tyrosine dimers between the $\mathrm{N}$-terminal $\mathrm{Y} 39$ and the C-terminal tyrosines of aSyn or A30P.

A
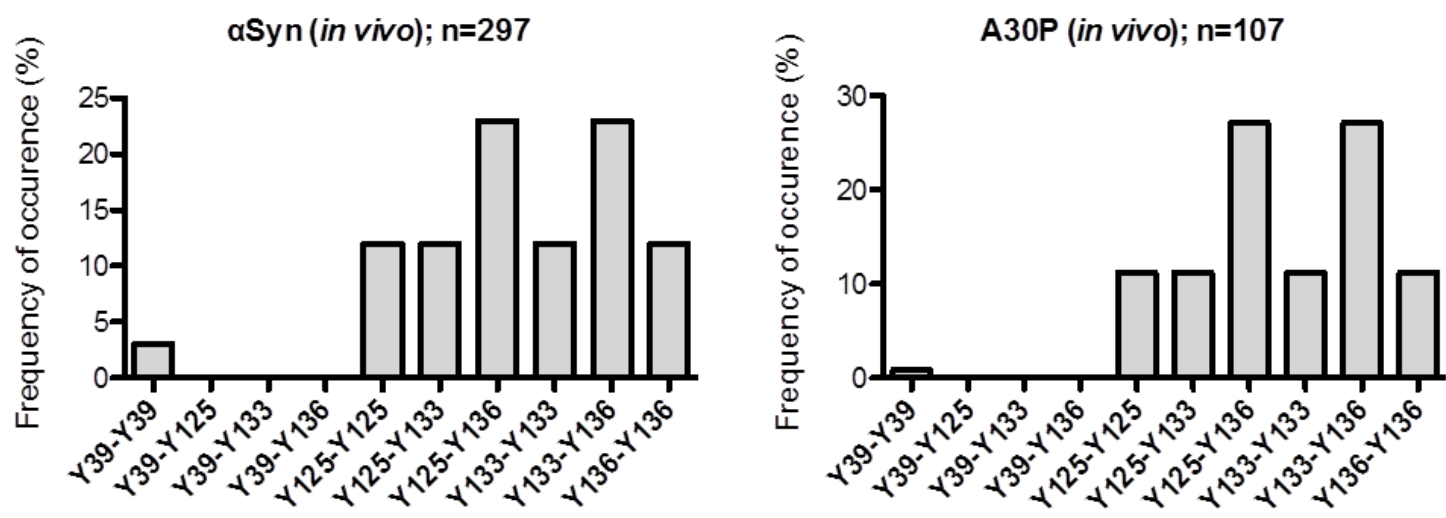

B
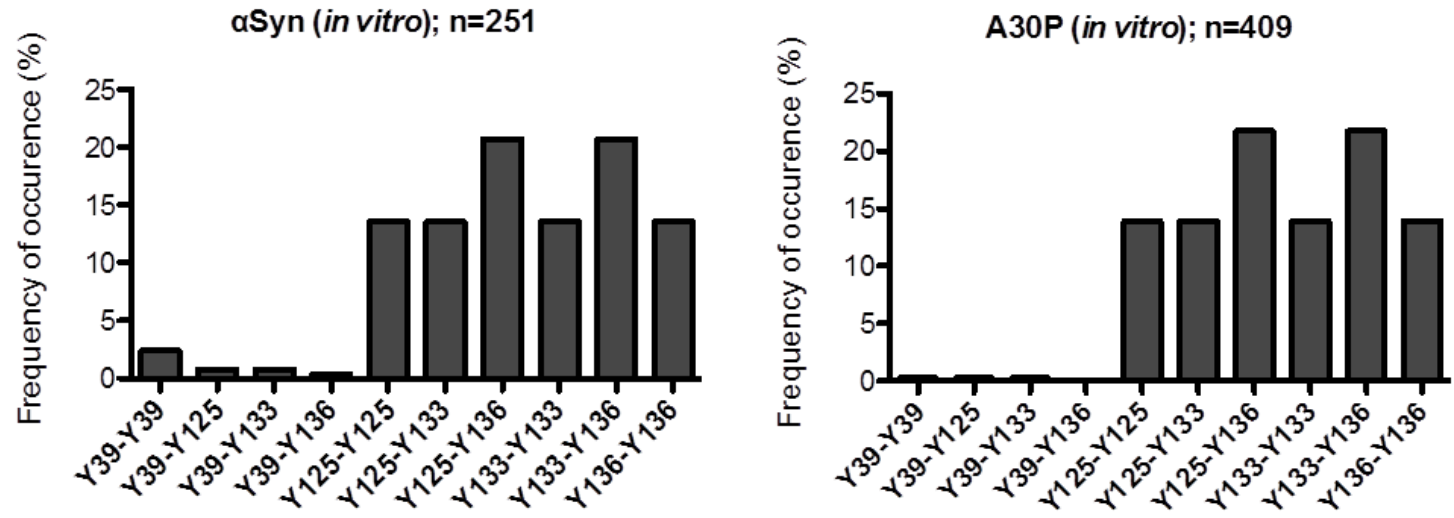

Figure 7. Analysis of di-tyrosine dimers from aSyn.

(A) Distribution of all identified di-tyrosine peptides for untreated (in vivo) aSyn (left diagram) and A30P (right diagram) protein samples. Identified combinations of crosslinked peptides are presented as percentage of $n(n=$ total number of MS2 spectra verified as crosslinked peptides). (B) Distribution of all identified di-tyrosine peptides for peroxynitrite (PON) treated (in vitro) aSyn (left diagram) and A30P (right diagram) protein samples. 
A

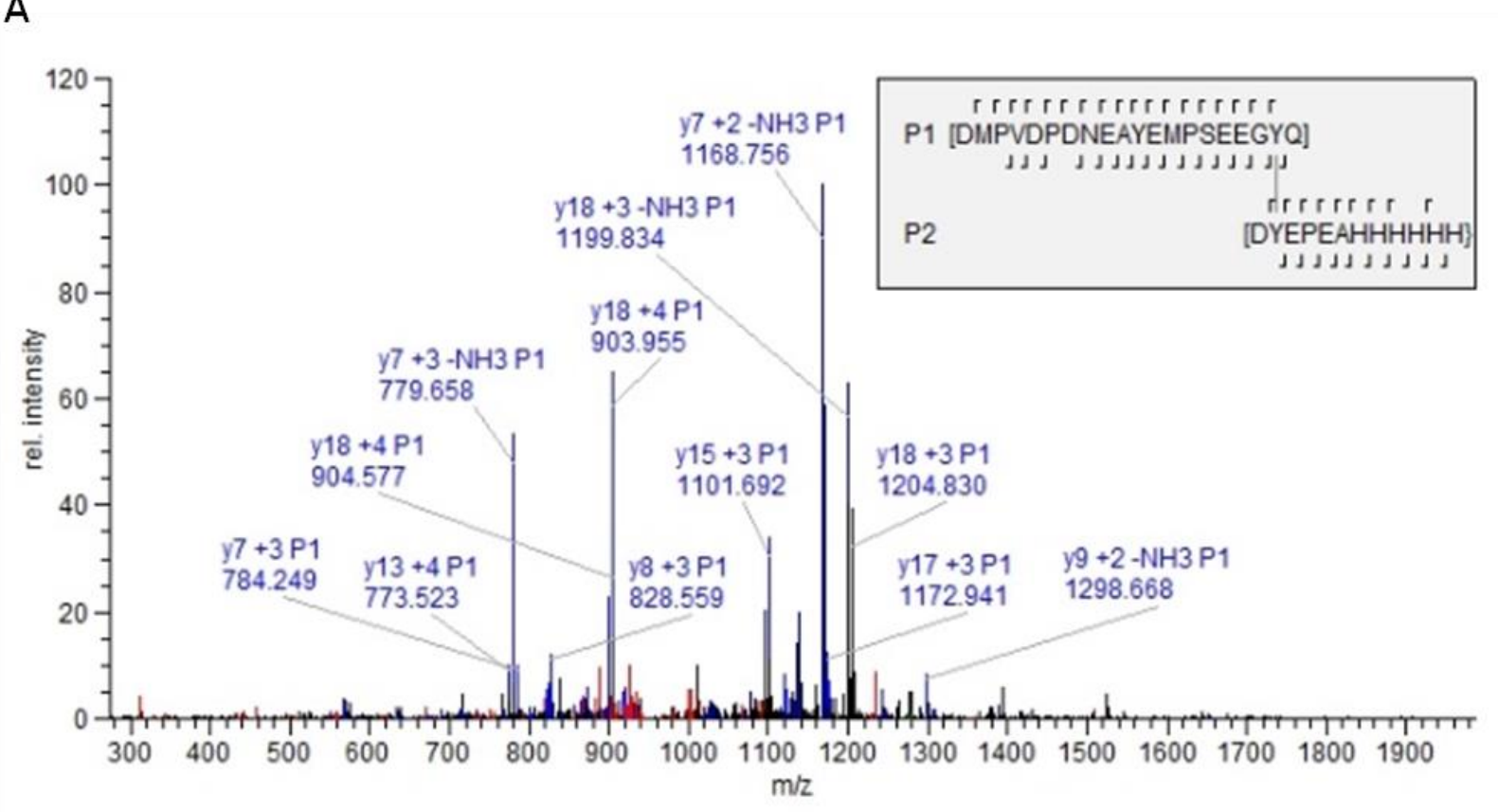

B

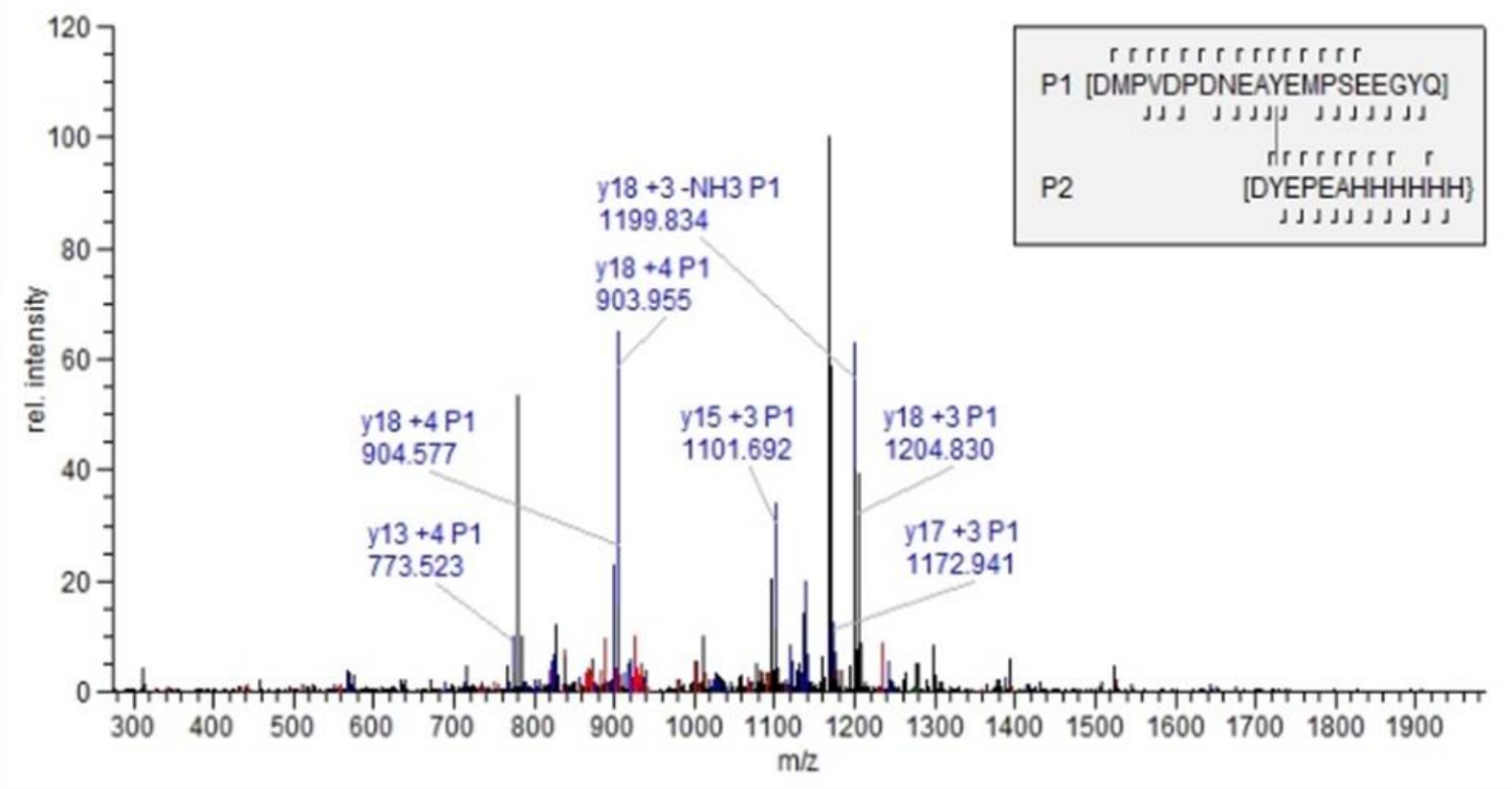

Figure 8. MS2 analysis of crosslinked peptides.

(A) Exemplary fragment ion MS2 spectrum of the crosslink between $\mathrm{Y} 133$ and $\mathrm{Y} 136$ of aSyn dimers. $y$-ions of the crosslinked peptides are represented in blue, while b-ions are represented in red. Fragmentation sites are indicated in the amino acid sequence. (B) Exemplary fragment ion MS2 spectrum of the crosslink between Y125 and Y136 of A30P dimers. 
These data suggest that the C-terminus of aSyn or A30P has an increased susceptibility for nitration and di-tyrosine formation compared to the N-terminus. Only $\mathrm{Y} 125$ is a major nitration site of A30P. In contrast, all three C-terminal tyrosines Y125, Y133 and Y136 of the wild-type aSyn are putative targets for nitration. Y133 is an additional strong and Y125 a weak phosphorylation site, respectively. Dimer formation through di-tyrosine follows a specific pattern for both tested aSyn proteins with predominant forms including $\mathrm{Y} 136$ interacting either with Y125 (Y125-Y136) or with Y133 (Y133-136).

\subsection{Tyrosine residues contribute to $\alpha$-synuclein cytotoxicity and aggregate formation}

The codons for the four tyrosine sites of aSyn and A30P (Y39, Y125, Y133 and Y136) were replaced in the corresponding genes by phenylalanine codons $(4(\mathrm{Y} / \mathrm{F}))$ to analyze the role of the tyrosine residues on aSyn dimer formation, cytotoxicity or aggregation. Fusion genes with GFP- or $\mathrm{HIS}_{6}$-tags were constructed and expressed. Here, it was assessed whether the quadruple $Y$ to $F$ replacements influence the dimerization of aSyn and A30P. Expression of aSyn and A30P as well as their 4(Y/F) mutants was induced for 12 hours. Tagged proteins were enriched by $\mathrm{Ni}^{2+}$ pull-down under denaturing conditions. Immunoblotting using aSyn antibodies as well as antibodies that specifically recognize di-tyrosines revealed that $4(\mathrm{Y} / \mathrm{F})$ mutants of aSyn or A30P had lost the potential to form dimers in vivo (Figure 9A).

Additional in vitro nitration with PON did also not result in any dimer or oligomer formation and served as control (Figure 9A). Immunoblotting analysis was carried out to determine in vivo nitrated aSyn using 3-nitrotyrosine specific antibodies (Figure 9B). The results demonstrated that the $4(\mathrm{Y} / \mathrm{F})$ variants of wild-type aSyn or A30P did not result in any nitration signal even after additional PON treatment. This is in contrast to wild-type aSyn with its four original tyrosine residues as control, where nitration is present in vivo and can be further increased by additional PON treatment. 

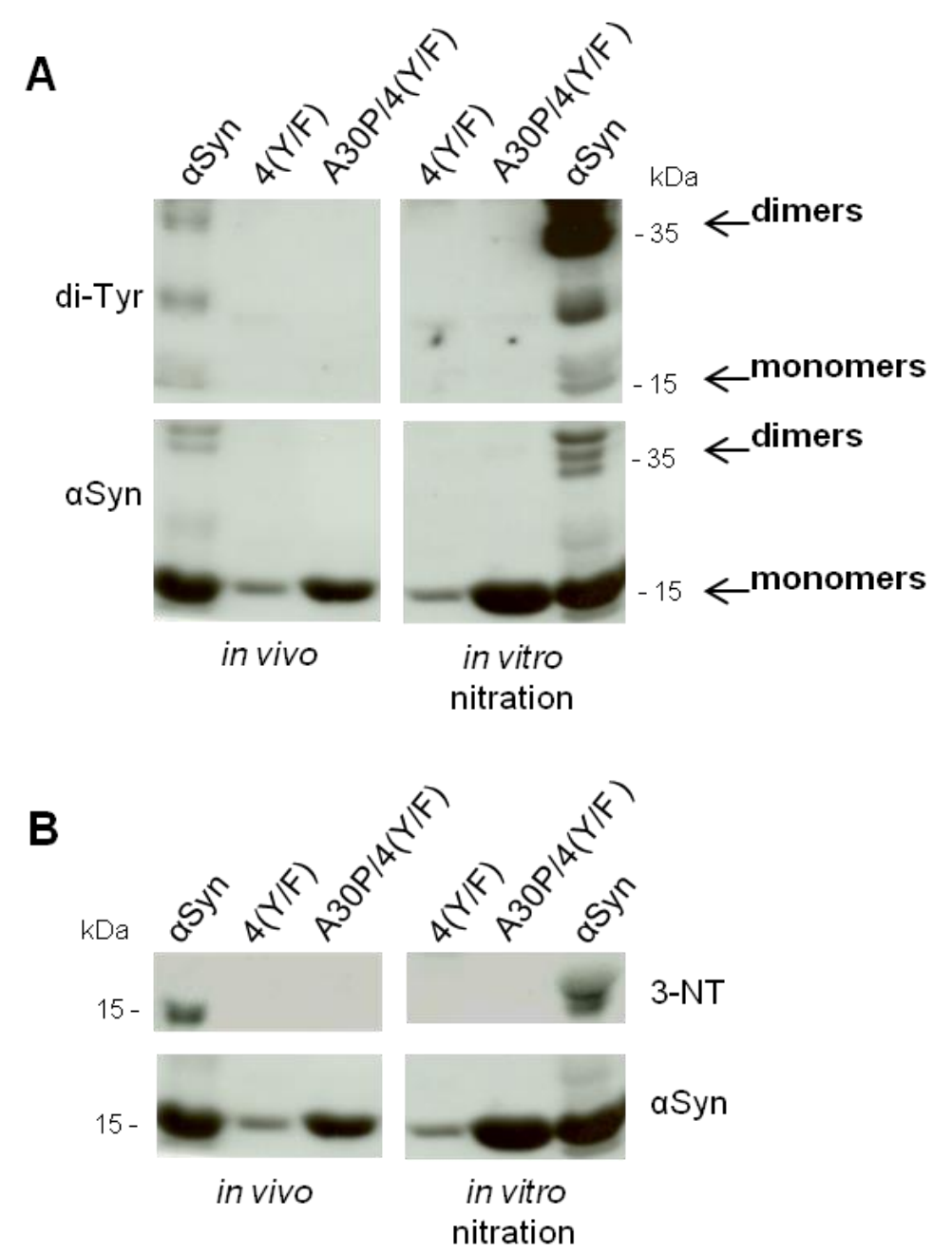

Figure 9. Mutation of tyrosines of aSyn prevents dimerization and nitration of aSyn.

(A) Expression of aSyn, A30P, 4(Y/F) and A30P/4(Y/F) aSyn was induced for 12 hours in galactose-containing medium and the proteins were enriched by $\mathrm{Ni}^{2+}$ pull-down from yeast cell extracts. For in vitro nitration, $1 \mu \mathrm{L}$ peroxynitrite (PON) was mixed with $15 \mu \mathrm{g}$ of aSyn extracts in the presence of $1 \mu \mathrm{L} 0.3 \mathrm{M} \mathrm{HCl}$. Immunoblotting with di-tyrosine antibody reveals a major band at about $36 \mathrm{kDa}$, corresponding to dimers. Additional bands with lower molecular weights are probably due to intramolecular di-tyrosine crosslinking. The same membrane was stripped and re-probed with aSyn antibody. (B) Immunoblotting using 3nitrotyrosine antibody (3-NT). Phenylalanine codon substitutions eliminate immunoreactivity. The same membrane was stripped and re-probed with aSyn antibody.

The growth impact of wild-type aSyn or the A30P variant were compared with that of the additional $4(\mathrm{Y} / \mathrm{F})$ substitutions by spotting analysis and in liquid medium, respectively (Figure 10). Substitutions of the four tyrosine residues in wild-type aSyn significantly improved growth on solid medium, whereas A30P aSyn growth was similar with tyrosine or instead with phenylalanine residues (Figure 10A). Growth in liquid medium resulted in similar effects, revealing significantly reduced growth inhibition of the $4(Y / F)$ mutant strain in comparison to wild-type aSyn (Figure 10B), whereas A30P and its $\mathrm{A} 30 \mathrm{P} / 4(\mathrm{Y} / \mathrm{F}$ ) derivative were growing similarly (Figure 10C). 
A

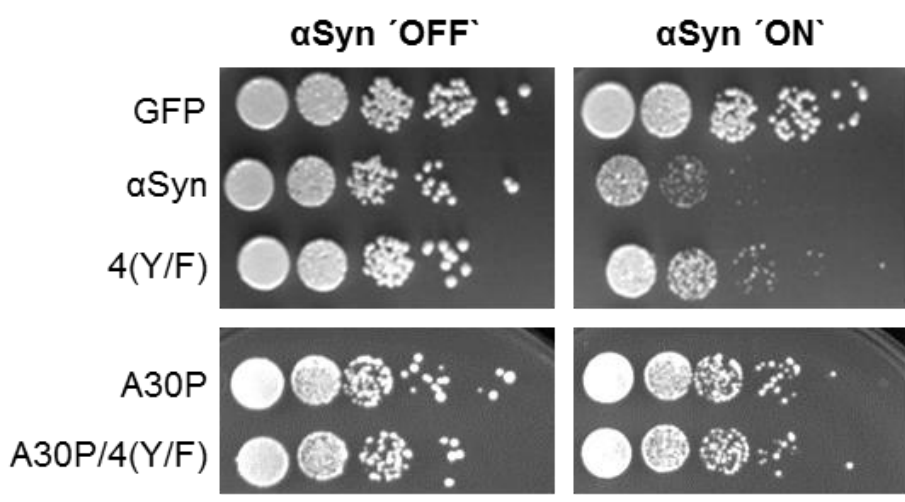

B

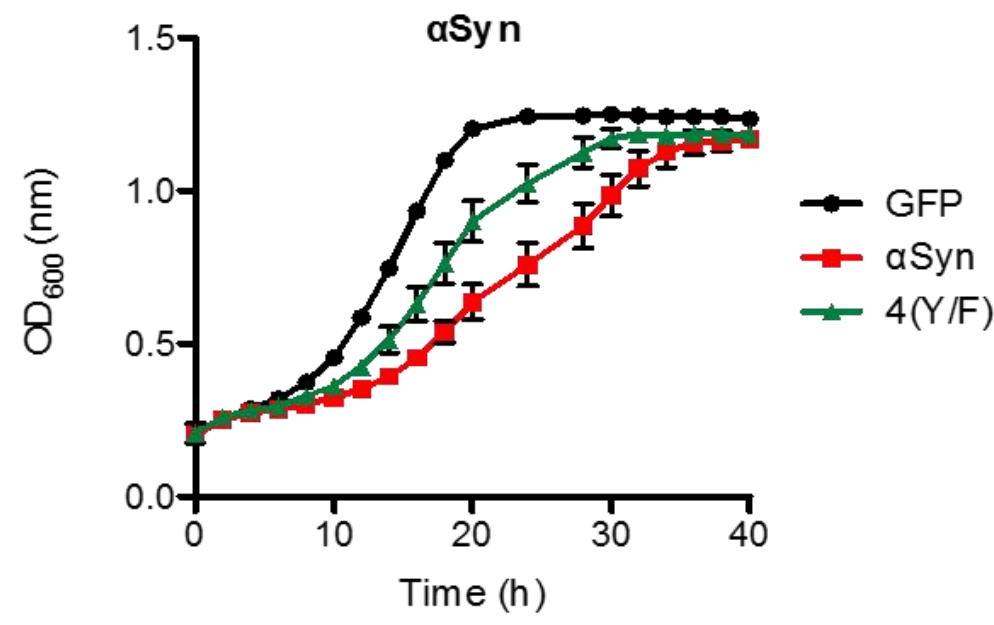

C

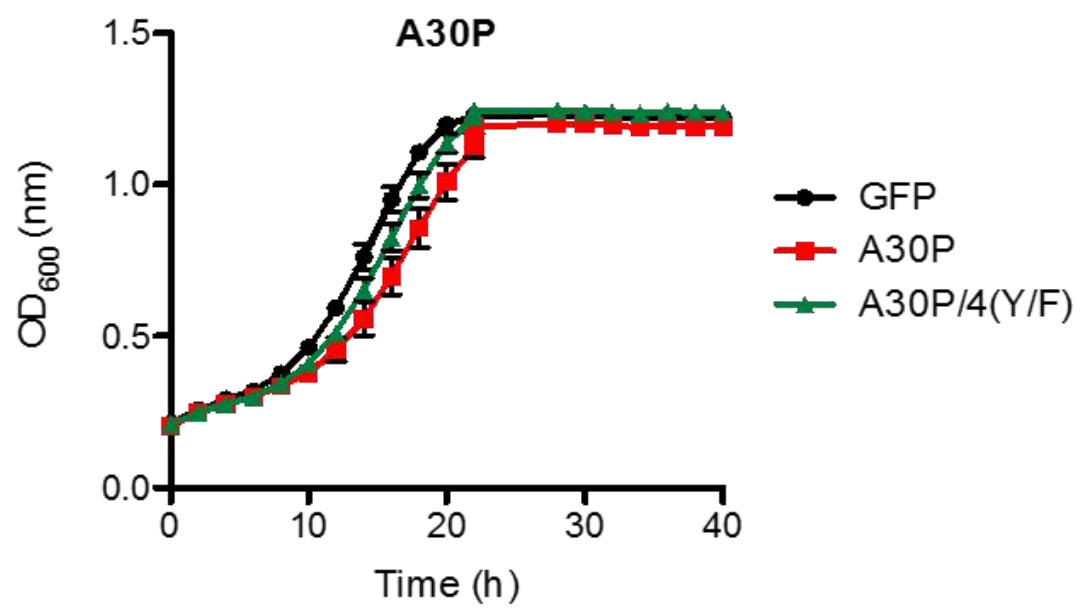

Figure 10. Blocking of $\alpha$ Syn tyrosine nitration decreases cytotoxicity.

(A) Spotting analysis of yeast cells expressing GAL 1-driven aSyn, A30P, 4(Y/F), A30P/4(Y/F) aSyn and GFP (control). Yeast cells were spotted in 10-fold dilutions on SC-Ura plates containing glucose ( $\alpha$ Syn 'OFF') or galactose ( $\alpha$ Syn 'ON'). (B) Cell growth analysis of yeast cells expressing aSyn, 4(Y/F) and GFP (control) in galactose-containing SC-Ura medium for 40 hours. Error bars represent standard deviations of three independent experiments. (C) Cell growth analysis of yeast cells expressing A30P, A30P/4(Y/F) aSyn and GFP (control), in galactose-containing SC-Ura medium for 40 hours. Error bars represent standard deviations of three independent experiments. 
It was assessed, whether the decrease in wild-type aSyn toxicity was related to the formation of aSyn inclusions (Figure 11A, B). No change in inclusion formation could be monitored when A30P was compared to A30P/4(Y/F). However, yeast cells expressing the 4(Y/F) aSyn variant formed less inclusions in comparison to wild-type aSyn (Figure 11A, B). Immunoblotting with aSyn antibody revealed that the protein levels of the different aSyn variants were similar (Figure $11 \mathrm{C}$ ), excluding that reduction of aggregates results from lower aSyn expression levels.

A

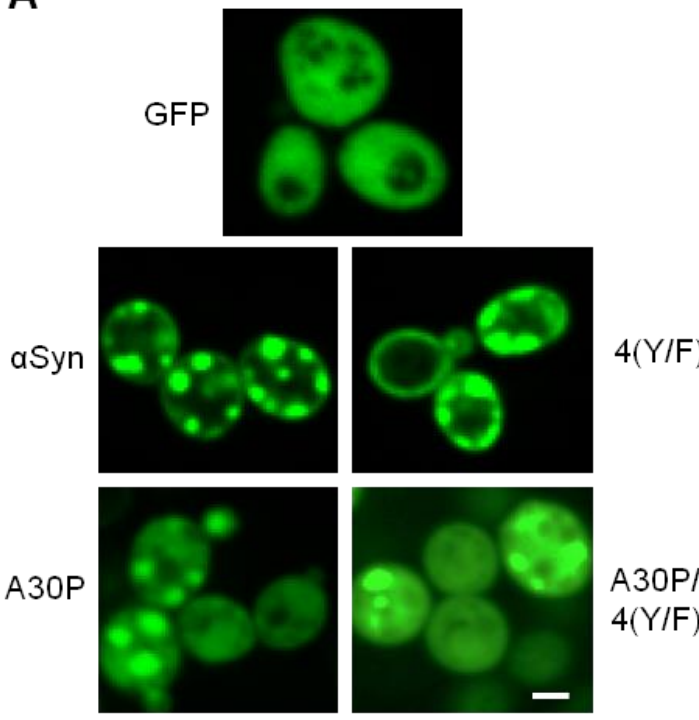

B

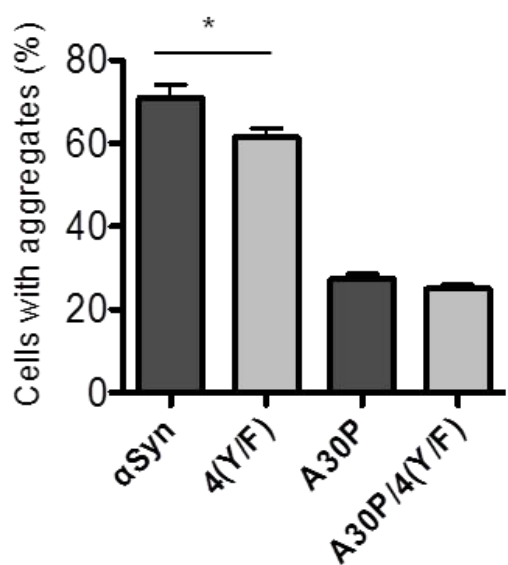

C

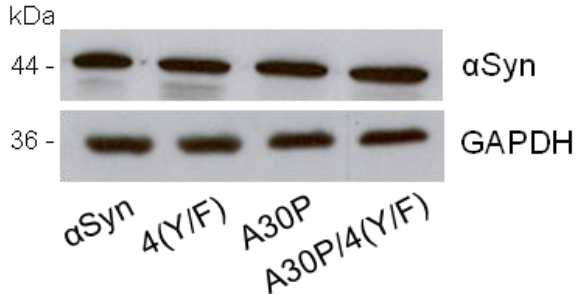

Figure 11. Blocking of aSyn tyrosine nitration decreases aggregation.

(A) Fluorescence microscopy of yeast cells, expressing indicated aSyn-GFP variants after six hours of induction in galactose-containing medium. Scale bar: $1 \mu \mathrm{m}$. (B) Quantification of the percentage of cells displaying aggregates after six hours induction in galactose-containing medium. Significance of differences was calculated with t-test $\left({ }^{*}, p<0.05, n=6\right)$. (C) Immunoblotting of protein crude extracts of GFP-tagged aSyn, 4(Y/F), A30P and A30P/4(Y/F) aSyn after six hours induction in galactose-containing medium. GAPDH antibody was used as loading control.

Taken together, only tyrosine replacements by phenylalanine in case of wild-type aSyn but not in case of an additional A30P substitution reduce aSyn-induced toxicity and inclusion formation. Accordingly, there is only growth improvement in the absence of an A30P substitution that correlates with decrease of intracellular accumulations of aSyn fluorescent foci. This supports that tyrosine residues that are responsible for nitration of aSyn contribute 
to the cytotoxic effect and inclusion formation of aSyn in yeast. This tyrosine-dependent effect is significantly less pronounced in the presence of an A30P codon mutation suggesting that A30P suppresses the tyrosine effect, which can be observed in wild-type aSyn. The presence of tyrosine residues in wild-type aSyn favor nitration and di-tyrosine crosslinking but offer only a minor contribution to inclusion formation.

\subsection{The nitric oxide oxidoreductase Yhb1 reduces A30P aggregation and toxicity}

The effect of nitrative stress on the toxicity and aggregation of wild-type and A30P mutant aSyn was examined. A yeast strain carrying a deletion in the yeast flavohemoglobin gene (YHB1), responsible for stress signaling, was used for enhancement of nitrative stress. Yhb1 is a nitric oxide oxidoreductase, which protects against nitration of cellular targets and against cell growth inhibition under aerobic or anaerobic conditions (Liu et al., 2000). Deletion of $\mathrm{YHB1}$ abolishes the nitric oxide (NO) consuming activity of yeast cells (Liu et al., 2000). The compound DETA-NONOate causes nitrative stress by acting as a NO donor.

The absence of the flavohemoglobin results in a growth impairment of the hypersensitive yhb1 deletion strain in comparison to wild-type under NO nitrative stress conditions (Figure 12A). The genes encoding wild-type or A30P aSyn, or GFP as a control, were expressed in $\Delta y h b 1$ or the isogenic wild-type background. Cell growth was compared in the absence of nitrative stress by spotting assays (Figure 12B). Wild-type aSyn was as well cytotoxic in the presence or absence of YHB1. This was different for A30P, where no cytotoxicity was observed in the presence of YHB1. However, expression of A30P in $\triangle y h b 1$ cells inhibited cell growth. This effect was verified by low copy plasmid expression of YHB1. Cells rescued with $Y H B 1$ showed the same growth phenotype as the original A30P or the GFP control in the YHB1 background (Figure 12B). 
A

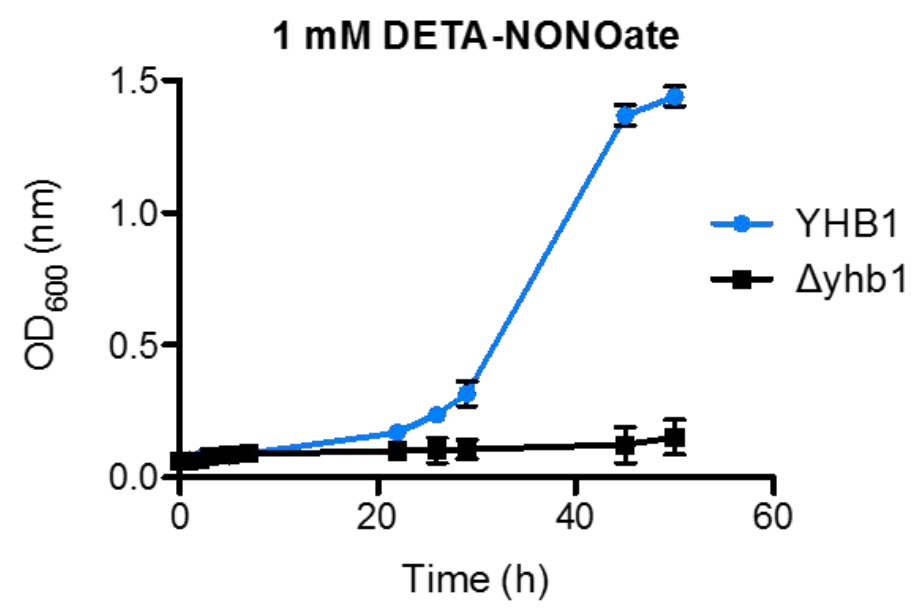

B

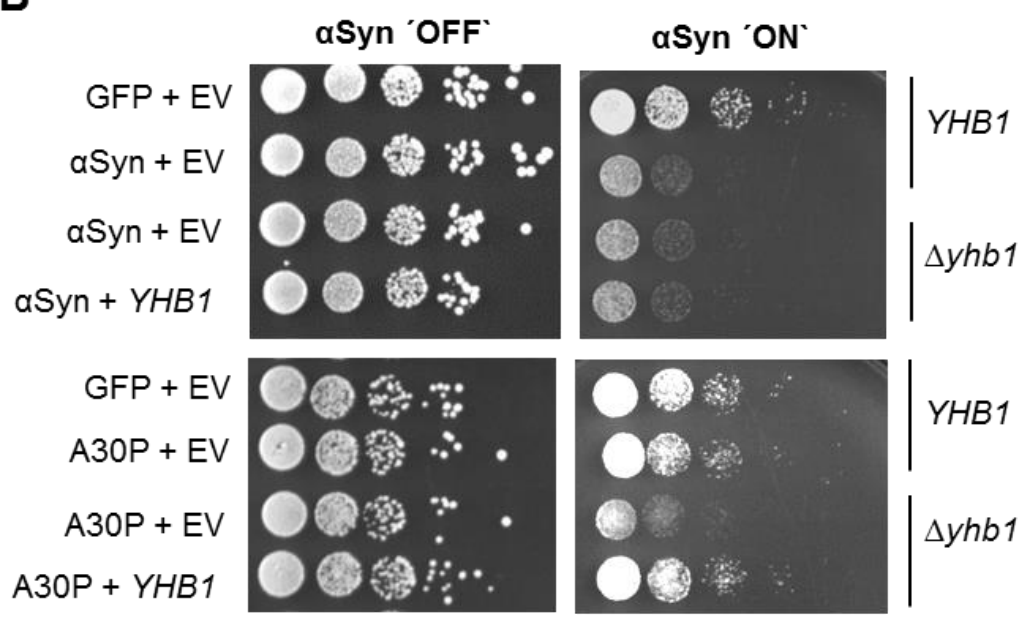

Figure 12. The nitric oxide oxidoreductase Yhb1 reduces A30P toxicity.

(A) Cell growth comparison of wild-type YHB1 and mutant $\Delta y h b 1$ yeast cells in the presence of the NO stress-mediating drug DETA-NONOate $(1 \mathrm{mM})$ in liquid galactose-containing SCUra medium. Error bars indicate standard deviations of three independent experiments. (B) Spotting analysis of $Y H B 1$ and $\Delta y h b 1$ yeast cells expressing aSyn (upper boxes) or A30P (lower boxes) compared to GFP and empty vector (EV) as control on non-inducing and galactose-inducing SC-Ura medium after three days.

The correlation between growth inhibition and aggregate formation of aSyn variants was examined. Cells expressing aSyn or A30P were imaged by fluorescence microscopy and the cells displaying aggregates were counted. Deletion of YHB1 resulted in an increased percentage of cells with A30P inclusions, whereas no significant difference was observed in cell expressing wild-type aSyn (Figure 13A). In agreement with the growth analyses, the complementation of the $\triangle y h b 1$ deletion by $Y H B 1$ rescued the lower aggregation potential of A30P (Figure 13A). 
A

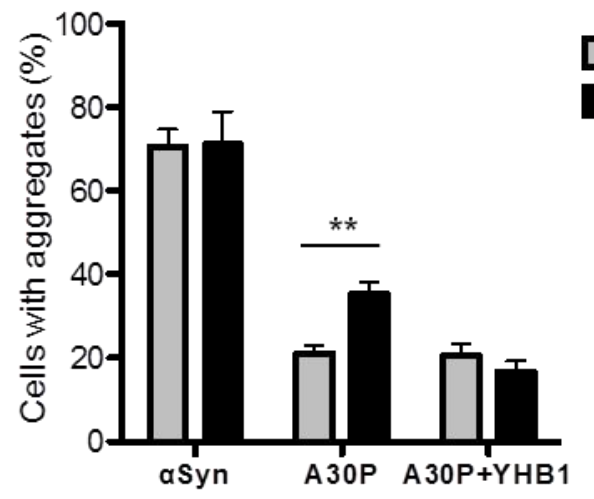

B

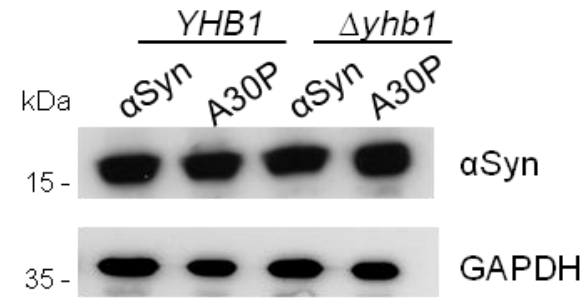

YHB1

$\triangle y h b 1$

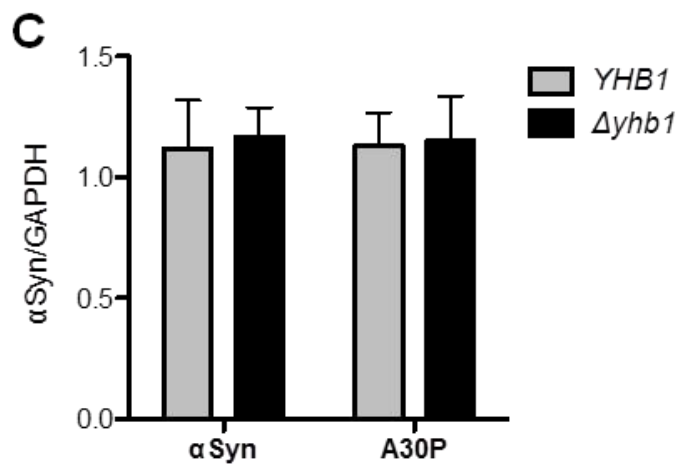

Figure 13. The nitric oxide oxidoreductase Yhb1 reduces A30P aggregation.

(A) Quantification of the percentage of cells displaying aSyn aggregates after six hours induction in galactose-containing medium. Significance of differences was calculated with ttest $\left({ }^{*}, p<0.01, n=6\right)$. (B) Immunoblotting of protein crude extracts of aSyn and A30P expressed in YHB1 and $\triangle y h b 1$ yeast after six hours induction in galactose-containing medium. GAPDH antibody was used as loading control. (C) Quantification of aSyn and A30P levels in YHB1 and $\triangle y h b 1$ yeast cells. Densitometric analysis of the immunodetection of $\alpha$ Syn and A30P relative to the intensity obtained for GAPDH $(n=3)$.

aSyn toxicity is dependent on the expression levels (Outeiro and Lindquist, 2003; Petroi et al., 2012). Thus, it was tested whether the A30P expression level is equal in $\Delta y h b 1$ mutant compared to YHB1 yeast. Immunoblot analysis revealed that the A30P variant is expressed at similar levels in both yeast backgrounds six hours after induction of gene expression (Figure 13B, C), excluding that differences in toxicity are due to different A30P expression levels.

\subsection{Overexpression of YHB1 impairs growth of Saccharomyces cerevisiae}

As previous results of this study have shown, YHB1 is a repressor of A30P aggregation and toxicity. To test whether this protein generally diminishes aSyn-induced toxicity and whether increasing the putative repressive function by overexpression leads to reduction of toxicity, YHB1 was cloned into a high copy vector and overexpressed with wild-type aSyn and A30P in wild-type yeast. Growth analysis on solid medium shows that expression of YHB1 with either empty vector or GFP inhibits growth of yeast cells (Figure 14A), indicating that overexpression of $Y H B 1$ triggers cell processes that harm the cells. In yeast, Yhb1 detoxifies cell targets from nitric oxide (NO) (Liu et al., 2000). NO is a free radical that reacts with superoxide to form peroxynitrite. This oxidant harms the cell by damaging proteins, lipids and 
DNA leading to dysfunction of important cell processes and cell death (Beckman, 1996). However, peroxynitrite was shown to have an important role for various cell signaling transduction pathways, due to its ability to nitrate tyrosine residues and thereby affecting phosphotyrosine-dependent signalling processes (Gow et al., 1996; Kong et al., 1996). Moreover, studies have found that peroxynitrite influences the activity of various kinases and phosphatases leading to up- or downregulation of signalling cascades (Kang et al., 2002; Klotz et al., 2000). Such examples of function variety demonstrate which dramatic influences the misbalance of peroxynitrite may induce in the cell. Overexpression of $Y H B 1$ changes the peroxynitrite levels, which may lead to misregulation of signalling pathways causing growth inhibition or cell death.
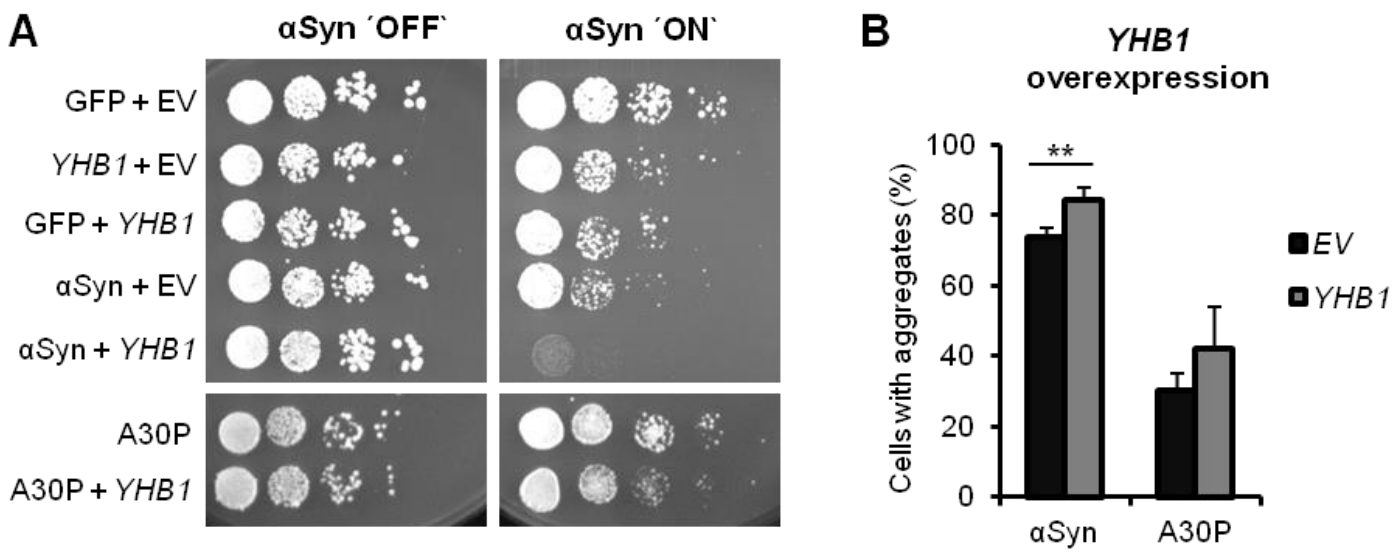

Figure 14. Overexpression of YHB1 impairs growth of Saccharomyces cerevisiae.

(A) Spotting assay of wild-type yeast cells expressing aSyn, A30P and GFP (control) with either empty vector (pME2792) as control or high copy of YHB1 on non-inducing and galactose-inducing SC-Ura medium after three days. (B) Quantification of the percentage of cells displaying aSyn and A30P aggregates after six hours induction in galactose-containing medium. Significance of differences was calculated with t-test $\left({ }^{* \star}, p<0.01, n=3\right)$.

When overexpressing wild-type aSyn together with $Y H B 1$, growth inhibition of the cells is severely enhanced. In contrast, co-expressing A30P with YHB1 only slightly inhibited growth similar to the control strains expressing the empty vector or GFP (Figure 14A). This suggests that the strong growth inhibition of wild-type aSyn and YHB1 expressing cells is an additive impact of coincidently overexpression of two genes causing cytotoxicity. Analysis of aggregation of wild-type aSyn and A30P co-expressing $Y H B 1$ demonstrated that strong growth inhibition induced by wild-type aSyn is accompanied by increase of aggregate formation (Figure 14B). However, aggregation of A30P was not significantly changed by YHB1 overexpression. The molecular target of Yhb1 is the small molecule nitric oxide. This free radical is the main source of nitrative stress but is also required as an endogenous signalling molecule involved in the regulation of different physiological processes. The observed growth inhibition of cells overexpressing YHB1 may result from disturbance of NOmediated cell processes. 


\subsection{Yhb1 decreases sensitivity of A30P expressing cells to nitrative stress}

Deletion of $Y H B 1$ constitutes an internal stress signal. The effect of nitrative stress on A30P was further investigated by adding external nitrative stress conditions. Growth tests in liquid culture were performed using DETA-NONOate, which reduces growth of the $\Delta y h b 1$ mutant but not of the wild-type strain (Figure 15A).

A

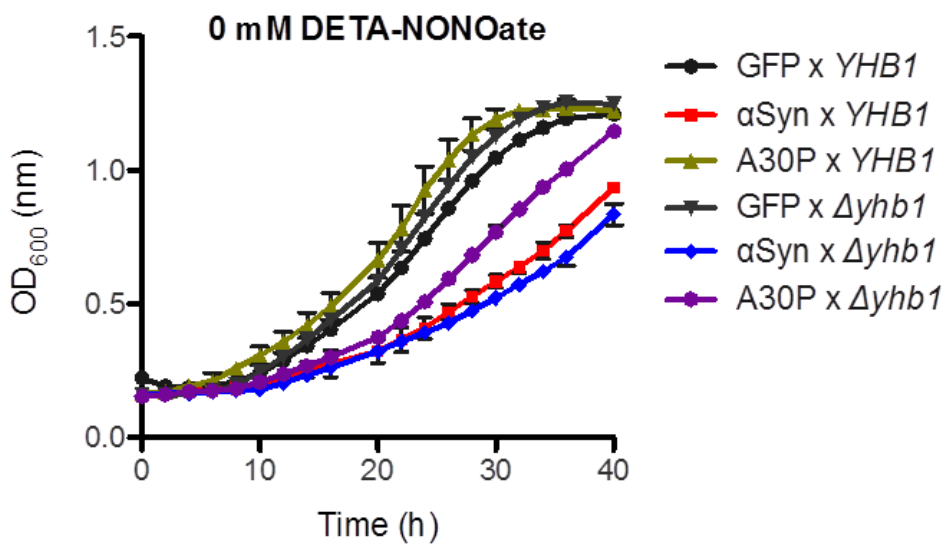

B

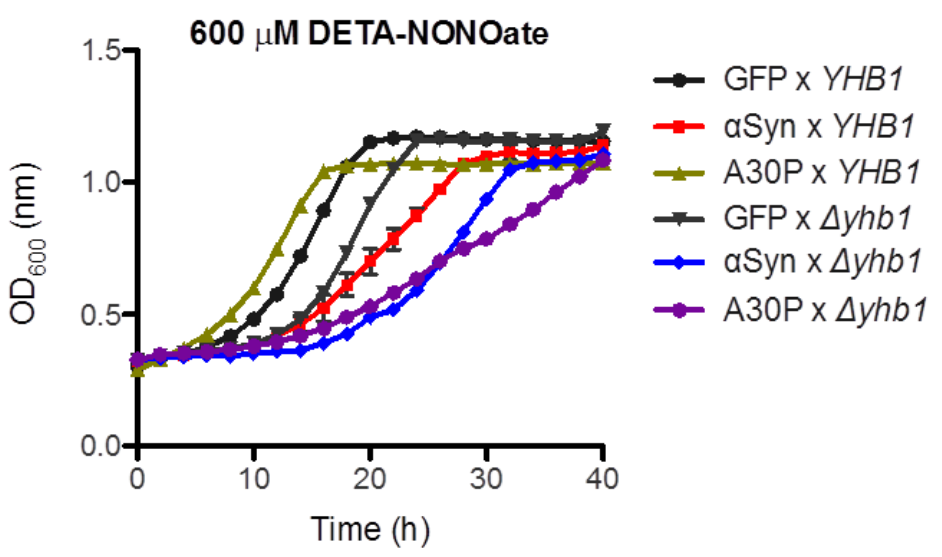

Figure 15. Yhb1 decreases sensitivity of A30P expressing cells to nitrative stress.

(A) Cell growth analysis of $Y H B 1$ and $\Delta y h b 1$ yeast cells expressing aSyn, A30P, 4(Y/F), A30P/4(Y/F) and GFP (control) after 40 hours induction in galactose-containing SC-Ura medium without DETA-NONOate. Error bars show standard deviations of three independent experiments. (B) Cell growth analysis of $Y H B 1$ and $\Delta y h b 1$ yeast cells expressing aSyn, A30P, 4(Y/F), A30P/4(Y/F) and GFP (control) with $600 \mu \mathrm{M}$ DETA-NONOate.

Cells expressing A30P aSyn grew uninhibited in the YHB1 wild-type background, whereas $\Delta y h b 1$ cells expressing A30P were less inhibited than aSyn, thus recapitulating the growth phenotype on solid medium (Figure 12B, 15A). In contrast, $\Delta y h b 1$ cells expressing both aSyn variants were equally impaired in growth under nitrative stress conditions (Figure 15B). This indicates that increase in nitrative stress changes A30P to a toxic protein in yeast cells 
comparable to wild-type aSyn. These results suggest a specific suppressive function of the nitric oxide oxidoreductase $\mathrm{Yhb} 1$ on A30P-induced aggregate formation and growth inhibition in yeast.

\section{7 a-synuclein expression does not affect the sensitivity of yeast cells to $\mathrm{H}_{2} \mathrm{O}_{2}$}

In addition to nitrative stress, oxidative stress was shown to be involved in the degeneration of dopaminergic neurons in PD. Increased levels of oxidized lipids, proteins and DNA was found in the substantia nigra of PD patients (Alam et al., 1997a; Alam et al., 1997b; Bosco et al., 2006). Moreover, in vitro studies showed that oxidative stress induces aggregation of aSyn when incubating with the reactive oxygen specie hydrogen peroxide $\left(\mathrm{H}_{2} \mathrm{O}_{2}\right)$. Therefore, the sensitivity of aSyn expressing wild-type and $\Delta y h b 1$ yeast cells to oxidative stress was analyzed by exposing the cells to $\mathrm{H}_{2} \mathrm{O}_{2}$ (Figure 16A). Sensitivity of yeast cells to $\mathrm{H}_{2} \mathrm{O}_{2}$ was concluded from the measured size of the growth inhibition area of cells grown on the surface of agar plates in the presence of a disc containing $\mathrm{H}_{2} \mathrm{O}_{2}$ (Figure 16B).
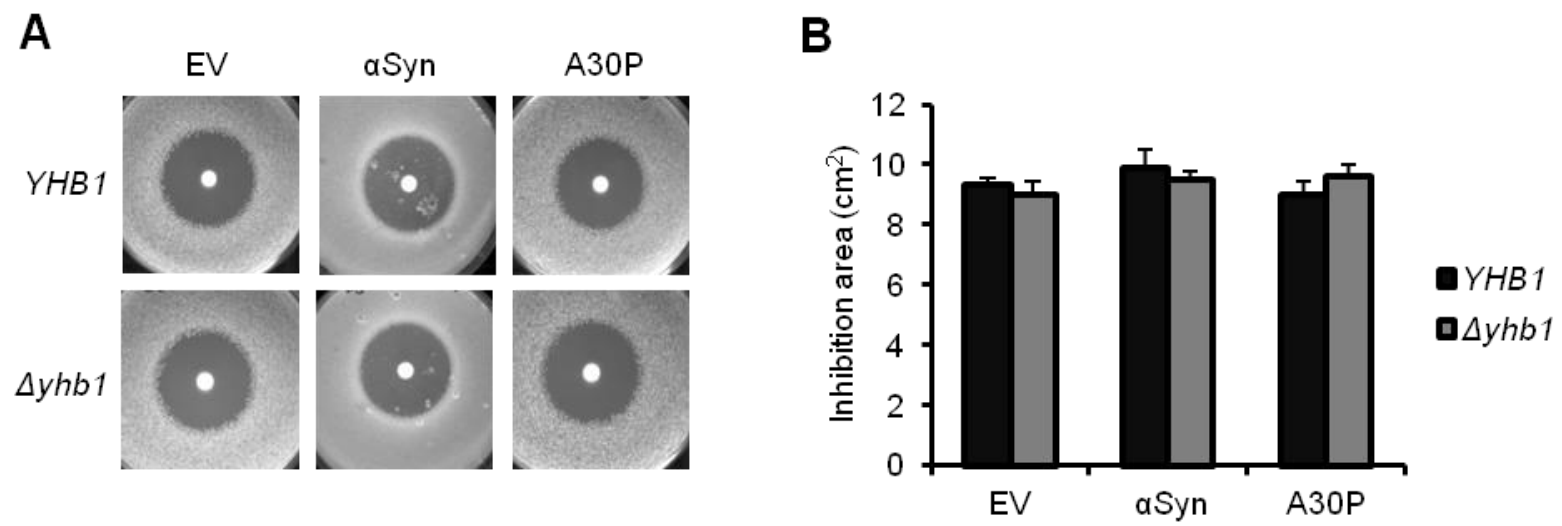

Figure 16. aSyn expression does not affect sensitivity of yeast cells to $\mathrm{H}_{2} \mathrm{O}_{2}$.

(A) Halo assay of YHB1 and $\triangle y h b 1$ yeast cells expressing aSyn or A30P compared to empty vector $(E V)$ as control on galactose-inducing SC-Ura medium in the presence of a Whatman paper disc containing $10 \mu \mathrm{L} 30 \% \mathrm{H}_{2} \mathrm{O}_{2}$ after three days. (B) Quantification of the inhibition area shown as $\mathrm{cm}^{2}$ after three days induction on galactose-containing medium. Significance of differences was calculated with t-test $(n=2)$.

aSyn and A30P expressing wild-type cells exhibit an equal inhibition area as the control cells expressing the empty vector (Figure 16) suggesting that expression of both aSyn variants does not change sensitivity of the yeast cells to $\mathrm{H}_{2} \mathrm{O}_{2}$. Moreover, the inhibition area of $\Delta y h b 1$ cells was similar to that of wild-type yeast cells, indicating that deletion of YHB1 does not affect the susceptibility of yeast to oxidative stress. This result revealed that $\alpha$ Syn expressing cells exhibit low sensitivity to $\mathrm{H}_{2} \mathrm{O}_{2}$ under the used experimental conditions, which is not influenced by increased nitrative stress levels in YHB1 deletion yeast. 


\subsection{Blockage of tyrosine nitration protects against A30P toxicity and aggregate formation under nitrative stress}

The removal of the four tyrosines of aSyn as possible cellular nitration sites (4(Y/F)) might affect aSyn toxicity in yeast when the intracellular nitrative stress level is increased using the $\Delta y h b 1$ strain defective in stress protection. This was examined by comparing aSyn, A30P and their tyrosine to phenylalanine replacement derivatives $(4(Y / F))$, which were expressed in yeast with wild-type $Y H B 1$ or $\triangle y h b 1$ deletion background. Growth was analyzed by spotting analysis and in liquid medium (Figure 17A, B).

A

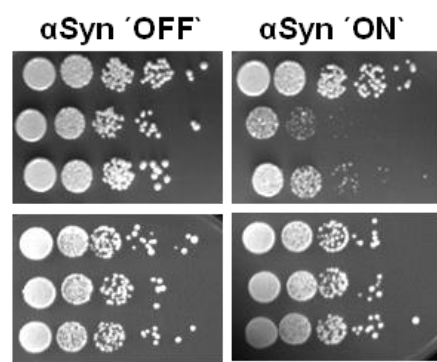

YHB1

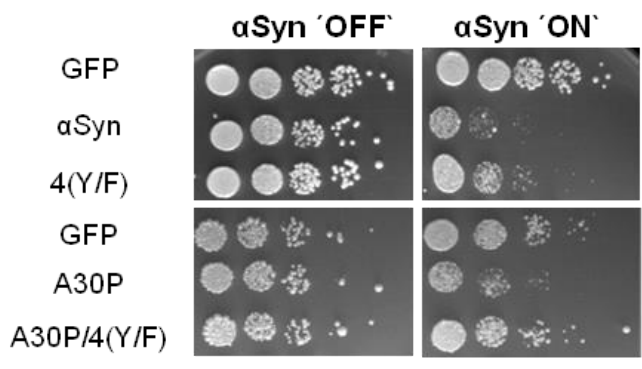

$\Delta y h b 1$
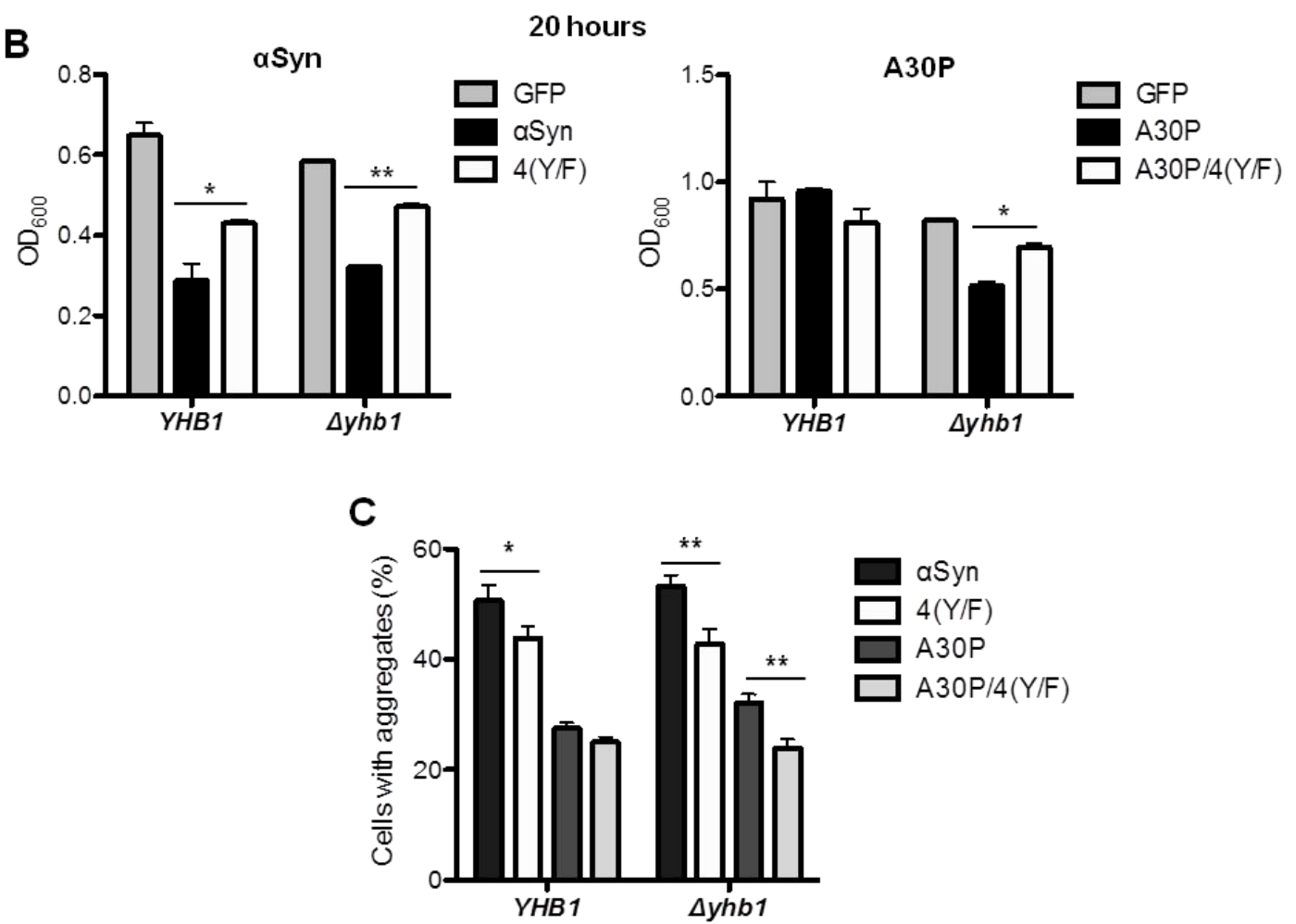

Figure 17. C-terminal tyrosine replacements of A30P decrease toxicity in $\Delta y h b 1$.

(A) Spotting analysis of aSyn, A30P, 4(Y/F) aSyn, A30P/4(Y/F) and GFP (control) expressed in $Y H B 1$ and $\triangle y h b 1$ yeast on non-inducing and galactose-inducing SC-Ura plates after three days of growth. (B) Cell growth analysis of YHB1 and $\triangle y h b 1$ yeast expressing aSyn, A30P, $4(\mathrm{Y} / \mathrm{F}), \mathrm{A} 30 \mathrm{P} / 4(\mathrm{Y} / \mathrm{F})$ and GFP (control) at time point 20 hours. Significance of differences was calculated with t-test $\left({ }^{*}, p<0.05 ;{ }^{* *}, p<0.01, \mathrm{n}=3\right)$. (C) Quantification of the percentage of cells displaying aSyn aggregates after six hours induction in galactose-containing SC-Ura medium. Significance of differences was calculated with t-test $\left({ }^{*}, p<0.05,{ }^{* *}, p<0.01, \mathrm{n}=6\right)$. 
Expression of 4(Y/F) aSyn with an intact $Y H B 1$ gene resulted in improved growth, whereas A30P toxicity was not affected (Figure 10, 17A, B). In the absence of the YHB1 gene, A30P delayed growth. However, 4(Y/F) A30P grew similar to the GFP control. A30P-mediated toxicity was related to the formation of inclusions (Figure 17C). These results corroborate that increased nitrative stress contributes to A30P toxicity by nitration of tyrosine residues. Nitration-deficient wild-type or A30P aSyn were less toxic and aggregated less, whereas an increase of intracellular nitrative stress resulted in growth retardation and increased aggregate formation of $\mathrm{A} 30 \mathrm{P}$ variant only when tyrosine resides were present.

\subsection{Yhb1 reduces the accumulation of reactive nitrogen species in A30P expressing cells}

Oxidative and nitrative stresses are implicated in the pathogenesis of PD (Danielson and Andersen, 2008; Dias et al., 2013). These stresses emerge from the accumulation of reactive intermediates such as ROS and RNS. ROS and RNS production was visualized in yeast cells. aSyn and A30P expression was induced for six hours and ROS and RNS specific dyes were applied to compare the production of the reactive species in YHB1 and $\Delta y h b 1$ cells by fluorescence microscopy and flow cytometry. Dihydrorhodamine 123 (DHR123) was used for ROS detection. The dye accumulates in cells, where it is oxidized by free radicals to the bright red fluorescent product rhodamine 123 (Figure 18A, B). Expression of A30P and its derivative $\mathrm{A} 30 \mathrm{P} / 4(\mathrm{Y} / \mathrm{F})$ did not significantly increase the number of cells accumulating ROS (Figure $18 \mathrm{C}$ ). In contrast, expression of wild-type aSyn as well as its $4(\mathrm{Y} / \mathrm{F})$ derivative strongly increased the number of cells that accumulate red fluorescence indicative for ROS. No difference in ROS accumulation was observed between the YHB1 wild-type and the $\Delta y h b 1$ mutant strain. 

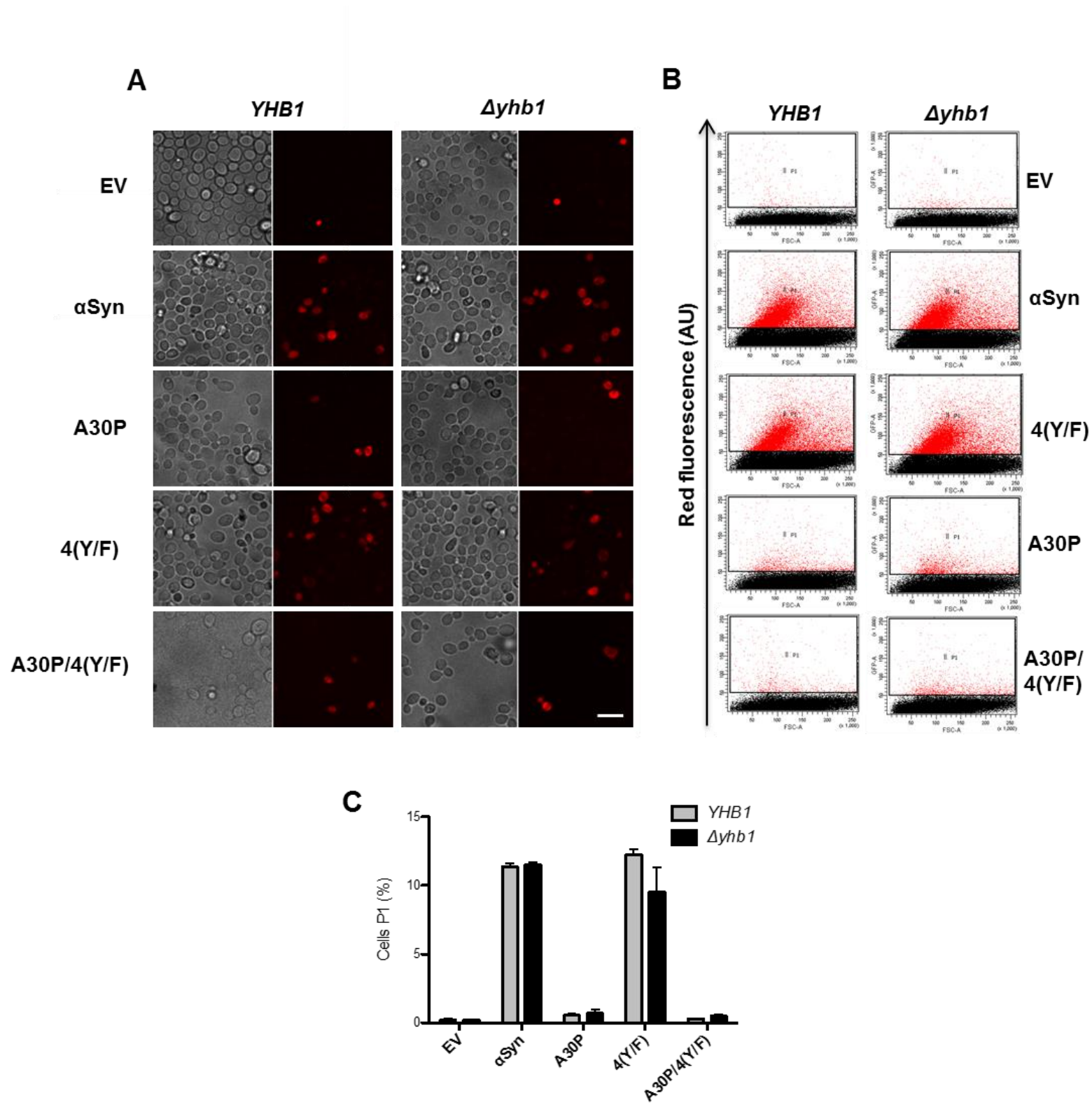

Figure 18. Expression of aSyn increases accumulation of ROS.

(A) aSyn and A30P were induced in galactose-containing medium for six hours in YHB1 wildtype or $\Delta y h b 1$ deletion yeast strains. Cells were incubated with $5 \mu \mathrm{g} / \mathrm{mL}$ dihydrorhodamine 123 (DHR123) as an indicator of high intracellular ROS accumulation for 1.5 hours and analyzed by live-cell fluorescence microscopy. Scale bar $=5 \mu \mathrm{m}$. (B) Fluorescent intensity of cells from (A), assessed with flow cytometry analysis. Forward scatter (FSC) and DHR123 fluorescence of cells after six hours induction of aSyn expression. (C) Quantification of aSyn and A30P expressing cells displaying ROS stained by DHR123 using flow cytometry. The percentage of the sub-population of yeast cells with higher fluorescent intensities (P1) than the background is presented.

DAF-2 DA (4,5-Diaminofluorescein diacetate) dye was used as a sensitive and highly specific fluorescent indicator for detection of NO (Figure 19A, B). Expression of both aSyn and A30P induced accumulation of reactive nitrogen species (Figure 19C). Interestingly, deletion of YHB1 significantly increased the number of cells exhibiting RNS when A30P 
variant was expressed. This effect was dependent on tyrosine residues since RNS accumulation in cells expressing A30P/4(Y/F) did not differ from empty vector control.

A

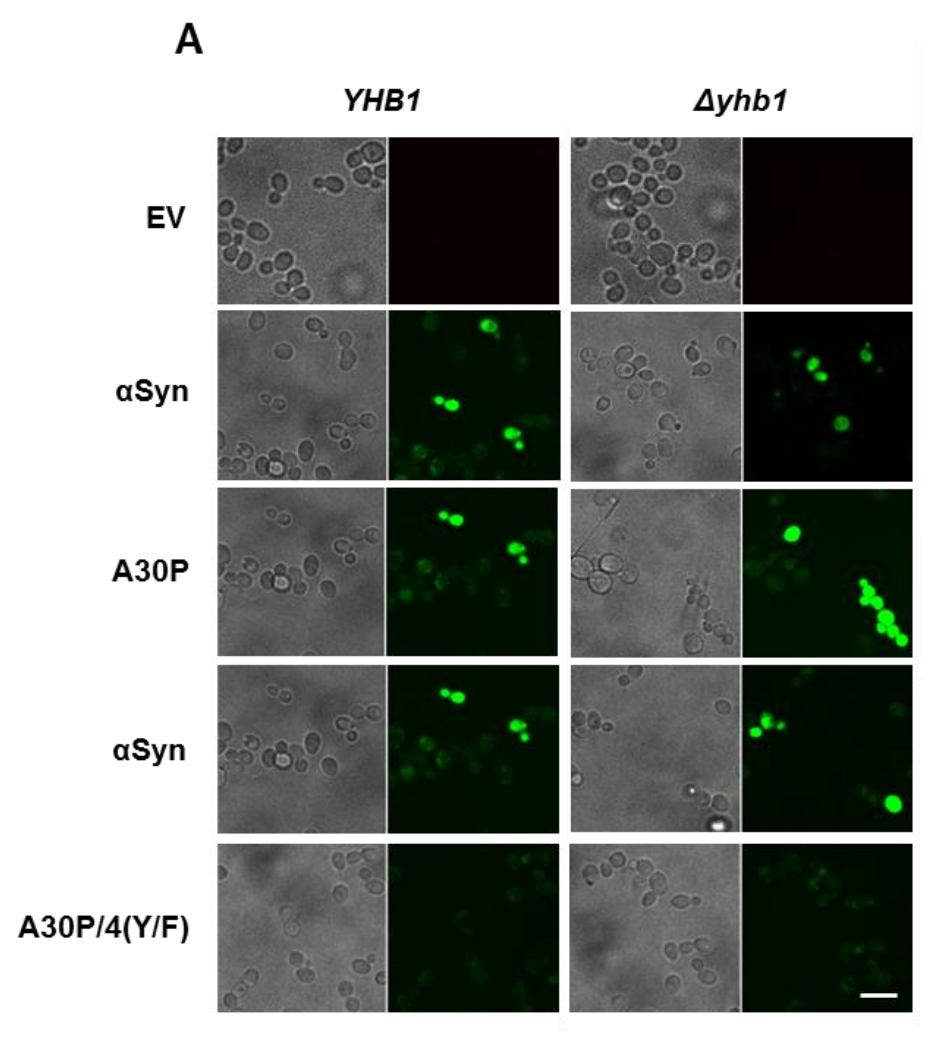

B

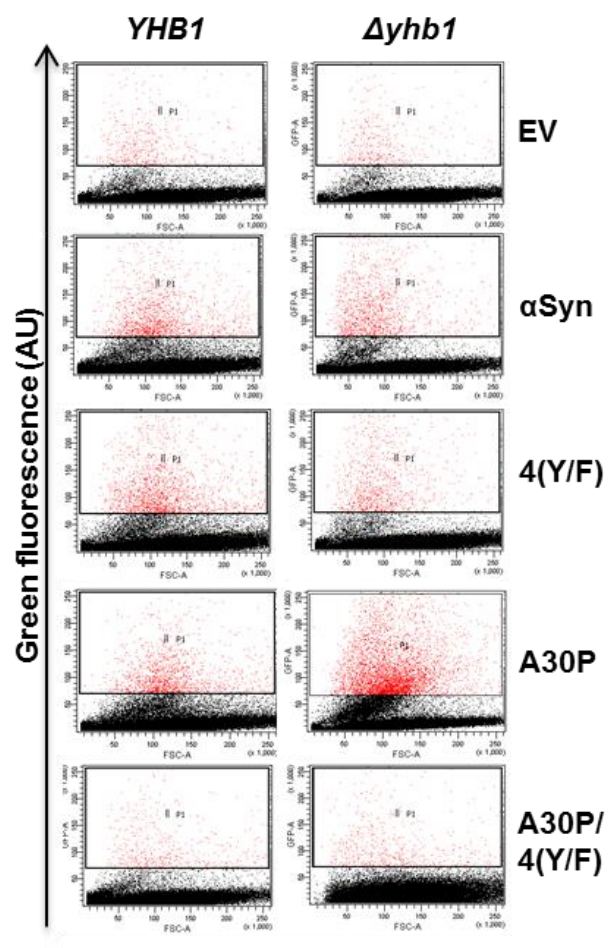

C

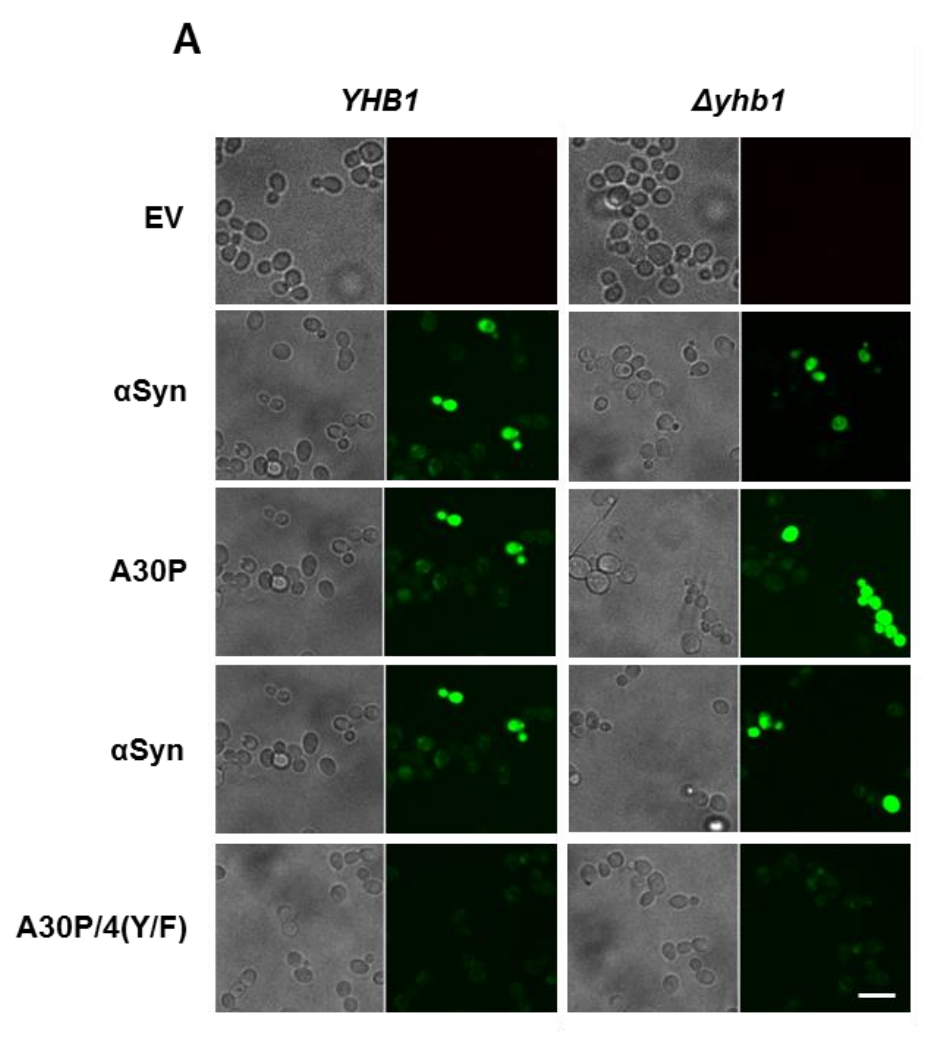

$\Delta y h b 1$

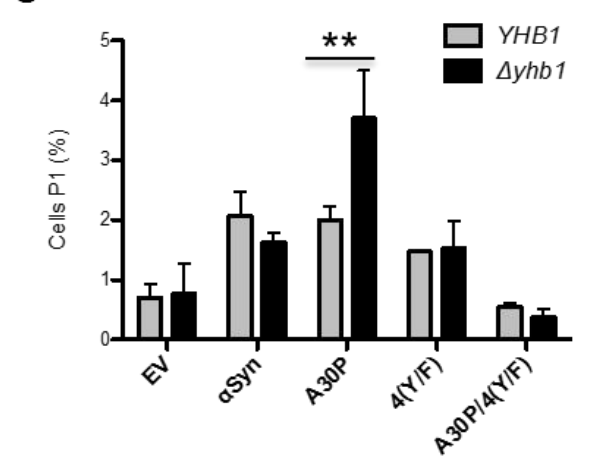

Figure 19. $\Delta y h b 1$ increases accumulation of reactive nitrogen species (RNS) in A30P expressing cells.

(A) Microscopy analysis of RNS stained cells. aSyn and A30P were induced in galactosecontaining SC-Ura medium for six hours in YHB1 and $\Delta y h b 1$ yeast strains. Cells were incubated with $25 \mu \mathrm{g} / \mathrm{mL}$ DAF-2 DA for one hour at $30{ }^{\circ} \mathrm{C}$ for visualization of RNS and analyzed by live-cell fluorescence microscopy. Scale bar $=5 \mu \mathrm{m}$. (B) Fluorescent intensity of cells from (A), assessed with flow cytometry analysis. Forward scatter (FSC) and DAF-2 DA fluorescence of cells after six hours induction of aSyn expression. (C) Quantification of aSyn and A30P expressing cells displaying RNS stained by DAF-2 DA using flow cytometry. The percentage of the sub-population of yeast cells with higher fluorescent intensities (P1) than the background is presented. Significance of differences was calculated with t-test $\left({ }^{* *}, p<\right.$ $0.01, \mathrm{n}=3)$. 
The results show that toxic wild-type aSyn expression induces significantly more ROS accumulation in yeast cells than non-toxic A30P. Accumulation of ROS species was not dependent on the presence of tyrosine residues or YHB1 gene. In contrast, both aSyn as well as A30P induce the accumulation of RNS for nitrative stress in yeast cells. The levels of RNS in A30P but not wild-type aSyn expressing cells are dependent on the presence of tyrosine residues and $Y H B 1$. The results suggest that Yhb1 attenuates the accumulation of RNS of A30P expressing cells.

\subsection{Yhb1 protects mitochondria from A30P toxicity}

Overexpression of aSyn and A30P leads to increased levels of RNS and higher sensitivity to NO stress in $\Delta y h b 1$ yeast. The Yhb1 protein is translocated into yeast mitochondria under hypoxic conditions where it detoxifies NO (Cassanova et al., 2005). Mitochondria are a major source of free radicals in the cells. Yhb1 is consuming NO, which inhibits mitochondrial respiration and thus increases the level of ROS. aSyn toxicity results in mitochondrial dysfunction and generation of ROS (Su et al., 2010). Overexpression of $\alpha$ Syn in mammalian cells results in mitochondrial fragmentation and involves a direct interaction of aSyn with mitochondrial membranes (Nakamura et al., 2011).

It was examined, whether deletion of YHB1 influences the mitochondrial morphology in aSyn and A30P aSyn expressing yeast cells. aSyn expression in the wild-type and $\Delta y h b 1$ background was induced for six hours in galactose medium and the mitochondria were visualized with a mitochondrial specific dye (MitoTracker Red). Yeast cells overexpressing GFP served as a control (Figure 20A). Co-localization of aSyn with mitochondria was not observed, which suggests that the described mitochondrial fraction of the protein might be small (Nakamura et al., 2011). The mitochondrial morphology was classified as tubular, partially fragmented or fully fragmented. In the control cells, the mitochondria revealed a ribbon-like tubular architecture, typical for healthy mitochondria. Cells expressing aSyn showed a dramatic increase in the percentage of cells with fully fragmented mitochondria (Figure 20A, B). 


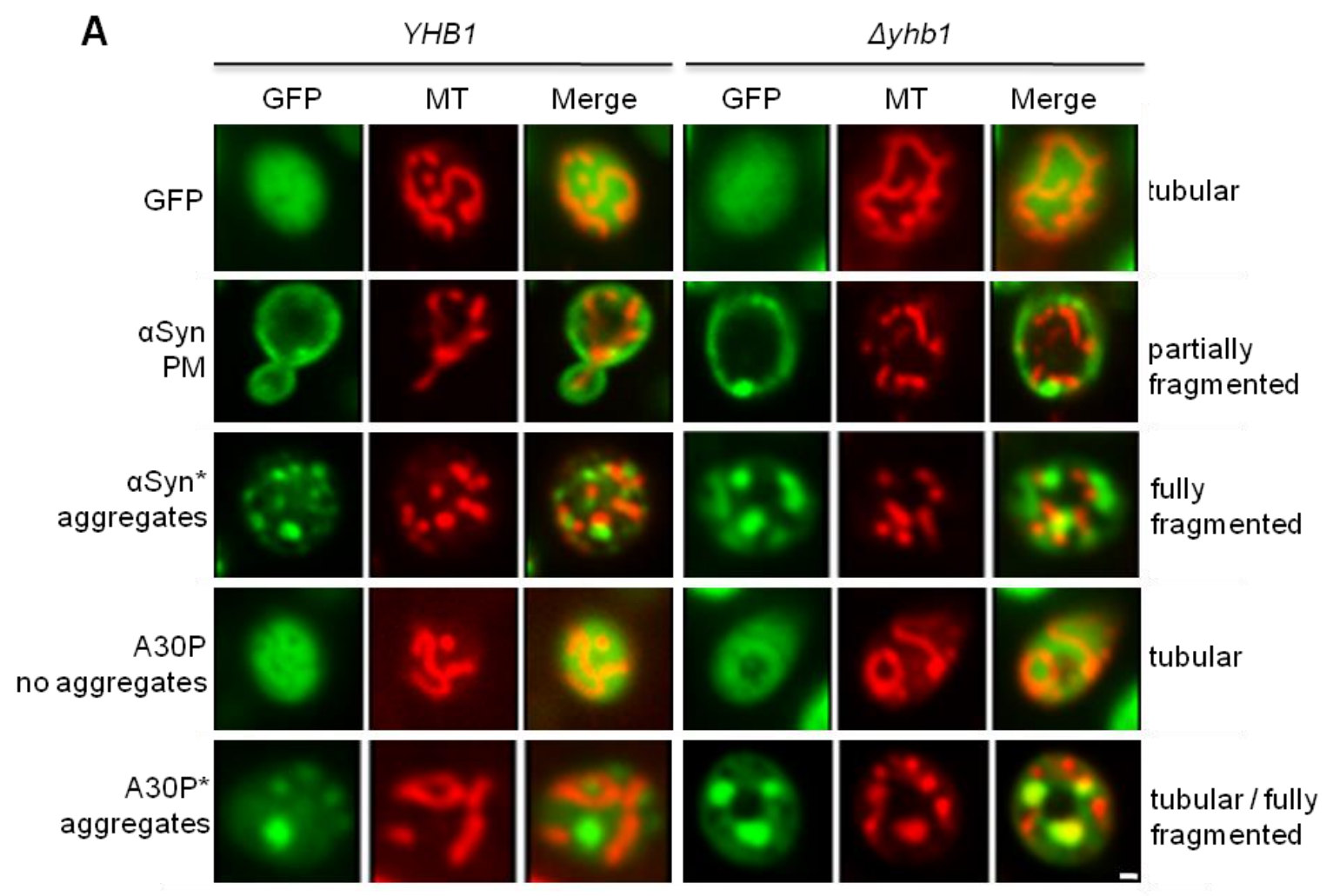

B

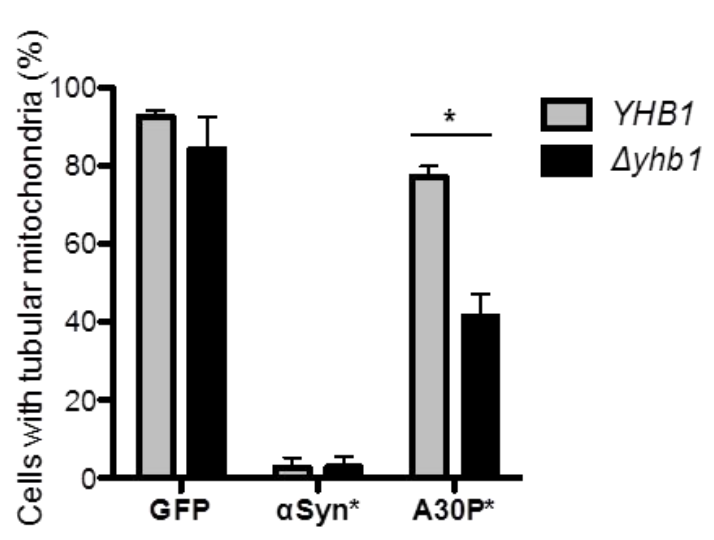

C

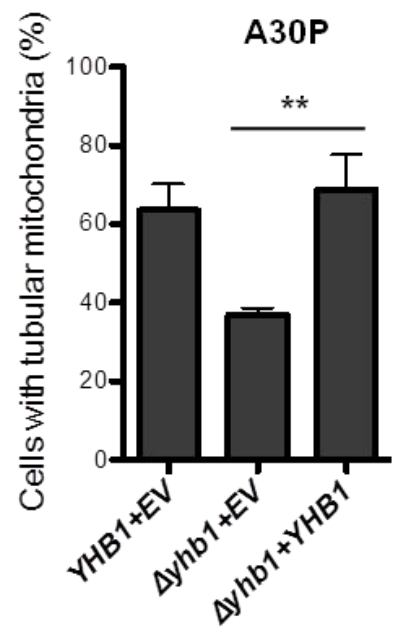

Figure 20. Yhb1 protects mitochondria from A30P toxicity.

(A) Live-cell fluorescence microscopy of YHB1 compared to $\triangle y h b 1$ yeast cells expressing GFP (control), aSyn or A30P after six hours induction in galactose-containing medium. MitoTracker Red was used to visualize mitochondria in the cells (MT panel). aSyn expressing cells with plasma membrane localization (PM) and with aggregates are visualized. Scale bar $=1 \mu \mathrm{M}$. (B) Quantification of yeast cells with tubular mitochondrial network. GFP: percentage

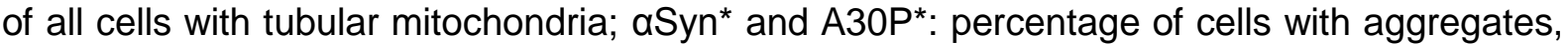
showing tubular mitochondria. At least 50 cells were counted per cell type and experiment. Significance of differences was calculated with t-test $\left({ }^{*}, p<0.05, \mathrm{n}=4\right)$. (C) Quantification of yeast cells with tubular mitochondrial network for rescue of A30P phenotype. A30P with empty vector (EV) in YHB1 and $\triangle y h b 1$ strain and A30P co-transformed with YHB1 on lowcopy vector in $\triangle y h b 1$ strain. A30 ${ }^{*}$ : percentage of cells with aggregates, showing tubular mitochondria. Significance of differences was calculated with t-test $\left({ }^{* *}, p<0.01, \mathrm{n}=3\right)$. 
Cells with and without inclusions were considered separately for statistical evaluation. Cells with plasma-membrane localization of the GFP-signal, typical aSyn localization for early stages of expression or lower expression levels, revealed partially fragmented mitochondrial architecture. aSyn expressing cells with aggregates had fully fragmented mitochondria. In contrast to aSyn, A30P expressing cells with aggregates had mainly tubular mitochondria, similar to the control cells (Figure 20A). Deletion of YHB1 increased the percentage of cells with fully fragmented mitochondria almost two-fold (Figure 20B). Thus, the disrupted mitochondrial morphology in $\Delta y h b 1$ correlates with the increased levels of RNS (Figure 19) and diminished growth behavior of A30P expressing cells (Figure 12B). Complementation of the $\triangle y h b 1$ phenotype in $\mathrm{A} 30 \mathrm{P}$ expressing cells rescued the defect (Figure 20C), as mitochondrial morphology was recovered by expression of $Y H B 1$ on a low-copy vector. The result suggests that Yhb1 protects against A30P-induced cytotoxicity by preventing the mitochondrial fragmentation.

\subsection{Mitochondrial functionality is not affected by Yhb1 in A30P expressing yeast cells}

Analysis of mitochondrial morphology revealed an YHB1-dependent mitochondrial fragmentation upon A30P expression. In the next step, it was investigated how mitochondrial functionality is affected by $Y H B 1$ deletion. Mitochondrial respiration was assessed by measuring the oxygen consumption rate (OCR) under mitochondrial stress conditions by applying the mitochondrial inhibitors oligomycin $A$ and antimycin $A$ and the mitochondrial uncoupler fluoro-carbonyl cyanide phenylhydrazone (FCCP). After six hours induction of aSyn or A30P expression in YHB1 yeast cells, no significant differences in the basal respiration could be detected (Figure 21A). However, expression of aSyn and A30P in $\Delta y h b 1$ diminished basal respiration of the cells.

Interestingly, under stimulating conditions increased OCR was observed in $\Delta y h b 1$ cells expressing A30P compared to $\mathrm{YHB1}$ yeast, suggesting that these cells have higher reserve capacity (Figure 21B). Addition of oligomycin A, which is an inhibitor of the mitochondrial ATP synthase, had only a moderate inhibitory effect on OCR. It is known that the yeast ATP synthase is less sensitive to oligomycin $A$ than the animal mitochondrial ATP synthase. The gene YOR1 (Yeast Oligomycin Resistance) is responsible for the tolerance to this drug (Katzmann et al., 1995). Addition of antimycin A strongly inhibited respiration in all strains. The reported severe effect of antimycin $A$ on yeast mitochondrial respiration is in agreement with earlier investigations (Ocampo et al., 2012). The remaining oxygen consumption reveals the extent of non-mitochondrial sources of oxygen consumption in the cells (Figure 21C). 
Non-mitochondrial respiration results from oxygen consumption of cytosolic oxidase enzymes. The formation of reactive oxygen and nitrogen species was shown to increase non-mitochondrial respiration (Chacko et al., 2014; Dranka et al., 2010; Hill et al., 2012).

A

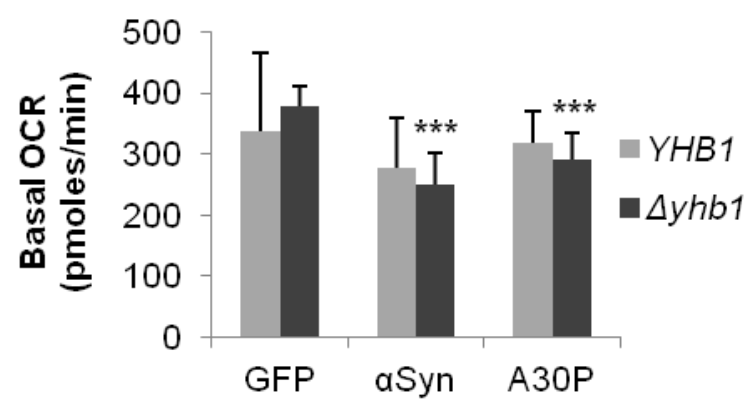

C

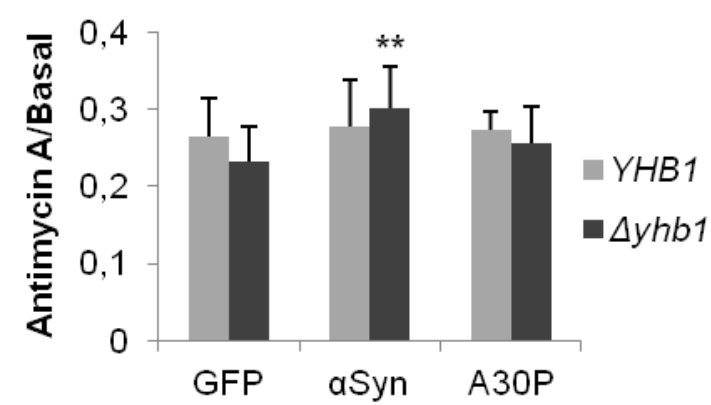

B

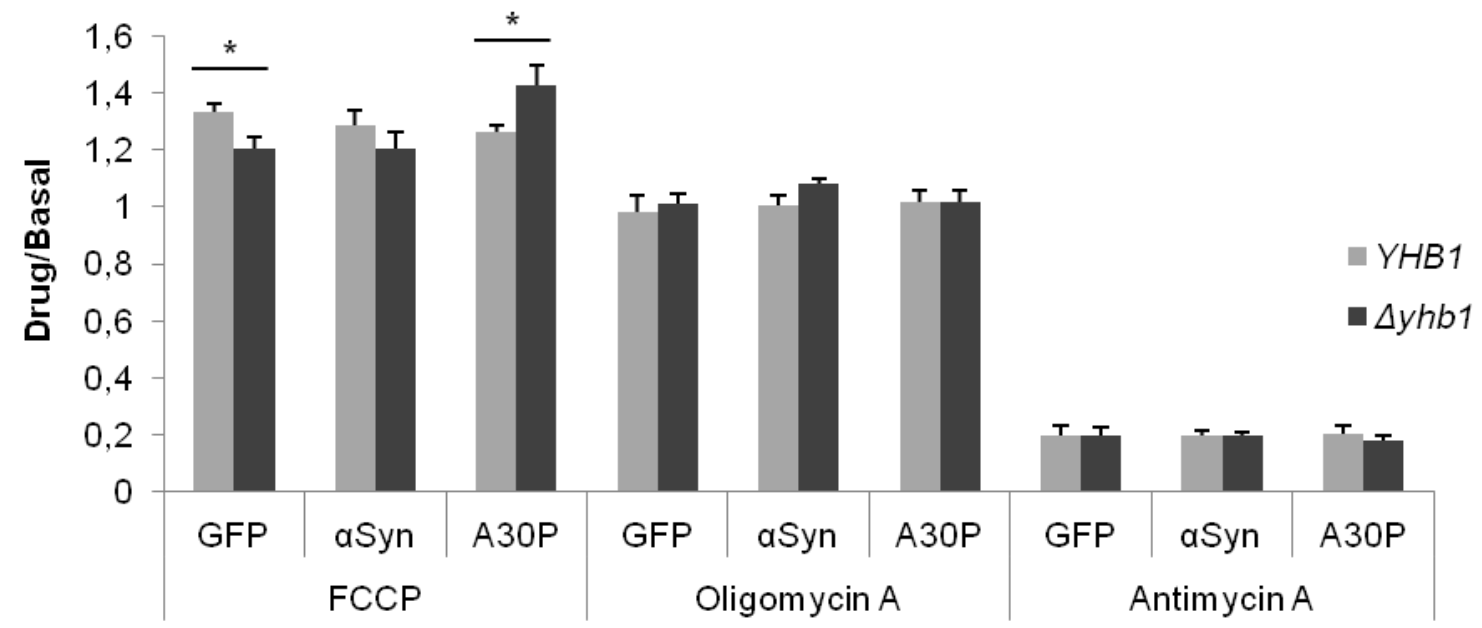

Figure 21. Mitochondrial functionality is not affected by Yhb1 in A30P expressing yeast cells.

(A) Measurement of basal oxygen consumption rate (OCR) of YHB1 and $\triangle y$ hb1 strains expressing aSyn, A30P and GFP (control) after six hours induction in galactose-containing SC-Ura medium. OCR is shown as absolute values in picomoles per minute after subtraction of non-mitochondrial respiration. Significance of differences was calculated with t-test ${ }^{* * *}, p$ $<0.001$ versus GFP control; $n=9$ ). (B) Shown is OCR of $Y H B 1$ and $\Delta y h b 1$ strains expressing aSyn, A30P and GFP (control) after six hours induction in galactose-containing SC-Ura medium normalized to basal respiration. OCR was measured after consecutive application of $2 \mu \mathrm{M}$ fluoro-carbonyl cyanide phenylhydrazone (FCCP), $20 \mu \mathrm{M}$ oligomycin A and $50 \mu \mathrm{M}$ antimycin A. OCR is shown as ratio normalized to basal respiration. Significance of differences was calculated with t-test $\left({ }^{*}, p<0.05, \mathrm{n}=9\right)$. (C) Shown is the non-mitochondrial respiration of YHB1 and $\triangle y h b 1$ strains expressing aSyn, A30P and GFP (control) after six hours aSyn induction as ratio of OCR of antimycin $A(50 \mu \mathrm{M})$ treated cells to basal OCR. Significance of differences was calculated with t-test $\left({ }^{* *}, p<0.01\right.$ versus GFP control; $\left.n=9\right)$. 
In wild-type yeast, no differences in non-mitochondrial respiration were observed between control cells expressing GFP and cells expressing the two aSyn variants (Figure 21C). However, $\Delta y h b 1$ cells expressing wild-type aSyn revealed increased non-mitochondrial respiration, which might be due to enhanced oxygen consumption by cytosolic oxidases or increased formation of of reactive oxygen and nitrogen species. These results indicate that aSyn-induced mitochondrial fragmentation does not compromise the bioenergetics of mitochondria when aSyn is overexpressed in yeast. However, non-mitochondrial oxygen consumption is varied in $\Delta y h b 1$ cells expressing wild-type aSyn.

\subsection{Human neuroglobin protects against $\alpha$-synuclein aggregate formation in yeast and in mammalian cells}

A BLAST search for human genes corresponding to yeast $Y H B 1$ revealed $49 \%$ similarities of the YHB1 globin domain to the gene for human neuroglobin (NGB) as a putative homolog. It was analyzed analyzed whether the human counterpart of yeast YHB1 can affect aSyn aggregation. Neuroglobins are oxygen-binding proteins that are highly conserved among vertebrates and are expressed in the central and peripheral nervous system. They provide protection against hypoxic induced cell injury in the brain, which is associated with ROS and RNS accumulation (Greenberg et al., 2008). Both Yhb1 and neuroglobin contain a globin domain and are members of the globin gene family. NGB was shown to diminish betaamyloid-induced neurotoxicity in vitro and to attenuate the phenotypes in a transgenic mouse model of Alzheimer's disease (Khan et al., 2007). NGB acts as an oxidative stressresponsive sensor for neuroprotection (Watanabe et al., 2012).

It was examined, whether human NGB affects aSyn or A30P growth and aggregate formation in yeast. Growth and aggregation of aSyn was not changed by the expression of the human NGB (Figure 22A, B). However, NGB expression in $\Delta y h b 1$ deletion strain rescued $\mathrm{A} 30 \mathrm{P}$ yeast growth (Figure 22A) and reduced the number of cells with $\mathrm{A30P}$ aggregates (Figure 22C). The effect of $N G B$ in yeast is similar to the impact of $Y H B 1$ on aSyn and A3OP growth and aggregate formation (Figure 12B, 13A). 
A

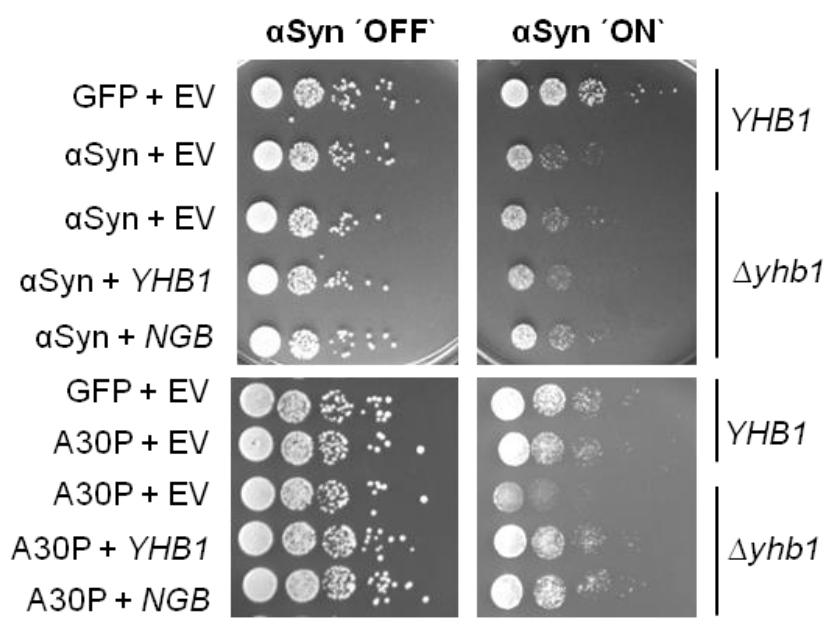

B

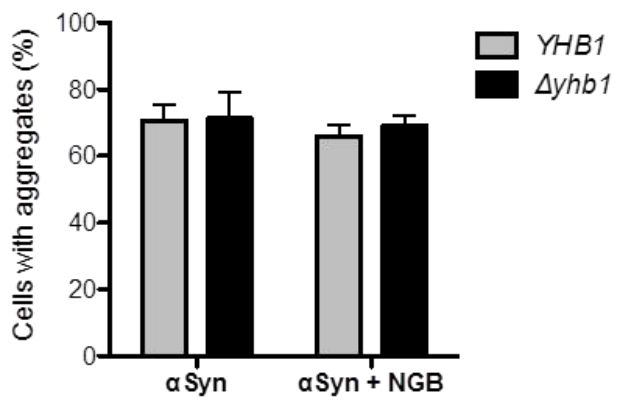

C

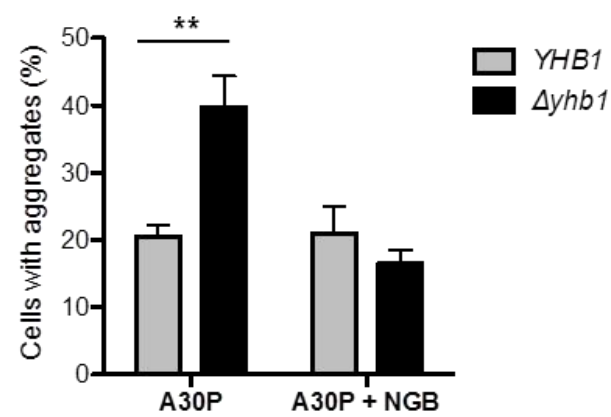

Figure 22. The human NGB gene for neuroglobin complements A30P growth in YHB1 deletion yeast.

(A) Spotting analysis of $Y H B 1$ and $\triangle y h b 1$ yeast cells co-expressing aSyn and GFP (control) (upper panel) or A30P and GFP (lower panel) with either empty vector as control or YHB1 and $N G B$, respectively on non-inducing and galactose-inducing SC-Ura medium after three days. (B) Quantification of the percentage of cells displaying aSyn aggregates after six hours induction in galactose-containing medium $(n=3)$. (C) Quantification of the percentage of cells displaying A30P aggregates after six hours induction in galactose-containing medium. Significance of differences was calculated with t-test $\left({ }^{* *}, p<0.01, \mathrm{n}=3\right)$.

It was examined, whether $N G B$ has not only a protective role against aSyn aggregate formation in yeast but also in mammalian cells. Human Neuroglioma cells (H4) served as established aSyn aggregation model, where aggregation of aSyn is induced by coexpressing C-terminally modified aSyn (SynT) and synphilin-1, aSyn-interacting protein that was also found in LBs (Engelender et al., 1999; Lazaro et al., 2014). H4 cells were cotransfected with SynT, Synphilin-1 and NGB or empty vector and aggregate formation of SynT was monitored (Figure 23).

Expression of $N G B$ reduced the number of cells with aggregates almost two-fold in comparison to the control and reduced the number of aggregates per cell (Figure 23A, B). These results support that similar to its yeast counterpart $Y H B 1$, the stress response gene $N G B$ is a putative suppressor of aSyn aggregation in mammalian cells. 
A
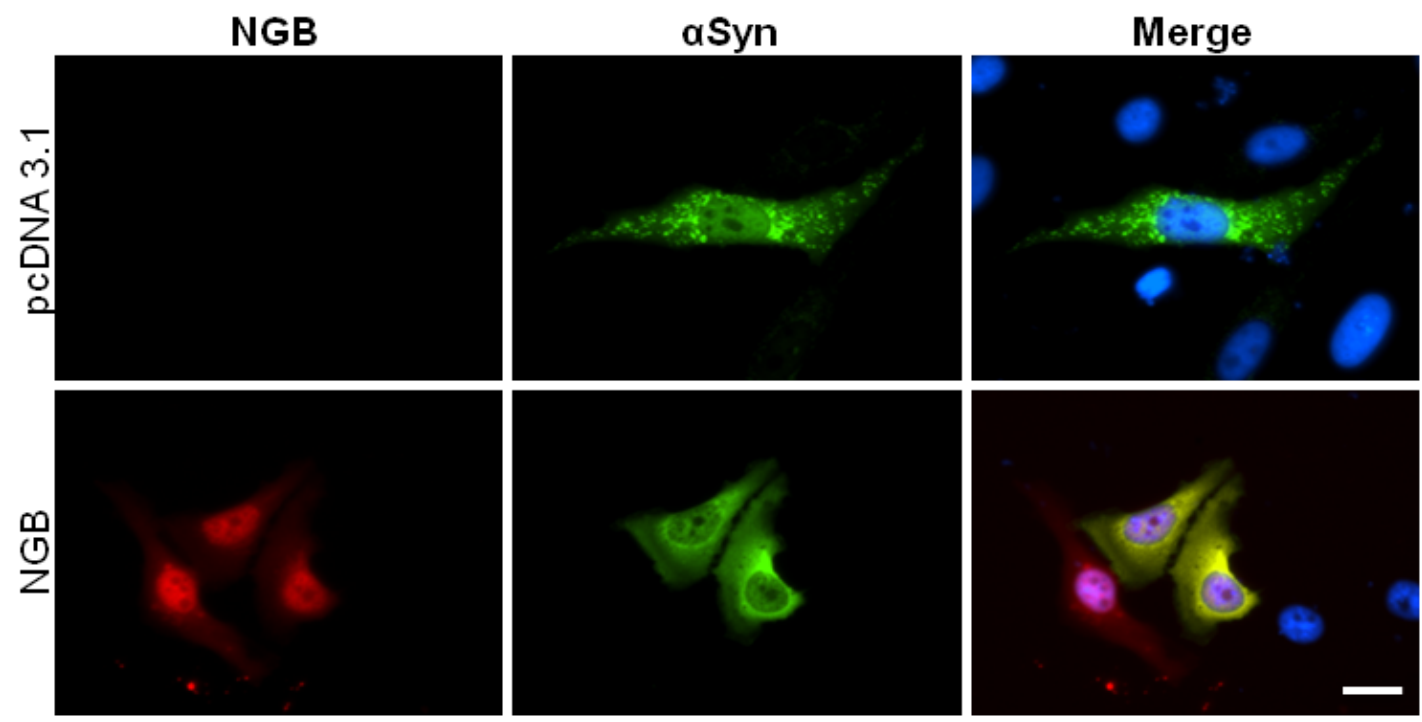

B

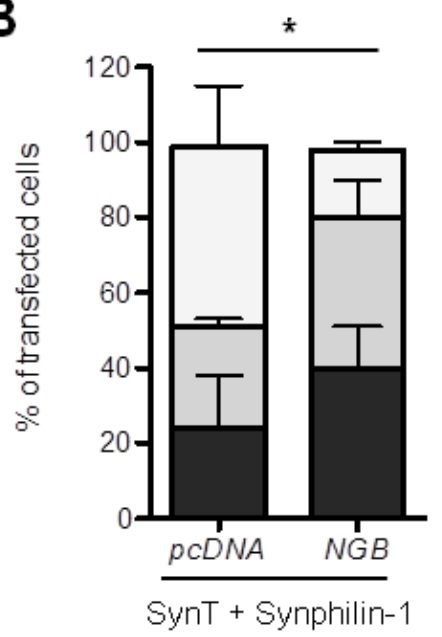

C

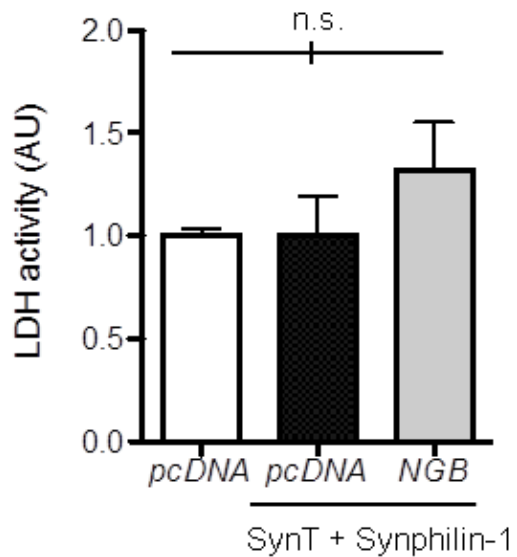

Figure 23. The human NGB gene for neuroglobin alters $\alpha$ Syn aggregation in mammalian cells.

(A) Fluorescence microscopy of $\mathrm{H} 4$ cells co-expressing SynT, Synphilin-1 and pcDNA (control) or NGB-mCherry. Nuclei are stained with Hoechst dye (blue). Scale bar $=30 \mu \mathrm{m}$. (B) Quantification of the percentage of $\mathrm{H} 4$ cells displaying aSyn inclusions after 48 hours after transfection. Cells were classified into three groups according to the number of aSynimmunoreactive inclusions observed: cells with 10 inclusions, cells with less than 10 inclusions and cells without inclusions. Significance of differences was calculated with one-way ANOVA $\left({ }^{*}, p<0.05, n=3\right)$. (C) Lactate dehydrogenase (LDH) activity measurements support that NGB is non-toxic for $\mathrm{H} 4$ cells. $\mathrm{H} 4$ cells transfected with empty mammalian expression vector pcDNA3.1, with empty pcDNA3.1 or pcDNA3.1 encoding neuroglobinmCherry (NGB) together with SynT and symphilin-1 (SynT+Synphilin-1) were analyzed. Media from indicated $\mathrm{H} 4$ cells were collected and the secretion of lactate LDH was determined as a measure of cytotoxicity. Significance of differences were calculated with ttest (not significant; $n=3$ ). 
Lactate dehydrogenase (LDH) measurements were performed to determine, whether there is an effect of NGB on cell toxicity. LDH is released into the cell culture medium upon damage of the plasma membrane and is, therefore, a widely used marker in cytotoxicity studies. LDH measurements were similar for all tested $\mathrm{H} 4$ cells (Figure 23C). The results support that the stress response gene $N G B$ does act as suppressor of aSyn aggregation without significantly affecting the cytotoxicity.

\subsection{Yhb1 affects nitration but not dimerization level of A30P}

It was assessed, whether the different cytotoxicity of $\alpha$ Syn and A30P in yeast correlates with different nitration levels of the two variants in wild-type yeast background and under increased nitrative stress in $\Delta y h b 1$ strain. Immunoblotting performed with two specific antibodies against nitrotyrosine (3-nitrotyrosine and nitro-Y39 aSyn) showed that aSyn and A30P are nitrated in the $Y H B 1$ as well as in $\triangle y h b 1$ yeast (Figure 24A).

A
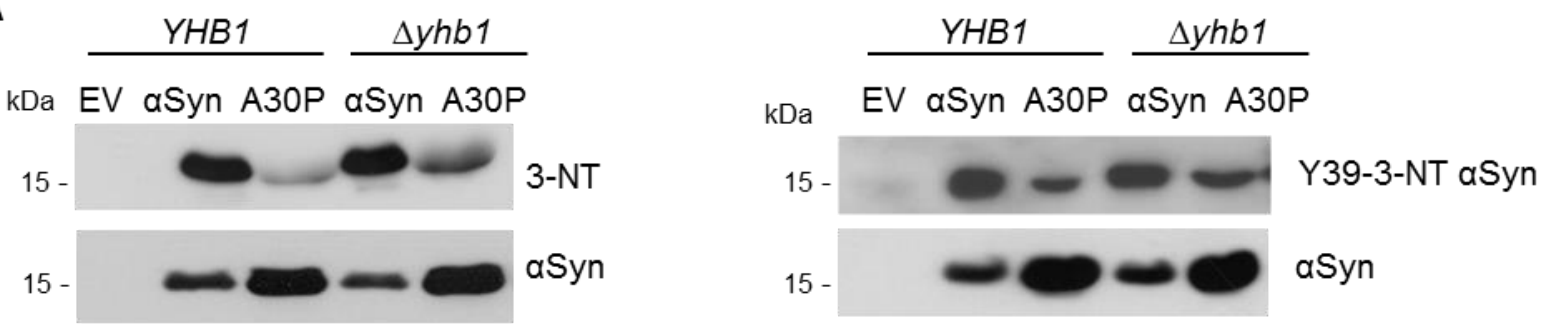

B 3-NT

Y39-3-NT aSyn

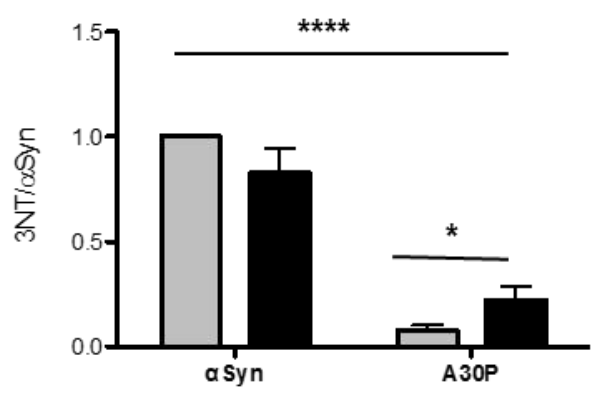

YHB1

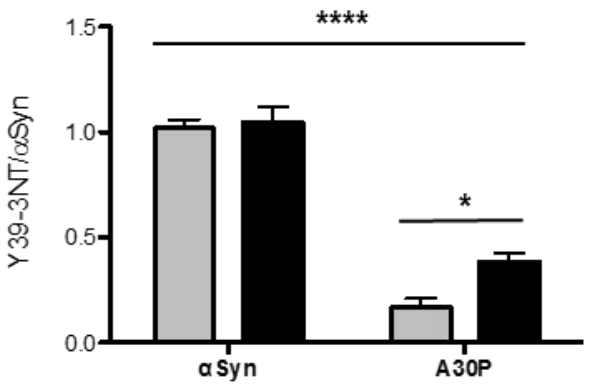

YHB1

$\triangle y h b 1$

Figure 24. Yhb1 affects nitration of A30P.

(A) Immunoblotting of 3-nitrotyrosine using 3-nitrotyrosine antibody (3-NT, left) and nitro-Y39 aSyn antibody (Y39-3-NT, right). Protein expression was induced for 12 hours in galactosecontaining SC-Ura medium. Concentrated protein extracts of $\mathrm{Ni}^{2+}$ pull down-enriched aSyn and A30P aSyn from YHB1 and $\triangle y h b 1$ yeast cells were applied. Cells expressing empty vector (EV) served as control. The same membranes were stripped and re-probed with aSyn antibody. (B) Quantification of aSyn and A30P nitration levels in YHB1 and $\triangle y h b 1$ yeast cells. Densitometric analysis of the immunodetection of nitrated aSyn and A30P relative to the intensity obtained for aSyn. Significance of differences was calculated with one-way ANOVA with Bonferroni's multiple comparison test $\left({ }^{*}, p<0.05 ;{ }^{* \star *}, p<0.0001 ; \mathrm{n}=3\right)$. 
Quantification of band intensities of both nitrated aSyn variants revealed significantly higher nitration level of aSyn in comparison to A30P. Deletion of YHB1 resulted in increase of A30P nitration level, whereas aSyn nitration level was not affected (Figure 24B).

A

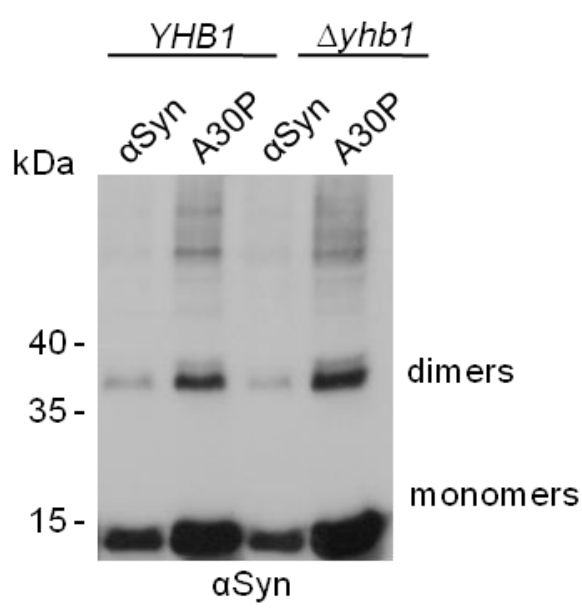

B

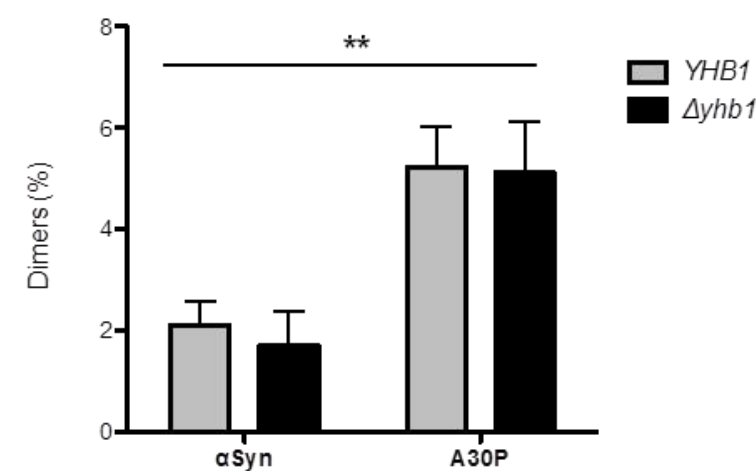

Figure 25. Yhb1 affects nitration but not dimerization of aSyn and A30P.

(A) Immunoblotting of aSyn enriched by $\mathrm{Ni}^{2+}$ pull-down with aSyn antibody. (B) Ratio of dimers relative to the sum of monomers and dimers. Densitometric analysis of the immunodetection of aSyn and A30P aSyn dimers, presented as percent of the total amount of aSyn detected per lane (monomer + dimer). Significance of differences was calculated with one-way ANOVA $\left.{ }^{* *}, p<0.01 ; n=4\right)$.

The increased nitration level does not correlate with an increased dimerization level of both $\alpha$ Syn variants. The dimerization was not influenced by nitrative stress enhancement (Figure $25 \mathrm{~A}, \mathrm{~B})$. The results suggest that nitration of aSyn contributes to the cytotoxicity of the protein, whereas dimer formation is in reverse correlation to toxicity.

\subsection{Tyrosine 133 is required for phosphorylation of $\alpha$-synuclein at serine 129}

Phosphorylation of $\mathrm{Y} 125$ is required in vitro as a priming event for efficient phosphorylation of S129 by casein kinase CK1 (Kosten et al., 2014). Phosphorylation of S129 is the major PTM of aSyn, found in $90 \%$ of the aggregated protein in neuronal inclusions of PD patients (Anderson et al., 2006). aSyn and A30P are phosphorylated at S129 in yeast by endogenous kinases and phosphorylation has a protective role against aSyn-induced toxicity and aggregate formation (Shahpasandzadeh et al., 2014; Tenreiro et al., 2014b). Given the importance of these PTM and the close proximity of serine and tyrosine residues at the Cterminus, it was assessed whether there is a cross-talk between modifications of tyrosine residues and phosphorylation of aSyn at S129 in vivo. Immunoblotting with an antibody that 
specifically recognizes aSyn phosphorylated at $\mathrm{Y} 133$ showed that both aSyn and A30P are phosphorylated at these residues, in accordance with our results from MS analysis (Figure 26A).

A

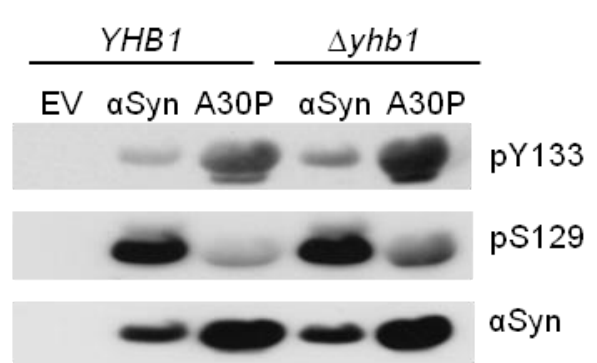

B
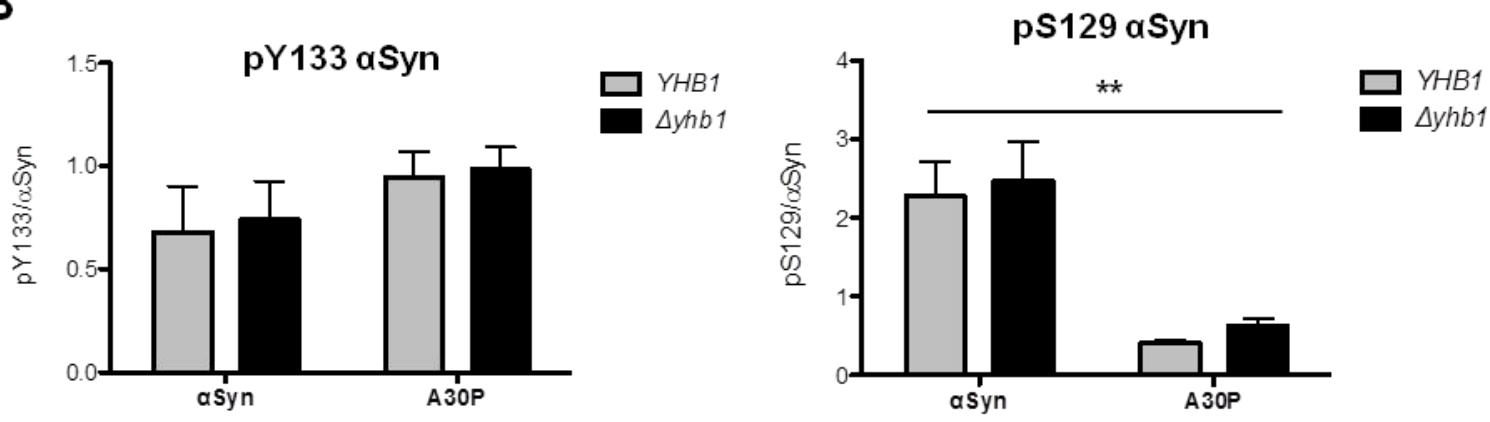

Figure 26. aSyn has a higher S129 phosphorylation level than A30P.

(A) Immunoblotting of aSyn and A30P expressed in YHB1 and $\Delta y h b 1$ yeast enriched by $\mathrm{Ni}^{2+}$ pull-down, using Y133 phosphorylation-specific aSyn antibody (pY133) and S129 phosphorylation-specific aSyn antibody (pS129). The same membrane was stripped and reprobed with aSyn antibody. (B) Quantification of aSyn and A30P Y133- and S129phosphorylation levels in YHB1 and $\triangle y h b 1$ yeast cells. Densitometric analysis of the immunodetection of pY133, pS129 aSyn and A30P relative to the intensity obtained for aSyn. Significance of differences was calculated with one-way ANOVA test $\left({ }^{* *}, p<0.01\right.$; $\mathrm{n}=4)$.

Quantification of $\mathrm{Y} 133$ phosphorylation revealed similar phosphorylation level of aSyn and A30P variant both in presence and absence of Yhb1 (Figure 26A, B). Next, it was analyzed whether there is a difference between S129 phosphorylation level of aSyn and A30P. S129 phosphorylation level of aSyn was much higher than that of A30P (Figure 26A, B).

Tyrosine to phenylalanine (Y/F) substitutions were analyzed for their effects on the phosphorylation level at S129. Y/F mutation of the $\mathrm{N}$-terminal tyrosine 39 as well as of the Cterminal Y125 and Y136 did not affect the phosphorylation status of S129 (Figure 27A). In contrast, mutation of $\mathrm{Y} 133$ had a drastic impact and resulted in complete loss of phosphorylation at S129. Yeast growth was compared in spotting assay as well as in liquid culture between yeast cells, expressing Y/F single mutants and S129A phosphorylation deficient mutant (Figure 27B, C). Yeast growth was measured after 20 hours induction of 
protein expression. Expression of $\mathrm{Y} 133 \mathrm{~F}$ resulted in significant growth inhibition in comparison with aSyn and other tyrosine mutants. S129A showed slight growth inhibition (Figure 27B, C) and significant increase in the number of cells with aggregates (Figure 27D).

A

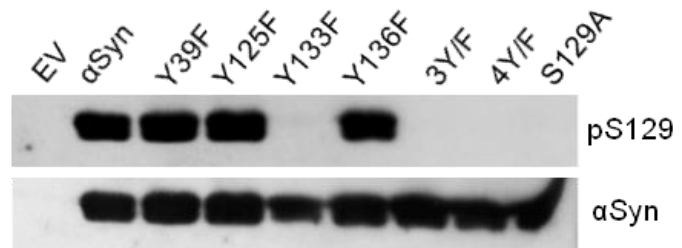

C

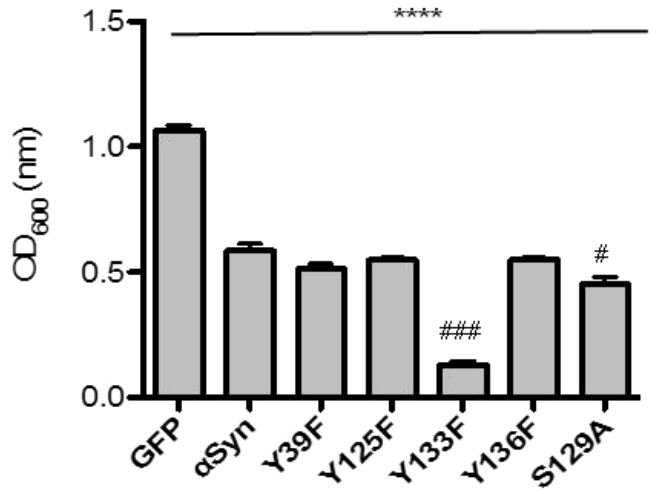

B

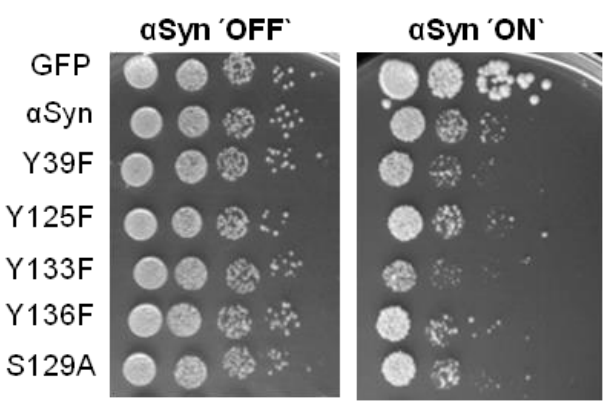

D

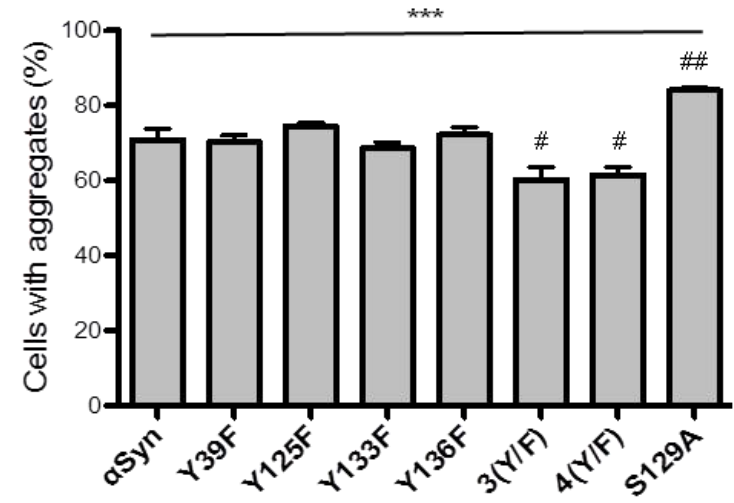

Figure 27. Tyrosine 133 is required for phosphorylation of aSyn at serine 129.

(A) Immunoblotting of crude extracts from yeast cells, expressing different aSyn variants after six hours induction of protein expression using S129 phosphorylation-specific aSyn antibody (pS129) and aSyn antibody. Cells expressing S129A mutant served as control. (B) Spotting analysis of aSyn and indicated mutant strains driven by the inducible GAL1promoter on non-inducing ('OFF': glucose) and inducing ('ON': galactose) SC-Ura medium after three days. Yeast cells overexpressing GFP served as control. (C) Cell growth analysis of cells expressing different aSyn variants and GFP (control) after 20 hours induction of expression in galactose-containing SC-Ura medium. Significance of differences was calculated with one-way ANOVA $\left({ }^{* * * *}, p<0.0001\right)$ or Dunnett's multiple comparison test $(\#, p$ $<0.05$; \#\#\#, $p<0.001, n=4$ ). (D) Quantification of the percentage of cells displaying aSyn aggregates after six hours induction in galactose-containing SC-Ura medium. Significance of differences was calculated with one-way ANOVA $\left.{ }^{* * *}, p<0.001\right)$ or Dunnett's multiple comparison test (\#, $p<0.05, \# \#, p<0.01$ versus $\alpha$ Syn; $n=6)$.

In addition to growth analysis, membrane integrity of the Y/F single mutants and S129A phosphorylation deficient mutant was examined to assess the cell viability of the mutants (Figure 28). Propidium iodide (PI) staining was used after 20 hours of protein induction as a sensitive method to determine the fraction of cells with compromised membrane integrity. 
A $\mathrm{PI}-20 \mathrm{~h}$
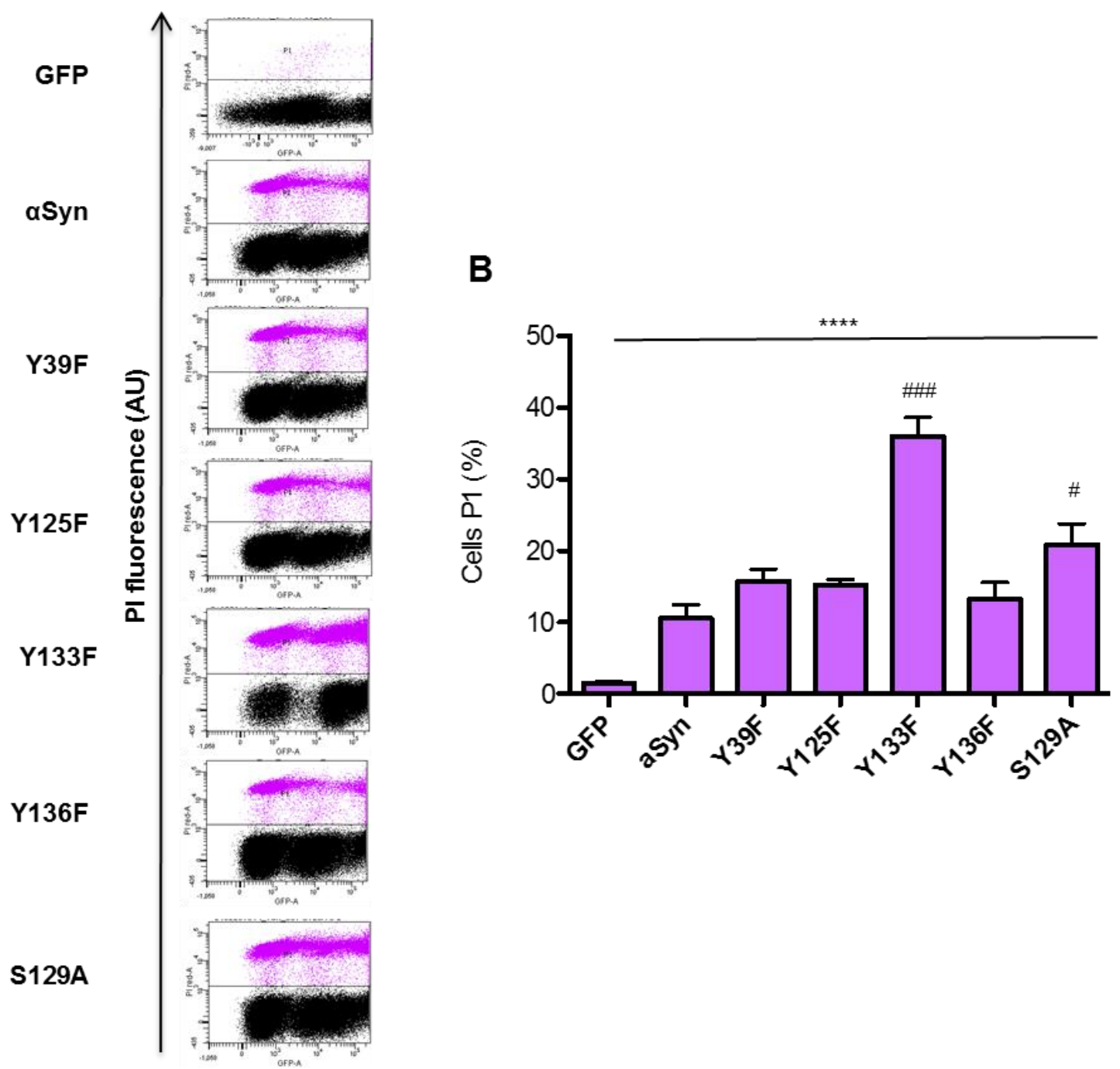

Figure 28. Y133F and S129A mutations increase aSyn-mediated cytotoxicity.

(A) Forward scatter (FSC) of cells assessed with flow cytometry analysis. Cells expressing different $\alpha$ Syn variants and GFP (control) after 20 hours induction of expression were stained with $12.5 \mu \mathrm{g} / \mathrm{mL} \mathrm{PI}$ for 30 minutes. Shown is one representative result from at least four independent experiments. (B) Quantification of cells expressing different aSyn variants and GFP (control) displaying Propidium lodide (PI) fluorescence after 20 hours induction of aSyn expression, assessed by flow cytometry. The percentage of PI-positive yeast cells with higher fluorescent intensities (P1) than the background is presented. Significance of differences was calculated with one-way ANOVA $\left({ }^{* * * *}, p<0.0001\right)$ or Dunnett's multiple comparison test (\#, $p<0.05$; \#\#\#, $p<0.001$ versus $\alpha$ Syn; $\mathrm{n}=4$ ).

Expression of Y133F and S129A significantly diminished membrane integrity, corroborating that expression of these mutants result in increased cytotoxicity. Flow cytometry measurements were performed to determine the accumulation of ROS and RNS in yeast cells, expressing the single mutants. DHR123 was used for detection of ROS (Figure 29A, C) and DAF-2 DA was used for detection of RNS (Figure 29B, D). 
A

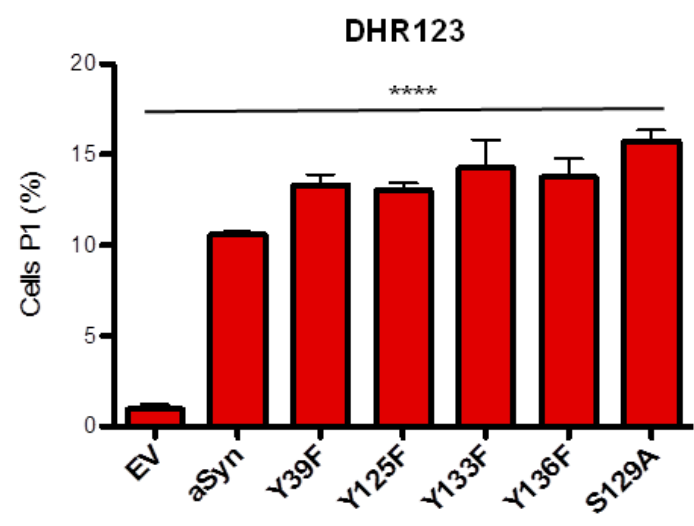

C

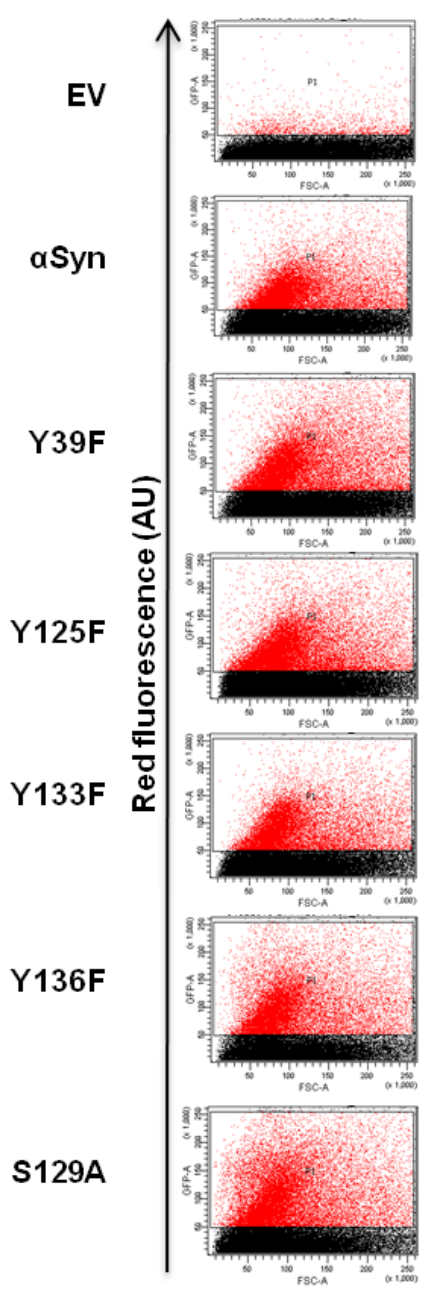

B

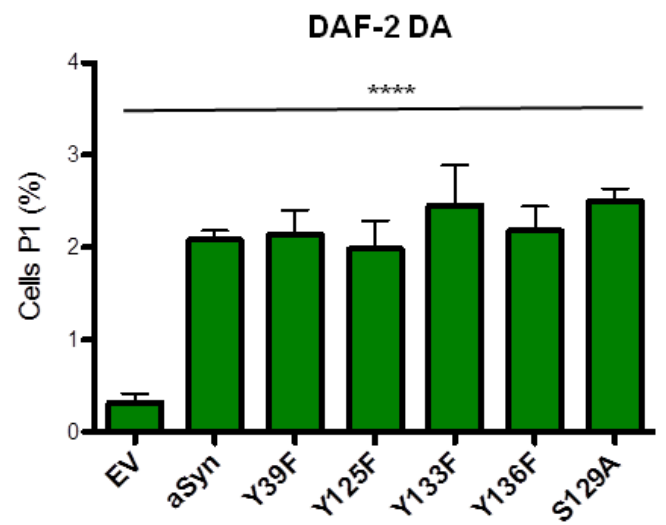

D

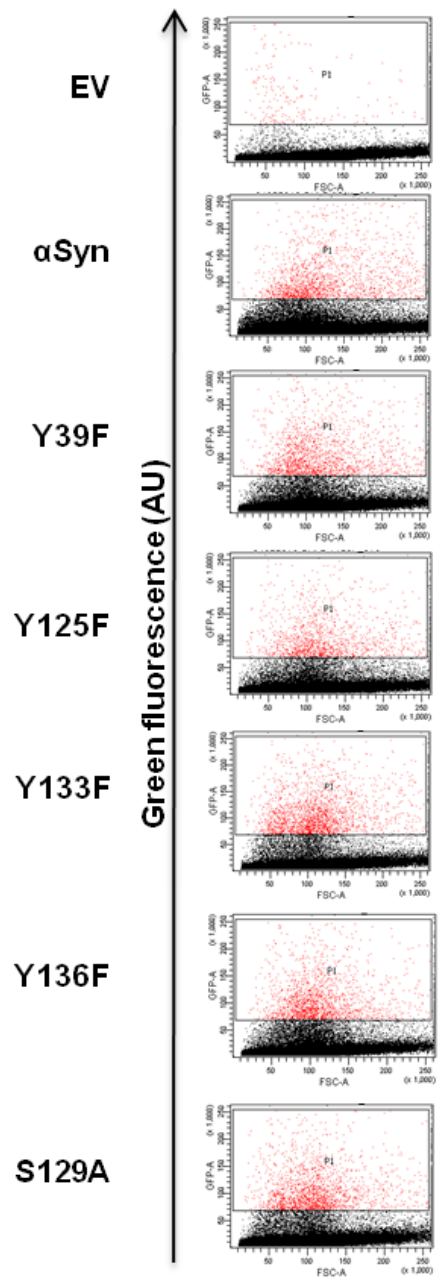

Figure 29. Tyrosine 133 mutation does not alter the accumulation of reactive oxygen and nitrogen species.

Quantification of cells expressing different aSyn variants displaying ROS (A) and RNS (B) assessed with flow cytometry analysis. aSyn expression was induced for six hours and the cells were stained for 1.5 hours with DHR123 to visualize ROS (A) and for 1.5 hours with DAF-2 DA to visualize RNS (B). Presented is the percentage of the sub-populations of yeast cells with higher fluorescent intensities (P1) than the background. Significance of differences was calculated with one-way ANOVA $\left.{ }^{* * * *}, p<0.0001 ; n=4\right) .(C, D)$ Forward scatter (FSC) of cells expressing different aSyn variants displaying DHR123 (C) and DAF-2 DA (D) fluorescence assessed with flow cytometry analysis. Shown is one representative result from at least four independent experiments. 
Expression of all mutants revealed a significant increase in the levels of ROS and RNS in comparison with the control, however, no significant differences were observed between the single mutants revealing that the enhanced toxicity of Y133F and S129A mutant is not due to higher accumulation of ROS or RNS. These results indicate that $Y 133$ is required for the protective effect of aSyn S129 phosphorylation in vivo. Expression of Y133F was more toxic than expression of the S129A phosphorylation deficient aSyn variant, suggesting additional protective contribution of Y133 modifications against aSyn cytotoxicity. The data support a complex cross-talk between nitration and phosphorylation of the C-terminal tyrosine residues and S129 phosphorylation of aSyn and A30P.

\subsection{C-terminal $\alpha$-synuclein modifications promote autophagy clearance of $\alpha$ - synuclein aggregates}

GAL1-promoter shut-off experiments were performed to study the role of aSyn PTMs on autophagy/vacuole and proteasome-mediated aggregate clearance of $\alpha$ Syn. The impact of blocking these systems by drug treatments was examined. Expression of aSyn was induced for four hours in galactose-containing medium and the cells were then shifted to glucosecontaining medium in order to repress the promoter. Cells were imaged four hours after promoter shut-off and the percentage of cells with inclusions was determined. Shut-off studies were performed with wild-type aSyn and the mutants 4(Y/F), S129A and Y133F. PMSF was used as an inhibitor of autophagy/vacuole to study the contribution of this pathway for aggregate clearance (Petroi et al., 2012). PMSF impairs the activity of many vacuolar serine proteases without interfering with proteasome function (Dubiel et al., 1992; Jones, 2002). Inhibition of autophagy resulted in inefficient aggregate clearance of aSyn, as shown previously (Petroi et al., 2012; Shahpasandzadeh et al., 2014). Mutations of the codons for the four tyrosines as well as the S129 and $\mathrm{Y} 133$ single exchanges resulted in similar aggregate clearance by inhibition of the autophagic proteases as in the control cells without drug (ethanol) (Figure 30A). This suggests that autophagy is less involved in aggregate clearance of these mutants and shows that autophagy-mediated aggregate clearance requires modifications of the tyrosines and S129.

The contribution of the proteasome on 4(Y/F), S129A and Y133F aSyn aggregate clearance was analyzed by applying the proteasome inhibitor MG132 (Lee and Goldberg, 1998). In contrast to autophagy impairment, cells expressing 4(Y/F) and S129A aSyn cleared inclusions equally as the wild-type aSyn (Figure 30B) when the proteasome system was impaired. 
A

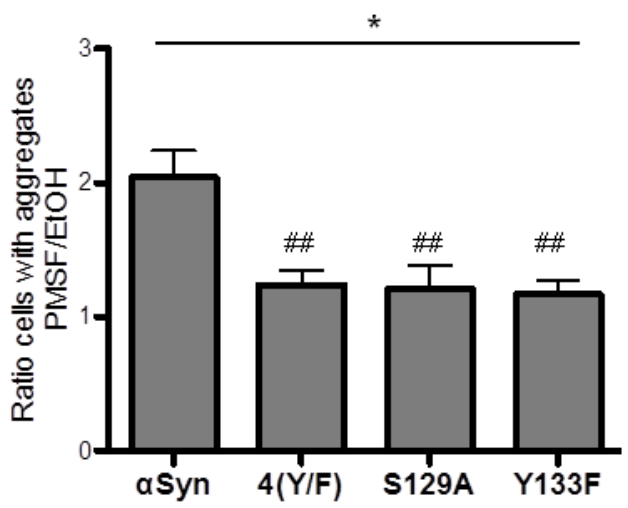

C

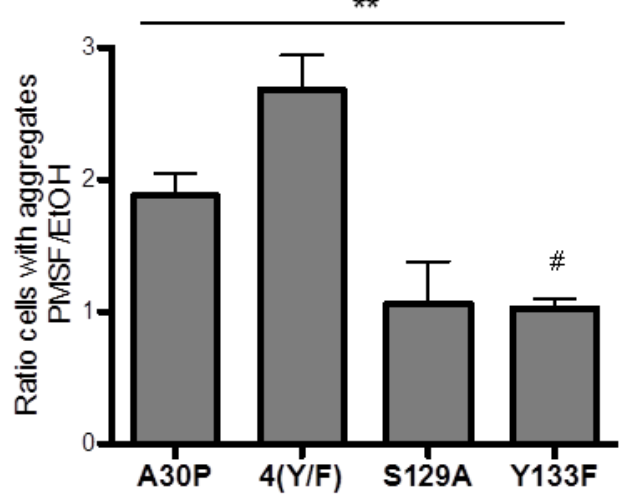

B Inhibition of proteasome

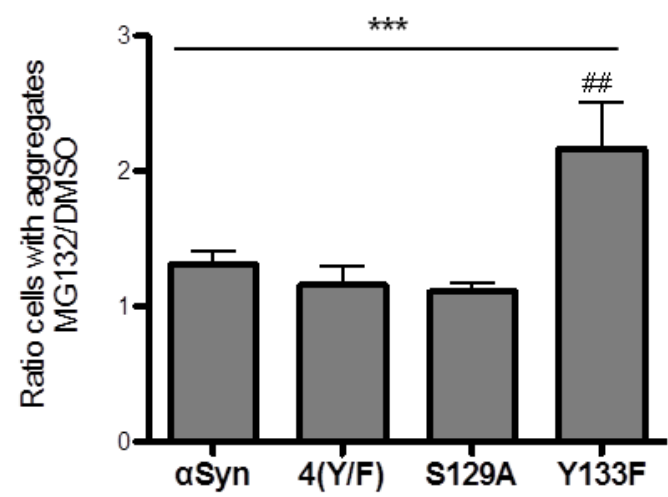

D

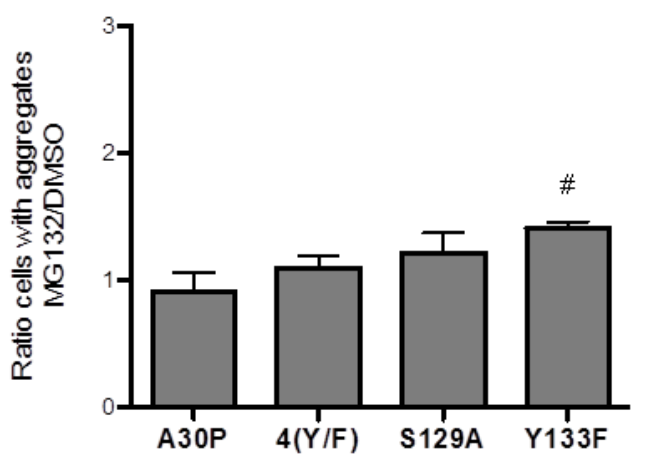

Figure 30. aSyn aggregate clearance after promoter shut-off.

$(A, C)$ Quantification of cells displaying aggregates of aSyn $(A)$ and A30P $(C)$ upon inhibition of autophagy by PMSF. Cells expressing aSyn (A) or A30P (C) and its 4(Y/F), S129A and Y133F variants were incubated in $2 \%$ galactose-containing media for four hours and shifted to $2 \%$ glucose-containing media supplemented with $1 \mathrm{mM} \mathrm{PMSF}$ dissolved in $\mathrm{EtOH}$ and only $\mathrm{EtOH}$ as a control. Cells with aggregates were counted after four hours GAL1-promoter shutoff and presented as ratio to the control $(\mathrm{EtOH})$. Significance of differences was calculated with one-way ANOVA $\left({ }^{*}, p<0.05 ;{ }^{* *}, p<0.01\right)$ or Dunnett's multiple comparison test $(\#, p<$ 0.05 ; \#\#, $p<0.01$ versus aSyn; $n=4)$. (B, D) Quantification of cells displaying aggregates of aSyn (B) and A30P (D) upon inhibition of the proteasome by MG132. Cells expressing aSyn (B) or A30P (D) and the indicated 4(Y/F), S129A and Y133F variants were incubated in $2 \%$ galactose-containing media for four hours and shifted to glucose medium, supplemented with $75 \mu \mathrm{M}$ MG132 dissolved in DMSO or only DMSO as a control. Cells with aggregates were counted after four hours GAL1-promoter shut-off and presented as ratio to the control (DMSO). Significance of differences was calculated with one-way ANOVA ( $\left.{ }^{* *}, p<0.001\right)$ or Dunnett's multiple comparison test (\#, $p<0.05$; \#, $p<0.01$ versus $\alpha$ Syn; $n=4)$.

These results corroborate previous findings showing a minor contribution of proteasomedependent clearance of aSyn aggregates (Petroi et al., 2012). However, cells expressing the Y133F mutant were unable to clear inclusions in a same manner as the wild-type, 4(Y/F) and S129A aSyn. This indicates that aSyn, which is not modified at $Y 133$, is degraded by the proteasomal pathway. The results suggest that PTMs of tyrosine residues and S129 promote 
the autophagy mediated aggregate clearance, whereas non-modified $Y 133$ residue is a key determinant for the targeting of the protein to the proteasome. Inhibition of autophagy of $\mathrm{A} 30 \mathrm{P}$ expressing cells revealed diminished clearance of aggregates of $\mathrm{A} 30 \mathrm{P}$ as well as the $\mathrm{A} 30 \mathrm{P} / 4(\mathrm{Y} / \mathrm{F})$ mutant indicating that degradation of the $\mathrm{A} 30 \mathrm{P} / 4(\mathrm{Y} / \mathrm{F})$ aggregates depends on the autophagy/vacuole system similarly to wild-type aSyn and A30P (Figure 30C). A30P/S129A and A30P/Y133F mutants were able to degrade aggregates efficiently upon autophagy inhibition, similar to S129A and Y133F. Proteasome impairment resulted in inefficient clearance of the A30P/Y133F mutant (Figure 30D). However, this impact was not as strong as in the aSyn Y133F mutant, confirming that the wild-type aSyn is strongly dependent on $\mathrm{Y} 133$ modification as a determinant for aggregate clearance. 


\section{Discussion}

In industrialized countries, better nutrition, growing health awareness and less heavy physical work result in improved quality of life. In addition, medical advances such as novel drugs, novel ways of diagnostic, preventive medicine and technological progress lead to increased life expectancy. However, extended life span correlates with an elevated risk for neurodegenerative disorders resulting in physical or mental impairments and a long period of suffering. Up to now, no curative therapies are available because most of the pathogenic causes are unknown. Therefore, study of human neurodegenerative diseases such as Parkinson's disease (PD) is becoming increasingly important.

The small neuronal protein aSyn is thought to be one of the most crucial factors in the pathogenesis of PD. aSyn is an intrinsically unfolded brain protein of 140 amino acids which is present in high concentration at presynaptic terminals as soluble or membrane-associated fractions. It is the major component of the fibrillary intracellular protein inclusions termed Lewy bodies that are associated with selective loss of dopamine-producing neurons in the substantia nigra in PD. Among other factors, posttranslational modifications were observed to alter the aggregation propensities of aSyn.

In this study, Saccharomyces cerevisiae was used as reference cell to study the function of posttranslational modifications such as nitration or phosphorylation on the toxicity of aSyn. Apart from understanding the behavior of aSyn in PD, this model system is also used for identification of new therapeutic strategies. When expressed in yeast, aSyn associates with the plasma membrane in a highly selective manner, before forming cytoplasmic inclusions through a concentration-dependent process (Outeiro and Lindquist, 2003; Petroi et al., 2012). aSyn accumulations, further referred to as aggregates, cause vesicle traffic defects, proteasome dysfunction, mitochondrial activity impairment and damage to cellular membranes. These cellular disorders in yeast are reminiscent to aSyn-related effects of PD (Chen et al., 2005; Outeiro and Lindquist, 2003).

Chemical reactive molecules such as reactive oxygen species (ROS) and reactive nitrogen species (RNS) are formed that damage the cell by causing oxidative and nitrative stress. Both cellular stresses are implicated in the pathogenesis of PD. Previous studies indicated that oxidative injury of aSyn, specifically nitration of tyrosine residues, contributes directly to the pathology of PD. However, the toxic mechanism involved in nitrative stress-induced damage or even the precise nitration sites leading to toxicity are not sufficiently examined. 


\subsection{Role of tyrosine nitration on $\alpha$-synuclein cytotoxicity}

In aSyn four tyrosines sites were discovered that serve as targets of nitration (Sevcsik et al., 2011). One is located in the membrane binding $\mathrm{N}$-terminus at residue 39 , and three near the C-terminus at residues 125, 133 and 136. All four tyrosines can be nitrated in the presence of oxidizing agents such as peroxynitrite (PON). These modifications lead to the accumulation of stable oligomers originating from covalent crosslinking through the formation of di-tyrosine species (Souza et al., 2000a).

Several examples in the literature indicate a contribution of aSyn nitration in aggregation and aSyn-related neuronal vulnerability and suggest an implication of nitrative stress in the pathogenic mechanism of PD (Giasson et al., 2000; Jenner and Olanow, 1996; McCormack et al., 2012; Olanow, 1990; Souza et al., 2000a; Yao et al., 2004). Nitrated aSyn was detected in LBs from post mortem brain tissue using 3-nitrotyrosine antibodies (Giasson et al., 2000). It has been observed that nitrated aSyn can be toxic to dopaminergic neurons in vitro as well as in vivo (Yu et al., 2010). Neuroinflammation followed by nitration of aSyn causes accumulation of aSyn aggregates and neurodegeneration in mice (Gao et al., 2008). Nitrated aSyn was observed to induce adaptive immune responses that exacerbate PD pathology in the MPTP mouse model (Benner et al., 2008). Increased nitrated aSyn levels were detected in peripheral blood mononuclear cells of idiopathic PD patients compared to healthy individuals (Prigione et al., 2010). There might be a direct link between nitrative damage and the onset and progression of neurodegenerative synucleinopathies, but the precise molecular mechanism that leads to the formation of pathological inclusions is still elusive. Concluding these evidences, oxidative and nitrative stress plays an important role in aSyn induced cytotoxicity and consequently in the pathogenesis of PD.

Phosphorylation at serine residue $\mathrm{S} 129$ represents the major protective phosphorylation site of aSyn, which is conserved from man to the baker's yeast as a eukaryotic Morbus Parkinson cell model. The effect of nitrative modifications of aSyn and their contribution towards aSyninduced cytotoxicity was investigated. A complex interplay was discovered between modifications of the C-terminal tyrosine residues and S129 phosphorylation (Figure 31). These tyrosine residues of aSyn can be phosphorylated or nitrated with drastic consequences for cellular growth. There is a strong preference of the C-terminus of aSyn for nitration or di-tyrosine formation. Nitration interferes with protective phosphorylation of S129, whereas di-tyrosine formation protects yeast cells. 


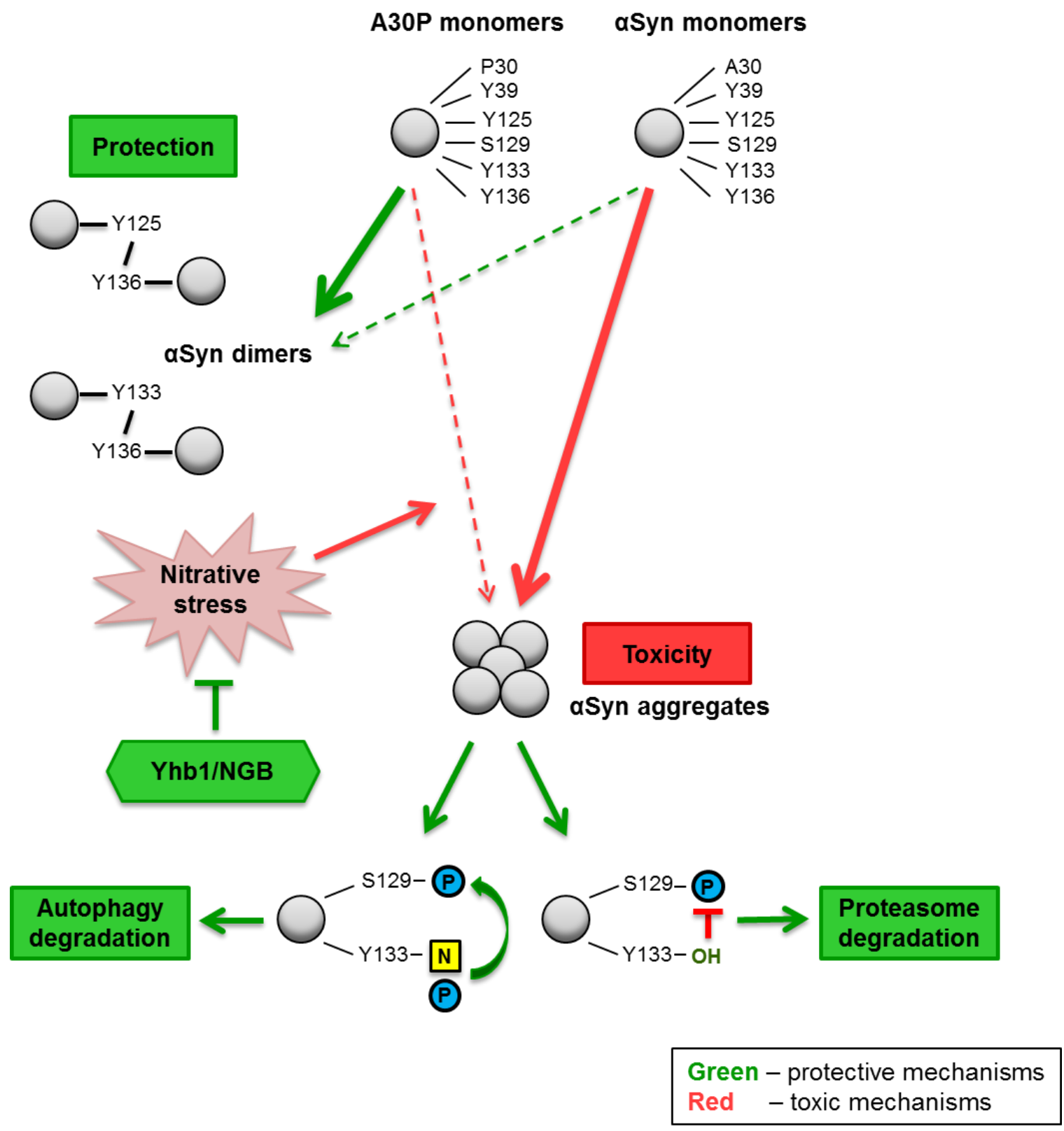

Figure 31. aSyn posttranslational modifications and nitrative stress in yeast.

Enhanced intracellular nitrative stress increases the protein nitration level and influences yeast growth and aggregation. The nitration of tyrosine residues acts as trigger for aSyn and A30P toxicity. Wild-type aSyn, which is highly nitrated, inhibits growth and shows a high aggregation rate. A30P is weakly nitrated and therefore, does not inhibit yeast growth and has a low aggregation propensity. Yhb1 and its human homolog NGB protect the cells against accumulation of nitrative species and diminish the aggregate formation. Increased aggregation contributes to ROS/RNS accumulation and mitochondrial fragmentation. Dityrosine crosslinked dimers are formed in reverse correlation to cytotoxicity and do not depend on Yhb1. A30P forms twice as many dimers as the toxic aSyn variant, suggesting that the di-tyrosine crosslinked dimers are not toxic species and are presumably part of a cellular detoxification pathway, sequestering the protein off-pathway of aSyn nucleation. The C-terminal tyrosine modifications have dual effect on the toxicity of the protein. Y133, which is nitrated and phosphorylated, is required for the protective phosphorylation at $\$ 129$ and for the autophagy degradation of aSyn aggregates. Non-modified Y133 promotes the proteasomal degradation of $\alpha$ Syn aggregates. N: nitration; P: phosphorylation. 
Expression of aSyn in yeast induces a number of cellular defects and efficiently mimics the aSyn-related effects of PD (Chen et al., 2005; Outeiro and Lindquist, 2003; Zabrocki et al., 2005). Among others, chemically reactive molecules such as ROS and RNS are formed that damage the cell by causing oxidative and nitrative stress which in turn contributes to cell death (Flower et al., 2005). Nitration reduces the binding affinity of aSyn to lipid vesicles and therefore disrupts aSyn-membrane interaction (Sevcsik et al., 2011). Hodora and colleagues concluded that nitration hinders aSyn to bind membrane lipids leading to increased unbound aSyn, which results in enhance of intracellular aggregates (Hodara et al., 2004).

Oxidative injury of aSyn, specifically nitration of tyrosine residues, has been widely discussed to contribute directly to the pathology of PD. Nitrative stress was proposed to induce aSyn aggregation as well as aSyn-induced pathology (Benner et al., 2008; Giasson et al., 2000; Liu et al., 2011; Paxinou et al., 2001; Ulrih et al., 2008; Yu et al., 2010). However, also opposing influence of nitrated aSyn has been shown (Uversky et al., 2005; Yamin et al., 2003b). Thus, the effect of nitrative aSyn modifications and their influence on the toxicity and aggregation of aSyn is still controversial. In this study, it was shown that PTMs on aSyn tyrosine residues have a dual impact on aSyn mediated growth inhibition of yeast cells (Figure 31). Previous studies suggested that nitration of aSyn might be responsible for the formation of the proteinaceous inclusions observed in PD brains and for the neuronal loss in the substantia nigra (Giasson et al., 2000; Yu et al., 2010). Here, it was shown that nitration increases the growth defect induced by aSyn in yeast cells. Tyrosine nitration increases aggregation, mitochondrial fragmentation and growth inhibition. A correlation between the growth impairment, mediated by $\alpha$ Syn and A30P and their nitration level was demonstrated. aSyn, which inhibits yeast growth and has a high aggregation level, is strongly nitrated. In contrast, A30P, which is not toxic to yeast and aggregates to a lesser extent, is weakly nitrated. Increased nitration of $\mathrm{A} 30 \mathrm{P}$ as a consequence of $\mathrm{YHB1}$ deletion leads to A30Pinduced toxicity in yeast cells, which indicates that nitration is able to convert a non-toxic to toxic specie.

\subsection{Role of Yhb1 and neuroglobin on a-synuclein cytotoxicity}

Expression of A30P in yeast has different toxicity properties from wild-type aSyn (Outeiro and Lindquist, 2003; Petroi et al., 2012). A30P is located in the cytoplasm, whereas aSyn is delivered to the plasma membrane. Overexpression from a high-copy number plasmid results in formation of $\mathrm{A} 30 \mathrm{P}$ fluorescent foci, however, the aggregation is transient and yeast cell growth is not affected. In Saccharomyces cerevisiae, the gene YHB1 (yeast flavohemoglobin) was identified to be implicated in oxidative and nitrative stress response (Cassanova et al., 2005). This gene encodes a nitric oxide oxidoreductase that belongs to 
the globin family. Yhb1 protects against nitration of cellular targets by NO detoxification (Liu et al., 2000) and was also shown to be involved in the control of ferric reductase activity and modulation of NO signaling pathways (Lewinska and Bartosz, 2006; Martinez-Ruiz and Lamas, 2009; Schildknecht and Ullrich, 2009). Using the $\Delta y h b 1$ mutant lacking the flavohemoglobin Yhb1, this study could demonstrate that nitration plays also a role for A30P and confirmed that nitration increases aggregation and growth inhibition (Figure 31). Yhb1 decreases the nitration level of the A30P variant of aSyn by reducing the accumulation of reactive nitrogen species, with the result that yeast cells can tolerate increased levels of this aSyn variant without significant growth inhibition. Deletion of the $Y H B 1$ yeast gene results in deficient cellular detoxification machinery towards $\mathrm{NO}$ and makes A30P as toxic as wild-type aSyn. This shows that the A30P nitration level is a crucial factor for gaining toxicity. Consequently, elimination of its putative NO-detoxifier Yhb1 results in stronger formation of toxic aSyn aggregates. Yhb1 reduced the level of nitrative stress in A30P expressing cells. Moreover, Yhb1 protected the A30P-expressing cells from mitochondrial fragmentation. aSyn-induced fragmentation of mitochondrial structure caused by direct interaction of aSyn with the mitochondrial membranes was already demonstrated (Nakamura et al., 2011). It was proposed that ROS accumulation induced by aSyn expression is an indirect effect due to mitochondrial dysfunction (Su et al., 2010). A connection between increased nitrative stress and mitochondrial fragmentation was found. This suggests a mechanistic model based on the specific ability of aSyn and A30P to form aggregates and damage mitochondria induced by nitrative stress.

A protein BLAST search for human homologues of yeast YHB1 identified similarity of Yhb1 to human neuroglobin (Figure 32).

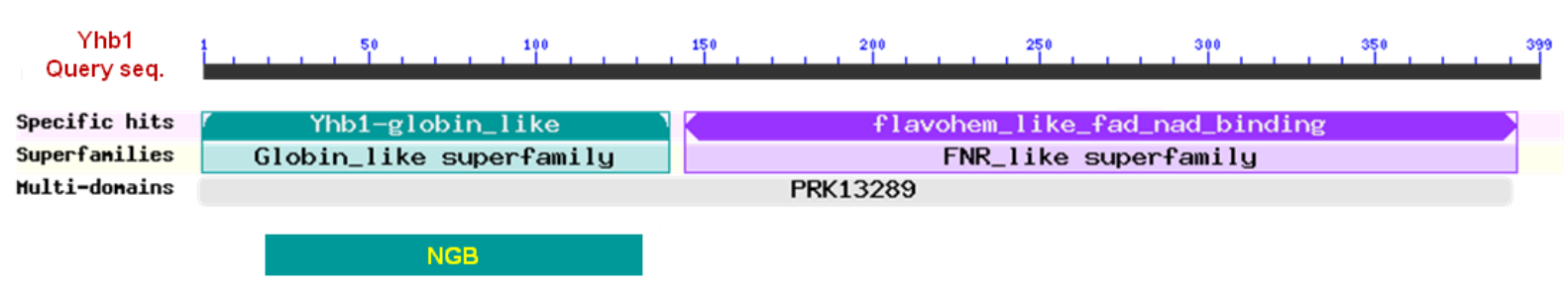

Figure 32. Putative conserved domain of Yhb1 and NGB.

Yhb1 amino acid sequence was used as query sequence (seq.) and analyzed by the blastp tool using UniProtKB/Swiss-Prot as database. The human neuroglobin (NGB) was identified as a hit with a score of 60.1 bits and an $E$ value of $5 e-11,28 \%$ identity and $49 \%$ similarities in the globin domain of Yhb1.

Analysis of neuroglobin (NGB), the human homologue of $Y H B 1$, in human cell lines (H4 cells) confirmed that this protein modulates aSyn aggregation. Expression of neuroglobin in mammalian cells reduced the number inclusions per cell. The yeast nitric oxidoreductase 
Yhb1 as well as its related human protein neuroglobin play protective roles against aSyn aggregation. Similar as Yhb1, NGB is a member of the globin family. In general, neuroglobins play a role as regulators of ROS, reservoir for oxygen, facilitator for oxygen transport and also acts as scavenger of nitric oxide. In human, neuroglobin is expressed primarily in neurons and protects against hypoxic neuronal death and ischemic brain injury (Wang et al., 2008). Furthermore, expression of neuroglobin protects against beta-amyloidinduced neurotoxicity in transgenic mice in vivo (Khan et al., 2007). Increased neuroglobin levels were observed in brain tissue of patients with early and moderately advanced Alzheimer's disease (AD) (Sun et al., 2013). Recent reports revealed that overexpression of neuroglobin prevents tau hyperphosphorylation at multiple AD-related sites (Chen et al., 2012). These data support our findings and imply NGB as a new therapeutic target in PD and other neurodegenerative diseases.

\subsection{Dimerization of $\alpha$-synuclein by covalent di-tyrosine crosslinking}

Beside nitration, the reaction between tyrosine and RNS can result in the formation of dityrosine bonds, leading to the formation of stable aSyn oligomers, including dimers and higher oligomeric structures. At low peroxynitrite level, di-tyrosine formation outcompetes the reaction of tyrosine nitration (Pfeiffer et al., 2000; Schildknecht et al., 2013) indicating a forced reaction to tyrosine nitration under nitrative stress. This study observed formation of dimers and oligomers in vivo without exposure of yeast cells to nitrating agents; therefore, they represent the consequence of endogenous nitrative stress. Previous studies already demonstrated nitration-induced oligomerization of aSyn (Norris et al., 2003; Souza et al., 2000a). There, treatment with nitrating agent resulted in the formation of aSyn dimers and oligomers crosslinked by di-tyrosine bonds. Using MS, this study characterized the tyrosine residues involved in covalent dimer formation and nitration and identified to what extend the different tyrosine residues are involved in the di-tyrosine formation and what are the precise positions of the respective tyrosines. This data is the first characterization of aSyn dimer species, formed in vivo and without additional exposure to nitrative agents.

The LC-MS results reveal strong preference of the C-terminal tyrosine residues for dimer formation with predominant forms including Y136 interacting either with Y125 (Y125-Y136) or with Y133 (Y133-136). Y39 was hardly involved in dimer formation under physiological conditions in yeast or in vitro after PON treatment. Recently, in vitro studies on aSyn oligomerization and di-tyrosine formation upon treatment with tetranitromethane (TMN) demonstrate a predominant formation of di-tyrosine dimers when Y39 is not available for nitration (Y39F) and suggest that the $\mathrm{N}$-terminal region of aSyn plays a role in $\mathrm{TMN}$-induced di-tyrosine formation of higher order oligomers (Burai et al., 2015). Previous studies 
described an increase of nitration at $\mathrm{Y} 39$ of aSyn in an oxidative cellular model of PD (Danielson et al., 2009), whereas data of this study reveal resistance of Y39 to 3-NT modification in comparison to the C-terminal tyrosine residues which are nitrated in vitro as well as in vivo. These results are corroborated by previous findings, where treatment of purified aSyn with PON did not result in nitration of Y39; however, all C-terminal residues were nitrated (Schildknecht et al., 2011).

Higher nitration levels of aSyn compared to A30P were also detected by LC-MS data confirming the results from immunoblot analyses. There, only one tyrosine residue is nitrated in A30P, whereas three aSyn residues are nitrated. These data reveal that aSyn dimers originating from di-tyrosine crosslinking are non-toxic species in contrast to nitrated aSyn (Figure 31). Covalent bonding of the di-tyrosines stabilizes the dimeric structures and consequently removes aSyn molecules from aggregation to toxic aggregates. aSyn protein lacking all four tyrosine residues forms less aggregates, however, the aggregate formation is not prevented. This indicates that tyrosine residues are not crucial for in vivo assembly of the protein to aggregates and suggests an independent pathogenic mechanism of aSyn aggregation. Similarly, nitration of aSyn was shown to promote formation of stable offpathway oligomeric species that inhibit aSyn fibrillation (Uversky et al., 2005; Yamin et al., 2003b). Thus, the formation of stable oligomers under oxidative stress conditions redirects the monomers to oligomers that do not contribute to fibril formation.

\subsection{Interplay between tyrosine nitration and serine 129 phosphorylation of $\alpha$ - synuclein in yeast}

This study revealed that C-terminal tyrosine 133 is required for the protective phosphorylation of aSyn at S129. aSyn C-terminal tyrosines Y125, Y133 and Y136 are in close proximity to $\mathbf{S 1 2 9}$, which raises the question whether there is an interplay between different PTMs at these residues. S129-phosphorylated aSyn is abundantly found in LBs (Anderson et al., 2006; Fujiwara et al., 2002). This phosphorylation site is conserved in yeast and can be used by several endogenous kinases (Wang et al., 2012). The effects of S129 phosphorylation are complex and the role of this modification on aSyn-induced toxicity and aggregation is still controversial (Tenreiro et al., 2014a). Phosphorylation of S129 was shown to play a role in the regulation of aSyn localization, aggregation and toxicity. Several mammalian models of PD have demonstrated a protective role of S129 phosphorylation on neuronal dysfunction (Gorbatyuk et al., 2008; Kuwahara et al., 2012). Contrary, neurotoxicity tests in rats revealed no protective role of S129 phosphorylation on aSyn toxicity (McFarland et al., 2009). Even a pathogenic effect of aSyn S129 phosphorylation was observed (Chen and Feany, 2005). 
In yeast, S129 phosphorylation has a protective role against growth impairment and aggregate formation (Popova et al., 2015; Shahpasandzadeh et al., 2014; Tenreiro et al., 2014b). Moreover, increased phosphorylation of aSyn mediated by PLK2 leads to aggregate clearance by the autophagy-vacuole system and suppresses cytotoxicity (Oueslati et al., 2013). Further yeast studies revealed that autophagy-dependent clearance of aSyn aggregates is stimulated by sumoylation of aSyn (Shahpasandzadeh et al., 2014). Inhibition of sumoylation results in increased toxicity, impaired autophagic clearance as well as in redirection of the aSyn aggregates to the proteasome. Expression of the human kinase GRK5 in yeast results in increased phosphorylation and ubiquitination of non-sumoylated aSyn, which promotes the autophagy- and proteasome-mediated clearance of aSyn aggregates. Further studies in yeast showed downregulation of aSyn aggregate clearance and increased toxicity by inhibition of S129 phosphorylation using the S129A mutant of aSyn (Tenreiro et al., 2014b).

Phosphorylation of the tyrosine residues of aSyn is less explored and the effects of this modification are still unclear, varying from protective to no impact on neurotoxicity and oligomerization (Chen et al., 2009; Ellis et al., 2001; Kosten et al., 2014; Nakamura et al., 2002; Nakamura et al., 2001; Negro et al., 2002; Papay et al., 2002). This study shows for the first time that tyrosine 133 is strictly required for phosphorylation at S129 in yeast. Tyrosine 133 can be nitrated or phosphorylated, as demonstrated by immunoblot analysis and MS analysis. These two PTMs might have opposing roles on the cellular toxicity of the protein. Phosphorylation might prevent tyrosine residues from nitration and vice versa. In this study, tyrosine to phenylalanine exchanges that abolishes both phosphorylation and nitration were used. There are no protective mechanisms exist in the cell, which do not depend on aggregate formation but support cellular survival. This suggests an even more complicated interplay between different aSyn modifications.

Recently, the role of site-specific nitration of aSyn was investigated using site-specifically nitrated synthetic proteins at Y39 and Y125 (Burai et al., 2015). The authors assessed the influence of nitration at Y125 and Y39 on PLK3-mediated in vitro phosphorylation at S129 and showed that tyrosine nitration does not prevent recognition of the protein by PLK3 and the subsequent phosphorylation at S129. These results strengthen the link between the Cterminal tyrosine and serine modifications, revealing a complex cross-talk between PTMs with different contributions to the cytotoxicity of aSyn (Figure 31).

Previously, it was shown that autophagy is the major pathway for aggregate clearance in yeast (Petroi et al., 2012). The phosphorylation state of aSyn influences the clearance mechanism of the protein. Blocking of $\mathbf{S 1 2 9}$ phosphorylation in yeast leads to impaired aggregate clearance by autophagy (Tenreiro et al., 2014b). Increased levels of S129 phosphorylation can suppress the defect of impaired aSyn sumoylation by rescuing the 
autophagic aggregate clearance and promoting the proteasomal clearance of aSyn (Shahpasandzadeh et al., 2014).

In this study, it was shown that posttranslational modifications of the four tyrosine residues, similar to S129 phosphorylation, promote the autophagic clearance of aSyn aggregates. Inhibition of autophagy rendered yeast cells unable to clear aSyn aggregates, however had no effect on the clearance of S129A, 4(Y/F) and Y133F mutants. Interestingly, Y133F mutant could not be degraded upon inhibition of the proteasome. Therefore, Y133 represents a key determinant for the degradation fate of aSyn. Phospho- and nitro-modifications at Y133 promote the autophagic clearance of the aggregates, whereas the non-modified Y133 protein is directed to the proteasomenatural amino acids that mimic the phosphorylation or nitration state of the tyrosine residue, thus restricting the investigation of the contribution of a single posttranslational modification at one and the same tyrosine residue in vivo. These results reveal Y133 as major tyrosine phosphorylation site in yeast, and only insignificant phosphorylation at Y125 was observed. This study reveals a correlation between tyrosine nitration and the cellular S129 phosphorylation level (Figure 31).

The wild-type aSyn has significantly higher nitration levels as well as increased protein populations with $\mathrm{S} 129$ phosphorylation but similar levels of $\mathrm{Y} 133$ phosphorylation when compared to its $\mathrm{A} 30 \mathrm{P}$ variant. These results suggest that rather nitration than phosphorylation at Y133 promotes S129 phosphorylation in yeast. Alternatively, nitration at Y133 might change the protein conformation and make S129 more accessible for protein kinases. The protective effect of $\mathrm{Y} 133$ was not accompanied with changes in the potential to form aggregates. The discrepancy between the clear protective effect of $Y 133$ on yeast growth without significant effect on inclusion formation suggests that additional yet elusive protective mechanisms exist in the cell, which do not depend on aggregate formation but support cellular survival. This suggests an even more complicated interplay between different aSyn modifications.

\subsection{C-terminal tyrosine residue modifications modulate $\alpha$-synuclein toxicity in yeast as unicellular model for Parkinson's disease}

The main goal in today's PD research is the discovery of the pathogenic mechanism causing PD which may help to find a cure for the disease. aSyn aggregation and formation of aSyn oligomeric species have been prososed as one of the pathophysiological mechanisms that participates in neurodegeneration. Therefore, studies uncovering the conditions leading to aSyn aggregation and toxicity are urgently required. In this study, nitration and phosphorylation of aSyn were analyzed. It was demonstrated that tyrosine nitration is not required for aggregate formation but is neccessary for covalently crosslinking of dimers and 
oligomers. The data reveal that nitration rather that dimer formation correlates with increased toxicity leading to mitochondrial fragmentation. Moreover, this study discloses a complex interplay between nitration and phosphorylation of aSyn C-terminal residues, deeply interconnected with nitrative stress, which determines the aggregate clearance by autophagy or ubiquitin-dependent $26 \mathrm{~S}$ proteasome pathways. The proposed model derived from yeast as unicellular eukaryotic cell provides interesting hints and insights for the study of aSyn posttranslational communications as it happens in the human brain and its connection to oligomer or aggregate formation and clearance (Figure 31). Furthermore, this study suggests the human NGB as a modulator of aSyn aggregation, which can be used to gain a deeper understanding into the cellular processes that trigger aSyn aggregation in human cells. 


\section{References}

Abeliovich, A., Schmitz, Y., Farinas, I., Choi-Lundberg, D., Ho, W.H., Castillo, P.E., Shinsky, N., Verdugo, J.M., Armanini, M., Ryan, A., Hynes, M., Phillips, H., Sulzer, D. and Rosenthal, A. (2000) Mice lacking alpha-synuclein display functional deficits in the nigrostriatal dopamine system. Neuron, 25, 239-252.

Ahn, B.H., Rhim, H., Kim, S.Y., Sung, Y.M., Lee, M.Y., Choi, J.Y., Wolozin, B., Chang, J.S., Lee, Y.H., Kwon, T.K., Chung, K.C., Yoon, S.H., Hahn, S.J., Kim, M.S., Jo, Y.H. and Min, D.S. (2002) alpha-Synuclein interacts with phospholipase $D$ isozymes and inhibits pervanadate-induced phospholipase D activation in human embryonic kidney-293 cells. $J$ Biol Chem, 277, 12334-12342.

Ahn, M., Kim, S., Kang, M., Ryu, Y. and Kim, T.D. (2006) Chaperone-like activities of alphasynuclein: alpha-synuclein assists enzyme activities of esterases. Biochem Biophys Res Commun, 346, 1142-1149.

Alam, Z.I., Daniel, S.E., Lees, A.J., Marsden, D.C., Jenner, P. and Halliwell, B. (1997a) A generalised increase in protein carbonyls in the brain in Parkinson's but not incidental Lewy body disease. J Neurochem, 69, 1326-1329.

Alam, Z.I., Jenner, A., Daniel, S.E., Lees, A.J., Cairns, N., Marsden, C.D., Jenner, P. and Halliwell, B. (1997b) Oxidative DNA damage in the parkinsonian brain: an apparent selective increase in 8-hydroxyguanine levels in substantia nigra. J Neurochem, 69, 1196-1203.

Anderson, J.P., Walker, D.E., Goldstein, J.M., de Laat, R., Banducci, K., Caccavello, R.J., Barbour, R., Huang, J., Kling, K., Lee, M., Diep, L., Keim, P.S., Shen, X., Chataway, T., Schlossmacher, M.G., Seubert, P., Schenk, D., Sinha, S., Gai, W.P. and Chilcote, T.J. (2006) Phosphorylation of Ser-129 is the dominant pathological modification of alphasynuclein in familial and sporadic Lewy body disease. J Biol Chem, 281, 29739-29752.

Appel-Cresswell, S., Vilarino-Guell, C., Encarnacion, M., Sherman, H., Yu, I., Shah, B., Weir, D., Thompson, C., Szu-Tu, C., Trinh, J., Aasly, J.O., Rajput, A., Rajput, A.H., Jon Stoessl, A. and Farrer, M.J. (2013) Alpha-synuclein p.H50Q, a novel pathogenic mutation for Parkinson's disease. Mov Disord, 28, 811-813.

Arawaka, S., Wada, M., Goto, S., Karube, H., Sakamoto, M., Ren, C.H., Koyama, S., Nagasawa, H., Kimura, H., Kawanami, T., Kurita, K., Tajima, K., Daimon, M., Baba, M., Kido, T., Saino, S., Goto, K., Asao, H., Kitanaka, C., Takashita, E., Hongo, S., Nakamura, T., Kayama, T., Suzuki, Y., Kobayashi, K., Katagiri, T., Kurokawa, K., Kurimura, M., Toyoshima, I., Niizato, K., Tsuchiya, K., Iwatsubo, T., Muramatsu, M., Matsumine, H. and Kato, T. (2006) The role of G-protein-coupled receptor kinase 5 in pathogenesis of sporadic Parkinson's disease. J Neurosci, 26, 9227-9238.

Athanassiadou, A., Voutsinas, G., Psiouri, L., Leroy, E., Polymeropoulos, M.H., Ilias, A., Maniatis, G.M. and Papapetropoulos, T. (1999) Genetic analysis of families with Parkinson disease that carry the Ala53Thr mutation in the gene encoding alpha-synuclein. Am J Hum Genet, 65, 555-558.

Auluck, P.K., Caraveo, G. and Lindquist, S. (2010) alpha-Synuclein: membrane interactions and toxicity in Parkinson's disease. Annu Rev Cell Dev Biol, 26, 211-233.

Baba, M., Nakajo, S., Tu, P.H., Tomita, T., Nakaya, K., Lee, V.M., Trojanowski, J.Q. and Iwatsubo, T. (1998) Aggregation of alpha-synuclein in Lewy bodies of sporadic Parkinson's disease and dementia with Lewy bodies. Am J Pathol, 152, 879-884. 
Bartels, T., Choi, J.G. and Selkoe, D.J. (2011) alpha-Synuclein occurs physiologically as a helically folded tetramer that resists aggregation. Nature, 477, 107-110.

Bartels, T., Kim, N.C., Luth, E.S. and Selkoe, D.J. (2014) N-alpha-acetylation of alphasynuclein increases its helical folding propensity, GM1 binding specificity and resistance to aggregation. PLoS One, 9, e103727.

Beckman, J.S. (1994) Peroxynitrite versus hydroxyl radical: the role of nitric oxide in superoxide-dependent cerebral injury. Ann N Y Acad Sci, 738, 69-75.

Beckman, J.S. (1996) Oxidative damage and tyrosine nitration from peroxynitrite. Chem Res Toxicol, 9, 836-844.

Benner, E.J., Banerjee, R., Reynolds, A.D., Sherman, S., Pisarev, V.M., Tsiperson, V., Nemachek, C., Ciborowski, P., Przedborski, S., Mosley, R.L. and Gendelman, H.E. (2008) Nitrated alpha-synuclein immunity accelerates degeneration of nigral dopaminergic neurons. PLoS One, 3, e1376.

Bennett, M.C., Bishop, J.F., Leng, Y., Chock, P.B., Chase, T.N. and Mouradian, M.M. (1999) Degradation of alpha-synuclein by proteasome. J Biol Chem, 274, 33855-33858.

Bertani, G. (1951) Studies on lysogenesis. I. The mode of phage liberation by lysogenic Escherichia coli. J Bacteriol, 62, 293-300.

Blum, H., Beier, H. and Gross, H.J. (1987) Improved silver staining of plant proteins, RNA and DNA in polyacrylamide gels. Electrophoresis, 8, 93-99.

Bonifacino, J.S. and Glick, B.S. (2004) The mechanisms of vesicle budding and fusion. Cell, 116, 153-166.

Bonifati, V., Rizzu, P., Squitieri, F., Krieger, E., Vanacore, N., van Swieten, J.C., Brice, A., van Duijn, C.M., Oostra, B., Meco, G. and Heutink, P. (2003) DJ-1(PARK7), a novel gene for autosomal recessive, early onset parkinsonism. Neurol Sci, 24, 159-160.

Borghi, R., Marchese, R., Negro, A., Marinelli, L., Forloni, G., Zaccheo, D., Abbruzzese, G. and Tabaton, M. (2000) Full length alpha-synuclein is present in cerebrospinal fluid from Parkinson's disease and normal subjects. Neurosci Lett, 287, 65-67.

Bosco, D.A., Fowler, D.M., Zhang, Q., Nieva, J., Powers, E.T., Wentworth, P., Jr., Lerner, R.A. and Kelly, J.W. (2006) Elevated levels of oxidized cholesterol metabolites in Lewy body disease brains accelerate alpha-synuclein fibrilization. Nat Chem Biol, 2, 249-253.

Botstein, D., Chervitz, S.A. and Cherry, J.M. (1997) Yeast as a model organism. Science, 277, 1259-1260.

Braak, H., Del Tredici, K., Rub, U., de Vos, R.A., Jansen Steur, E.N. and Braak, E. (2003) Staging of brain pathology related to sporadic Parkinson's disease. Neurobiol Aging, 24, 197211.

Bradford, M.M. (1976) A rapid and sensitive method for the quantitation of microgram quantities of protein utilizing the principle of protein-dye binding. Anal Biochem, 72, 248-254.

Brodsky, J.L. and Skach, W.R. (2011) Protein folding and quality control in the endoplasmic reticulum: Recent lessons from yeast and mammalian cell systems. Curr Opin Cell Biol, 23, 464-475. 
Burai, R., Ait-Bouziad, N., Chiki, A. and Lashuel, H.A. (2015) Elucidating the Role of SiteSpecific Nitration of alpha-Synuclein in the Pathogenesis of Parkinson's Disease via Protein Semisynthesis and Mutagenesis. J Am Chem Soc, 137, 5041-5052.

Burre, J., Sharma, M., Tsetsenis, T., Buchman, V., Etherton, M.R. and Sudhof, T.C. (2010) Alpha-synuclein promotes SNARE-complex assembly in vivo and in vitro. Science, 329, 1663-1667.

Campion, D., Martin, C., Heilig, R., Charbonnier, F., Moreau, V., Flaman, J.M., Petit, J.L., Hannequin, D., Brice, A. and Frebourg, T. (1995) The NACP/synuclein gene: chromosomal assignment and screening for alterations in Alzheimer disease. Genomics, 26, 254-257.

Cassanova, N., O'Brien, K.M., Stahl, B.T., McClure, T. and Poyton, R.O. (2005) Yeast flavohemoglobin, a nitric oxide oxidoreductase, is located in both the cytosol and the mitochondrial matrix: effects of respiration, anoxia, and the mitochondrial genome on its intracellular level and distribution. J Biol Chem, 280, 7645-7653.

Chacko, B.K., Kramer, P.A., Ravi, S., Benavides, G.A., Mitchell, T., Dranka, B.P., Ferrick, D., Singal, A.K., Ballinger, S.W., Bailey, S.M., Hardy, R.W., Zhang, J., Zhi, D. and Darley-Usmar, V.M. (2014) The Bioenergetic Health Index: a new concept in mitochondrial translational research. Clin Sci (Lond), 127, 367-373.

Chandra, S., Chen, X., Rizo, J., Jahn, R. and Sudhof, T.C. (2003) A broken alpha-helix in folded alpha-Synuclein. J Biol Chem, 278, 15313-15318.

Chandra, S., Fornai, F., Kwon, H.B., Yazdani, U., Atasoy, D., Liu, X., Hammer, R.E., Battaglia, G., German, D.C., Castillo, P.E. and Sudhof, T.C. (2004) Double-knockout mice for alpha- and beta-synucleins: effect on synaptic functions. Proc Natl Acad Sci U S A, 101, 14966-14971.

Chartier-Harlin, M.C., Kachergus, J., Roumier, C., Mouroux, V., Douay, X., Lincoln, S., Levecque, C., Larvor, L., Andrieux, J., Hulihan, M., Waucquier, N., Defebvre, L., Amouyel, P., Farrer, M. and Destee, A. (2004) Alpha-synuclein locus duplication as a cause of familial Parkinson's disease. Lancet, 364, 1167-1169.

Chaudhuri, K.R., Healy, D.G. and Schapira, A.H. (2006) Non-motor symptoms of Parkinson's disease: diagnosis and management. Lancet Neurol, 5, 235-245.

Chen, L. and Feany, M.B. (2005) Alpha-synuclein phosphorylation controls neurotoxicity and inclusion formation in a Drosophila model of Parkinson disease. Nat Neurosci, 8, 657-663.

Chen, L., Jin, J., Davis, J., Zhou, Y., Wang, Y., Liu, J., Lockhart, P.J. and Zhang, J. (2007) Oligomeric alpha-synuclein inhibits tubulin polymerization. Biochem Biophys Res Commun, 356, 548-553.

Chen, L., Periquet, M., Wang, X., Negro, A., McLean, P.J., Hyman, B.T. and Feany, M.B. (2009) Tyrosine and serine phosphorylation of alpha-synuclein have opposing effects on neurotoxicity and soluble oligomer formation. J Clin Invest, 119, 3257-3265.

Chen, L.M., Xiong, Y.S., Kong, F.L., Qu, M., Wang, Q., Chen, X.Q., Wang, J.Z. and Zhu, L.Q. (2012) Neuroglobin attenuates Alzheimer-like tau hyperphosphorylation by activating Akt signaling. $J$ Neurochem, 120, 157-164.

Chen, Q., Thorpe, J. and Keller, J.N. (2005) Alpha-synuclein alters proteasome function, protein synthesis, and stationary phase viability. J Biol Chem, 280, 30009-30017. 
Chen, X., de Silva, H.A., Pettenati, M.J., Rao, P.N., St George-Hyslop, P., Roses, A.D., Xia, Y., Horsburgh, K., Ueda, K. and Saitoh, T. (1995) The human NACP/alpha-synuclein gene: chromosome assignment to 4q21.3-q22 and Taql RFLP analysis. Genomics, 26, 425-427.

Cherry, J.M., Hong, E.L., Amundsen, C., Balakrishnan, R., Binkley, G., Chan, E.T., Christie, K.R., Costanzo, M.C., Dwight, S.S., Engel, S.R., Fisk, D.G., Hirschman, J.E., Hitz, B.C., Karra, K., Krieger, C.J., Miyasato, S.R., Nash, R.S., Park, J., Skrzypek, M.S., Simison, M., Weng, S. and Wong, E.D. (2012) Saccharomyces Genome Database: the genomics resource of budding yeast. Nucleic Acids Res, 40, D700-705.

Chinta, S.J., Mallajosyula, J.K., Rane, A. and Andersen, J.K. (2010) Mitochondrial alphasynuclein accumulation impairs complex I function in dopaminergic neurons and results in increased mitophagy in vivo. Neurosci Lett, 486, 235-239.

Choi, B.K., Choi, M.G., Kim, J.Y., Yang, Y., Lai, Y., Kweon, D.H., Lee, N.K. and Shin, Y.K. (2013) Large alpha-synuclein oligomers inhibit neuronal SNARE-mediated vesicle docking. Proc Natl Acad Sci U S A, 110, 4087-4092.

Clayton, D.F. and George, J.M. (1998) The synucleins: a family of proteins involved in synaptic function, plasticity, neurodegeneration and disease. Trends Neurosci, 21, 249-254.

Conway, K.A., Harper, J.D. and Lansbury, P.T. (1998) Accelerated in vitro fibril formation by a mutant alpha-synuclein linked to early-onset Parkinson disease. Nat Med, 4, 1318-1320.

Conway, K.A., Harper, J.D. and Lansbury, P.T., Jr. (2000) Fibrils formed in vitro from alphasynuclein and two mutant forms linked to Parkinson's disease are typical amyloid. Biochemistry, 39, 2552-2563.

Cooper, A.A., Gitler, A.D., Cashikar, A., Haynes, C.M., Hill, K.J., Bhullar, B., Liu, K., Xu, K., Strathearn, K.E., Liu, F., Cao, S., Caldwell, K.A., Caldwell, G.A., Marsischky, G., Kolodner, R.D., Labaer, J., Rochet, J.C., Bonini, N.M. and Lindquist, S. (2006) Alpha-synuclein blocks ER-Golgi traffic and Rab1 rescues neuron loss in Parkinson's models. Science, 313, 324328.

Corpet, F. (1988) Multiple sequence alignment with hierarchical clustering. Nucleic Acids Res, 16, 10881-10890.

Crawford, M.J., Sherman, D.R. and Goldberg, D.E. (1995) Regulation of Saccharomyces cerevisiae flavohemoglobin gene expression. J Biol Chem, 270, 6991-6996.

Crow, J.P. (1997) Dichlorodihydrofluorescein and dihydrorhodamine 123 are sensitive indicators of peroxynitrite in vitro: implications for intracellular measurement of reactive nitrogen and oxygen species. Nitric Oxide, 1, 145-157.

Danielson, S.R. and Andersen, J.K. (2008) Oxidative and nitrative protein modifications in Parkinson's disease. Free Radic Biol Med, 44, 1787-1794.

Danielson, S.R., Held, J.M., Schilling, B., Oo, M., Gibson, B.W. and Andersen, J.K. (2009) Preferentially increased nitration of alpha-synuclein at tyrosine-39 in a cellular oxidative model of Parkinson's disease. Anal Chem, 81, 7823-7828.

Davidson, W.S., Jonas, A., Clayton, D.F. and George, J.M. (1998) Stabilization of alphasynuclein secondary structure upon binding to synthetic membranes. J Biol Chem, 273, 9443-9449.

de Lau, L.M. and Breteler, M.M. (2006) Epidemiology of Parkinson's disease. Lancet Neurol, $5,525-535$. 
de Rijk, M.C., Launer, L.J., Berger, K., Breteler, M.M., Dartigues, J.F., Baldereschi, M., Fratiglioni, L., Lobo, A., Martinez-Lage, J., Trenkwalder, C. and Hofman, A. (2000) Prevalence of Parkinson's disease in Europe: A collaborative study of population-based cohorts. Neurologic Diseases in the Elderly Research Group. Neurology, 54, S21-23.

Desplats, P., Lee, H.J., Bae, E.J., Patrick, C., Rockenstein, E., Crews, L., Spencer, B., Masliah, E. and Lee, S.J. (2009) Inclusion formation and neuronal cell death through neuronto-neuron transmission of alpha-synuclein. Proc Natl Acad Sci U S A, 106, 13010-13015.

Devi, L., Raghavendran, V., Prabhu, B.M., Avadhani, N.G. and Anandatheerthavarada, H.K. (2008) Mitochondrial import and accumulation of alpha-synuclein impair complex I in human dopaminergic neuronal cultures and Parkinson disease brain. J Biol Chem, 283, 9089-9100.

Dexter, D.T. and Jenner, P. (2013) Parkinson disease: from pathology to molecular disease mechanisms. Free Radic Biol Med, 62, 132-144.

Di Fonzo, A., Chien, H.F., Socal, M., Giraudo, S., Tassorelli, C., Iliceto, G., Fabbrini, G., Marconi, R., Fincati, E., Abbruzzese, G., Marini, P., Squitieri, F., Horstink, M.W., Montagna, P., Libera, A.D., Stocchi, F., Goldwurm, S., Ferreira, J.J., Meco, G., Martignoni, E., Lopiano, L., Jardim, L.B., Oostra, B.A., Barbosa, E.R. and Bonifati, V. (2007) ATP13A2 missense mutations in juvenile parkinsonism and young onset Parkinson disease. Neurology, 68, 1557-1562.

Dias, V., Junn, E. and Mouradian, M.M. (2013) The role of oxidative stress in Parkinson's disease. J Parkinsons Dis, 3, 461-491.

Dixon, C., Mathias, N., Zweig, R.M., Davis, D.A. and Gross, D.S. (2005) Alpha-synuclein targets the plasma membrane via the secretory pathway and induces toxicity in yeast. Genetics, 170, 47-59.

Dorval, V. and Fraser, P.E. (2006) Small ubiquitin-like modifier (SUMO) modification of natively unfolded proteins tau and alpha-synuclein. J Biol Chem, 281, 9919-9924.

Dranka, B.P., Hill, B.G. and Darley-Usmar, V.M. (2010) Mitochondrial reserve capacity in endothelial cells: The impact of nitric oxide and reactive oxygen species. Free Radic Biol Med, 48, 905-914.

Dubiel, W., Ferrell, K., Pratt, G. and Rechsteiner, M. (1992) Subunit 4 of the 26 S protease is a member of a novel eukaryotic ATPase family. J Biol Chem, 267, 22699-22702.

Duda, J.E., Giasson, B.I., Chen, Q., Gur, T.L., Hurtig, H.I., Stern, M.B., Gollomp, S.M., Ischiropoulos, H., Lee, V.M. and Trojanowski, J.Q. (2000) Widespread nitration of pathological inclusions in neurodegenerative synucleinopathies. Am J Pathol, 157, 14391445.

Ebrahimi-Fakhari, D., Cantuti-Castelvetri, I., Fan, Z., Rockenstein, E., Masliah, E., Hyman, B.T., McLean, P.J. and Unni, V.K. (2011) Distinct roles in vivo for the ubiquitin-proteasome system and the autophagy-lysosomal pathway in the degradation of alpha-synuclein. $J$ Neurosci, 31, 14508-14520.

El-Agnaf, O.M., Salem, S.A., Paleologou, K.E., Cooper, L.J., Fullwood, N.J., Gibson, M.J., Curran, M.D., Court, J.A., Mann, D.M., Ikeda, S., Cookson, M.R., Hardy, J. and Allsop, D. (2003) Alpha-synuclein implicated in Parkinson's disease is present in extracellular biological fluids, including human plasma. FASEB J, 17, 1945-1947. 
Ellis, C.E., Schwartzberg, P.L., Grider, T.L., Fink, D.W. and Nussbaum, R.L. (2001) alphasynuclein is phosphorylated by members of the Src family of protein-tyrosine kinases. $J$ Biol Chem, 276, 3879-3884.

Emmanouilidou, E., Stefanis, L. and Vekrellis, K. (2010) Cell-produced alpha-synuclein oligomers are targeted to, and impair, the $26 \mathrm{~S}$ proteasome. Neurobiol Aging, 31, 953-968.

Engelender, S., Kaminsky, Z., Guo, X., Sharp, A.H., Amaravi, R.K., Kleiderlein, J.J., Margolis, R.L., Troncoso, J.C., Lanahan, A.A., Worley, P.F., Dawson, V.L., Dawson, T.M. and Ross, C.A. (1999) Synphilin-1 associates with alpha-synuclein and promotes the formation of cytosolic inclusions. Nat Genet, 22, 110-114.

Fairbanks, G., Steck, T.L. and Wallach, D.F. (1971) Electrophoretic analysis of the major polypeptides of the human erythrocyte membrane. Biochemistry, 10, 2606-2617.

Fearnley, J.M. and Lees, A.J. (1991) Ageing and Parkinson's disease: substantia nigra regional selectivity. Brain, 114, 2283-2301.

Fedorow, H., Tribl, F., Halliday, G., Gerlach, M., Riederer, P. and Double, K.L. (2005) Neuromelanin in human dopamine neurons: comparison with peripheral melanins and relevance to Parkinson's disease. Prog Neurobiol, 75, 109-124.

Flower, T.R., Chesnokova, L.S., Froelich, C.A., Dixon, C. and Witt, S.N. (2005) Heat shock prevents alpha-synuclein-induced apoptosis in a yeast model of Parkinson's disease. $J \mathrm{Mol}$ Biol, 351, 1081-1100.

Foulds, P.G., Mitchell, J.D., Parker, A., Turner, R., Green, G., Diggle, P., Hasegawa, M., Taylor, M., Mann, D. and Allsop, D. (2011) Phosphorylated alpha-synuclein can be detected in blood plasma and is potentially a useful biomarker for Parkinson's disease. FASEB J, 25, 4127-4137.

Franssens, V., Boelen, E., Anandhakumar, J., Vanhelmont, T., Buttner, S. and Winderickx, J. (2010) Yeast unfolds the road map toward alpha-synuclein-induced cell death. Cell Death Differ, 17, 746-753.

Frein, D., Schildknecht, S., Bachschmid, M. and Ullrich, V. (2005) Redox regulation: a new challenge for pharmacology. Biochem Pharmacol, 70, 811-823.

Fujiwara, H., Hasegawa, M., Dohmae, N., Kawashima, A., Masliah, E., Goldberg, M.S., Shen, J., Takio, K. and Iwatsubo, T. (2002) alpha-Synuclein is phosphorylated in synucleinopathy lesions. Nat Cell Biol, 4, 160-164.

Fulwyler, M.J. (1965) Electronic separation of biological cells by volume. Science, 150, 910911.

Galvin, J.E., Lee, V.M. and Trojanowski, J.Q. (2001) Synucleinopathies: clinical and pathological implications. Arch Neurol, 58, 186-190.

Gao, H.M., Kotzbauer, P.T., Uryu, K., Leight, S., Trojanowski, J.Q. and Lee, V.M. (2008) Neuroinflammation and oxidation/nitration of alpha-synuclein linked to dopaminergic neurodegeneration. J Neurosci, 28, 7687-7698.

German, D.C., Manaye, K., Smith, W.K., Woodward, D.J. and Saper, C.B. (1989) Midbrain dopaminergic cell loss in Parkinson's disease: computer visualization. Ann Neurol, 26, 507514. 
German, D.C., Manaye, K.F., Sonsalla, P.K. and Brooks, B.A. (1992) Midbrain dopaminergic cell loss in Parkinson's disease and MPTP-induced parkinsonism: sparing of calbindin-D28kcontaining cells. Ann N Y Acad Sci, 648, 42-62.

Giasson, B.I., Duda, J.E., Murray, I.V., Chen, Q., Souza, J.M., Hurtig, H.I., Ischiropoulos, H., Trojanowski, J.Q. and Lee, V.M. (2000) Oxidative damage linked to neurodegeneration by selective alpha-synuclein nitration in synucleinopathy lesions. Science, 290, 985-989.

Giasson, B.I., Murray, I.V., Trojanowski, J.Q. and Lee, V.M. (2001) A hydrophobic stretch of 12 amino acid residues in the middle of alpha-synuclein is essential for filament assembly. $J$ Biol Chem, 276, 2380-2386.

Gibb, W.R. and Lees, A.J. (1988) The relevance of the Lewy body to the pathogenesis of idiopathic Parkinson's disease. J Neurol Neurosurg Psychiatry, 51, 745-752.

Gibb, W.R. and Lees, A.J. (1991) Anatomy, pigmentation, ventral and dorsal subpopulations of the substantia nigra, and differential cell death in Parkinson's disease. J Neurol Neurosurg Psychiatry, 54, 388-396.

Gitler, A.D., Bevis, B.J., Shorter, J., Strathearn, K.E., Hamamichi, S., Su, L.J., Caldwell, K.A., Caldwell, G.A., Rochet, J.C., McCaffery, J.M., Barlowe, C. and Lindquist, S. (2008) The Parkinson's disease protein alpha-synuclein disrupts cellular Rab homeostasis. Proc Natl Acad Sci U S A, 105, 145-150.

Gitler, A.D., Chesi, A., Geddie, M.L., Strathearn, K.E., Hamamichi, S., Hill, K.J., Caldwell, K.A., Caldwell, G.A., Cooper, A.A., Rochet, J.C. and Lindquist, S. (2009) Alpha-synuclein is part of a diverse and highly conserved interaction network that includes PARK9 and manganese toxicity. Nat Genet, 41, 308-315.

Giupponi, G., Pycha, R., Erfurth, A., Hausmann, A. and Conca, A. (2008) [Depressive symptoms and the Idiopathic Parkinson's Syndrome (IPS): a review]. Neuropsychiatr, 22, 7182.

Goers, J., Manning-Bog, A.B., McCormack, A.L., Millett, I.S., Doniach, S., Di Monte, D.A., Uversky, V.N. and Fink, A.L. (2003) Nuclear localization of alpha-synuclein and its interaction with histones. Biochemistry, 42, 8465-8471.

Goffeau, A., Barrell, B.G., Bussey, H., Davis, R.W., Dujon, B., Feldmann, H., Galibert, F., Hoheisel, J.D., Jacq, C., Johnston, M., Louis, E.J., Mewes, H.W., Murakami, Y., Philippsen, P., Tettelin, H. and Oliver, S.G. (1996) Life with 6000 genes. Science, 274, 546, 563-547.

Goldberg, A.L. (2003) Protein degradation and protection against misfolded or damaged proteins. Nature, 426, 895-899.

Golovko, M.Y., Barcelo-Coblijn, G., Castagnet, P.I., Austin, S., Combs, C.K. and Murphy, E.J. (2009) The role of alpha-synuclein in brain lipid metabolism: a downstream impact on brain inflammatory response. Mol Cell Biochem, 326, 55-66.

Goncalves, S. and Outeiro, T.F. (2013) Assessing the subcellular dynamics of alphasynuclein using photoactivation microscopy. Mol Neurobiol, 47, 1081-1092.

Gorbatyuk, O.S., Li, S., Sullivan, L.F., Chen, W., Kondrikova, G., Manfredsson, F.P., Mandel, R.J. and Muzyczka, N. (2008) The phosphorylation state of Ser-129 in human alphasynuclein determines neurodegeneration in a rat model of Parkinson disease. Proc Natl Acad Sci U S A, 105, 763-768. 
Gotze, M., Pettelkau, J., Schaks, S., Bosse, K., Ihling, C.H., Krauth, F., Fritzsche, R., Kuhn, U. and Sinz, A. (2012) StavroX--a software for analyzing crosslinked products in protein interaction studies. J Am Soc Mass Spectrom, 23, 76-87.

Gow, A.J., Duran, D., Malcolm, S. and Ischiropoulos, H. (1996) Effects of peroxynitriteinduced protein modifications on tyrosine phosphorylation and degradation. FEBS Lett, 385, 63-66.

Greenbaum, E.A., Graves, C.L., Mishizen-Eberz, A.J., Lupoli, M.A., Lynch, D.R., Englander, S.W., Axelsen, P.H. and Giasson, B.I. (2005) The E46K mutation in alpha-synuclein increases amyloid fibril formation. J Biol Chem, 280, 7800-7807.

Greenberg, D.A., Jin, K. and Khan, A.A. (2008) Neuroglobin: an endogenous neuroprotectant. Curr Opin Pharmacol, 8, 20-24.

Guerrero, E., Vasudevaraju, P., Hegde, M.L., Britton, G.B. and Rao, K.S. (2013) Recent advances in alpha-synuclein functions, advanced glycation, and toxicity: implications for Parkinson's disease. Mol Neurobiol, 47, 525-536.

Guthrie, C. and Fink, G.F. (1991) Guide to yeast genetics and molecular biology. Methods Enzymol, 194, 1-863.

Hardy, J., Cai, H., Cookson, M.R., Gwinn-Hardy, K. and Singleton, A. (2006) Genetics of Parkinson's disease and parkinsonism. Ann Neurol, 60, 389-398.

Hartwell, L.H. (2002) Nobel Lecture. Yeast and cancer. Biosci Rep, 22, 373-394.

Hasegawa, M., Fujiwara, H., Nonaka, T., Wakabayashi, K., Takahashi, H., Lee, V.M., Trojanowski, J.Q., Mann, D. and Iwatsubo, T. (2002) Phosphorylated alpha-synuclein is ubiquitinated in alpha-synucleinopathy lesions. J Biol Chem, 277, 49071-49076.

Hashimoto, M., Hsu, L.J., Xia, Y., Takeda, A., Sisk, A., Sundsmo, M. and Masliah, E. (1999) Oxidative stress induces amyloid-like aggregate formation of NACP/alpha-synuclein in vitro. Neuroreport, 10, 717-721.

Hashimoto, M. and Masliah, E. (1999) Alpha-synuclein in Lewy body disease and Alzheimer's disease. Brain Pathol, 9, 707-720.

Hill, B.G., Benavides, G.A., Lancaster, J.R., Jr., Ballinger, S., Dell'Italia, L., Jianhua, Z. and Darley-Usmar, V.M. (2012) Integration of cellular bioenergetics with mitochondrial quality control and autophagy. Biol Chem, 393, 1485-1512.

Hodara, R., Norris, E.H., Giasson, B.I., Mishizen-Eberz, A.J., Lynch, D.R., Lee, V.M. and Ischiropoulos, H. (2004) Functional consequences of alpha-synuclein tyrosine nitration: diminished binding to lipid vesicles and increased fibril formation. J Biol Chem, 279, 4774647753.

Hoffman, C.S. and Winston, F. (1987) A ten-minute DNA preparation from yeast efficiently releases autonomous plasmids for transformation of Escherichia coli. Gene, 57, 267-272.

Hornykiewicz, O. (2001) Chemical neuroanatomy of the basal ganglia--normal and in Parkinson's disease. J Chem Neuroanat, 22, 3-12.

Hsu, L.J., Sagara, Y., Arroyo, A., Rockenstein, E., Sisk, A., Mallory, M., Wong, J., Takenouchi, T., Hashimoto, M. and Masliah, E. (2000) alpha-synuclein promotes mitochondrial deficit and oxidative stress. Am J Pathol, 157, 401-410. 
Huang, Z., Xu, Z., Wu, Y. and Zhou, Y. (2011) Determining nuclear localization of alphasynuclein in mouse brains. Neuroscience, 199, 318-332.

Hughes, T.R. (2002) Yeast and drug discovery. Funct Integr Genomics, 2, 199-211.

Inoue, H., Nojima, H. and Okayama, H. (1990) High efficiency transformation of Escherichia coli with plasmids. Gene, 96, 23-28.

Ischiropoulos, H. (1998) Biological tyrosine nitration: a pathophysiological function of nitric oxide and reactive oxygen species. Arch Biochem Biophys, 356, 1-11.

Ito, H., Fukuda, Y., Murata, K. and Kimura, A. (1983) Transformation of intact yeast cells treated with alkali cations. J Bacteriol, 153, 163-168.

Jakes, R., Spillantini, M.G. and Goedert, M. (1994) Identification of two distinct synucleins from human brain. FEBS Lett, 345, 27-32.

Jankovic, J. (2008) Parkinson's disease: clinical features and diagnosis. J Neurol Neurosurg Psychiatry, 79, 368-376.

Jenner, P. and Olanow, C.W. (1996) Oxidative stress and the pathogenesis of Parkinson's disease. Neurology, 47, S161-170.

Jensen, P.H., Nielsen, M.S., Jakes, R., Dotti, C.G. and Goedert, M. (1998) Binding of alphasynuclein to brain vesicles is abolished by familial Parkinson's disease mutation. $J$ Biol Chem, 273, 26292-26294.

Jo, E., Fuller, N., Rand, R.P., St George-Hyslop, P. and Fraser, P.E. (2002) Defective membrane interactions of familial Parkinson's disease mutant A30P alpha-synuclein. $J \mathrm{Mol}$ Biol, 315, 799-807.

Jones, E.W. (2002) Vacuolar proteases and proteolytic artifacts in Saccharomyces cerevisiae. Methods Enzymol, 351, 127-150.

Junn, E. and Mouradian, M.M. (2002) Human alpha-synuclein over-expression increases intracellular reactive oxygen species levels and susceptibility to dopamine. Neurosci Lett, 320, 146-150.

Kang, K.W., Choi, S.H. and Kim, S.G. (2002) Peroxynitrite activates NF-E2-related factor 2/antioxidant response element through the pathway of phosphatidylinositol 3-kinase: the role of nitric oxide synthase in rat glutathione S-transferase A2 induction. Nitric Oxide, 7, 244-253.

Karpinar, D.P., Balija, M.B., Kugler, S., Opazo, F., Rezaei-Ghaleh, N., Wender, N., Kim, H.Y., Taschenberger, G., Falkenburger, B.H., Heise, H., Kumar, A., Riedel, D., Fichtner, L., Voigt, A., Braus, G.H., Giller, K., Becker, S., Herzig, A., Baldus, M., Jackle, H., Eimer, S., Schulz, J.B., Griesinger, C. and Zweckstetter, M. (2009) Pre-fibrillar alpha-synuclein variants with impaired beta-structure increase neurotoxicity in Parkinson's disease models. Embo J, 28, 3256-3268.

Karube, H., Sakamoto, M., Arawaka, S., Hara, S., Sato, H., Ren, C.H., Goto, S., Koyama, S., Wada, M., Kawanami, T., Kurita, K. and Kato, T. (2008) N-terminal region of alpha-synuclein is essential for the fatty acid-induced oligomerization of the molecules. FEBS Lett, 582, 36933700 .

Katzmann, D.J., Hallstrom, T.C., Voet, M., Wysock, W., Golin, J., Volckaert, G. and MoyeRowley, W.S. (1995) Expression of an ATP-binding cassette transporter-encoding gene 
(YOR1) is required for oligomycin resistance in Saccharomyces cerevisiae. Mol Cell Biol, 15, 6875-6883.

Khan, A.A., Mao, X.O., Banwait, S., Jin, K. and Greenberg, D.A. (2007) Neuroglobin attenuates beta-amyloid neurotoxicity in vitro and transgenic Alzheimer phenotype in vivo. Proc Natl Acad Sci U S A, 104, 19114-19119.

Kiely, A.P., Asi, Y.T., Kara, E., Limousin, P., Ling, H., Lewis, P., Proukakis, C., Quinn, N., Lees, A.J., Hardy, J., Revesz, T., Houlden, H. and Holton, J.L. (2013) alpha-Synucleinopathy associated with G51D SNCA mutation: a link between Parkinson's disease and multiple system atrophy? Acta Neuropathol, 125, 753-769.

Kitada, T., Asakawa, S., Hattori, N., Matsumine, H., Yamamura, Y., Minoshima, S., Yokochi, M., Mizuno, Y. and Shimizu, N. (1998) Mutations in the parkin gene cause autosomal recessive juvenile parkinsonism. Nature, 392, 605-608.

Klionsky, D.J. and Emr, S.D. (2000) Autophagy as a regulated pathway of cellular degradation. Science, 290, 1717-1721.

Klotz, L.O., Schieke, S.M., Sies, H. and Holbrook, N.J. (2000) Peroxynitrite activates the phosphoinositide 3-kinase/Akt pathway in human skin primary fibroblasts. Biochem J, $352 \mathbf{P t}$ 1, 219-225.

Kojima, H., Sakurai, K., Kikuchi, K., Kawahara, S., Kirino, Y., Nagoshi, H., Hirata, Y. and Nagano, T. (1998) Development of a fluorescent indicator for nitric oxide based on the fluorescein chromophore. Chem Pharm Bull (Tokyo), 46, 373-375.

Kong, S.K., Yim, M.B., Stadtman, E.R. and Chock, P.B. (1996) Peroxynitrite disables the tyrosine phosphorylation regulatory mechanism: Lymphocyte-specific tyrosine kinase fails to phosphorylate nitrated cdc2(6-20)NH2 peptide. Proc Natl Acad Sci U S A, 93, 3377-3382.

Kontopoulos, E., Parvin, J.D. and Feany, M.B. (2006) Alpha-synuclein acts in the nucleus to inhibit histone acetylation and promote neurotoxicity. Hum Mol Genet, 15, 3012-3023.

Kosten, J., Binolfi, A., Stuiver, M., Verzini, S., Theillet, F.X., Bekei, B., van Rossum, M. and Selenko, P. (2014) Efficient modification of alpha-synuclein serine 129 by protein kinase CK1 requires phosphorylation of tyrosine 125 as a priming event. ACS Chem Neurosci, 5, 12031208.

Kowall, N.W., Hantraye, P., Brouillet, E., Beal, M.F., McKee, A.C. and Ferrante, R.J. (2000) MPTP induces alpha-synuclein aggregation in the substantia nigra of baboons. Neuroreport, 11, 211-213.

Kruger, R., Kuhn, W., Muller, T., Woitalla, D., Graeber, M., Kosel, S., Przuntek, H., Epplen, J.T., Schols, L. and Riess, O. (1998) Ala30Pro mutation in the gene encoding alphasynuclein in Parkinson's disease. Nat Genet, 18, 106-108.

Kuwahara, T., Tonegawa, R., Ito, G., Mitani, S. and Iwatsubo, T. (2012) Phosphorylation of alpha-synuclein protein at Ser-129 reduces neuronal dysfunction by lowering its membrane binding property in Caenorhabditis elegans. J Biol Chem, 287, 7098-7109.

Laemmli, U.K. (1970) Cleavage of structural proteins during the assembly of the head of bacteriophage T4. Nature, 227, 680-685.

Lavedan, C. (1998) The synuclein family. Genome Res, 8, 871-880. 
Lazaro, D.F., Rodrigues, E.F., Langohr, R., Shahpasandzadeh, H., Ribeiro, T., Guerreiro, P., Gerhardt, E., Krohnert, K., Klucken, J., Pereira, M.D., Popova, B., Kruse, N., Mollenhauer, B., Rizzoli, S.O., Braus, G.H., Danzer, K.M. and Outeiro, T.F. (2014) Systematic comparison of the effects of alpha-synuclein mutations on its oligomerization and aggregation. PLoS Genet, 10, e1004741.

Lee, D.H. and Goldberg, A.L. (1996) Selective inhibitors of the proteasome-dependent and vacuolar pathways of protein degradation in Saccharomyces cerevisiae. J Biol Chem, 271, 27280-27284.

Lee, D.H. and Goldberg, A.L. (1998) Proteasome inhibitors: valuable new tools for cell biologists. Trends Cell Biol, 8, 397-403.

Lee, H.J., Khoshaghideh, F., Patel, S. and Lee, S.J. (2004) Clearance of alpha-synuclein oligomeric intermediates via the lysosomal degradation pathway. J Neurosci, 24, 1888-1896.

Lee, H.J., Shin, S.Y., Choi, C., Lee, Y.H. and Lee, S.J. (2002) Formation and removal of alpha-synuclein aggregates in cells exposed to mitochondrial inhibitors. J Biol Chem, 277, 5411-5417.

Lee, P.Y., Costumbrado, J., Hsu, C.Y. and Kim, Y.H. (2012) Agarose gel electrophoresis for the separation of DNA fragments. J Vis Exp, 20, 3923.

Lesage, S., Anheim, M., Letournel, F., Bousset, L., Honore, A., Rozas, N., Pieri, L., Madiona, K., Durr, A., Melki, R., Verny, C. and Brice, A. (2013) G51D alpha-synuclein mutation causes a novel parkinsonian-pyramidal syndrome. Ann Neurol, 73, 459-471.

Lewinska, A. and Bartosz, G. (2006) Yeast flavohemoglobin protects against nitrosative stress and controls ferric reductase activity. Redox Rep, 11, 231-239.

Li, J., Uversky, V.N. and Fink, A.L. (2001) Effect of familial Parkinson's disease point mutations A30P and A53T on the structural properties, aggregation, and fibrillation of human alpha-synuclein. Biochemistry, 40, 11604-11613.

Liu, C., Apodaca, J., Davis, L.E. and Rao, H. (2007) Proteasome inhibition in wild-type yeast Saccharomyces cerevisiae cells. Biotechniques, 42, 158, 160, 162.

Liu, L., Zeng, M., Hausladen, A., Heitman, J. and Stamler, J.S. (2000) Protection from nitrosative stress by yeast flavohemoglobin. Proc Natl Acad Sci U S A, 97, 4672-4676.

Liu, Y., Qiang, M., Wei, Y. and He, R. (2011) A novel molecular mechanism for nitrated \{alpha\}-synuclein-induced cell death. J Mol Cell Biol, 3, 239-249.

Lorenzen, N., Lemminger, L., Pedersen, J.N., Nielsen, S.B. and Otzen, D.E. (2014) The Nterminus of alpha-synuclein is essential for both monomeric and oligomeric interactions with membranes. FEBS Lett, 588, 497-502.

Luk, K.C., Kehm, V., Carroll, J., Zhang, B., O'Brien, P., Trojanowski, J.Q. and Lee, V.M. (2012a) Pathological alpha-synuclein transmission initiates Parkinson-like neurodegeneration in nontransgenic mice. Science, 338, 949-953.

Luk, K.C., Kehm, V.M., Zhang, B., O'Brien, P., Trojanowski, J.Q. and Lee, V.M. (2012b) Intracerebral inoculation of pathological alpha-synuclein initiates a rapidly progressive neurodegenerative alpha-synucleinopathy in mice. J Exp Med, 209, 975-986. 
Lundblad, M., Decressac, M., Mattsson, B. and Bjorklund, A. (2012) Impaired neurotransmission caused by overexpression of alpha-synuclein in nigral dopamine neurons. Proc Natl Acad Sci U S A, 109, 3213-3219.

Lymar, S.V. and Hurst, J.K. (1998) Radical nature of peroxynitrite reactivity. Chem Res Toxicol, 11, 714-715.

Machiya, Y., Hara, S., Arawaka, S., Fukushima, S., Sato, H., Sakamoto, M., Koyama, S. and Kato, T. (2010) Phosphorylated alpha-synuclein at Ser-129 is targeted to the proteasome pathway in a ubiquitin-independent manner. J Biol Chem, 285, 40732-40744.

Mager, W.H. and Winderickx, J. (2005) Yeast as a model for medical and medicinal research. Trends Pharmacol Sci, 26, 265-273.

Mahul-Mellier, A.L., Fauvet, B., Gysbers, A., Dikiy, I., Oueslati, A., Georgeon, S., Lamontanara, A.J., Bisquertt, A., Eliezer, D., Masliah, E., Halliday, G., Hantschel, O. and Lashuel, H.A. (2014) c-Abl phosphorylates alpha-synuclein and regulates its degradation: implication for alpha-synuclein clearance and contribution to the pathogenesis of Parkinson's disease. Hum Mol Genet, 23, 2858-2879.

Maroteaux, L., Campanelli, J.T. and Scheller, R.H. (1988) Synuclein: a neuron-specific protein localized to the nucleus and presynaptic nerve terminal. $J$ Neurosci, 8, 2804-2815.

Maroteaux, L. and Scheller, R.H. (1991) The rat brain synucleins; family of proteins transiently associated with neuronal membrane. Brain Res Mol Brain Res, 11, 335-343.

Martinez-Ruiz, A. and Lamas, S. (2009) Two decades of new concepts in nitric oxide signaling: from the discovery of a gas messenger to the mediation of nonenzymatic posttranslational modifications. IUBMB Life, 61, 91-98.

Martinez-Vicente, M., Talloczy, Z., Kaushik, S., Massey, A.C., Mazzulli, J., Mosharov, E.V., Hodara, R., Fredenburg, R., Wu, D.C., Follenzi, A., Dauer, W., Przedborski, S., Ischiropoulos, H., Lansbury, P.T., Sulzer, D. and Cuervo, A.M. (2008) Dopamine-modified alpha-synuclein blocks chaperone-mediated autophagy. J Clin Invest, 118, 777-788.

Masuda-Suzukake, M., Nonaka, T., Hosokawa, M., Oikawa, T., Arai, T., Akiyama, H., Mann, D.M. and Hasegawa, M. (2013) Prion-like spreading of pathological alpha-synuclein in brain. Brain, 136, 1128-1138.

McCormack, A.L., Mak, S.K. and Di Monte, D.A. (2012) Increased alpha-synuclein phosphorylation and nitration in the aging primate substantia nigra. Cell Death Dis, 3, e315.

McFarland, N.R., Fan, Z., Xu, K., Schwarzschild, M.A., Feany, M.B., Hyman, B.T. and McLean, P.J. (2009) Alpha-synuclein S129 phosphorylation mutants do not alter nigrostriatal toxicity in a rat model of Parkinson disease. J Neuropathol Exp Neurol, 68, 515-524.

McLean, P.J., Kawamata, H. and Hyman, B.T. (2001) Alpha-synuclein-enhanced green fluorescent protein fusion proteins form proteasome sensitive inclusions in primary neurons. Neuroscience, 104, 901-912.

Meselson, M. and Yuan, R. (1968) DNA restriction enzyme from E. coli. Nature, 217, 11101114.

Moncada, S. (1999) Nitric oxide: discovery and impact on clinical medicine. J R Soc Med, 92, 164-169. 
Mumberg, D., Muller, R. and Funk, M. (1994) Regulatable promoters of Saccharomyces cerevisiae: comparison of transcriptional activity and their use for heterologous expression. Nucleic Acids Res, 22, 5767-5768.

Munoz, A.J., Wanichthanarak, K., Meza, E. and Petranovic, D. (2012) Systems biology of yeast cell death. FEMS Yeast Res, 12, 249-265.

Nakamura, K., Nemani, V.M., Azarbal, F., Skibinski, G., Levy, J.M., Egami, K., Munishkina, L., Zhang, J., Gardner, B., Wakabayashi, J., Sesaki, H., Cheng, Y., Finkbeiner, S., Nussbaum, R.L., Masliah, E. and Edwards, R.H. (2011) Direct membrane association drives mitochondrial fission by the Parkinson disease-associated protein alpha-synuclein. $J$ Biol Chem, 286, 20710-20726.

Nakamura, T., Yamashita, H., Nagano, Y., Takahashi, T., Avraham, S., Avraham, H., Matsumoto, M. and Nakamura, S. (2002) Activation of Pyk2/RAFTK induces tyrosine phosphorylation of alpha-synuclein via Src-family kinases. FEBS Lett, 521, 190-194.

Nakamura, T., Yamashita, H., Takahashi, T. and Nakamura, S. (2001) Activated Fyn phosphorylates alpha-synuclein at tyrosine residue 125. Biochem Biophys Res Commun, 280, 1085-1092.

Negro, A., Brunati, A.M., Donella-Deana, A., Massimino, M.L. and Pinna, L.A. (2002) Multiple phosphorylation of alpha-synuclein by protein tyrosine kinase Syk prevents eosin-induced aggregation. FASEB J, 16, 210-212.

Norris, E.H., Giasson, B.I., Ischiropoulos, H. and Lee, V.M. (2003) Effects of oxidative and nitrative challenges on alpha-synuclein fibrillogenesis involve distinct mechanisms of protein modifications. J Biol Chem, 278, 27230-27240.

Obeso, J.A., Rodriguez-Oroz, M.C., Rodriguez, M., Arbizu, J. and Gimenez-Amaya, J.M. (2002) The basal ganglia and disorders of movement: pathophysiological mechanisms. News Physiol Sci, 17, 51-55.

Ocampo, A., Liu, J., Schroeder, E.A., Shadel, G.S. and Barrientos, A. (2012) Mitochondrial respiratory thresholds regulate yeast chronological life span and its extension by caloric restriction. Cell Metab, 16, 55-67.

Olanow, C.W. (1990) Oxidation reactions in Parkinson's disease. Neurology, 40, suppl 32-37; discussion 37-39.

Oliveira, L.M., Falomir-Lockhart, L.J., Botelho, M.G., Lin, K.H., Wales, P., Koch, J.C., Gerhardt, E., Taschenberger, H., Outeiro, T.F., Lingor, P., Schule, B., Arndt-Jovin, D.J. and Jovin, T.M. (2015) Elevated alpha-synuclein caused by SNCA gene triplication impairs neuronal differentiation and maturation in Parkinson's patient-derived induced pluripotent stem cells. Cell Death Dis, 6, e1994.

Oueslati, A., Fournier, M. and Lashuel, H.A. (2010) Role of post-translational modifications in modulating the structure, function and toxicity of alpha-synuclein: implications for Parkinson's disease pathogenesis and therapies. Prog Brain Res, 183, 115-145.

Oueslati, A., Schneider, B.L., Aebischer, P. and Lashuel, H.A. (2013) Polo-like kinase 2 regulates selective autophagic alpha-synuclein clearance and suppresses its toxicity in vivo. Proc Natl Acad Sci U S A, 110, E3945-3954.

Outeiro, T.F. and Lindquist, S. (2003) Yeast cells provide insight into alpha-synuclein biology and pathobiology. Science, 302, 1772-1775. 
Paleologou, K.E., Oueslati, A., Shakked, G., Rospigliosi, C.C., Kim, H.Y., Lamberto, G.R., Fernandez, C.O., Schmid, A., Chegini, F., Gai, W.P., Chiappe, D., Moniatte, M., Schneider, B.L., Aebischer, P., Eliezer, D., Zweckstetter, M., Masliah, E. and Lashuel, H.A. (2010) Phosphorylation at $\mathrm{S} 87$ is enhanced in synucleinopathies, inhibits alpha-synuclein oligomerization, and influences synuclein-membrane interactions. J Neurosci, 30, 31843198.

Papay, R., Zuscik, M.J., Ross, S.A., Yun, J., McCune, D.F., Gonzalez-Cabrera, P., Gaivin, R., Drazba, J. and Perez, D.M. (2002) Mice expressing the alpha(1B)-adrenergic receptor induces a synucleinopathy with excessive tyrosine nitration but decreased phosphorylation. $J$ Neurochem, 83, 623-634.

Parihar, M.S., Parihar, A., Fujita, M., Hashimoto, M. and Ghafourifar, P. (2008) Mitochondrial association of alpha-synuclein causes oxidative stress. Cell Mol Life Sci, 65, 1272-1284.

Parihar, M.S., Parihar, A., Fujita, M., Hashimoto, M. and Ghafourifar, P. (2009) Alphasynuclein overexpression and aggregation exacerbates impairment of mitochondrial functions by augmenting oxidative stress in human neuroblastoma cells. Int J Biochem Cell Biol, 41, 2015-2024.

Parkinson, J. (2002) An essay on the shaking palsy. 1817. J Neuropsychiatry Clin Neurosci, 14, 223-236; discussion 222.

Paxinou, E., Chen, Q., Weisse, M., Giasson, B.I., Norris, E.H., Rueter, S.M., Trojanowski, J.Q., Lee, V.M. and Ischiropoulos, H. (2001) Induction of alpha-synuclein aggregation by intracellular nitrative insult. J Neurosci, 21, 8053-8061.

Petroi, D., Popova, B., Taheri-Talesh, N., Irniger, S., Shahpasandzadeh, H., Zweckstetter, M., Outeiro, T.F. and Braus, G.H. (2012) Aggregate clearance of alpha-synuclein in Saccharomyces cerevisiae depends more on autophagosome and vacuole function than on the proteasome. J Biol Chem, 287, 27567-27579.

Pfeiffer, S., Schmidt, K. and Mayer, B. (2000) Dityrosine formation outcompetes tyrosine nitration at low steady-state concentrations of peroxynitrite. Implications for tyrosine modification by nitric oxide/superoxide in vivo. J Biol Chem, 275, 6346-6352.

Pillon, B., Dubois, B., Cusimano, G., Bonnet, A.M., Lhermitte, F. and Agid, Y. (1989) Does cognitive impairment in Parkinson's disease result from non-dopaminergic lesions? J Neurol Neurosurg Psychiatry, 52, 201-206.

Polymeropoulos, M.H., Lavedan, C., Leroy, E., Ide, S.E., Dehejia, A., Dutra, A., Pike, B., Root, H., Rubenstein, J., Boyer, R., Stenroos, E.S., Chandrasekharappa, S., Athanassiadou, A., Papapetropoulos, T., Johnson, W.G., Lazzarini, A.M., Duvoisin, R.C., Di lorio, G., Golbe, L.I. and Nussbaum, R.L. (1997) Mutation in the alpha-synuclein gene identified in families with Parkinson's disease. Science, 276, 2045-2047.

Popova, B., Kleinknecht, A. and Braus, G.H. (2015) Posttranslational Modifications and Clearing of alpha-Synuclein Aggregates in Yeast. Biomolecules, 5, 617-634.

Porath, J., Carlsson, J., Olsson, I. and Belfrage, G. (1975) Metal chelate affinity chromatography, a new approach to protein fractionation. Nature, 258, 598-599.

Prigione, A., Piazza, F., Brighina, L., Begni, B., Galbussera, A., Difrancesco, J.C., Andreoni, S., Piolti, R. and Ferrarese, C. (2010) Alpha-synuclein nitration and autophagy response are induced in peripheral blood cells from patients with Parkinson disease. Neurosci Lett, 477, 610. 
Pronin, A.N., Morris, A.J., Surguchov, A. and Benovic, J.L. (2000) Synucleins are a novel class of substrates for G protein-coupled receptor kinases. J Biol Chem, 275, 26515-26522.

Qing, H., Wong, W., McGeer, E.G. and McGeer, P.L. (2009) Lrrk2 phosphorylates alpha synuclein at serine 129: Parkinson disease implications. Biochem Biophys Res Commun, $387,149-152$.

Radi, R. (2004) Nitric oxide, oxidants, and protein tyrosine nitration. Proc Natl Acad Sci U S A, 101, 4003-4008.

Radi, R. (2012) Protein tyrosine nitration: biochemical mechanisms and structural basis of functional effects. Acc Chem Res, 46, 550-559.

Rappsilber, J., Mann, M. and Ishihama, Y. (2007) Protocol for micro-purification, enrichment, pre-fractionation and storage of peptides for proteomics using StageTips. Nat Protoc, 2, 1896-1906.

Recasens, A., Dehay, B., Bove, J., Carballo-Carbajal, I., Dovero, S., Perez-Villalba, A., Fernagut, P.O., Blesa, J., Parent, A., Perier, C., Farinas, I., Obeso, J.A., Bezard, E. and Vila, M. (2014) Lewy body extracts from Parkinson disease brains trigger alpha-synuclein pathology and neurodegeneration in mice and monkeys. Ann Neurol, 75, 351-362.

Recchia, A., Debetto, P., Negro, A., Guidolin, D., Skaper, S.D. and Giusti, P. (2004) Alphasynuclein and Parkinson's disease. FASEB J, 18, 617-626.

Rott, R., Szargel, R., Haskin, J., Bandopadhyay, R., Lees, A.J., Shani, V. and Engelender, S. (2011) alpha-Synuclein fate is determined by USP9X-regulated monoubiquitination. Proc Natl Acad Sci U S A, 108, 18666-18671.

Sacino, A.N., Brooks, M., Thomas, M.A., McKinney, A.B., Lee, S., Regenhardt, R.W., McGarvey, N.H., Ayers, J.I., Notterpek, L., Borchelt, D.R., Golde, T.E. and Giasson, B.I. (2014) Intramuscular injection of alpha-synuclein induces CNS alpha-synuclein pathology and a rapid-onset motor phenotype in transgenic mice. Proc Natl Acad Sci U S A, 111, 10732-10737.

Sahay, S., Ghosh, D., Dwivedi, S., Anoop, A., Mohite, G.M., Kombrabail, M., Krishnamoorthy, G. and Maji, S.K. (2015) Familial Parkinson disease-associated mutations alter the site-specific microenvironment and dynamics of alpha-synuclein. J Biol Chem, 290, 7804-7822.

Saiki, R.K., Gelfand, D.H., Stoffel, S., Scharf, S.J., Higuchi, R., Horn, G.T., Mullis, K.B. and Erlich, H.A. (1988) Primer-directed enzymatic amplification of DNA with a thermostable DNA polymerase. Science, 239, 487-491.

Sancenon, V., Lee, S.A., Patrick, C., Griffith, J., Paulino, A., Outeiro, T.F., Reggiori, F., Masliah, E. and Muchowski, P.J. (2012) Suppression of alpha-synuclein toxicity and vesicle trafficking defects by phosphorylation at S129 in yeast depends on genetic context. Hum Mol Genet, 21, 2432-2449.

Sanger, F., Nicklen, S. and Coulson, A.R. (1992) DNA sequencing with chain-terminating inhibitors. 1977. Biotechnology, 24, 104-108.

Schildknecht, S., Gerding, H.R., Karreman, C., Drescher, M., Lashuel, H.A., Outeiro, T.F., Di Monte, D.A. and Leist, M. (2013) Oxidative and nitrative alpha-synuclein modifications and proteostatic stress: implications for disease mechanisms and interventions in synucleinopathies. J Neurochem, 125, 491-511. 
Schildknecht, S., Pape, R., Muller, N., Robotta, M., Marquardt, A., Burkle, A., Drescher, M. and Leist, M. (2011) Neuroprotection by minocycline caused by direct and specific scavenging of peroxynitrite. J Biol Chem, 286, 4991-5002.

Schildknecht, S. and Ullrich, V. (2009) Peroxynitrite as regulator of vascular prostanoid synthesis. Arch Biochem Biophys, 484, 183-189.

Schmid, A.W., Fauvet, B., Moniatte, M. and Lashuel, H.A. (2013) Alpha-synuclein posttranslational modifications as potential biomarkers for Parkinson disease and other synucleinopathies. Mol Cell Proteomics, 12, 3543-3558.

Sekiyama, K., Takamatsu, Y., Waragai, M. and Hashimoto, M. (2014) Role of genomics in translational research for Parkinson's disease. Biochem Biophys Res Commun, 452, 226235.

Sevcsik, E., Trexler, A.J., Dunn, J.M. and Rhoades, E. (2011) Allostery in a disordered protein: oxidative modifications to alpha-synuclein act distally to regulate membrane binding. J Am Chem Soc, 133, 7152-7158.

Shahpasandzadeh, H., Popova, B., Kleinknecht, A., Fraser, P.E., Outeiro, T.F. and Braus, G.H. (2014) Interplay between sumoylation and phosphorylation for protection against alphasynuclein inclusions. J Biol Chem, 289, 31224-31240.

Sharma, N., Brandis, K.A., Herrera, S.K., Johnson, B.E., Vaidya, T., Shrestha, R. and Debburman, S.K. (2006) alpha-Synuclein budding yeast model: toxicity enhanced by impaired proteasome and oxidative stress. J Mol Neurosci, 28, 161-178.

Sharon, R., Goldberg, M.S., Bar-Josef, I., Betensky, R.A., Shen, J. and Selkoe, D.J. (2001) alpha-Synuclein occurs in lipid-rich high molecular weight complexes, binds fatty acids, and shows homology to the fatty acid-binding proteins. Proc Natl Acad Sci U S A, 98, 9110-9115.

Shevchenko, A., Wilm, M., Vorm, O. and Mann, M. (1996) Mass spectrometric sequencing of proteins silver-stained polyacrylamide gels. Anal Chem, 68, 850-858.

Shimura, H., Schlossmacher, M.G., Hattori, N., Frosch, M.P., Trockenbacher, A., Schneider, R., Mizuno, Y., Kosik, K.S. and Selkoe, D.J. (2001) Ubiquitination of a new form of alphasynuclein by parkin from human brain: implications for Parkinson's disease. Science, 293, 263-269.

Singleton, A.B., Farrer, M., Johnson, J., Singleton, A., Hague, S., Kachergus, J., Hulihan, M., Peuralinna, T., Dutra, A., Nussbaum, R., Lincoln, S., Crawley, A., Hanson, M., Maraganore, D., Adler, C., Cookson, M.R., Muenter, M., Baptista, M., Miller, D., Blancato, J., Hardy, J. and Gwinn-Hardy, K. (2003) alpha-Synuclein locus triplication causes Parkinson's disease. Science, 302, 841.

Sivaraman, T., Kumar, T.K., Jayaraman, G. and Yu, C. (1997) The mechanism of 2,2,2trichloroacetic acid-induced protein precipitation. J Protein Chem, 16, 291-297.

Snyder, H., Mensah, K., Theisler, C., Lee, J., Matouschek, A. and Wolozin, B. (2003) Aggregated and monomeric alpha-synuclein bind to the S6' proteasomal protein and inhibit proteasomal function. J Biol Chem, 278, 11753-11759.

Soper, J.H., Roy, S., Stieber, A., Lee, E., Wilson, R.B., Trojanowski, J.Q., Burd, C.G. and Lee, V.M. (2008) Alpha-synuclein-induced aggregation of cytoplasmic vesicles in Saccharomyces cerevisiae. Mol Biol Cell, 19, 1093-1103. 
Souza, J.M., Giasson, B.I., Chen, Q., Lee, V.M. and Ischiropoulos, H. (2000a) Dityrosine cross-linking promotes formation of stable alpha -synuclein polymers. Implication of nitrative and oxidative stress in the pathogenesis of neurodegenerative synucleinopathies. $J$ Biol Chem, 275, 18344-18349.

Souza, J.M., Giasson, B.I., Lee, V.M. and Ischiropoulos, H. (2000b) Chaperone-like activity of synucleins. FEBS Lett, 474, 116-119.

Specht, C.G., Tigaret, C.M., Rast, G.F., Thalhammer, A., Rudhard, Y. and Schoepfer, R. (2005) Subcellular localisation of recombinant alpha- and gamma-synuclein. Mol Cell Neurosci, 28, 326-334.

Spillantini, M.G., Crowther, R.A., Jakes, R., Hasegawa, M. and Goedert, M. (1998) alphaSynuclein in filamentous inclusions of Lewy bodies from Parkinson's disease and dementia with lewy bodies. Proc Natl Acad Sci U S A, 95, 6469-6473.

Spillantini, M.G. and Goedert, M. (2000) The alpha-synucleinopathies: Parkinson's disease, dementia with Lewy bodies, and multiple system atrophy. Ann N Y Acad Sci, 920, 16-27.

Spillantini, M.G., Schmidt, M.L., Lee, V.M., Trojanowski, J.Q., Jakes, R. and Goedert, M. (1997) Alpha-synuclein in Lewy bodies. Nature, 388, 839-840.

Su, L.J., Auluck, P.K., Outeiro, T.F., Yeger-Lotem, E., Kritzer, J.A., Tardiff, D.F., Strathearn, K.E., Liu, F., Cao, S., Hamamichi, S., Hill, K.J., Caldwell, K.A., Bell, G.W., Fraenkel, E., Cooper, A.A., Caldwell, G.A., McCaffery, J.M., Rochet, J.C. and Lindquist, S. (2010) Compounds from an unbiased chemical screen reverse both ER-to-Golgi trafficking defects and mitochondrial dysfunction in Parkinson's disease models. Dis Model Mech, 3, 194-208.

Sun, F., Mao, X., Xie, L., Greenberg, D.A. and Jin, K. (2013) Neuroglobin protein is upregulated in Alzheimer's disease. J Alzheimers Dis, 36, 659-663.

Sung, V.W. and Nicholas, A.P. (2013) Nonmotor symptoms in Parkinson's disease: expanding the view of Parkinson's disease beyond a pure motor, pure dopaminergic problem. Neurol Clin, 31, S1-16.

Takahashi, T., Yamashita, H., Nakamura, T., Nagano, Y. and Nakamura, S. (2002) Tyrosine 125 of alpha-synuclein plays a critical role for dimerization following nitrative stress. Brain Res, 938, 73-80.

Taus, T., Kocher, T., Pichler, P., Paschke, C., Schmidt, A., Henrich, C. and Mechtler, K. (2011) Universal and confident phosphorylation site localization using phosphoRS. $J$ Proteome Res, 10, 5354-5362.

Tenreiro, S., Eckermann, K. and Outeiro, T.F. (2014a) Protein phosphorylation in neurodegeneration: friend or foe? Front Mol Neurosci, 7, 42.

Tenreiro, S., Munder, M.C., Alberti, S. and Outeiro, T.F. (2013) Harnessing the power of yeast to unravel the molecular basis of neurodegeneration. $J$ Neurochem, 127, 438-452.

Tenreiro, S., Reimao-Pinto, M.M., Antas, P., Rino, J., Wawrzycka, D., Macedo, D., RosadoRamos, R., Amen, T., Waiss, M., Magalhaes, F., Gomes, A., Santos, C.N., Kaganovich, D. and Outeiro, T.F. (2014b) Phosphorylation modulates clearance of alpha-synuclein inclusions in a yeast model of Parkinson's disease. PLoS Genet, 10, e1004302.

Thayanidhi, N., Helm, J.R., Nycz, D.C., Bentley, M., Liang, Y. and Hay, J.C. (2010) Alphasynuclein delays endoplasmic reticulum (ER)-to-Golgi transport in mammalian cells by antagonizing ER/Golgi SNAREs. Mol Biol Cell, 21, 1850-1863. 
Tofaris, G.K., Layfield, R. and Spillantini, M.G. (2001) alpha-synuclein metabolism and aggregation is linked to ubiquitin-independent degradation by the proteasome. FEBS Lett, $509,22-26$.

Totterdell, S. and Meredith, G.E. (2005) Localization of alpha-synuclein to identified fibers and synapses in the normal mouse brain. Neuroscience, 135, 907-913.

Towbin, H., Staehelin, T. and Gordon, J. (1979) Electrophoretic transfer of proteins from polyacrylamide gels to nitrocellulose sheets: procedure and some applications. Proc Natl Acad Sci U S A, 76, 4350-4354.

Ulrih, N.P., Barry, C.H. and Fink, A.L. (2008) Impact of Tyr to Ala mutations on alphasynuclein fibrillation and structural properties. Biochim Biophys Acta, 1782, 581-585.

Uversky, V.N., Li, J. and Fink, A.L. (2001) Metal-triggered structural transformations, aggregation, and fibrillation of human alpha-synuclein. A possible molecular NK between Parkinson's disease and heavy metal exposure. J Biol Chem, 276, 44284-44296.

Uversky, V.N., Yamin, G., Munishkina, L.A., Karymov, M.A., Millett, I.S., Doniach, S., Lyubchenko, Y.L. and Fink, A.L. (2005) Effects of nitration on the structure and aggregation of alpha-synuclein. Brain Res Mol Brain Res, 134, 84-102.

Valente, E.M., Bentivoglio, A.R., Dixon, P.H., Ferraris, A., lalongo, T., Frontali, M., Albanese, A. and Wood, N.W. (2001) Localization of a novel locus for autosomal recessive early-onset parkinsonism, PARK6, on human chromosome 1p35-p36. Am J Hum Genet, 68, 895-900.

Vamvaca, K., Volles, M.J. and Lansbury, P.T., Jr. (2009) The first N-terminal amino acids of alpha-synuclein are essential for alpha-helical structure formation in vitro and membrane binding in yeast. $\mathrm{J} \mathrm{Mol} \mathrm{Biol,} \mathrm{389,} \mathrm{413-424.}$

van Rooijen, B.D., Claessens, M.M. and Subramaniam, V. (2009) Lipid bilayer disruption by oligomeric alpha-synuclein depends on bilayer charge and accessibility of the hydrophobic core. Biochim Biophys Acta, 1788, 1271-1278.

Vila, M., Vukosavic, S., Jackson-Lewis, V., Neystat, M., Jakowec, M. and Przedborski, S. (2000) Alpha-synuclein up-regulation in substantia nigra dopaminergic neurons following administration of the parkinsonian toxin MPTP. J Neurochem, 74, 721-729.

Vilchez, D., Saez, I. and Dillin, A. (2014) The role of protein clearance mechanisms in organismal ageing and age-related diseases. Nat Commun, 5, 5659.

Visanji, N.P., Wislet-Gendebien, S., Oschipok, L.W., Zhang, G., Aubert, I., Fraser, P.E. and Tandon, A. (2011) Effect of Ser-129 phosphorylation on interaction of alpha-synuclein with synaptic and cellular membranes. J Biol Chem, 286, 35863-35873.

Wang, S., Xu, B., Liou, L.C., Ren, Q., Huang, S., Luo, Y., Zhang, Z. and Witt, S.N. (2012) alpha-Synuclein disrupts stress signaling by inhibiting polo-like kinase Cdc5/Plk2. Proc Natl Acad Sci U S A, 109, 16119-16124.

Wang, W. and Malcolm, B.A. (1999) Two-stage PCR protocol allowing introduction of multiple mutations, deletions and insertions using QuikChange Site-Directed Mutagenesis. Biotechniques, 26, 680-682.

Wang, X., Liu, J., Zhu, H., Tejima, E., Tsuji, K., Murata, Y., Atochin, D.N., Huang, P.L., Zhang, C. and Lo, E.H. (2008) Effects of neuroglobin overexpression on acute brain injury and long-term outcomes after focal cerebral ischemia. Stroke, 39, 1869-1874. 
Watanabe, S., Takahashi, N., Uchida, H. and Wakasugi, K. (2012) Human neuroglobin functions as an oxidative stress-responsive sensor for neuroprotection. J Biol Chem, 287, 30128-30138.

Waxman, E.A. and Giasson, B.I. (2008) Specificity and regulation of casein kinase-mediated phosphorylation of alpha-synuclein. J Neuropathol Exp Neurol, 67, 402-416.

Waxman, E.A., Mazzulli, J.R. and Giasson, B.I. (2009) Characterization of hydrophobic residue requirements for alpha-synuclein fibrillization. Biochemistry, 48, 9427-9436.

Webb, J.L., Ravikumar, B., Atkins, J., Skepper, J.N. and Rubinsztein, D.C. (2003) AlphaSynuclein is degraded by both autophagy and the proteasome. J Biol Chem, 278, 2500925013.

Weinreb, P.H., Zhen, W., Poon, A.W., Conway, K.A. and Lansbury, P.T., Jr. (1996) NACP, a protein implicated in Alzheimer's disease and learning, is natively unfolded. Biochemistry, 35, 13709-13715.

Winner, B., Jappelli, R., Maji, S.K., Desplats, P.A., Boyer, L., Aigner, S., Hetzer, C., Loher, T., Vilar, M., Campioni, S., Tzitzilonis, C., Soragni, A., Jessberger, S., Mira, H., Consiglio, A., Pham, E., Masliah, E., Gage, F.H. and Riek, R. (2011) In vivo demonstration that alphasynuclein oligomers are toxic. Proc Natl Acad Sci U S A, 108, 4194-4199.

Witt, S.N. and Flower, T.R. (2006) alpha-Synuclein, oxidative stress and apoptosis from the perspective of a yeast model of Parkinson's disease. FEMS Yeast Res, 6, 1107-1116.

Woodcock, D.M., Crowther, P.J., Doherty, J., Jefferson, S., DeCruz, E., Noyer-Weidner, M., Smith, S.S., Michael, M.Z. and Graham, M.W. (1989) Quantitative evaluation of Escherichia coli host strains for tolerance to cytosine methylation in plasmid and phage recombinants. Nucleic Acids Res, 17, 3469-3478.

Xu, S., Zhou, M., Yu, S., Cai, Y., Zhang, A., Ueda, K. and Chan, P. (2006) Oxidative stress induces nuclear translocation of C-terminus of alpha-synuclein in dopaminergic cells. Biochem Biophys Res Commun, 342, 330-335.

Yamin, G., Glaser, C.B., Uversky, V.N. and Fink, A.L. (2003a) Certain metals trigger fibrillation of methionine-oxidized alpha-synuclein. J Biol Chem, 278, 27630-27635.

Yamin, G., Uversky, V.N. and Fink, A.L. (2003b) Nitration inhibits fibrillation of human alphasynuclein in vitro by formation of soluble oligomers. FEBS Lett, 542, 147-152.

Yao, D., Gu, Z., Nakamura, T., Shi, Z.Q., Ma, Y., Gaston, B., Palmer, L.A., Rockenstein, E.M., Zhang, Z., Masliah, E., Uehara, T. and Lipton, S.A. (2004) Nitrosative stress linked to sporadic Parkinson's disease: S-nitrosylation of parkin regulates its E3 ubiquitin ligase activity. Proc Natl Acad Sci U S A, 101, 10810-10814.

Yu, S., Li, X., Liu, G., Han, J., Zhang, C., Li, Y., Xu, S., Liu, C., Gao, Y., Yang, H., Ueda, K. and Chan, P. (2007) Extensive nuclear localization of alpha-synuclein in normal rat brain neurons revealed by a novel monoclonal antibody. Neuroscience, 145, 539-555.

Yu, Z., Xu, X., Xiang, Z., Zhou, J., Zhang, Z., Hu, C. and He, C. (2010) Nitrated alphasynuclein induces the loss of dopaminergic neurons in the substantia nigra of rats. PLoS One, 5, e9956.

Zabrocki, P., Bastiaens, I., Delay, C., Bammens, T., Ghillebert, R., Pellens, K., De Virgilio, C., Van Leuven, F. and Winderickx, J. (2008) Phosphorylation, lipid raft interaction and traffic of alpha-synuclein in a yeast model for Parkinson. Biochim Biophys Acta, 1783, 1767-1780. 
Zabrocki, P., Pellens, K., Vanhelmont, T., Vandebroek, T., Griffioen, G., Wera, S., Van Leuven, F. and Winderickx, J. (2005) Characterization of alpha-synuclein aggregation and synergistic toxicity with protein tau in yeast. Febs J, 272, 1386-1400.

Zarranz, J.J., Alegre, J., Gomez-Esteban, J.C., Lezcano, E., Ros, R., Ampuero, I., Vidal, L., Hoenicka, J., Rodriguez, O., Atares, B., Llorens, V., Gomez Tortosa, E., del Ser, T., Munoz, D.G. and de Yebenes, J.G. (2004) The new mutation, E46K, of alpha-synuclein causes Parkinson and Lewy body dementia. Ann Neurol, 55, 164-173.

Zhao, X.J., Raitt, D., P, V.B., Clewell, A.S., Kwast, K.E. and Poyton, R.O. (1996) Function and expression of flavohemoglobin in Saccharomyces cerevisiae. Evidence for a role in the oxidative stress response. J Biol Chem, 271, 25131-25138.

Zhu, M., Li, J. and Fink, A.L. (2003) The association of alpha-synuclein with membranes affects bilayer structure, stability, and fibril formation. J Biol Chem, 278, 40186-40197.

Zimprich, A., Biskup, S., Leitner, P., Lichtner, P., Farrer, M., Lincoln, S., Kachergus, J., Hulihan, M., Uitti, R.J., Calne, D.B., Stoessl, A.J., Pfeiffer, R.F., Patenge, N., Carbajal, I.C., Vieregge, P., Asmus, F., Muller-Myhsok, B., Dickson, D.W., Meitinger, T., Strom, T.M., Wszolek, Z.K. and Gasser, T. (2004) Mutations in LRRK2 cause autosomal-dominant parkinsonism with pleomorphic pathology. Neuron, 44, 601-607. 


\section{List of Figures}

Figure 1. Schematic overview of human aSyn with the three distinct domains. ................... 6

Figure 2. Posttranslational modifications of aSyn in Lewy bodies. .................................. 9

Figure 3. Tyrosine nitration and di-tyrosine formation. ..............................................11

Figure 4. Localization of $\alpha$ Syn in yeast and its impact on growth....................................16

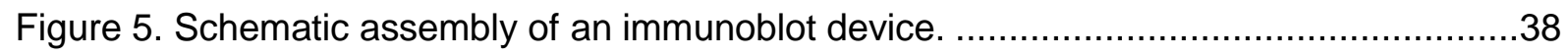

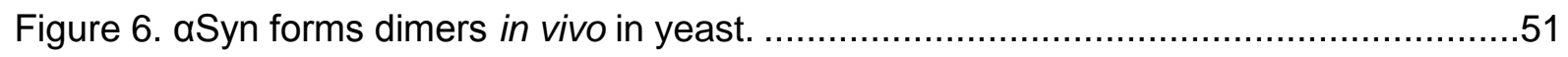

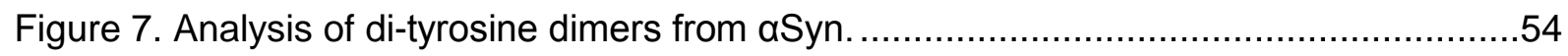

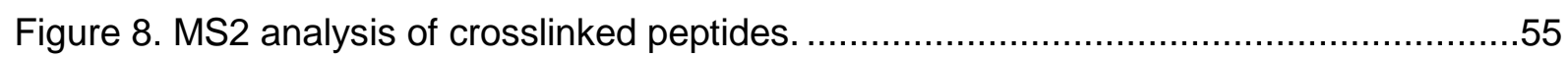

Figure 9. Mutation of tyrosines of aSyn prevents dimerization and nitration of aSyn. ..........57

Figure 10. Blocking of aSyn tyrosine nitration decreases cytotoxicity. .............................58

Figure 11. Blocking of aSyn tyrosine nitration decreases aggregation. .............................59

Figure 12. The nitric oxide oxidoreductase Yhb1 reduces A30P toxicity............................61

Figure 13. The nitric oxide oxidoreductase Yhb1 reduces A30P aggregation. .....................62

Figure 14. Overexpression of YHB1 impairs growth of Saccharomyces cerevisiae. ............63

Figure 15. Yhb1 decreases sensitivity of A30P expressing cells to nitrative stress.............64

Figure 16. aSyn expression does not affect sensitivity of yeast cells to $\mathrm{H}_{2} \mathrm{O}_{2} \ldots \ldots \ldots \ldots \ldots \ldots \ldots . .65$

Figure 17. C-terminal tyrosine replacements of A30P decrease toxicity in $\Delta y h b 1 \ldots \ldots \ldots \ldots \ldots 6$

Figure 18. Expression of $\alpha$ Syn increases accumulation of ROS. ......................................68

Figure 19. $\Delta y h b 1$ increases accumulation of reactive nitrogen species (RNS) in A30P

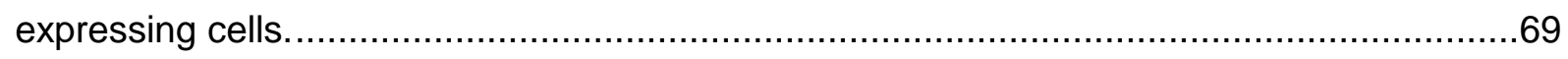

Figure 20. Yhb1 protects mitochondria from A30P toxicity............................................. 71

Figure 21. Mitochondrial functionality is not affected by Yhb1 in A30P expressing yeast cells.

Figure 22. The human $N G B$ gene for neuroglobin complements $A 30 \mathrm{P}$ growth in $Y H B 1$

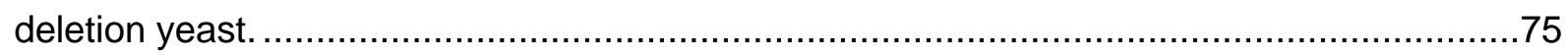

Figure 23. The human NGB gene for neuroglobin alters aSyn aggregation in mammalian

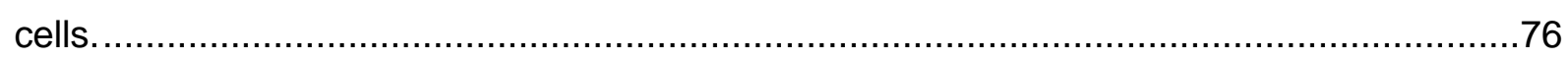

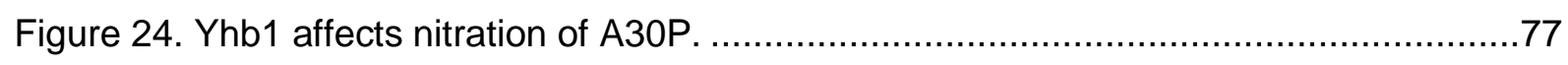

Figure 25. Yhb1 affects nitration but not dimerization of $a$ Syn and A30P...........................78

Figure 26. aSyn has a higher S129 phosphorylation level than A30P................................79

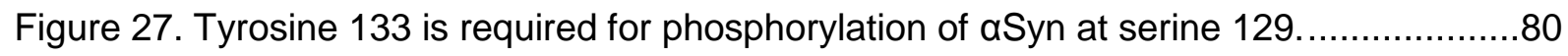

Figure 28. Y133F and S129A mutations increase aSyn-mediated cytotoxicity.....................81

Figure 29. Tyrosine 133 mutation does not alter the accumulation of reactive oxygen and

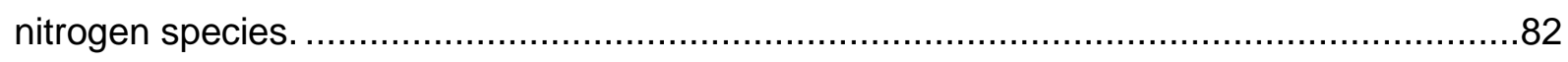

Figure 30. aSyn aggregate clearance after promoter shut-off.....................................84 
Figure 31. aSyn posttranslational modifications and nitrative stress in yeast......................88

Figure 32. Putative conserved domain of Yhb1 and NGB...........................................90 


\section{List of Tables}

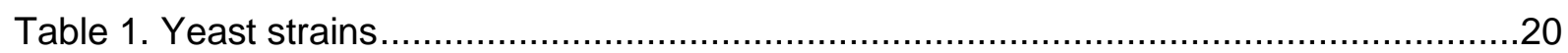

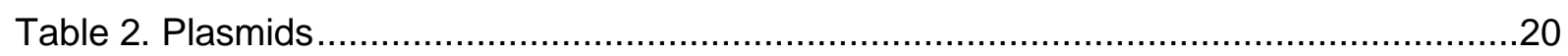

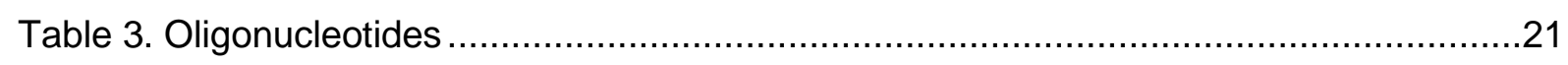

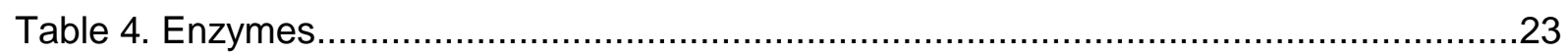

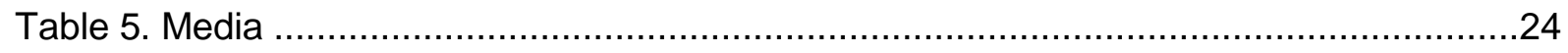

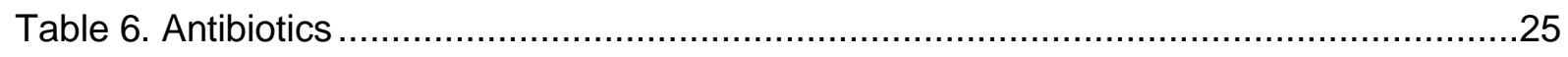

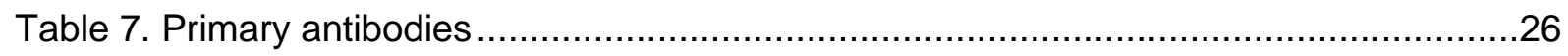

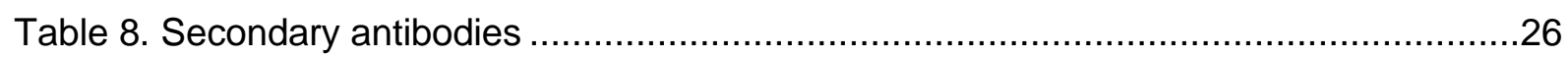

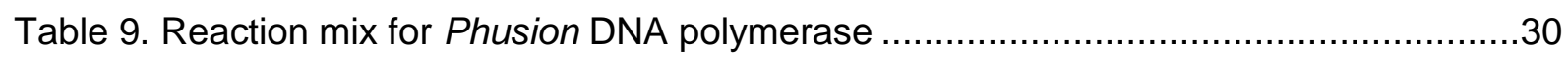

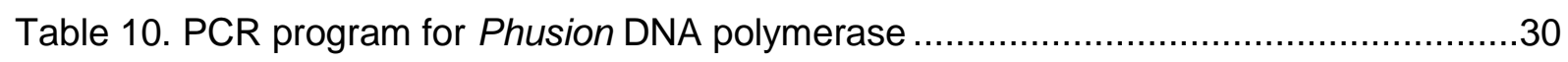

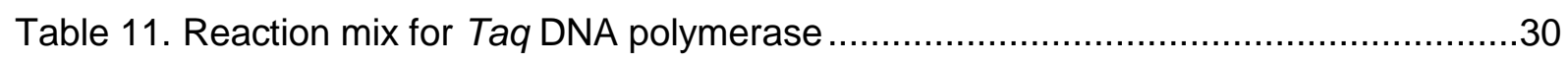

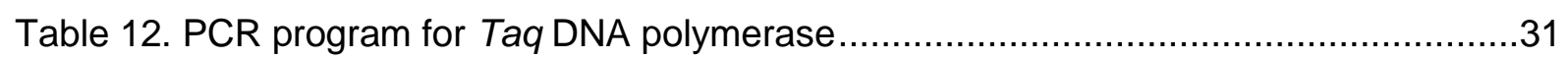

Table 13. Reaction mix for PfuTurbo Cx hotstart DNA polymerase .....................................32

Table 14. PCR program for PfuTurbo Cx hotstart DNA polymerase ...................................32

Table 15. Determination of nitrated peptides from aSyn and A30P..................................52

Table 16. Phospho-peptides identified by MS/MS. .......................................................53

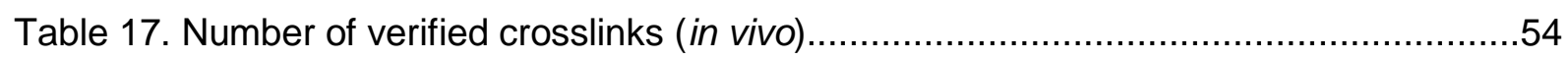




\section{Abbreviations}

\begin{tabular}{|c|c|}
\hline$\%$ & percent \\
\hline $2 \mu(2 \mu m)$ & 2 micrometer high-copy yeast expression vector \\
\hline$\mu g$ & microgram \\
\hline$\mu \mathrm{L}$ & microliter \\
\hline$\mu \mathrm{m}$ & micrometer \\
\hline$\mu \mathrm{M}$ & micromolar \\
\hline 3-NT & 3-nitrotyrosine \\
\hline$\AA$ & Ångström \\
\hline AA & amino acids \\
\hline Ade $(A)$ & adenine \\
\hline Ala $(A)$ & alanine \\
\hline $\mathrm{Amp}^{\mathrm{R}}$ & ampicillin resistance \\
\hline ANOVA & analysis of variance \\
\hline approx. & approximately \\
\hline APS & ammonium persulfate \\
\hline $\operatorname{Arg}(\mathrm{R})$ & arginine \\
\hline AS & ammonium sulfate \\
\hline Asn $(\mathrm{N})$ & asparagine \\
\hline Asp (D) & aspartic acid \\
\hline aSyn & a-synuclein \\
\hline ATG & autophagy-related gene \\
\hline ATP & adenosine triphosphate \\
\hline ATP13A2 & ATPase type 13 A2 \\
\hline BLAST & basic local alignment search tool \\
\hline bp & base pair(s) \\
\hline BSA & bovine serum albumin \\
\hline${ }^{\circ} \mathrm{C}$ & degree Celsius \\
\hline cDNA & complementary DNA \\
\hline CEN/ARS & centromere/autonomously replicating sequence \\
\hline CKs & casein kinases \\
\hline $\mathrm{cm}$ & centimeter \\
\hline CMV & cytomegalovirus \\
\hline C-terminus & carboxy terminus \\
\hline ctrl & control \\
\hline CYC1 & cytochrome C-1 \\
\hline
\end{tabular}




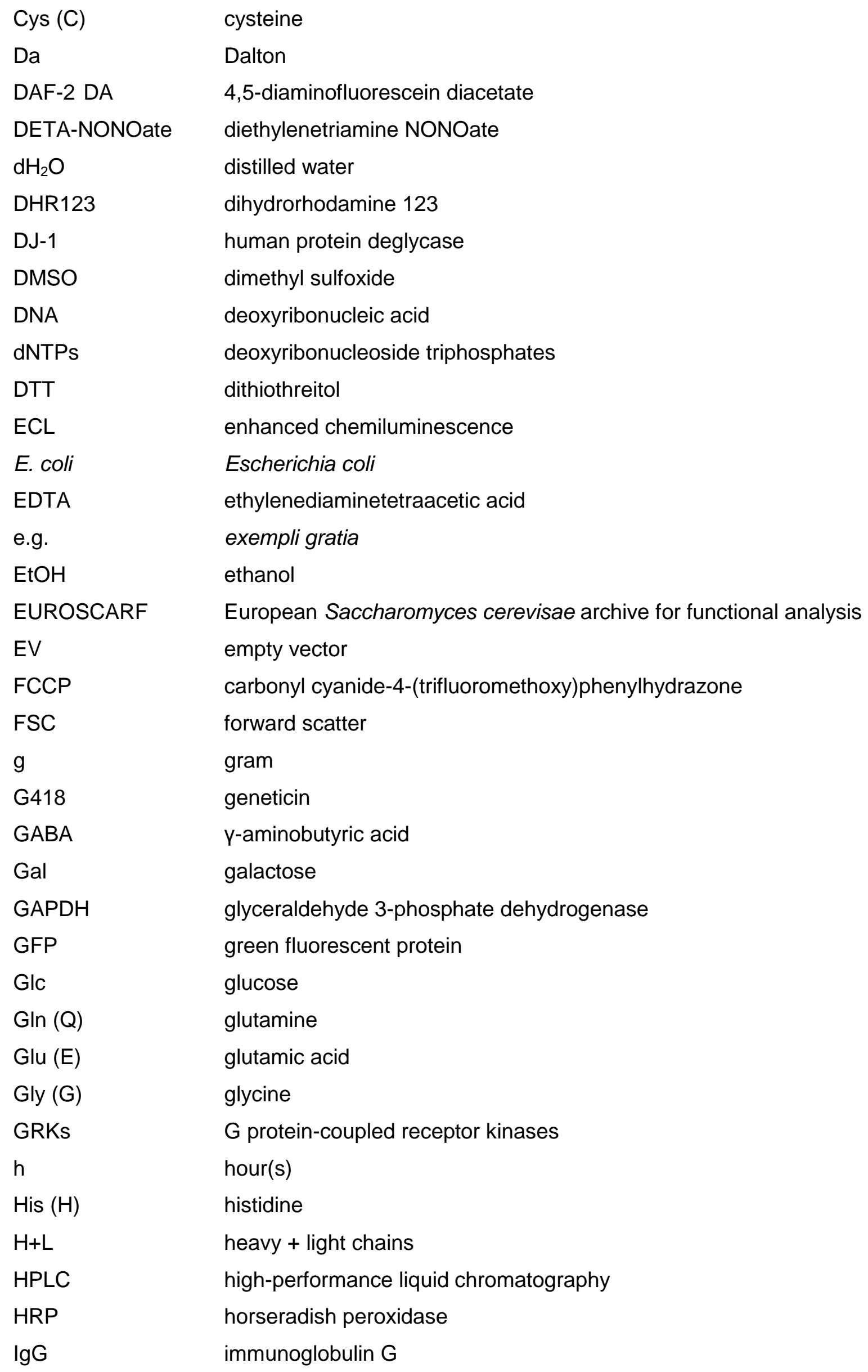




\begin{tabular}{|c|c|}
\hline Ile (I) & isoleucine \\
\hline kanMX4 & kanamycin resistance \\
\hline $\mathrm{kb}$ & kilobase pair(s) \\
\hline $\mathrm{kDa}$ & kilodalton \\
\hline kV & kilovolt \\
\hline L & liter \\
\hline LB & lysogeny broth \\
\hline LBs & Lewy bodies \\
\hline LC-MS & liquid chromatography-mass spectrometry \\
\hline LDH & lactate dehydrogenase \\
\hline Leu (L) & leucine \\
\hline LiOAc & lithium acetate \\
\hline $\log$ & decadic logarithm \\
\hline LRRK2s & leucine-rich repeat kinases \\
\hline Lys (K) & lysine \\
\hline M & molar \\
\hline MATa & mating type a \\
\hline Met (M) & methionine \\
\hline $\mathrm{mg}$ & milligram \\
\hline MG132 & N-benzyloxycarbonyl-L-leucyl-L-leucyl-L-leucinal \\
\hline $\min$ & minute(s) \\
\hline $\mathrm{mL}$ & milliliter \\
\hline $\mathrm{mm}$ & millimeter \\
\hline $\mathrm{mM}$ & millimolar \\
\hline MM & minimal medium \\
\hline MPTP & 1-methyl-4-phenyl-1,2,3,6-tetrahydropyridine \\
\hline mRNA & messenger ribonucleic acid \\
\hline MS & mass spectrometry \\
\hline MT & mitochondria \\
\hline MV & minimal medium plus vitamins \\
\hline $\mathrm{n}$ & number \\
\hline NAC & non-amyloid- $\beta$ component \\
\hline $\mathrm{ng}$ & nanogram \\
\hline NGB & neuroglobin \\
\hline $\mathrm{nm}$ & nanometer \\
\hline $\mathrm{nM}$ & nanomolar \\
\hline n.s. & not significant \\
\hline
\end{tabular}




\begin{tabular}{|c|c|}
\hline NTA & nitrilotriacetic acid \\
\hline N-terminus & amino terminus \\
\hline OCR & oxygen consumption rate \\
\hline $\mathrm{OD}_{600}$ & optical density measured at a wavelength of 600 nanometer \\
\hline ori & origin of replication \\
\hline PA & polyacrylamide \\
\hline PABA & para-aminobenzoic acid \\
\hline PAGE & polyacrylamide gel electrophoresis \\
\hline PBS & phosphate buffered saline \\
\hline PCR & polymerase chain reaction \\
\hline PD & Parkinson's disease \\
\hline PEG & polyethylene glycol \\
\hline Pfu & Pyrococcus furiosus \\
\hline $\mathrm{P} 1$ & population of cells \\
\hline $\mathrm{pH}$ & potentia hydrogenii \\
\hline Phe $(F)$ & phenylalanine \\
\hline $\mathrm{PI}$ & propidium iodide \\
\hline PIM & protease inhibitor mix \\
\hline PINK1 & PTEN-induced putative kinase 1 \\
\hline PLKs & polo-like kinases \\
\hline pmol & picomol \\
\hline PMSF & phenylmethanesulfonyl fluoride \\
\hline PON & peroxynitrite \\
\hline ppm & parts per million \\
\hline Pro $(P)$ & proline \\
\hline PTM & posttranslational modification \\
\hline PVDF & polyvinylidene fluoride \\
\hline Raff & raffinose \\
\hline RFP & red fluorescent protein \\
\hline RNA & ribonucleic acid \\
\hline RNS & reactive nitrogen species \\
\hline ROS & reactive oxygen species \\
\hline rpm & rounds per minute \\
\hline $\mathrm{RT}$ & room temperature \\
\hline SC & synthetic complete \\
\hline S. cerevisiae & Saccharomyces cerevisiae \\
\hline SDS & sodium dodecyl sulfate \\
\hline
\end{tabular}




\begin{tabular}{|c|c|}
\hline sec & second(s) \\
\hline SEM & standard error of the mean \\
\hline $\operatorname{Ser}(S)$ & serine \\
\hline SN & substantia nigra \\
\hline SNARE & soluble N-ethylmaleimide-sensitive-factor attachment receptor \\
\hline SNCA & synuclein alpha \\
\hline SS & single stranded salmon sperm DNA \\
\hline SUMO & small ubiquitin-like modifier \\
\hline TAE & Tris-acetate-EDTA \\
\hline Taq & Thermus aquaticus \\
\hline TBST & Tris-buffered saline with Tween \\
\hline TCA & trichloroacetic acid \\
\hline TE & Tris-HCl, EDTA \\
\hline TEMED & tetramethylethylenediamine \\
\hline $\operatorname{Thr}(\mathrm{T})$ & threonine \\
\hline Tm & melting temperature \\
\hline TMN & tetranitromethane \\
\hline Tris & tris-(hydroxymethyl)-aminomethane \\
\hline tRNA & transfer ribonucleic acid \\
\hline $\operatorname{Trp}(\mathrm{W})$ & tryptophan \\
\hline Tween & polyoxyethylen(20)-sorbitan-monolaurat \\
\hline $\operatorname{Tyr}(Y)$ & tyrosine \\
\hline$U$ & enzyme unit(s) \\
\hline UPS & ubiquitin-proteasome system \\
\hline Ura (U) & uracil \\
\hline UTR & untranslated region \\
\hline UV & ultraviolet \\
\hline UV/VIS & ultraviolet and visible spectroscopy \\
\hline V & volt \\
\hline Val (V) & valine \\
\hline$v / v$ & volume per volume \\
\hline $\mathrm{w} / \mathrm{v}$ & weight per volume \\
\hline WT & wild-type \\
\hline YEPD & yeast extract peptone dextrose \\
\hline Yhb1 & yeast flavohemoglobin \\
\hline YNB & yeast nitrogen base \\
\hline
\end{tabular}




\section{Acknowledgements}

Finally, it is my pleasure to express my appreciation to all, who supported me during the time of my PhD work!

I would like to express my sincere gratitude to Prof. Gerhard Braus for providing me the great chance to join his research group and carry out my $\mathrm{PhD}$ thesis under his supervision. I am very grateful for his excellent mentoring, advisement and patience.

My very special appreciation goes to Dr. Blagovesta Popova for her great help and encouragements in this project. I am very grateful for her endless patience and kindness.

I would like to thank my thesis committee members Prof. Tiago Outeiro for the cooperation and inspiring discussions and Prof. Blanche Schwappach for her feedback on my projects during the years.

I would like to extend my thanks to Maria Meyer for her endless kindness, excellent technical assistance and great patience in everyday laboratory practice. I would also like to thanks Dr. Oliver Valerius and Dr. Kerstin Schmitt for handling all my LC-MS samples and sharing their expertise in in vitro nitration. I am very grateful for all their helpful support and instructions in the evaluation of LC-MS data.

I am very grateful to Diana Lázaro for performing the aggregation study in mammalian cells (Figure 23) and fruitful discussions. Moreover, my gratefulness goes to Raquel Pinho for invaluable insights into the Seahorse analysis.

I also want to thank all members of the Department of Molecular Microbiology and Genetics. During my PhD work I enjoyed a very pleasant working atmosphere in a very helpful research team. Thanks for scientific support, useful suggestions and friendly words. In particular, my very special thank goes to all my colleagues from Lab 1.110 for their friendship and support.

Moreover, I would like to thank the bachelor students Lara Schmitz, Maria Kuzyakova, Alexander Hempelmann and the Master student Sina Kristin Stumpf, who contributed to my thesis with their experiments. I would like to thank my colleagues Dr. Blagovesta Popova and Sabine Thieme for proof-reading my thesis.

I deeply appreciate to carry out my $\mathrm{PhD}$ study as a member of the doctoral program "Molecular Physiology of the Brain" of the Göttingen Graduate School for Neurosciences, Biophysics, and Molecular Biosciences (GGNB). The CMPB seminars and retreats gave me 
the opportunity for scientific learning and exchanging experiences in PD-related research. Especially, I would like to thank Prof. Michael Hörner for coordinating the program. I am grateful to GGNB for supporting me with "Travel Grants" to present my results in various international conferences that gave me impulses and new ideas and inspired me for further work steps.

My dearest appreciation goes to my husband Alexander for his patience, love and moral support. Last, I would like to thank my parents and all my dear friends, who always believed in me and encouraged me also in hard times. 


\title{
Curriculum Vitae
}

\author{
Personal details \\ Alexandra Kleinknecht (née Juckert) \\ Born $22^{\text {nd }}$ of August, 1986 \\ in Jawlenka / Kazakhstan
}

\section{Education and Academic Qualification}

08/2004 - 06/2007 Gymnasium Johanneum, Lingen (Ems), Germany

Abitur: university entrance qualification (June 2007)

10/2007 - 09/2010 Georg-August-Universität Göttingen, Germany

Bachelor of Science in Molecular Biology

Bachelor thesis at the German Primate Center, Department of Primate Genetics (Prof. Dr. Lutz Walter / Dr. Jens Gruber) - subject: "Zelltypabhängigkeit der regulatorischen Funktion der snoRNA HBI-43 und U60“

10/2010 - 09/2012 Georg-August-Universität Göttingen, Germany

Master of Science in Microbiology and Biochemistry

Master thesis at the Institute for Microbiology and Genetics, Department of Molecular Microbiology and Genetics (Prof. Dr. Gerhard Braus / Dr. Blagovesta Popova) - subject: "Modulators of $\alpha$-synuclein toxicity in yeast model of Parkinson's disease"

\section{2/2012 - 07/2016 Georg-August-Universität Göttingen, Germany}

$\mathrm{PhD}$ student in the doctoral program "Molecular Physiology of the Brain" (CMPB) of the Göttingen Graduate School for Neurosciences and Molecular Biosciences (GGNB)

$\mathrm{PhD}$ thesis at the Institute for Microbiology and Genetics, Department of Molecular Microbiology and Genetics (Prof. Dr. Gerhard Braus) subject: "C-terminal tyrosine residue modifications modulate $\alpha$ synuclein toxicity in yeast as unicellular model for Parkinson's disease" 